Thèse

Présentée par

\title{
LAURENT GRANGE
}

Pour obtenir le titre de

Docteur de l'Université Joseph Fourier -Grenoble I

(Arrêtés ministériels du 5 juillet 1984 et du 30 mars 1992)

Spécialité Sciences de la Vie et de la Santé

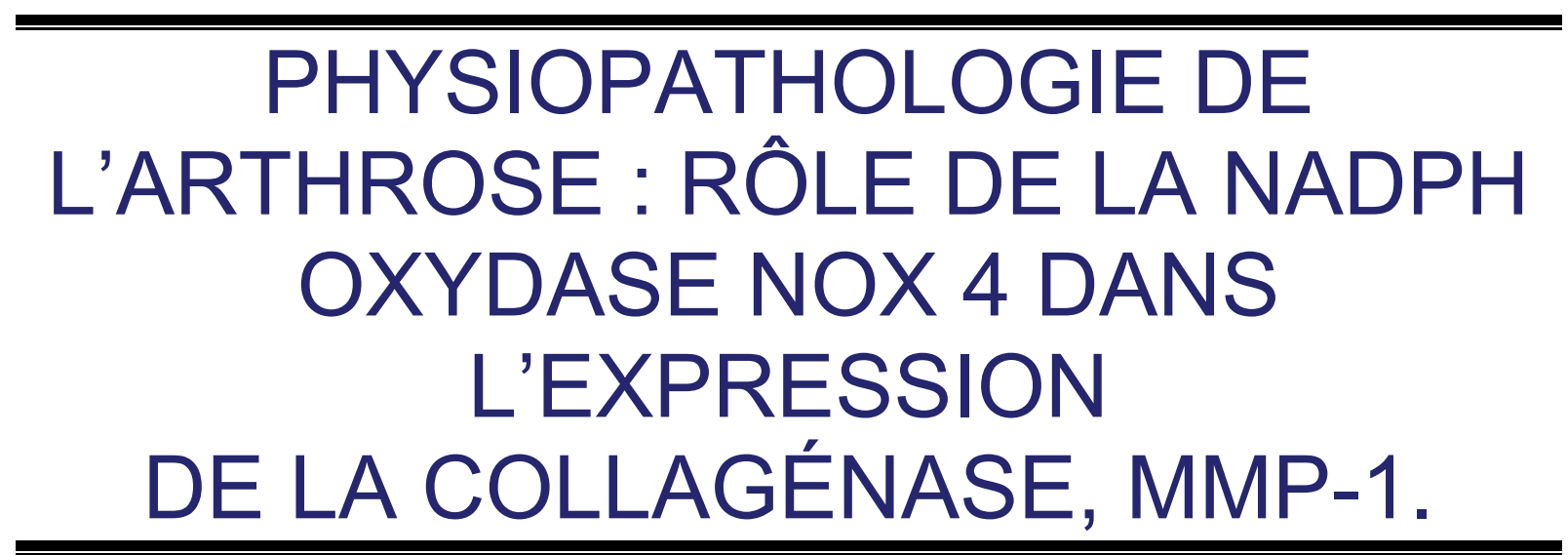

Soutenue le vendredi 16 février 2007.

Composition du jury :

Président :

Professeur Robert Juvin

Rapporteurs :

Professeur Philippe Birembaut

Examinateurs :

Docteur Jean Claude Monboisse

Directeur de thèse :

Professeur Philippe Gaudin

Docteur Bernard Lardy

Professeur Francoise Morel

Thèse préparée au sein du Groupe de Recherche et d'Etude du processus inflammatoire

GREPI-TIMC-IMAG UMR CNRS 5525,

Laboratoire d'Enzymologie, CHU A. Michallon, Grenoble 


\section{Remerciements}

Je tiens à remercier

Monsieur le Professeur P. Birembaut pour avoir accepté de juger ce travail en espérant poursuivre notre collaboration dans le cadre de la dégénérescence discale

Monsieur le docteur JC. Monboisse pour avoir accepté de juger ce travail

Madame le Professeur F. Morel, sans qui cette thèse n'aurait pu exister, pour m'avoir accueilli au sein du GREPI, moi le clinicien. Sa compétence, son expérience et sa patience ont permis l'accomplissement de ce travail.

Monsieur le Professeur R. Juvin, pour m'avoir accueilli et fais confiance au sein du service de Rhumatologie, ainsi que d'avoir accepté de me libérer du temps pour réaliser ce travail scientifique et d'avoir accepté également la présidence du jury de cette thèse.

Monsieur le Professeur P. Gaudin pour son aide précieuse, sa disponibilité permanente dans les domaines médicaux, biochimiques et encore plein d'autres et d'avoir supervisé ce travail durant ces six longues années

Bernardo. Lardy S. Vergnaud, C trocme et Sylvie Berthier d'avoir accepté de me supporter, de me materner, et de m'orienter au quotidien à la paillasse.

Chuongounet N'Guyen l'egual contributor pour m'avoir aidé dans la partie de biologie moléculaire et le petit Yannick pour son aide en Cytométrie de flux ; mais aussi pour être tous les deux de très bon compagnons de fête et à Madhia pour son œil microscopique...

A Olivier pour les bons moments passés avec lui, desolé pour les blagues peu intellectuelles.

Les copines d'amour et de toujours, de confidences, de fêtes et de voile Sylvie Candice et lolote..... Vive le champagne.......

A l'ensemble des membres du GREPI, et à l'ensemble des enzymologues-boys and girls, et les petits nouveaux européens et ennes pour leur amitié, leur patience, leurs aides diverses....pensées spéciales à Michèle, Anny, et Cécile.

A Marie ange Castaldin et au docteur Bruno Gintz pour leur relecture critique.

L'ensemble de l'équipe de Rhumatologie pour avoir supportée mes absences, et notamment les petits derniers Cyril, béa, alex, Rachel, dana, Athan, et Irina en effet......

A Benoit, Prisca et ts mes amis de fêtes A Lomick ........

A Jean Marc, Laurence, Yannick et Christine mes amis de toujours

$A$, mes parents, ma sœur et au petit Alexis et toute ma famille

Je les remercie du soutien qu'ils m'ont apporté durant la réalisation de ce travail. 
SOMMAIRE 


\section{Sommaire}

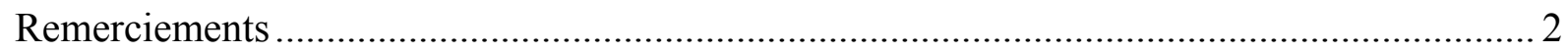

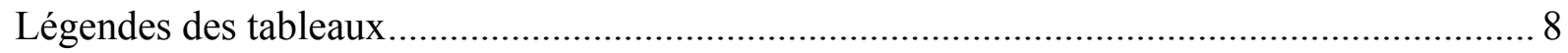

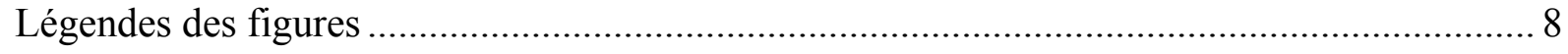

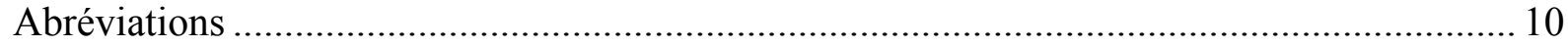

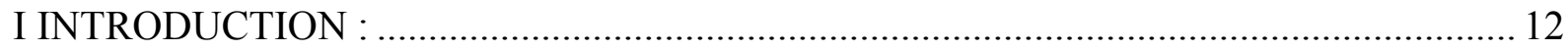

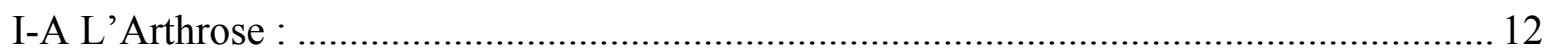

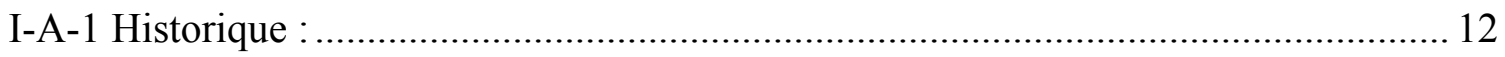

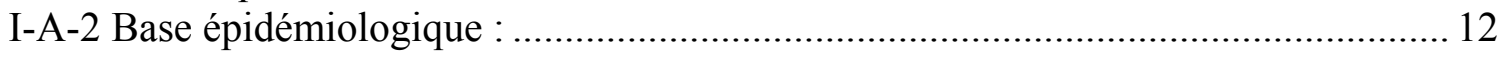

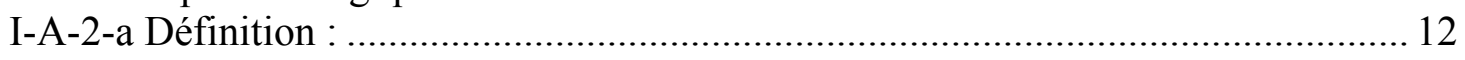

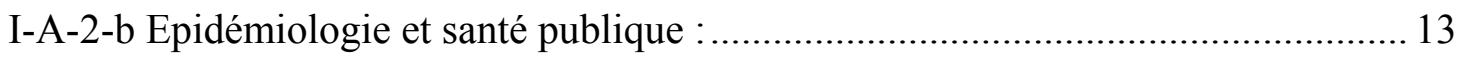

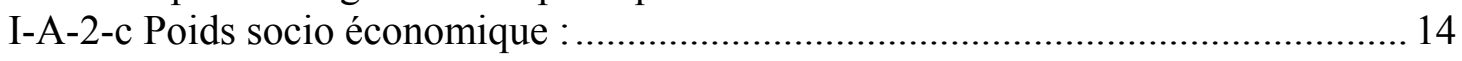

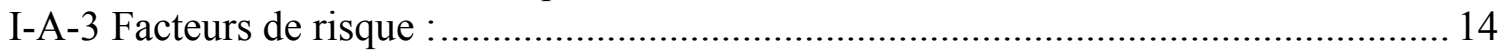

I-A-4 Signes cliniques et radiologiques de l'arthrose :............................................... 15

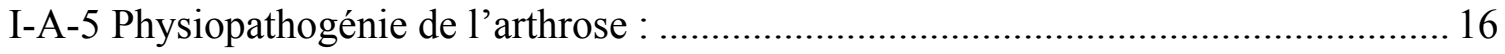

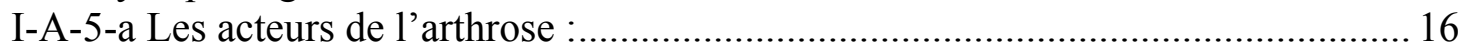

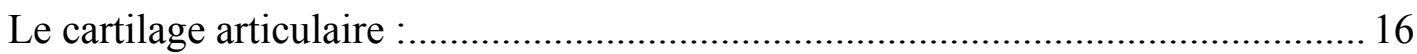

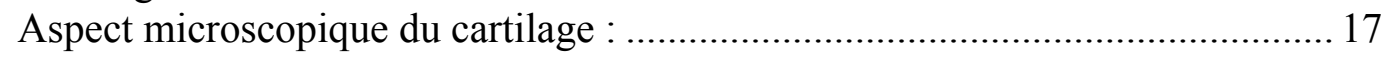

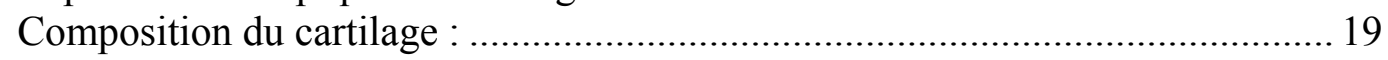

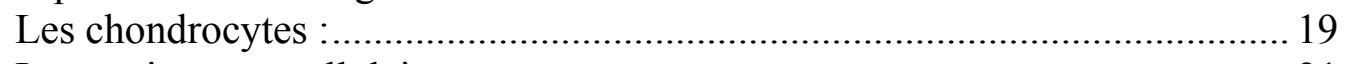

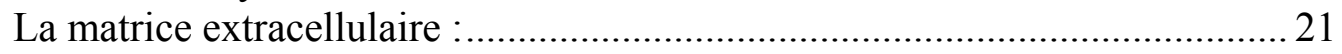

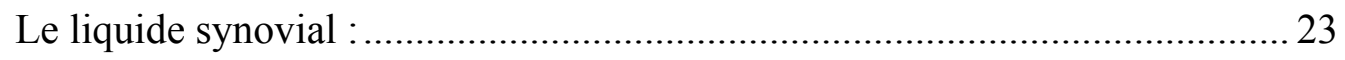

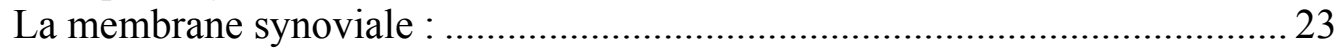

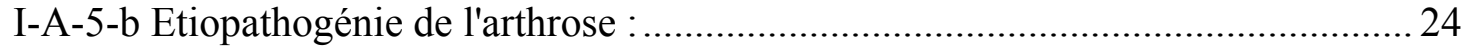

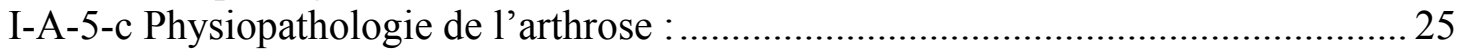

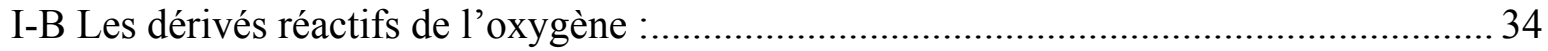

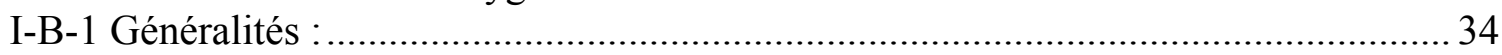

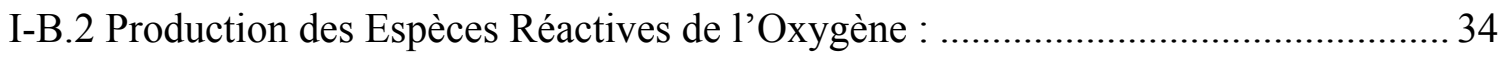

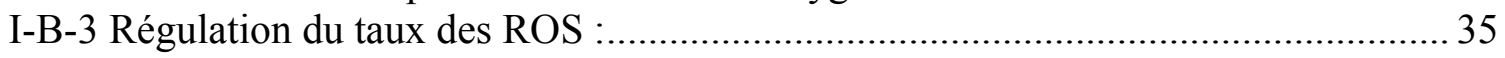

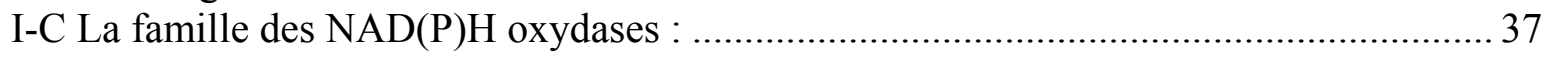

I-C-1 La famille des NAD(P)H oxydases des cellules phagocytaires : .......................... 37

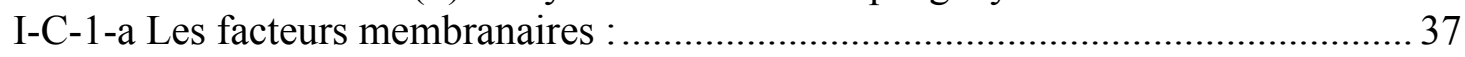

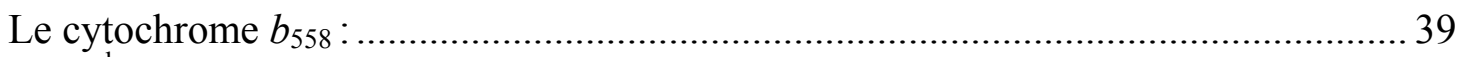

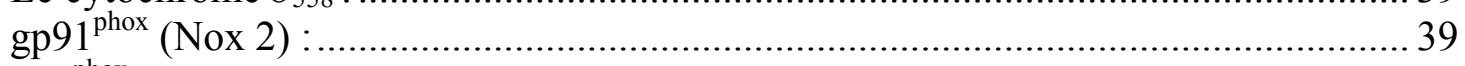

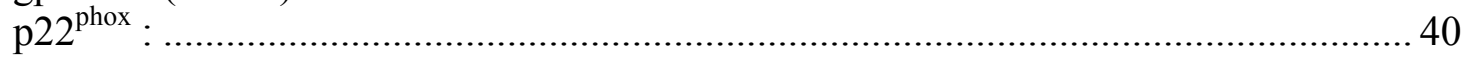

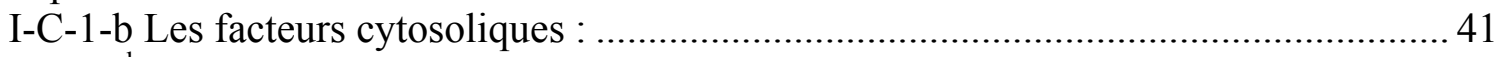

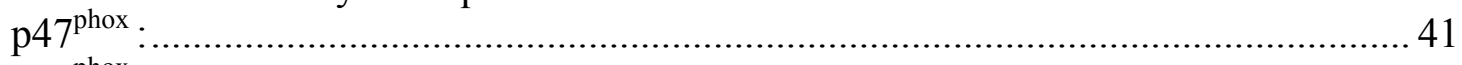

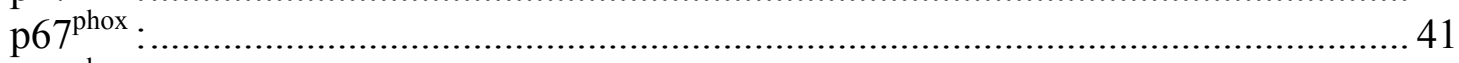

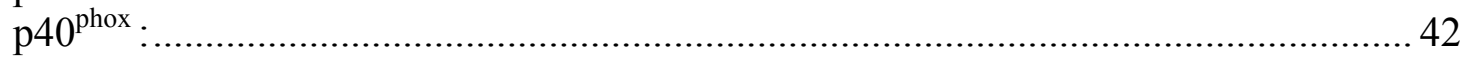

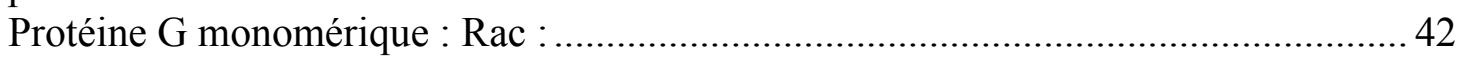

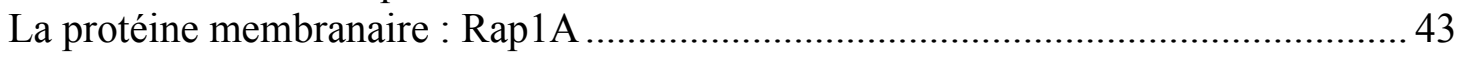

I-C-2. La famille des NADPH Oxydases des cellules non phagocytaires : ..................... 43

I-C-2-a Régulation de la production des ions superoxyde par les Nox $_{\mathrm{s}}$ non

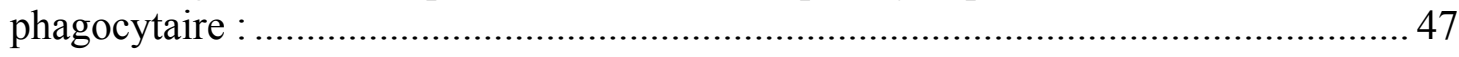

I-C-2-b Rôle potentiel des Nox $_{\mathrm{s}}$ dans certaines voies de signalisation : ....................... 47

I-C-2-c Facteurs potentiellement associés aux protéines Nox $_{\mathrm{s}}$ non phagocytaire : ..... 49

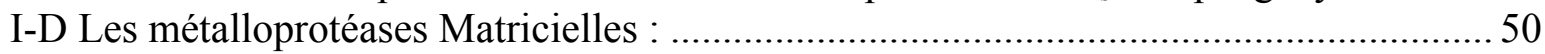

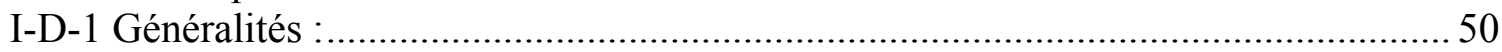




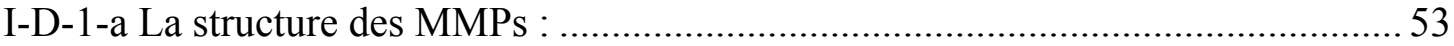

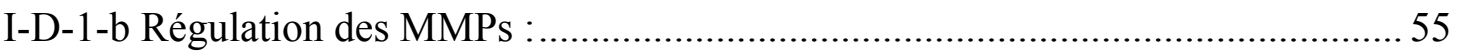

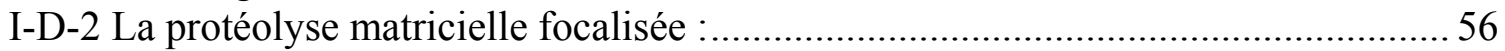

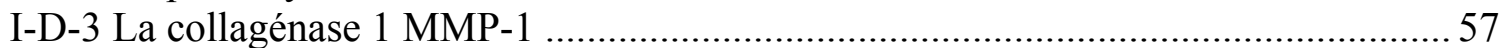

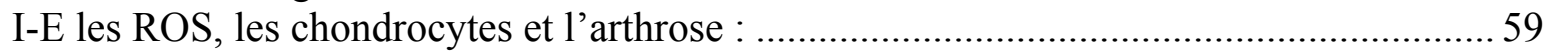

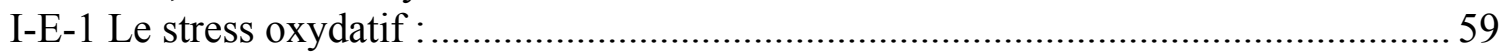

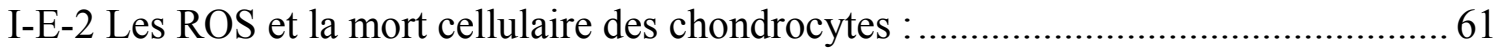

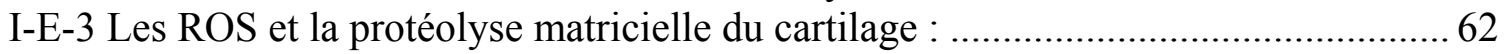

I-E-4 Les ROS et la signalisation intra cellulaire dans le chondrocyte : ............................6 63

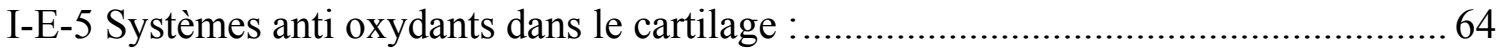

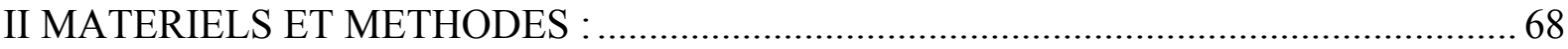

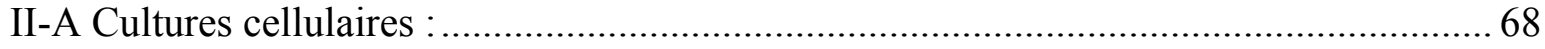

II-A-1 Les lignées de chondrocytes immortalisés par le virus SV40 :...........................68

II-A-2- Obtention des lymphocytes B immortalisés par le virus Epstein-Barr (cellules

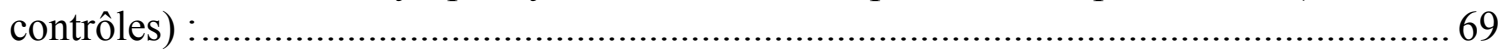

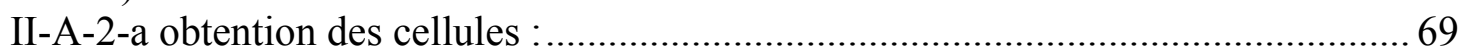

II-A-2-b Immortalisation des cellules et entretien : ................................................... 69

II-A-3 Obtention des polynucléaires neutrophiles à partir de sang vieilli ou "buffy coat" :

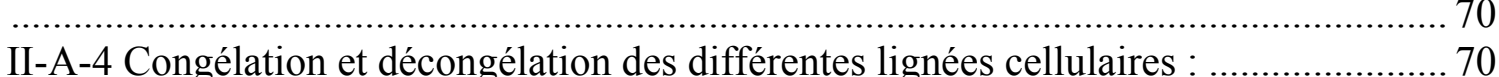

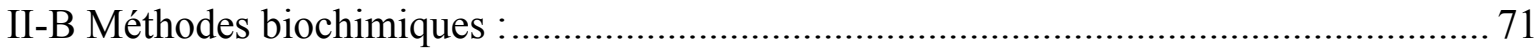

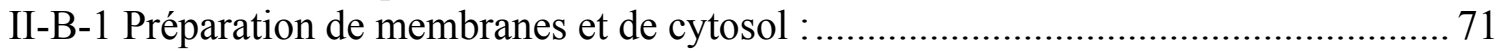

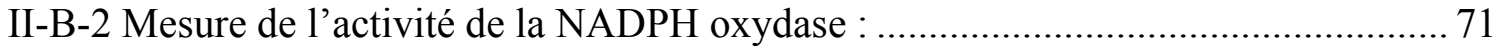

II-B-2-a Mesure de la production de $\mathrm{H}_{2} \mathrm{O}_{2}$ par luminescence :................................... 72

II-B-2-b Système de reconstitution acellulaire hétérologue : mesure de la production

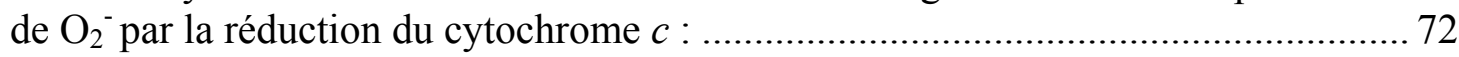

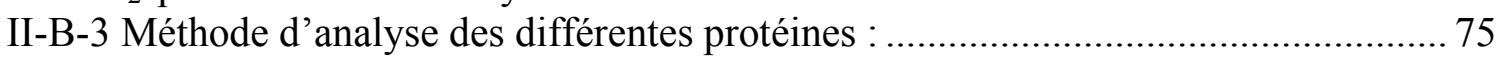

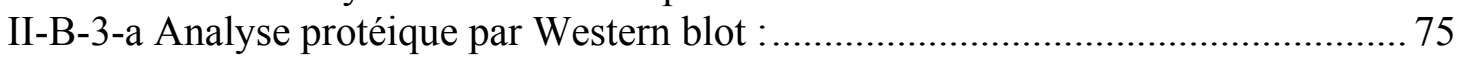

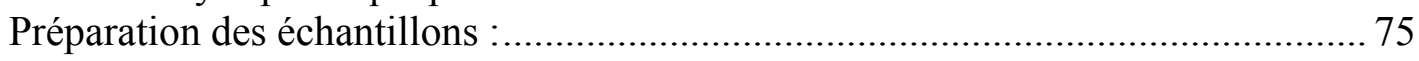

Electrophorèse en gel d'acrylamide en présence de SDS :................................. 75

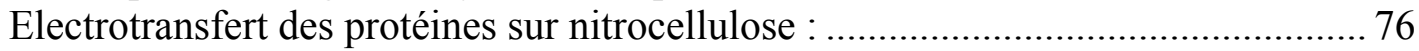

Immunodétection par anticorps couplés à la peroxydase :................................... 77

II-B-3-b Méthode de dosage des protéines : ............................................................. 77

II-B-3-c Spectres différentiels redox du cytochrome $b_{558}$ des 3 lignées de chondrocytes

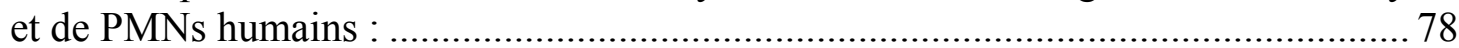

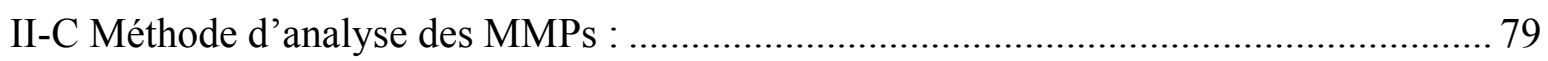

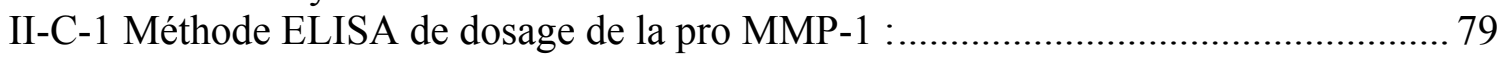

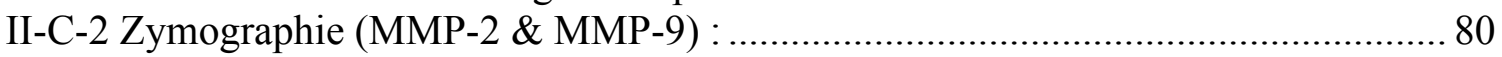

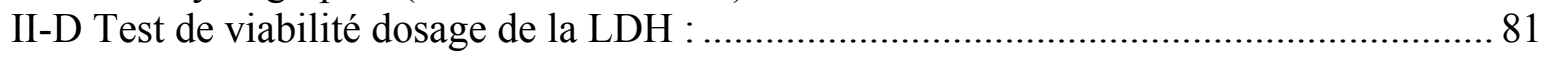

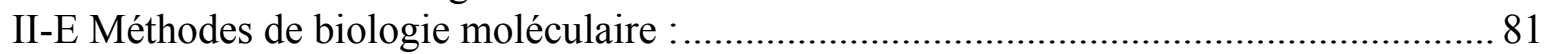

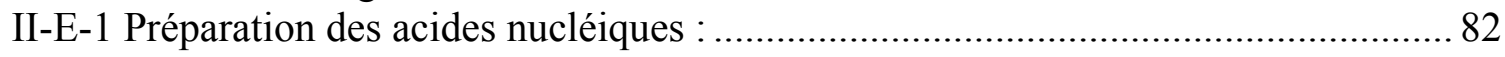

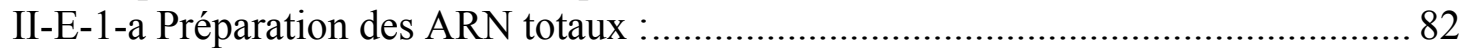

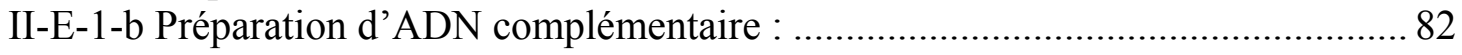

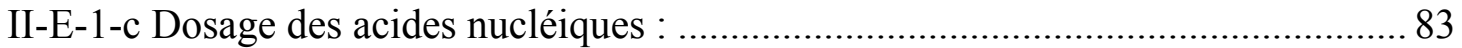

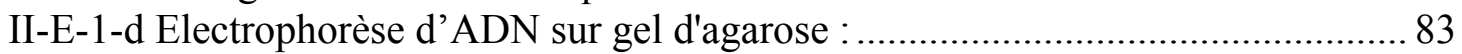

II-E-2 Réaction d'amplification en chaîne par la polymérase (PCR) :............................ 83

II-E-3 Construction de plasmides exprimant les différentes isoformes de Nox4 et Nox2 :

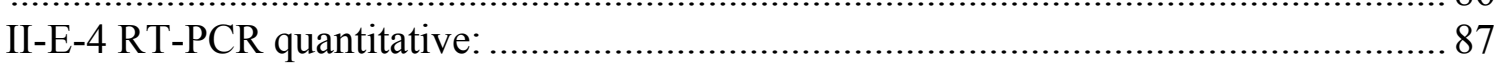

II-E-5 Purification des fragments d'ADN sur gel d'agarose et séquençage : .................. 89 
II-E-6 Méthodes de Transfection des lignées chondrocytaires : ................................... 90

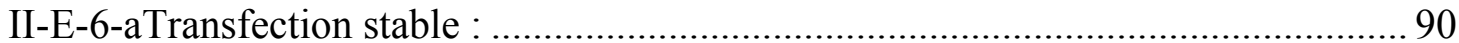

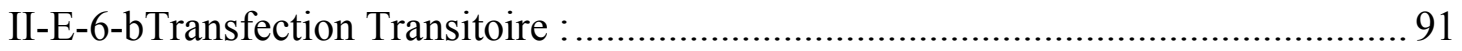

II-F. Mesure de l'effet du stress cytokinique h IL-1 $\beta$ sur l'expression métalloprotéasique :

II-F-1 Stimulation par l'hIL1- $\beta$ sur les lignées de chondrocytes C-20/A4 :.................. 92

II-F-2 Impact de l'inhibition des ROS (TIRON / DPI) sur la sécrétion de la pro MMP-1 :

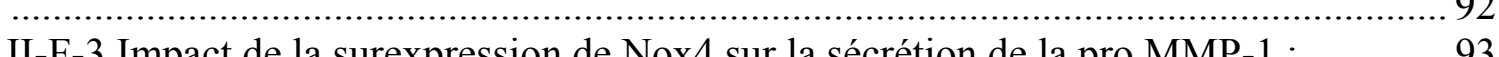

II-F-3 Impact de la surexpression de Nox4 sur la sécrétion de la pro MMP-1 :.............. 93

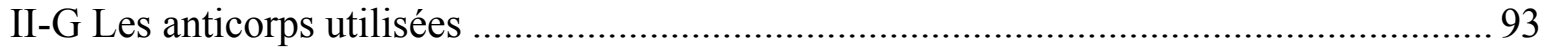

II-H Mesure de la production de $\mathrm{O}_{2}{ }^{-}$par oxydation du DHE par microscopie à fluorescence

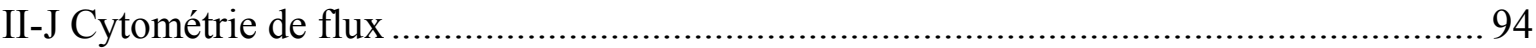

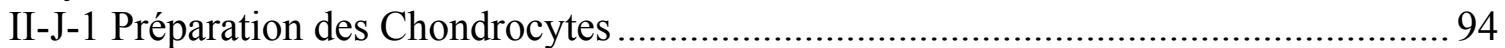

II-J-1-a Chondrocytes intacts fixés et non perméabilisés.......................................... 94

II-J-1-b Chondrocytes intacts Fixés et perméabilisés ............................................. 95

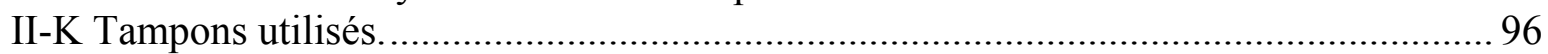

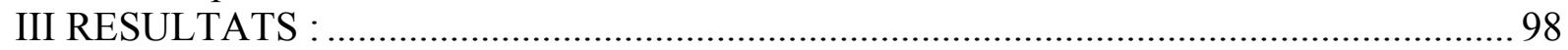

III-A Analyse phénotypique en terme de Nox et de leurs partenaires au niveau transcriptionnel et protéique dans un modèle cellulaire de trois lignées de chondrocytes $(\mathrm{C}$ -

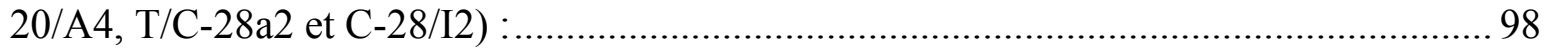

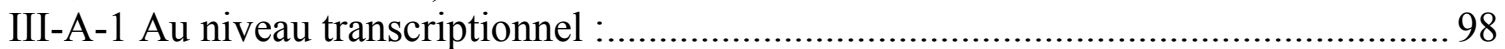

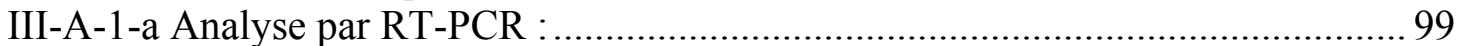

III-A-1-b Analyse par séquençage des gènes incriminés :....................................... 100

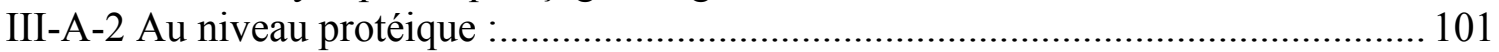

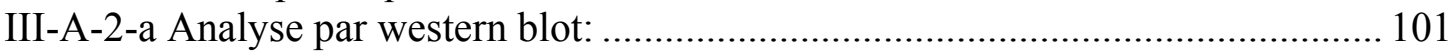

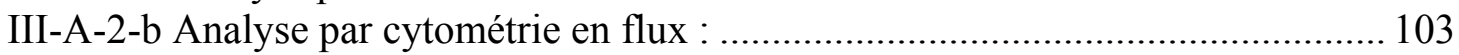

III-A-2-c Analyse par étude du spectre différentiel redox du cytochrome $b_{558}: \ldots \ldots .105$

III-B La mesure d'activité NAD(P)H oxydase sur les chondrocytes :................................ 106

III-B-1 Dosage de l'activité NAD(P)H oxydase par la méthode de chimiluminescence sur

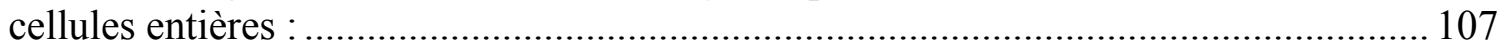

III-B-2 Mesure de l'activité NAD(P)H oxydase après reconstitution en milieu

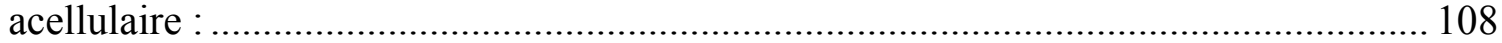

III-C Mesure de l'effet du stress cytokinique par interleukine $1 \beta$ humaine (hIL-1 $)$ ) sur

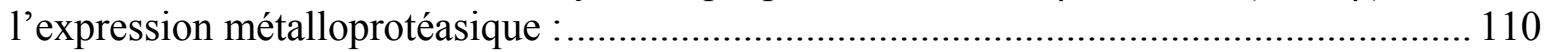

III-C-1 Mise au point et validation de l'expérimentation ......................................... 110

III-C-1-a Détermination du temps optimal d'incubation en présence hIL- $\beta$ : .......... 110

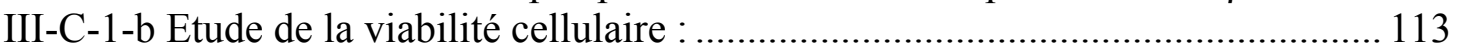

III-C-1-c Effet de l'hIL-1 $\beta$, à 23h d'incubation sur l'expression de la pro-MMP-1 : 114

III-C-1-d Effet de l'hIL-1 $\beta$, sur l'expression métalloprotéasique des gélatinases

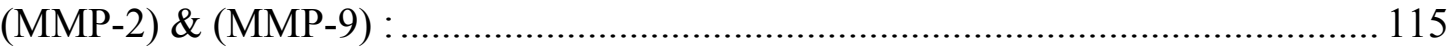

III-C-2 Impact de la modulation de la voie dépendante des ROS sur l'expression métalloprotéasique de la proMMP-1 en présence d'hIL-1 $\beta$ : ..................................... 117

III-C-2-a Etude de la viabilité cellulaire des chondrocytes C-20/A4 en co-incubation

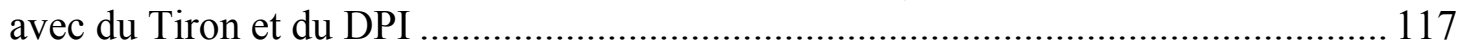

III-C-2-b Effet de l'hIL-1 $\beta$, à 23h d'incubation en présence de TIRON ou de DPI sur

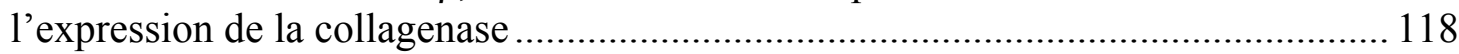

III-D Impact de la surexpression de Nox4 sur l'expression métalloprotéasique de proMMP-

1 dans la lignée $\mathrm{C} 20 / \mathrm{A} 4$ : 
III-D-1 Validation de la surexpression stable de Nox4A-V5/his, Nox4B-V5/his, et

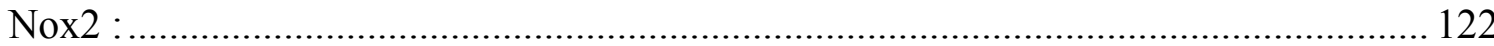

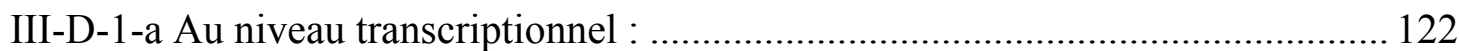

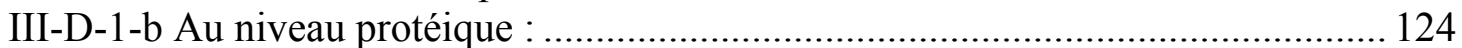

III-D-2 Impact sur l'activité NAD(P)H oxydase des lignées surexprimant Nox4A ou

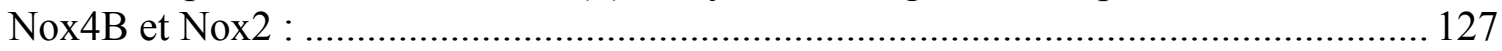

III-D-2-a Détermination de la production de ROS par la méthode d'oxydation du

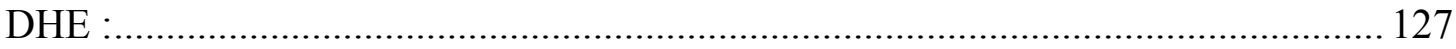

III-D-2-b Détermination de la production de ROS par chimiluminescence dans les chondrocytes surexpimant Nox4:

III-D-3 Impact de la modulation de la production de ROS sur sur l'expression de la pro MMP-1 dans les lignées surexprimant Nox4A, Nox4B ou Nox2 en présence d'hIL-1 $\beta$ :

作

: 142

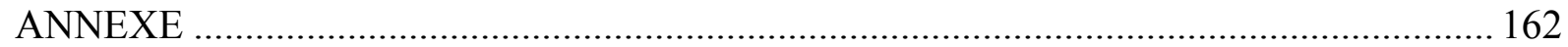




\section{Légendes des tableaux}

TABLEAU 1 CYTOKINES ET FACTEURS DE CROISSANCE DE L'ARTICULATION ARTHROSIQUE : ACTIVITES POTENTIELLES ET ORIGINES (WESTACOTT, 1996, MAZIERES 1997)

TABlEAU 2 FAMille DES MMPs HUMAINES (D’APRES NAGASE ET COLL. 1997 \& 1999ET ACTUALISE SEPTEMBRE 2006).

TABLEAU 3 : PREPARATION DES GELS DE SDS-PAGE...... 52

TABLEAU 4 AMORCES OLIGONUCLEOTIDIQUES UTILISEES 76

TABLEAU 5 ANTICORPS MONO CLONAUX ET POLYCLONAUX UTILISES AVEC LA SEQUENCE PROTEIQUE DE LEUR EPITOPE RESPECTIF

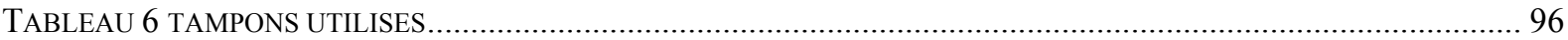

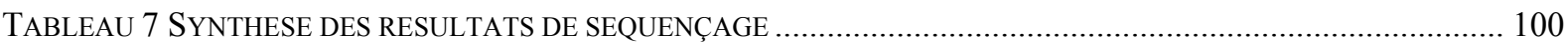

TABLEAU 8 SYNTHESE DU PHENOTYPE DES CELLULES DE LA LIGNEE C-20/A4 ............................................ 106

TABLEAU 9 VIABILITE CELLULAIRE APRES STRESS CYTOKINIQUE PAR HIL-B APRES 23H D'INCUBATION SUR LA LIGNEE DE CHONDROCYTES (C-20/A4) PAR LA METHODE D'EXCLUSION AU BLEU TRYPAN....................... 113

\section{Légendes des figures}

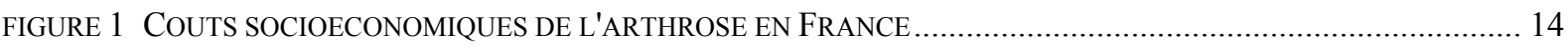

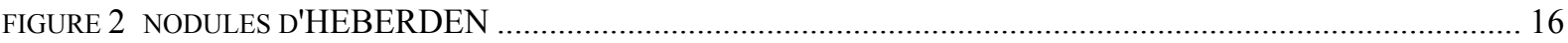

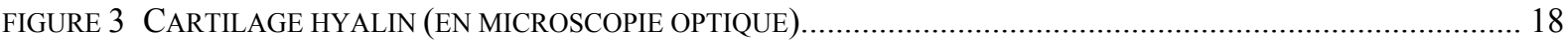

FIGURE 4 CHONDROCYTES EN CULTURE (MICROSCOPIE ELECTRONIQUE A BALAYAGE). .....................................20

FIGURE 5 STRUCTURE DES PROTEOGLYCANES ET SCHEMA DE LA MATRICE EXTRACELLULAIRE DU CARTILAGE

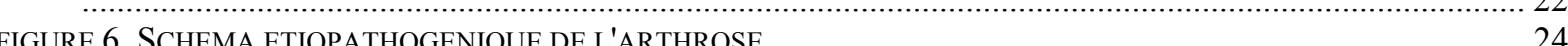

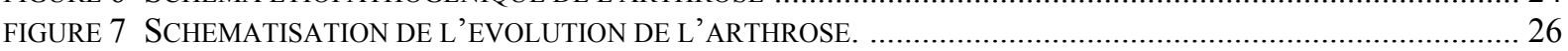

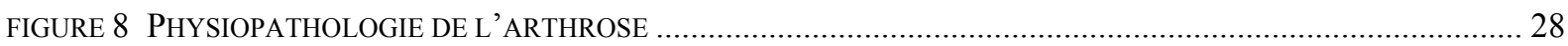

FIGURE 9 BALANCE DES CYTOKINES ET DES FACTEURS DE CROISSANCE EN FONCTION DE LEURS MODES D'ACTION

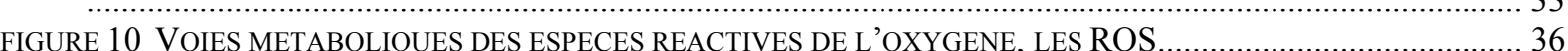

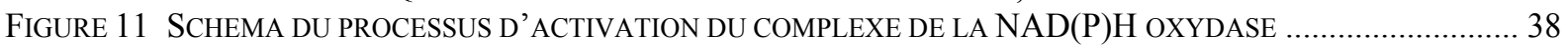

FIGURE 12 MODELE DU COMPLEXE TRIMERIQUE P40-P47-P67 ${ }^{\text {PHOX }}$ DANS LES CELLULES AU REPOS.......................... 39

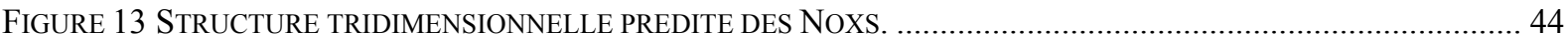

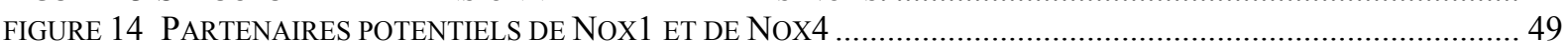

FIGURE 15 STRUCTURE EN DOMAINES DES METALLOPROTEASES MATRICIELLES .............................................. 54

FIGURE 16 PRINCIPALE VOIE DE SIGNALISATION REGULANT LA TRANSCIPTION DE LA COLLAGENASE-1 DANS LES

CHONDROCYTES APRES UNE STIMULATION PAR L'IL-1 .................................................................... 58

FIGURE 17 REPRESENTATION SCHEMATIQUE DES PRINCIPALES SOURCES DE ROS DANS LE CHONDROCYTE.......... 61

FIGURE 18 VOIES DE SIGNALISATION IMPLIQUEES ET MECANISMES DE REGULATION PAR LES ROS DANS LE

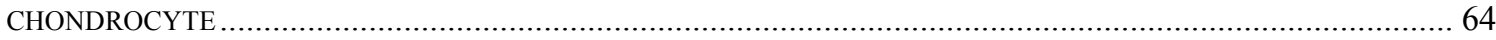

FiguRE 19 CHONDROCYTE C-20/A4 EN CULTURE (PHOTOGRAPHIE MICROSCOPIE OPTIQUE X 250) .....................6 68

FigurE 20 DETERMINATION DE LA CONCENTRATION OPTIMALE D'ACIDE ARACHIDONIQUE (AA) A UTILISER POUR

LA MESURE DE L'ACTIVITE NAD)P)H OXYDASE IN VITRO, PAR REDUCTION DU NBT ............................... 74

FIGURE 21 SPECTRE REDOX DU CYTOCHROME B $_{558}$ PURIFIE A PARTIR DE PMN ............................................ 78

FIGURE 22 GAMME D'ETALONNAGE DU DOSAGE DE LA PRO-MMP-1 PAR TECHNIQUE ELISA ....... 79

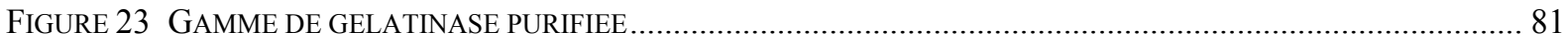

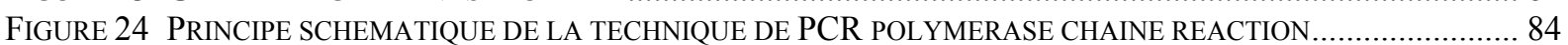

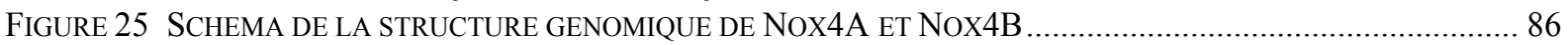

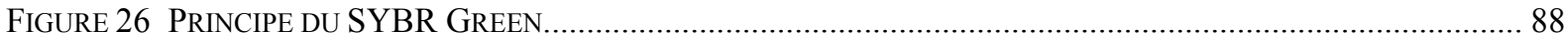

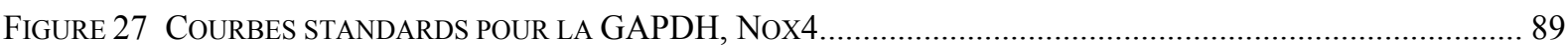

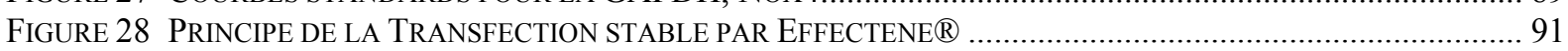

FIGURE 29 ANALYSE TRANSCRIPTIONELLE PAR RT-PCR DE L'EXPRESSION DES NOX ET DE LEURS PARTENAIRES SUR LES LIGNEES C-20/A4, T/C-28A2, C-28/I2 ..................................................................... 99

FIGURE 30 IMMUNOBLOTS DES TROIS LIGNEES DE CHONDROCYTES (C-20/A4, T/C-28A2 ET

C-28/I2).- SDS-PAGE $10 \%$. 


\section{Sommaire}

FIGURE 31 ANALYSE DE L'EXPRESSION PROTEIQUE DE NOX4, GP91 ${ }^{\text {PHOX }}$ ET P22 $2^{\text {PHOX }}$ PAR CYTOMETRIE EN FLUX SUR LA LIGNEE C-20/A4.

FIGURE 32 SPECTRES DIFFERENTIEL REDOX D’EXTRAIT TRITON X 100 1\% MEMBRANAIRE DE TROIS LIGNEES DE CHONDROCYTES COMPAREES A CELUI DE PMN HUMAINS

FIGURE 33 DOSAGE DE L'ACTIVITE OXYDASE PAR CHIMILUMINESCENCE SUR CELLULES ENTIERES DE LA LIGNEE C20/A4

FIGURE 34 MESURE D'ACTIVITE NAD(P)H OXYDASE RECONSTITUEE EN MILIEU ACELLULAIRE AVEC LE SYSTEME HETEROLOGUE « MEMBRANES CHONDROCYTE / CYTOSOL NEUTROPHILES HUMAINS »........................... 109

FIGURE 35 SCHEMA SIMPLIFIE DU DESIGN DE L'EXPERIMENTATION DE DETERMINATION DU TEMPS OPTIMAL D'INCUBATION EN PRESENCE D' HIL-1ß.

FIGURE 36 EFFET DE L'HIL-1ß SUR L'EXPRESSION DE LA PRO MMP-1 DANS LE SURNAGENT DU MILIEU DE CULTURE AU COURS DU TEMPS : DETERMINATION DU TEMPS OPTIMAL D'INCUBATION ....

FigURE 37 VIABILITE CELLULAIRE APRES STRESS CYTOKINIQUE PAR HIL-B APRES 23H D'INCUBATION SUR LA LIGNEE DE CHONDROCYTES (C-20/A4).

FIGURE 38 EXPRESSION DE LA PRO MMP-1 SOUS HIL-1B APRES 23H D'INCUBATION PAR LA LIGNEE CHONDROCYTAIRE C-20/A4.

FIGURE 39 ZYMOGRAPHIE SUR MINI- GEL DE POLY-ACRYLAMIDE CONTENANT $0.5 \%$ DE GELATINE DE SURNAGEANT DE MILIEU DE CULTURE DE CHONDROCYTE C-20/A4 A T0 ET AT23H APRES INCUBATION EN PRESENCE DE 500PG/ML D'HIL-1 ß HUMAINE

Figure 40 MESURE DE LA VIABILITE CELLULAIRE DES CHONDROCYTES C-20/A4 APRES 23H D'INCUBATION EN

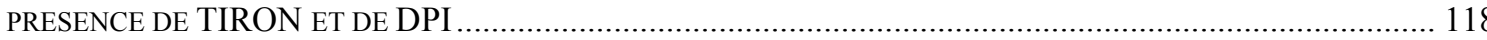

Figure 41 MESURE DE LA VIABILITE CELLULAIRE DES CHONDROCYTES C-20/A4 APRES 23H D'INCUBATION EN PRESENCE OU NON DE TIRON, DE DPI ET D' HIL-1 § ..................................................................... 119

FIGURE 42 EFFET SUR LES CHONDROCYTES C-20/A4 DE L'HIL-1 (500 NG/ML) MODULE PAR LA CO-INCUBATION AVEC DU TIRON ( $5 \mathrm{MM})$ OU DU DPI $(10 \mu \mathrm{M})$ SUR L'EXPRESSION DE LA PRO MMP-1 APRES 23H D'INCUBATION.

FIGURE 43 EFFICACITE D'EXPRESSION DES PLASMIDES D'INTERETS SUR LES CELLULES C-20/A4 TRANSFECTEES

FIGURE 44 EXPRESSION PROTEIQUE DE NOX2 ET NOX4 PAR CYTOMETRIE DE FLUX...................................... 125

FIGURE 45 EXPRESSION PROTEIQUE DE NOX4 PAR SPECTRES REDOX DIFFERENTIELS DU CYTOCHROMEB $558 \ldots . . .126$

FIGURE 46 DETERMINATION DE LA PRODUCTION DE RADICAL OXYDANT PAR LA METHODE D'OXYDATION DU DHE EN MICROSCOPIE A FLUORESCENCE.

FIGURE 47 DOSAGE DE L'ACTIVITE OXYDASE PAR CHIMILUMINESCENCE SUR CELLULE ENTIERE DE LA LIGNEE C20/A4

FIGURE 48 MODULATION DE L'EXPRESSION DE LA PRO-MMP-1 PAR NOX4 SUR LA LIGNEE CHONDROCYTAIRE C20/A4

FIGURE 49 MODULATION DE L'EXPRESSION DE LA PRO-MMP-1 PAR NOX4 SUR LA LIGNEE CHONDROCYTAIRE C20/A4 NOX4A-V5/HIS APRES TRANSFECTION AVEC UN PLASMIDE CODANT POUR UN DOMINANT NEGATIF DE Nox4

Figure 50 PROPOSITION DE LA SCHEMATISATION DU ROLE DE NOX4 DANS LA PHYSIOPATHOLOGIE DE 


\section{Abréviations}

\begin{tabular}{|c|c|}
\hline AA & Acide Arachidonique \\
\hline $\mathrm{AC}$ & Anticorps \\
\hline ADAMT & A DisintegrinAnd Metalloproteinase with Thrombospondin motifs \\
\hline $\mathrm{ADN}$ & Acide désoxyribonucléique \\
\hline $\mathrm{ADNc}$ & ADN complémentaire \\
\hline ARN & Acide ribonucléique \\
\hline ARNm & Acide ribonucléique messager \\
\hline DFP & Diisopropyl fluorophosphate \\
\hline DHE & Dihydroethidium \\
\hline DMEM & « Dubelcco's Modified Eagle's Medium » \\
\hline DMF & Diméthyl formamide \\
\hline DMSO & Dimethyl sulfoxyde \\
\hline DPI & Diphényliodonium \\
\hline EBSS & Earle's Balanced Salt Solution \\
\hline EGTA & Acide ethyléne glycoltetraacétique \\
\hline EDTA & Acide ethylene diamine tetraacétique \\
\hline ELISA & Enzyme Linked ImmunoSorbent Assay \\
\hline FAD & Flavine adénine dinucléotide \\
\hline FMLP & Formyl-méthionyl-leucyl-phénylalanine \\
\hline GTP $\gamma \mathrm{S}$ & Guanosine-5'-O- (3-thiotriphosphate) \\
\hline $\mathrm{H}_{2} \mathrm{O}_{2}$ & Peroxyde d'hydrogène \\
\hline HEPES & Acide hydroxyéthyl-pipérazine-éthane-sulfonique \\
\hline HRPO & Horse Radish Peroxidase \\
\hline IG & Immunoglobuline \\
\hline IL $1-\beta$ & Interleukine-1beta \\
\hline $\mathrm{kDa}$ & Kilodaltons \\
\hline LB-EBV & Lymphocytes B immortalisés par le virus d'Epstein-Barr \\
\hline $\mathrm{LDH}$ & Lactate dehydrogenase \\
\hline MMP & Matrix Metalloprotéinase \\
\hline NAC & $N$-Acetyl Cysteine \\
\hline $\mathrm{NAD}(\mathrm{P}) \mathrm{H}$ & Nicotinamide adénine dinucléotide phosphate (forme réduite) \\
\hline $\mathrm{NE}$ & Nombre d'événements \\
\hline NBT & Nitrobleu de Tétrazolium \\
\hline $\mathrm{O}_{2}^{-}$ & Ions superoxyde \\
\hline $\mathrm{pb}$ & Paires de bases \\
\hline PBS & Tampon phosphate isotonique « Phosphate Buffer Saline » \\
\hline PCR & «Polymerase chain reaction $»$ \\
\hline PG & Protéoglycane \\
\hline PHOX & Phagocyte oxidase \\
\hline PMA & «Phorbol myristate acétate » \\
\hline PMSF & Phényl méthyl sulfonyl fluorure \\
\hline PMN & Polynucléaires neutrophiles \\
\hline $\mathrm{p} / \mathrm{V}$ & Poids pour volume \\
\hline RLU & «Relative Luminescent Unit » \\
\hline ROS & «Reactive Oxygen Species » \\
\hline SDS & Sodium dodécyl sulfate \\
\hline SDS-PAGE & Electrophorèse en gel polyacrylamide en présence de SDS \\
\hline SOD & Superoxyde dismutase \\
\hline SVF & Sérum de veau fœtal \\
\hline TAE & Tampon « Tris- Acétate -EDTA » \\
\hline TBE & Tampon « Tris-Borate-EDTA » \\
\hline TIMP & Tissue Inhibitor of Metalloprotéinase \\
\hline TLCK & No-p-Tosyl-L-Lysyl-Chlorométhyléthylène diamine \\
\hline TNF- $\alpha$ & Tumor Necrosis Factor \\
\hline TRIS & Tris (hydroxyméthyl) aminométhane \\
\hline U.A. & Unité arbitraire \\
\hline UV & Ultra-violet \\
\hline $\mathrm{v} / \mathrm{v}$ & Volume pour volume \\
\hline WT & Wild type ou sauvage \\
\hline
\end{tabular}


INTRODUCTION 


\section{INTRODUCTION :}

L'arthrose est une pathologie ostéo-articulaire centrée sur le cartilage, très fréquente, avec des conséquences fonctionnelles et socio économiques extrêmement importantes. Sa physiopathologie est complexe car de nombreux facteurs (mécaniques, humoraux, cytokiniques, cliniques) interviennent dans sa genèse et son développement. Nous proposons dans ce travail, de nous focaliser sur le stress oxydant et ses conséquences sur les mécanismes à l'origine de l'arthrose.

\section{I-A L'Arthrose :}

\section{I-A-1 Historique :}

L'arthrose est une pathologie rhumatismale ayant probablement toujours existé. En effet on retrouve des stigmates de lésions arthrosiques sur des squelettes du paléolithique. Ses premières descriptions documentées remontent au XVIII ${ }^{\mathrm{e}}$ siècle où Hunter décrit l'arthrite sèche de la hanche (Hunter 1743). Puis plus tard, Heberden décrit les nodosités des interphalangiennes distales retrouvées dans l'arthrose digitale (Heberden 1802).

La première vraie description anatomique remonte au $\mathrm{XIX}^{\mathrm{e}}$ siècle où Cruveilhier parle d'usure du cartilage (Cruveihier 1824).

Adams en 1857 puis Charcot en 1890 font la première description anatomoclinique contemporaine de l'arthrose sous le terme de rhumatisme chronique dégénératif (Adams 1857,

\section{Charcot 1890)}

Il faut attendre 1909 pour voir apparaître la séparation claire et moderne sur un plan nosologique, de l'arthrose, de la goutte, de l'arthrite tuberculeuse et de la polyarthrite rhumatoïde (Nicols 1909).

\section{I-A-2 Base épidémiologique :}

\section{I-A-2-a Définition :}

En 1994, l'OMS, (Organisation Mondiale de la Santé) et «l'American Academy of Orthopaedic Surgeons » ont proposé une définition officielle de cette pathologie :

« L'arthrose est la résultante des phénomènes mécaniques et biologiques qui déstabilisent l'équilibre entre la synthèse et la dégradation du cartilage et de l'os sous-chondral. Ce déséquilibre peut être initié par de multiples facteurs : génétiques, de croissance, métaboliques 
et traumatiques. L'arthrose touche tous les tissus de l'articulation diarthrodiale et se manifeste par des modifications morphologiques, biochimiques, moléculaires et biomécaniques des cellules et de la matrice cartilagineuse conduisant à un ramollissement, une fissuration, une ulcération et une perte du cartilage articulaire, une sclérose de l'os sous-chondral avec production d'ostéophytes et de kystes sous-chondraux. Quand elle devient symptomatique, l'arthrose entraîne douleur et raideur articulaires, un éventuel épanchement articulaire avec des degrés variables d'inflammation locale. »

Cette définition n'est qu'un reflet partiel d'une physiopathologie beaucoup plus complexe. Cependant elle reflète bien les différentes approches possibles de l'arthrose (Mazieres, 1989)

- Moléculaire du biochimiste.

- Morphologique de l'anatomopathologiste.

- Clinique du praticien.

- Iconographique du radiologue.

\section{I-A-2-b Epidémiologie et santé publique :}

L'arthrose est une affection rhumatologique chronique, extrêmement fréquente, touchant plus de $60 \%$ de la population âgée en France soit plus de 9 à 10 millions de patients dont 4 à 6 millions cliniquement symptomatiques (Le Pen et coll. 2005). Elle est la seconde cause d'invalidité après les maladies cardio-vasculaires (Felson et coll. 1988).

Sa prévalence générale (pourcentage de cas dans une population donnée à un moment donné) relevée par des dépistages radiologiques systématiques est de $52 \%$ des adultes pour une seule localisation. En fait elle varie en fonction de l'âge. Ainsi, dans les tranches d'âge les plus élevées, cette prévalence atteint $85 \%$. L'homme est aussi souvent affecté que la femme jusqu'à la cinquantaine. Au-delà (c'est-à-dire après l'âge de la ménopause) la fréquence augmente beaucoup plus chez la femme.

L'arthrose a un impact non négligeable sur la qualité de vie entrainant gêne fonctionnelle et douleurs. Une étude récente de Fautrel démontre que, sur une population de 10.412 patients (moyenne d'âge moyen de 66.2 ans avec un sex ratio F/M à 1,96) ayant consulté pour arthrose en France en 2000, 80 \% ont une limitation de leur activité quotidienne et 64,4 \% des patients ayant encore une activité professionnelle ont une gêne durant leur travail (Fautrel et coll. 2005). 


\section{I-A-2-c Poids socio économique :}

Le poids socio économique de l'arthrose est extrêmement lourd. Ainsi, en France, en 1989, on chiffre les coûts directs et indirects de l'arthrose à plus de 6 milliards de francs par an (Figure 1). Elle est responsable annuellement de 8,7 millions de consultations qui génèrent 14 millions d'ordonnances, 300000 examens radiologiques au moins, 100000 journées d'hospitalisation. Elle représente en 1993 0,8 \% des dépenses de santé en France (Levy et coll. 1993). En effet, chaque année en France, l'arthrose est la principale cause de mise en place des 50000 prothèses de hanches et 20000 prothèses de genoux

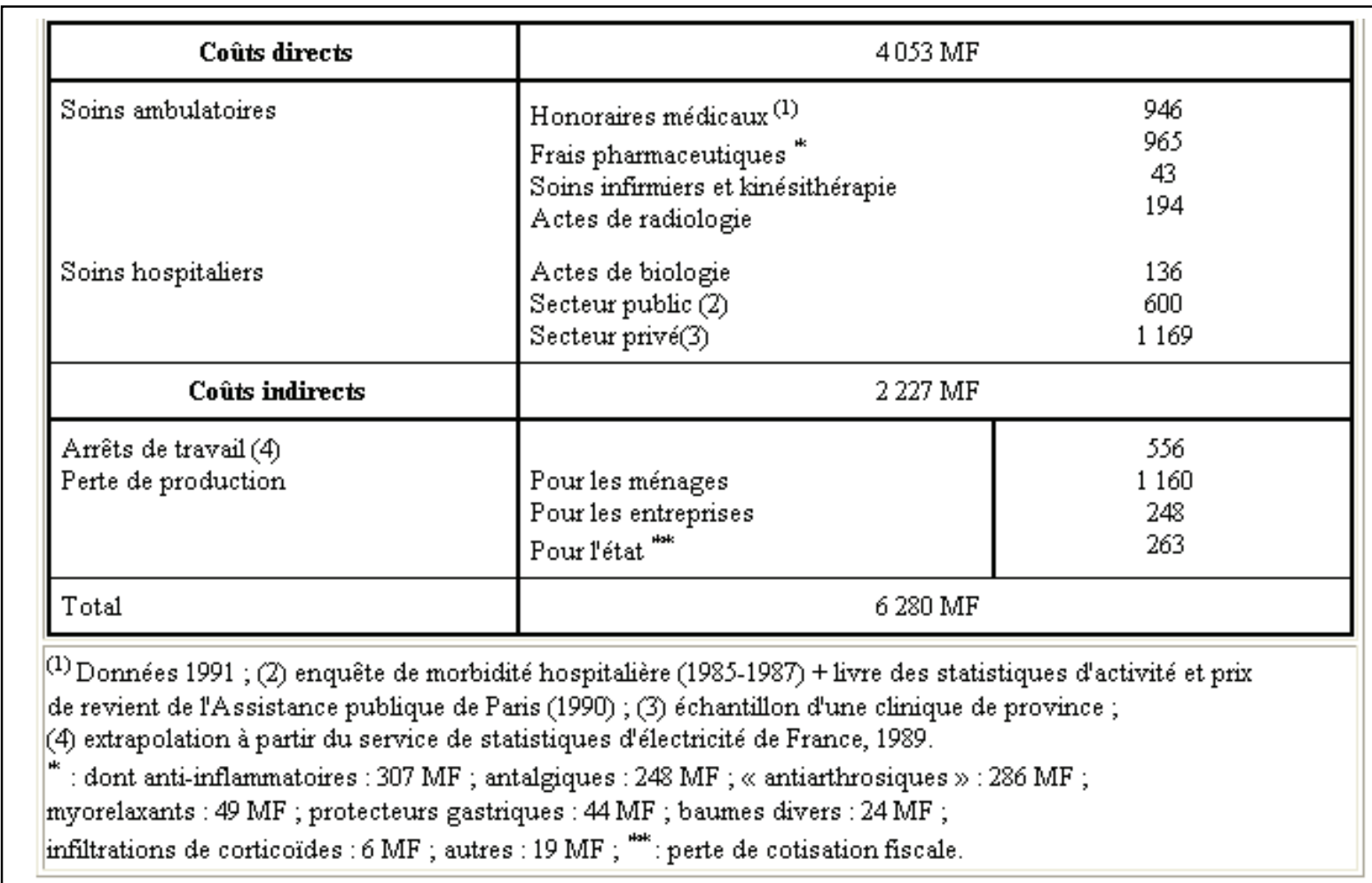

\section{Figure 1 Coûts socioéconomiques de l'arthrose en France}

(en millions de francs) tiré de Mazières EMC, 1997 selon Levy, 1993)

\section{I-A-3 Facteurs de risque :}

Les facteurs de risque sont multiples et imparfaitement définis. On retrouve de manière certaine l'âge, l'ethnie, le surpoids et le sexe féminin.

L'arthrose des genoux est ainsi plus fréquente chez les Noires américaines et les Jamaïcaines que chez les Blanches, alors que la coxarthrose est plus rare en Jamaïque, en Afrique du Sud, au Nigeria ou au Libéria qu'en Europe.

Les œstrogènes jouent-ils un rôle protecteur contre l'arthrose ? Certaines études semblent démontrer un lien entre ostrogènes et arthrose, d'autres non. Récemment, l'absence de 
traitement hormonal de la ménopause semble être retrouvée comme facteur de risque d'arthrose digitale et de gonarthrose par une équipe australienne (Szoeke et coll. 2006).

Les traumatismes et micro traumatismes répétés, soit au cours de la vie professionnelle, de loisirs, ou de sports sont aussi des facteurs de risque reconnus. Les sports collectifs, de contact, surtout pratiqués en compétition, et débutés avant la puberté, sont les plus «arthrogènes » (Lane et coll. 1995)

En fonction des localisations, différents facteurs de risque spécifiques sont retrouvés comme l'obésité pour la gonarthrose et l'arthrose digitale, ou l'activité physique réalisée dans les premières années de la vie adulte (Szoeke et coll. 2006).

Les facteurs héréditaires semblent aussi être importants notamment dans l'arthrose digitale.

Par exemple l'arthrose serait liée à la présence de certains allèles de l'antigène d'histocompatibilité HLA-DRB1 dans une population italienne (Rovetta et coll. 2006). Une anomalie du gène codant pour le télopeptide du procollagène II en position $519 \mathrm{du}$ codon, transformant une cystéine en arginine est liée à une arthrose familiale au niveau des hanches et des genoux (Palotie et coll. 1989).

Le tabac semble à l'inverse être quant à lui plutôt protecteur (Felson et coll. 1989, Szoeke et coll. 2006).

Enfin les déformations articulaires (comme le défaut d'alignement en varus ou valgus par exemple) dans la gonarthrose et les lésions intra articulaires font le lit de l'arthrose.

\section{I-A-4 Signes cliniques et radiologiques de l'arthrose :}

L'arthrose est un syndrome anatomoclinique fait d'une douleur mécanique évoluant parfois par poussées, associée à une raideur et une déformation à un stade tardif, parfois à un épanchement articulaire. L'évolution est faite de poussées aigues (poussée « douloureuse » ou « congestive» ou « inflammatoire ») pouvant évoluer sur un mode plus chronique fait de douleurs et d'impotence fonctionnelle qui affectent la vie quotidienne de ces patients.

Les signes cardinaux de l'arthrose sont

- Douleur mécanique survenant à l'effort ou à la mise en charge, donc souvent en fin de journée, en début d'évolution pour être plus permanente avec l'évolution de la maladie. Elle est calmée par le repos. Elle ne réveille pas le malade endormi. 
- Raideur articulaire avec impotence fonctionnelle, limitation d'amplitude articulaire et déformation des articulations (nodule d'Heberden et de Bouchart par exemple cf. Figure 2)

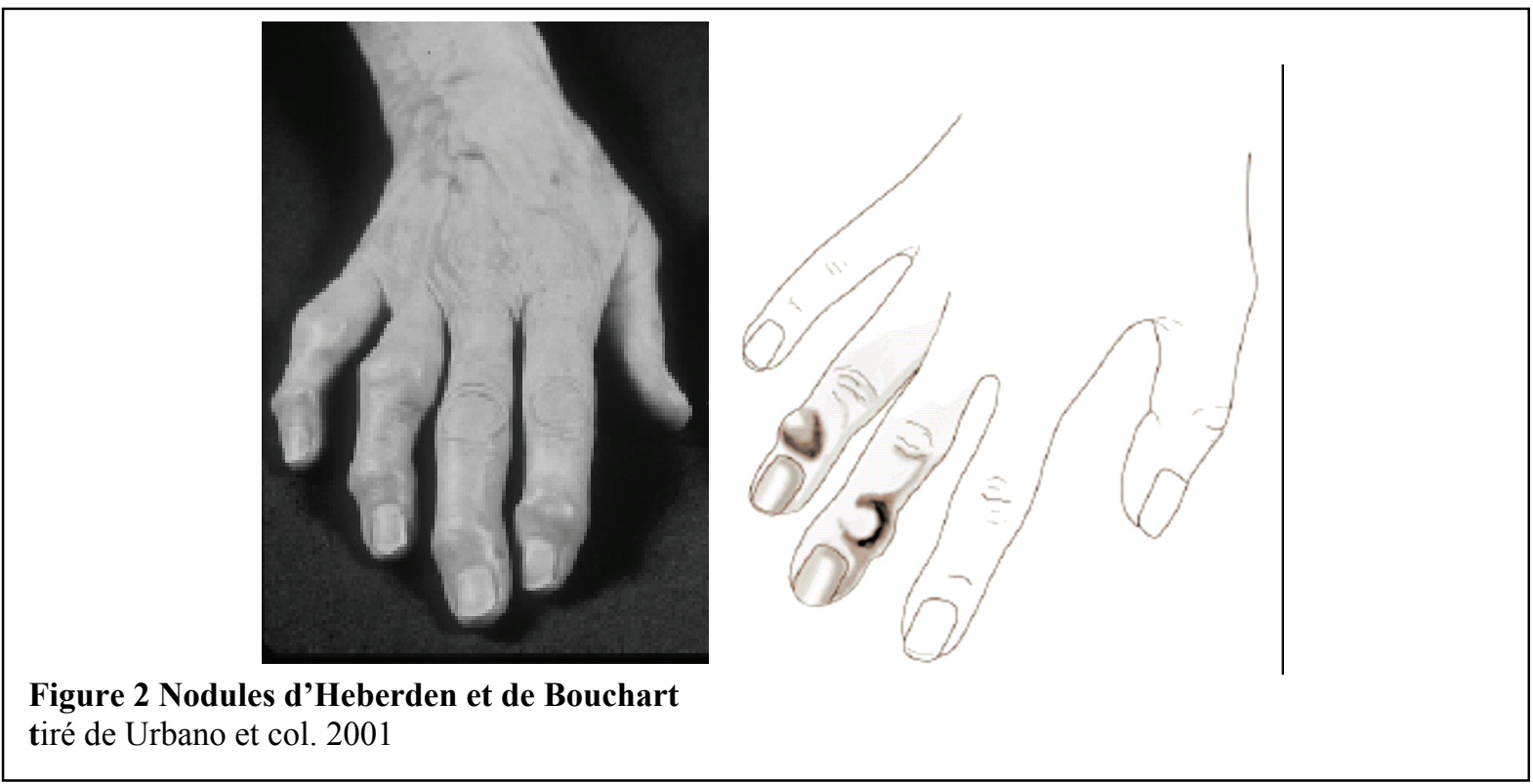

- Un épanchement articulaire de type mécanique est parfois retrouvé et caractérisé par la présence de moins de 2000 éléments blancs $/ \mathrm{mm}^{3}$.

Sur le plan radiologique on retrouve les signes classiques :

- un pincement articulaire

- une sclérose sous-chondrale plus ou moins associée à des géodes.

- une ostéophytose implantée à la jonction os-cartilage.

\section{I-A-5 Physiopathogénie de l'arthrose :}

\section{I-A-5-a Les acteurs de l'arthrose :}

\section{Le cartilage articulaire :}

Il assure le glissement des surfaces osseuses grâce à un coefficient de friction extrêmement faible. Il est résistant, élastique et lubrifié. Il joue un rôle d'amortisseur, et absorbe les pressions auxquelles il est soumis.

Sur le plan histologique, le cartilage articulaire est un tissu conjonctif dont l'aspect translucide lui a donné le nom de «hyalin». Ce type de cartilage contient peu de fibres et uniquement des 
fibres de collagène de petit calibre. Il ne comporte aucun vaisseau artériel, veineux ou lymphatique et aucune fibre de terminaison nerveuse.

Le cartilage articulaire se présente comme un tissu ferme, élastique, légèrement dépressible, à la surface lisse à l'œil nu, brillante, blanc bleuté chez le sujet jeune et blanc jaunâtre chez le sujet âgé. Il est dépourvu d'une grande capacité de régénération et se nourrit par capillarité dans le liquide articulaire, mais également grâce à des échanges avec l'os sous-chondral. La pression hydrostatique qu'il subit joue un rôle vital dans sa nutrition (Vignon et coll. 1980).

Le cartilage est une structure vivante mais son renouvellement est extrêmement lent. Il est pratiquement nul pour le collagène de type II au cours de la vie, et la demi-vie des protéoglycanes de la matrice extra cellulaire est de 1000 jours (Chevalier et coll. 1998). Il existe un turnover normal faible en péricellulaire du collagène dans le cartilage des sujets jeunes qui augmente chez les sujets plus âgés avec un marquage des collagènes dénaturés et dégradés plus intense et plus diffus.

En outre, l'activité métabolique et la réponse au stress mécanique varient d'une articulation à l'autre. En particulier, il a été montré à partir de cartilages issus de la cheville que ceux-ci possédaient un taux élevé d'inhibiteurs des enzymes matricielles qui pourrait rendre compte de la très faible prévalence de l'arthrose dans cette localisation. (Cole et coll. 2003).

\section{Aspect microscopique du cartilage :}

Le cartilage articulaire est constitué de 4 couches histologiques de la superficie vers la profondeur (Buckwalter et coll. 1998, Chevalier et coll. 2005) (Figure 3).

- La couche superficielle ou tangentielle est en contact avec le liquide synovial et sert de glissement aux pièces articulaires. Elle représente 5 à $10 \%$ de la hauteur totale du cartilage. Cette couche peut être subdivisée en deux zones: la zone en contact avec le liquide synovial composée d'un film de micro fibrilles avec peu de protéoglycanes et pas ou peu de cellules, et une zone plus profonde contenant des chondrocytes plats et ellipsoïdaux, de grand axe parallèles à la surface articulaire. Les chondrocytes synthétisent du collagène de type I et III. Les fibrilles de collagène sont orientées parallèlement à la surface articulaire ce qui contribue fortement aux propriétés mécaniques du tissu en apportant une plus grande résistance aux tensions et aux pressions que dans les zones plus profondes. 
- La couche intermédiaire ou transitionnelle possède des fibres de collagène de types II, IX, et XI qui s'entrecroisent obliquement en un réseau non orienté moins dense que celui de la surface articulaire (arcades de Benninghoff). L'épaisseur de cette zone, la plus riche en protéoglycanes, représente environ 40 à $45 \%$ de l'épaisseur totale du cartilage. Les chondrocytes, de morphologie plus arrondie, sont plus actifs que dans la couche superficielle.

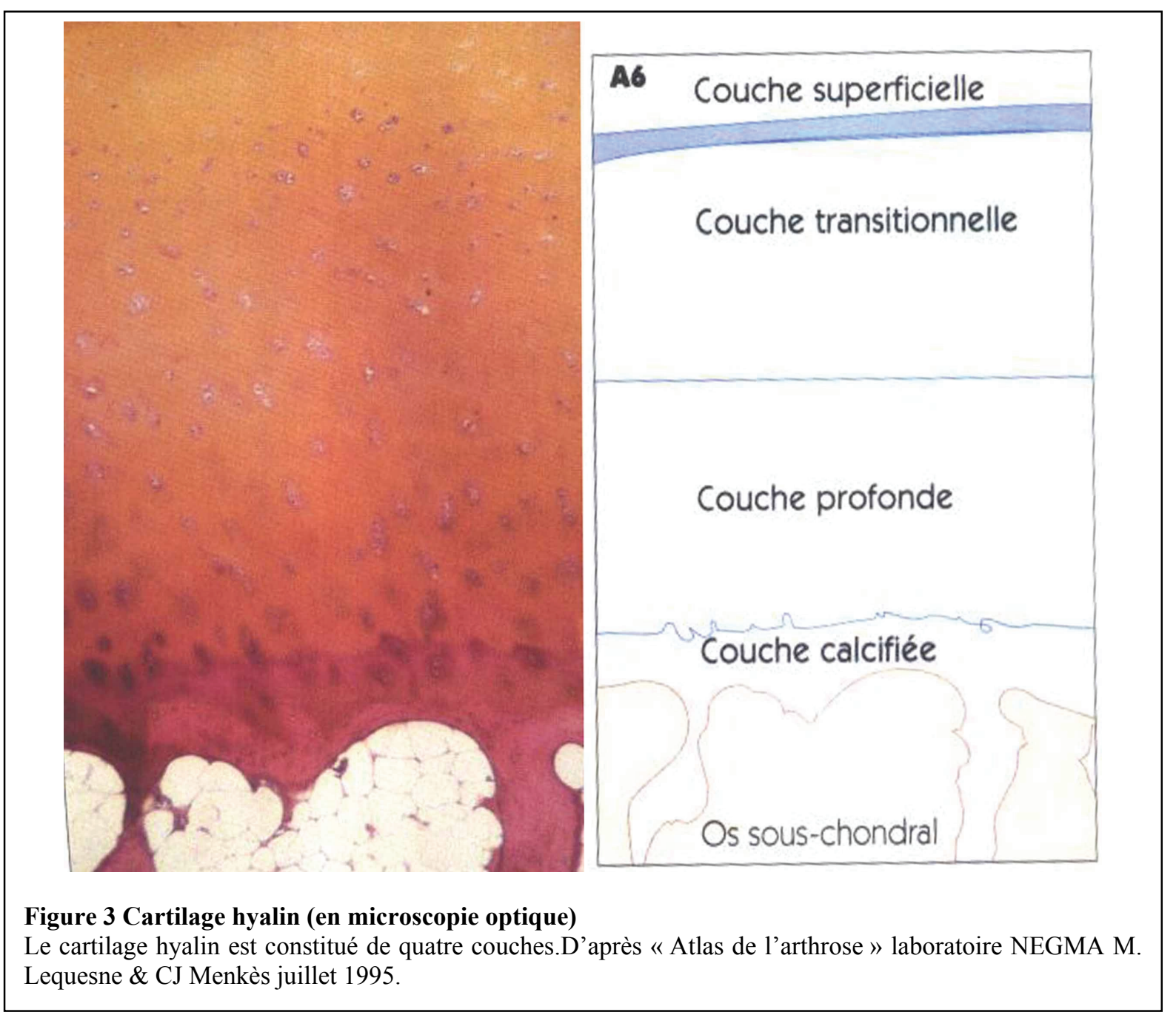

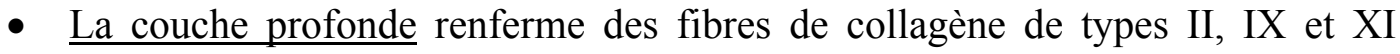
d'orientation perpendiculaire à la surface articulaire. Elle est par ailleurs, la région la plus pauvre en eau et la plus riche en protéoglycanes. Elle représente 40 à $45 \%$ de l'épaisseur du cartilage et renferme des chondrocytes abondants et ronds avec un aspect prolifératif dans la partie supérieure de cette couche.

- La couche calcifiée sert de zone d'ancrage aux fibres de collagène sur l'os et représente 5 à $10 \%$ de l'épaisseur totale du cartilage. 
La jonction entre la zone non calcifiée et la zone calcifiée est nettement visible en histologie et correspond à la «tidemark» ou front de minéralisation. Cette couche est caractérisée par la présence de cristaux d'hydroxyapatite et d'amas calciques au contact des fibres de collagène. Celle-ci correspond à un enchevêtrement extrêmement dense de fibres de collagène.

La jonction entre le cartilage calcifié et l'os sous-chondral est très irrégulière. Cette ligne de jonction a une résistance considérable. Elle est perforée par de rares vaisseaux venant des cavités de la moelle osseuse sous jacente.

\section{Composition du cartilage :}

Le cartilage hyalin est composé de chondrocytes (1\%) situés au sein d'une matrice extracellulaire principalement composée d'eau (65 à $80 \%$ du poids humide) et de macromolécules, essentiellement des protéines et des glycosaminoglycanes (20 à 35\% du poids humide du cartilage). Les fibres de collagène représentent environ $50 \%$ du poids sec, les glycoprotéines 15 à $20 \%$ du poids sec, et les protéoglycanes, dont la concentration varie en fonction de la profondeur et des régions anatomiques, 30 à $35 \%$ du poids sec (Chevalier et coll. 2005).

\section{Les chondrocytes :}

Le chondrocyte (Figure 4) unique type cellulaire du cartilage articulaire, est enfermé dans une matrice dite « extracellulaire », avec un environnement immédiat pauvre en collagène de type II, formant avec la cellule un « chondron ».

L'ensemble des chondrocytes n'occupe que le dixième du volume total. De plus, cette densité cellulaire varie en fonction de la profondeur du cartilage. La zone superficielle comporte le plus de cellules. Il semble exister un nombre fixe de chondrocytes qui décroît à partir de 20 ans chez l'homme. Cette densité cellulaire est variable en fonction de l'individu et, pour un même individu, du type d'articulation considéré.

Le chondrocyte est riche en lysosomes, en mitochondries et en vacuoles de glycogène. Il utilise essentiellement le glucose comme substrat énergétique. En raison du caractère avasculaire du cartilage (le pourcentage d' $\mathrm{O}_{2}$ est ici, inférieur à 7\%), il reçoit peu d'oxygène et donc doit privilégier la voie de la glycolyse anaérobie. Il a cependant besoin d'un minimum d'O$_{2}$, pour assurer ses fonctions cellulaires de base, ainsi selon la concentration d'oxygène du 
milieu ambiant cette cellule peut moduler et orienter son métabolisme. Le chondrocyte se nourrit par capillarité à partir du liquide synovial. Il a été montré que les chondrocytes des couches les plus superficielles pouvaient avoir en partie un fonctionnement aérobie par diffusion de $\mathrm{l}^{\prime} \mathrm{O}_{2}$ présent dans le liquide synovial. Les chondrocytes ne migrent pas et se multiplient peu ou pas dans un cartilage articulaire normal (Chevalier et coll. 2005).

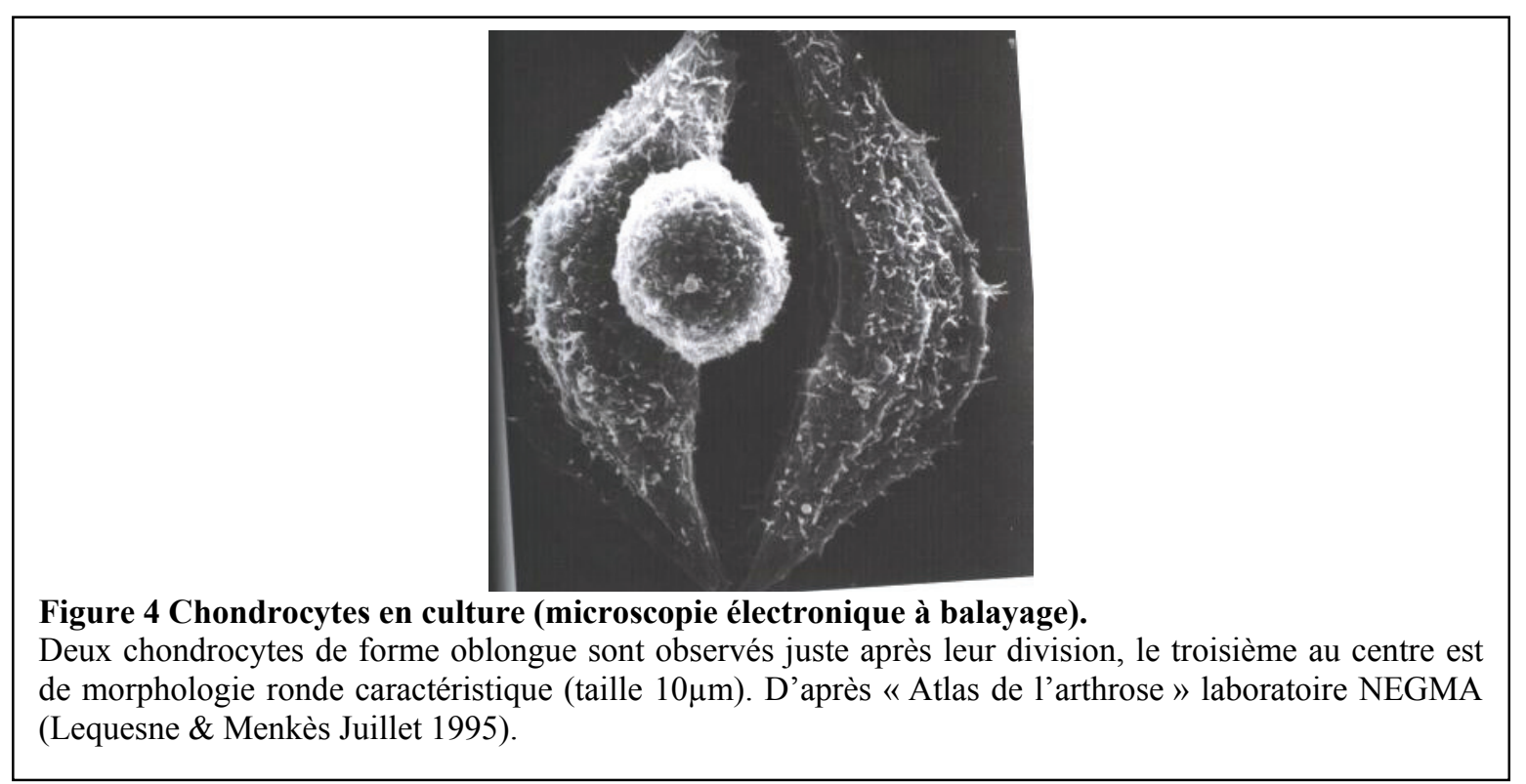

De plus, le chondrocyte doit consommer une quantité importante de glucose qu'il convertit en glucosamine pour réaliser la synthèse des protéoglycanes.

Le chondrocyte exprime de nombreux récepteurs à sa surface, en particulier des intégrines qui se comportent comme des mécanorécepteurs. Ces intégrines «agrafent» les différentes molécules présentes dans l'environnement direct du chondrocyte. Un changement (chimique ou physique), susceptible de désorganiser l'environnement cellulaire (équivalent d'une « déformation de la matrice »), va agir comme un signal pour le chondrocyte qui réagira en s'activant. Ainsi, le métabolisme du chondrocyte dépend de l'intensité et du rythme des pressions cycliques auquel il est soumis et qui déterminent son comportement métabolique.

Il est important de souligner que le chondrocyte est non seulement capable de produire la matrice extracellulaire mais également les enzymes capables de la dégrader : les protéases matricielles. En effet le chondrocyte est responsable en grande partie de l'homéostasie du cartilage qui est en renouvellement lent et le détruit autant qu'il le synthétise en condition normale.

Il possède ainsi l'ensemble du répertoire génétique lui permettant de synthétiser les différents produits de la matrice et des enzymes. 
Dans des cas pathologiques, il peut ainsi produire les cytokines pro-inflammatoires comme l'IL-1 ou le TNF-alpha provoquant la destruction du cartilage par augmentation de la synthèse et de l'activité des métalloprotéinases (Dijkgraaf et coll. 1995).

Les chondrocytes sont séparés de la matrice extracellulaire du cartilage par un espace péri cellulaire particulier où le $\mathrm{pH}$ est plus acide $(\mathrm{pH} 6,1)$ que dans le reste du tissu $(\mathrm{pH} 7,4)$. Les enzymes lysosomiales (cathepsines B) qui y sont libérées, étant activées par le pH acide, peuvent donc dégrader la matrice extracellulaire (Thenet et coll. 1992).

Le métabolisme des chondrocytes est en permanence influencé par les conditions physicochimiques qui règnent dans cet espace péri cellulaire (Wilkins et coll. 1995). Ainsi, l'application cyclique de forces sur des fragments de cartilage retentit sur le $\mathrm{pH}$ qui règne dans cet espace mais également sur la forme des chondrocytes. Il en résulte une modification des microfilaments d'actine du cytosquelette qui peut induire ou modifier l'expression de certains gènes. Il existe donc un lien direct entre les conditions physiques et physico-chimiques qui règnent autour du chondrocyte et son activité métabolique (Sommarin et coll. 1989).

L'activité du chondrocyte est régulée par des facteurs mécaniques, la déformation de la matrice engendrant des signaux mécaniques, électriques et physico-chimiques. Des facteurs de croissance assurent la régulation de l'activité cellulaire. Il s'agit de « l'Insulin-like growth factor » (IGF) (Burch et coll. 1986), du « Transforming Growth Factor bêta » (TGF $\beta$ ) et des «Bone Morphogenetic Proteins » (BMP) (Wang et coll. 1988, 1990) qui exprimés par le chondrocyte stimulent la synthèse des constituants de la matrice.

La matrice extracellulaire :

Les composants majeurs de la matrice extracellulaire (MEC) du cartilage sont l'eau (65-80\% du poids humide du tissu), les collagènes (10-30\% du poids humide) et les protéoglycanes (5$10 \%$ du poids humide) (Chevalier et coll. 2005).

La matrice est composée d'un réseau rigide de fibres de collagène fibrillaire de type II qui forme une armature solide (Figure 5). L'organisation des fibres de collagène de type II dans le cartilage ne se fait pas au hasard. Dans la couche la plus superficielle elles sont parallèles et permettent de résister aux forces de tension. Dans les couches les plus profondes, les fibrilles de collagène sont plus denses, plus épaisses, disposées autour des chondrocytes de façon plus anarchique et prenant une disposition perpendiculaire à la surface du cartilage dans la profondeur de celui-ci. Le collagène de type II, est un homotrimère formé de trois chaînes $\alpha 1$ représente $95 \%$ du collagène du cartilage. Les collagènes mineurs étant les collagènes de types VI, IX, X et XI 
Le protéoglycane est un polymère d'agrécanes (Figure 5). Cette molécule est formée d'une protéine porteuse sur laquelle viennent se fixer des molécules de glycosaminoglycanes représentées par de longues chaînes de chondroïtine sulfate ou de kératane sulfate. Ces monomères appelés agrécanes viennent à leur tour se brancher par l'intermédiaire d'une protéine de liaison sur une longue chaîne d'acide hyaluronique pour former des polymères de protéoglycanes. Ces agrécanes se regroupent en macro agrégats en se liant sur un autre glycosaminoglycane: l'acide hyaluronique. En raison de leur pouvoir hydrophile, les protéoglycanes retiennent les molécules d'eau et mettent sous tension les fibres de collagène.
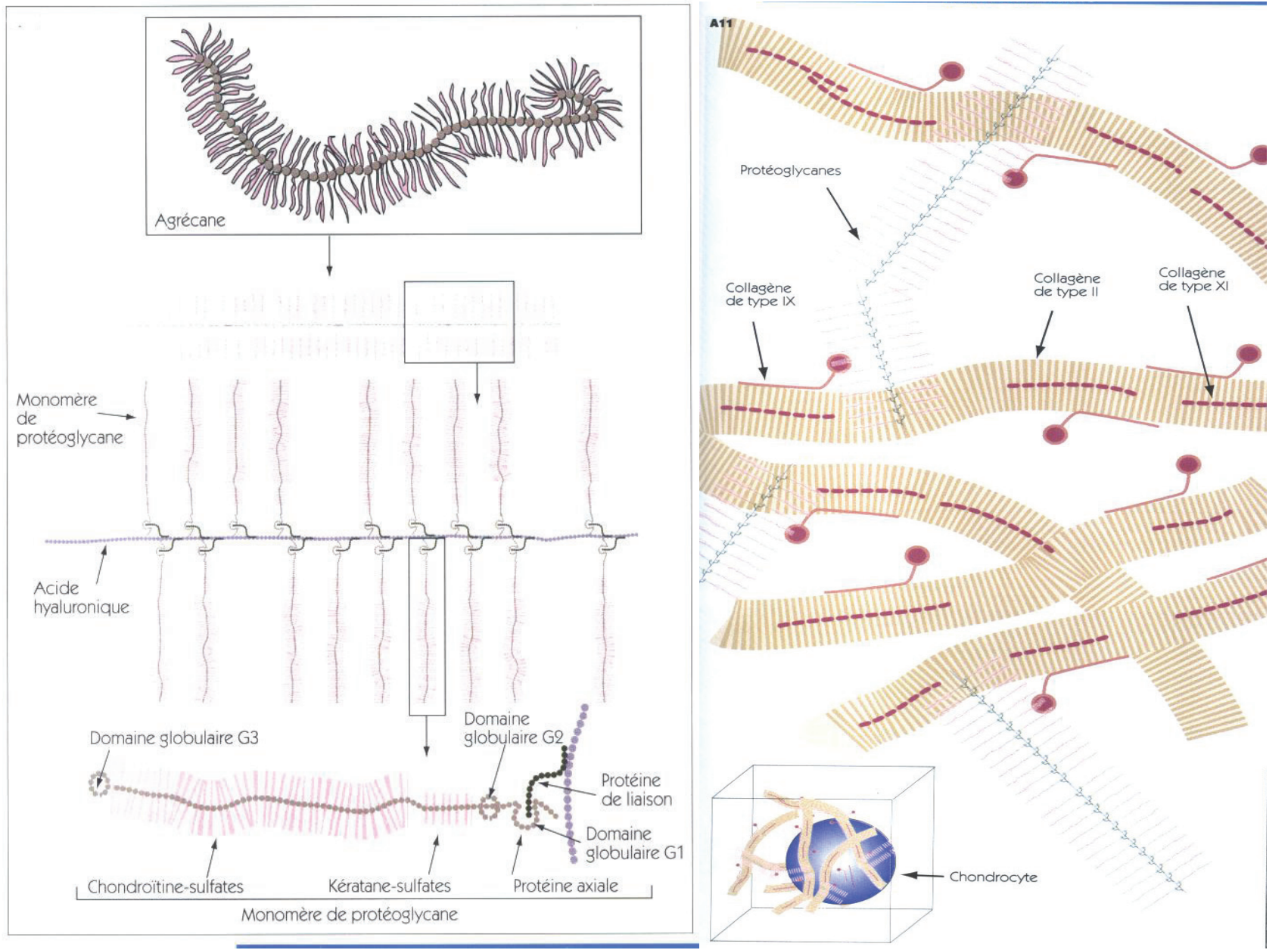

Figure 5 Structure des protéoglycanes (partie de gauche) et Schéma de la matrice extracellulaire du cartilage. le collagène forme un réseau fibrillaire tridimensionnel. La matrice est composée de fibre de collagène et de protéoglycanes D’après « Atlas de l'arthrose » laboratoire NEGMA M. Lequesne \& CJ Menkès Juillet 1995.

Sous l'effet de forces appliquées sur l'articulation, il se produit une sorte de mouvement de va et vient des molécules d'eau qui ont fait comparer ces protéoglycanes à d'énormes éponges.

Le maintien de l'ensemble de cette structure est assuré par de nombreuses protéines dites adhésives (COMP, fibromoduline, fibronectine) qui ont pour fonction de lier les 
macromolécules entre elles et de se lier aux protéines du chondrocyte. Il apparaît d'emblée que la structure très cohésive du cartilage lui permet d'assurer ses fonctions mécaniques.

De nombreuses autres protéines (anchorine CII, COMP, fibronectine, ténascine) interviennent également dans l'assemblage de la matrice et l'homéostasie du cartilage.

$\mathrm{Au}$ total, dans un cartilage mature adulte tout est parfaitement autorégulé : la survie des chondrocytes, l'équilibre synthèse/destruction de la matrice, l'architecture de la matrice.

\section{Le liquide synovial :}

Il s'agit d'un lubrifiant articulaire qui est également liquide nourricier du cartilage. C'est un liquide incolore, transparent secrété par les synoviocytes de la membrane synoviale qui tapisse la face interne de la capsule articulaire. Ce liquide lubrifie les surfaces articulaires et facilite le glissement de celles-ci au cours du mouvement. L'acide hyaluronique est son principal constituant.

\section{La membrane synoviale :}

La membrane synoviale tapisse les cavités articulaires, bourses séreuses et gaines tendineuses. Elle assure la trophicité du cartilage articulaire par le biais de la sécrétion du liquide synovial. Elle est composée essentiellement de fibres élastiques et de tissu adipeux. Elle apparaît macroscopiquement comme une membrane fine, lisse, de couleur jaune pâle, au travers de laquelle on distingue des vaisseaux de petit calibre et le tissu fibreux de la capsule. Elle constitue une barrière de filtration et de défense et se compose de 2 couches :

- la couche profonde qui fusionne avec la capsule. Elle renferme de nombreux vaisseaux, du tissu fibreux, des adipocytes, des fibroblastes, des lymphocytes et des macrophages.

- la couche superficielle en bordure composée d'une ou deux assises cellulaires de synoviocytes, qui synthétisent l'acide hyaluronique

La membrane synoviale représente une membrane d'échange et de filtration entre le liquide synovial et le sang. Les synoviocytes sont capables de produire différents acteurs pro inflammatoires intervenant dans l'arthrose comme par exemple, certaines cytokines telles que l'IL-1, l'IL-6, des radicaux libres, de la prostaglandine $\mathrm{E}_{2}$, et un certain nombre de métalloprotéases comme les MMP-1, MMP-3, MMP-9, MMP-10, MMP-12, MMP-17, MMP23, MMP-28, ADAMTS4, ADAMTS9 et ADAMTS16 (Davidson et coll. 2006). Enfin, elle participe activement aux phénomènes douloureux au cours de l'arthrose et des maladies inflammatoires, par son importante innervation. 


\section{I-A-5-b Etiopathogénie de l'arthrose :}

Les contraintes mécaniques essentiellement en pression semblent être la principale cause d'arthrose qu'elles soit physiologiques ou supra physiologiques aboutissant toutes à la dégénérescence du cartilage articulaire. (Figure 6).

En fait il faut distinguer deux grands types d'arthrose :

- Les arthroses liées à une pression supra physiologique s'exerçant sur un cartilage normal (on parle alors d'arthrose secondaire).

C'est le cas des dysplasies (dysplasie de hanche), des instabilités (rupture du ligament croisé antérieur, hyperlaxité), des surcharges (pondérale ou fonctionnelle par hyper utilisation sportive ou professionnelle), des incongruences articulaires (méniscectomie, maladie de LeggPerthes-Calvé, fracture intra-articulaire, cals vicieux de fractures diaphysaires).

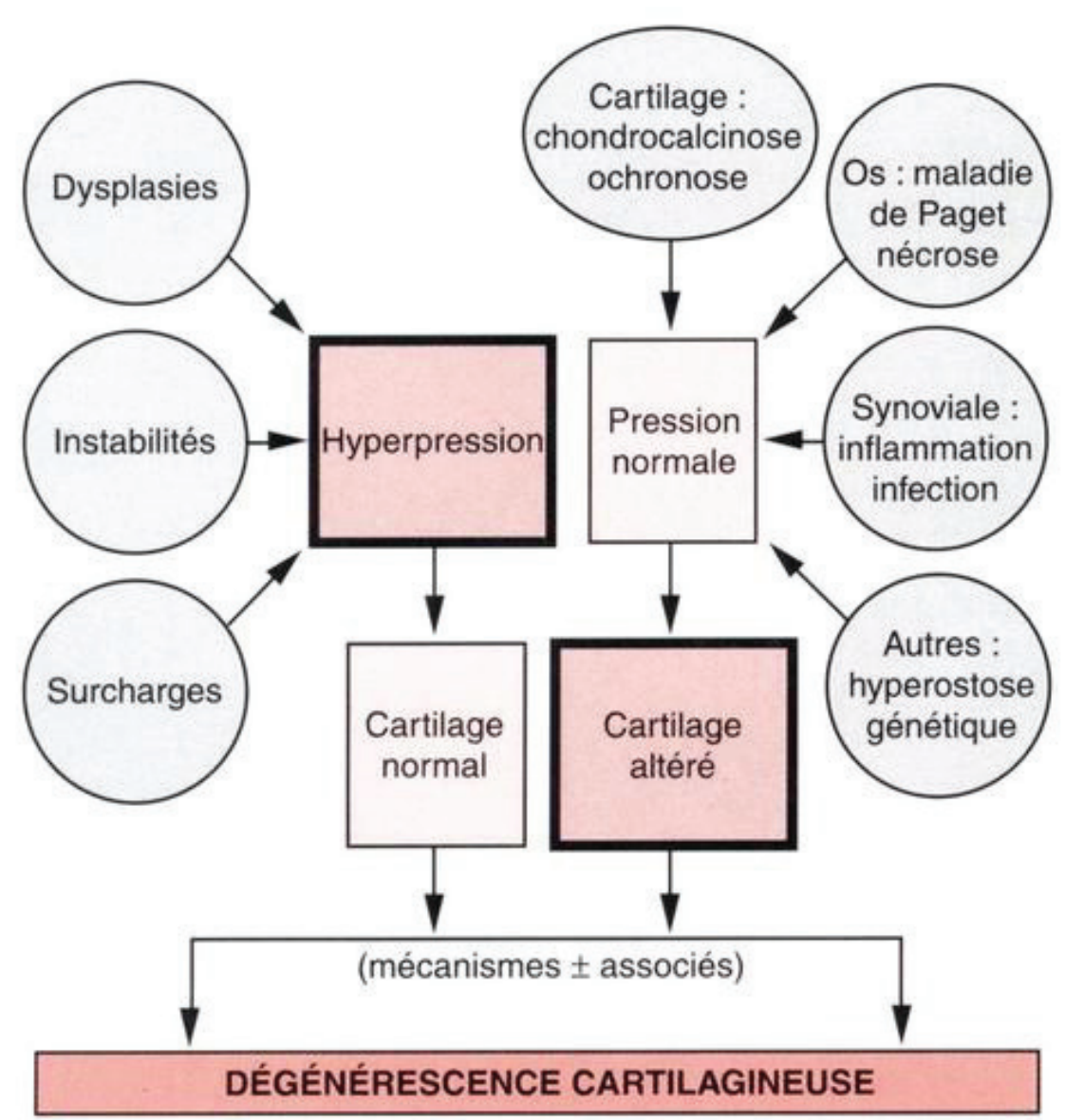

Figure 6 Schéma étiopathogénique de l'arthrose. (Tiré de Mazières EMC, 1993)

L'arthrose est liée à une dégénérescence cartilagineuse liée soit à une hyperpression sur un cartilage normal (arthroses mécaniques), soit à une pression normale s'exerçant sur un cartilage fragile (arthroses structurales) ou enfin soit une conjugaison des deux mécanismes. 
- Les arthroses peuvent être liées à une pression normale mais s'exerçant sur un cartilage anormal et fragile, (on parle alors d'arthrose primaire). C'est aussi le cas des formes héréditaires d'arthrose.

Les causes de cette fragilisation peuvent être intra-cartilagineuses (chondrocalcinose, ochronose, traumatisme direct ou contusion du cartilage), sous-chondrales (ostéonécrose épiphysaire, maladie de Paget, hyperparathyroïdie) ou à point de départ synovial (fragilisation par l'interleukine IL-1 et la collagénase (MMP1) venant d'une synoviale inflammatoire ou infectieuse).

En fait dans la plupart des cas l'origine de l'arthrose est le plus souvent multifactorielle, faisant considérer l'arthrose plus comme un syndrome qu'une véritable maladie en tant que telle.

\section{I-A-5-c Physiopathologie de l'arthrose :}

Sur un plan macroscopique, cette pathologie dégénérative correspond à une dégradation du cartilage. Progressivement apparaissent fissures, remaniements de l'os sous chondral et développement d'ostéophytes sur les zones non portantes pour aboutir aux pincements puis à la disparition de l'espace articulaire (Figure 7). Cette chronologie semble évoluer en trois stades qui se succèdent, sachant que sur une surface cartilagineuse, les lésions ne sont pas forcément toutes au même stade évolutif.

- Stade initial

(Schéma A sur la Figure 7)

$\mathrm{Au}$ stade initial, le cartilage est oedématié. Cette réponse à l'agression initiale du tissu peut être assimilée à une tentative de réparation du cartilage sous l'effet de facteurs de croissance chondrocytaires, qui va échouer pour des raisons encore mal comprises. Ainsi l'activation des chondrocytes va augmenter leur activité anabolique et catabolique (Buckwalter et coll. 1998). Dans un premier temps, l'équilibre entre production des protéines matricielles et enzymes de dégradation (métalloprotéinases) est maintenu. Mais, très rapidement, s'installe une synthèse défaillante avec des protéoglycanes de taille inférieure et synthèse d'un néocollagène (de type I), dont les propriétés biomécaniques sont moins bonnes. Cette activité anabolique va également se traduire par la production d'ostéophytes sous l'influence de facteurs de croissance tels que le TGF- $\beta$. L'os sous-chondral riche en facteurs de croissance semble jouer un rôle dans la tentative de réparation des lésions cartilagineuses.

L'orientation des fibres de collagène proches de la surface va progressivement disparaître et l'espace entre les fibres va s'accroître, aboutissant à une diminution de la résistance du 
cartilage responsable de fissures que l'on va voir apparaître dans le stade intermédiaire. Quoiqu'il en soit il y a surproduction de protéoglycannes qui entraînent une hyperhydratation néfaste, aboutissant au ramollissement du cartilage ou chondromalacie.

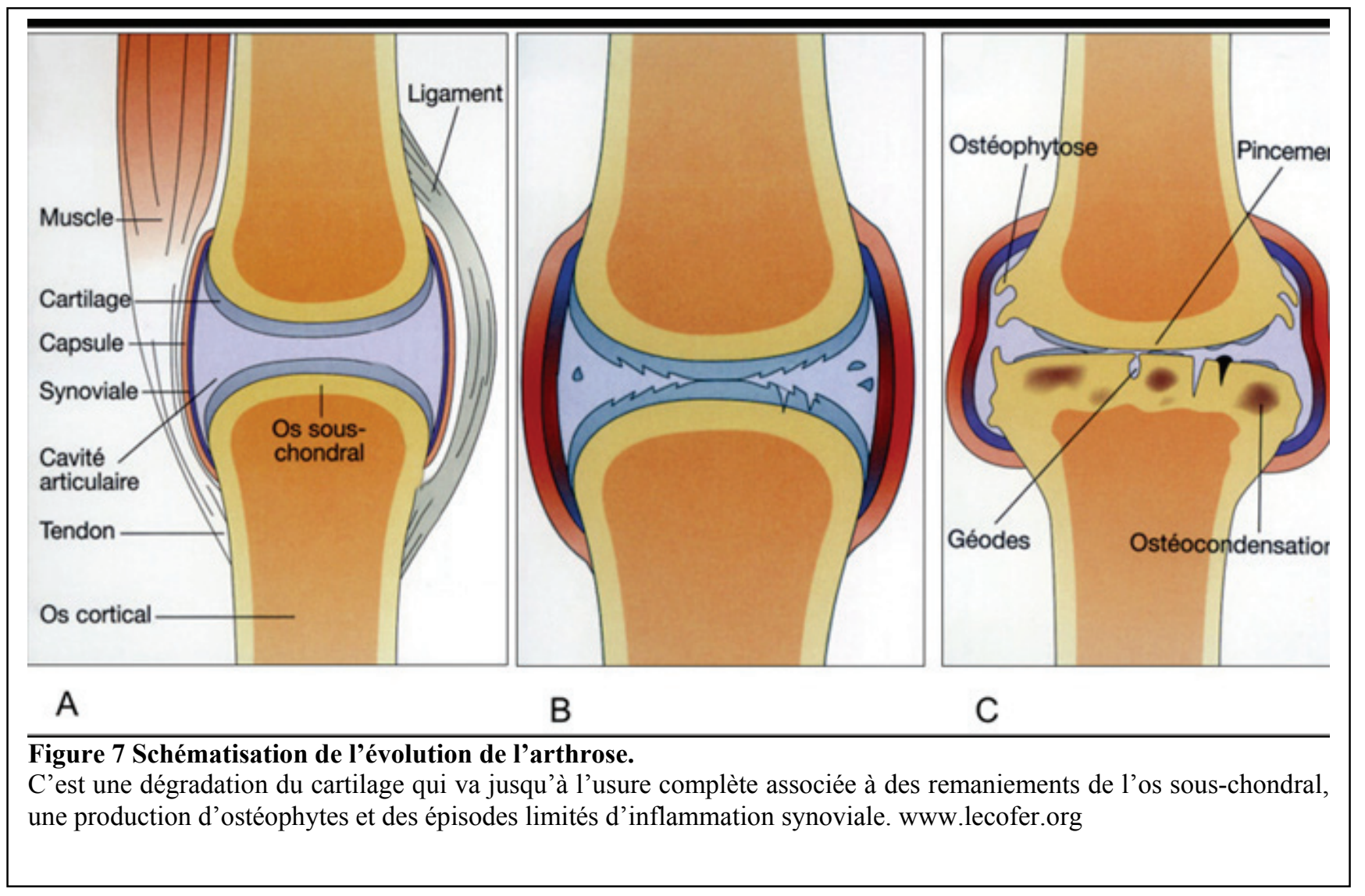

- $\quad$ Stade intermédiaire

(Schéma B sur la Figure 7)

Le stade 2 est caractérisé par l'apparition de fissures superficielles dues à une protéolyse matricielle exacerbée.

Il existe à ce stade, une hyperactivité catabolique des chondrocytes qui libèrent des cytokines pro inflammatoires, IL-1 $\beta, \mathrm{TNF}-\alpha$. Sous l'influence de ces cytokines, les chondrocytes libèrent d'autres facteurs pro inflammatoires comme les dérivés radicalaires de l'oxygène, le monoxyde d'azote (NO), des enzymes protéolytiques (métalloprotéases et agrécanases) et glycolytiques mais aussi de la phospholipase A2, et des prostaglandines. L'hyperactivité enzymatique va petit à petit déborder les capacités d'inhibition enzymatiques. En parallèle, ces cellules ont aussi une activité anabolique forte mais qui, progressivement, va s'épuiser aboutissant à la destruction du cartilage (destruction autocrine) (Buckwalter et coll. 1998). Destruction d'autant plus rapide, que les cytokines produites (IL-1 et TNF), commandent aussi l'inhibition de la synthèse des composants naturels du cartilage. 
En parallèle, le chondrocyte peut se différencier en un fibrochondrocyte synthétisant des composants normalement absents ou présents en faible quantité, comme le néocollagène de type I, le versicane, ou la fibronectine et d'autres protéines non collagéniques de qualité et de résistance moindre que les composants normaux du cartilage.

Par ailleurs, sous l'action délétère de l'IL-1ß ou du NO, il existe aussi une accélération du cycle de maturation cellulaire qui amène à une prolifération des chondrocytes puis à leur hypertrophie et enfin à leur mort par apoptose (Dozin et coll. 2002).

A ce stade, l'os sous-chondral est un acteur important dans l'altération du cartilage. En effet il est le siège d'une augmentation du remodelage osseux en faveur de l'ostéoformation, médié par des cytokines synthétisées par les ostéoblastes adjacents au cartilage. Toutes ces modifications conduisent à plus ou moins long terme à des remaniements de l'os souschondral avec l'appariton de macro géodes (Freemont et coll. 1996).

Finalement, défaut de réponse anabolique, déséquilibre entre enzymes et inhibiteurs, mort cellulaire par nécrose, ou par apoptose du chondrocyte, s'additionnent et contribuent à la dégradation de la matrice extra cellulaire.

\section{- Stade final}

(Schéma C sur la Figure 7)

À un stade avancé, la destruction gagne les couches profondes mettant à nu l'os souschondral.

Il persiste des chondrocytes hypertrophiques, ou en voie d'apoptose, ainsi qu'un tissu fibrocartilagineux.

L'activation de la membrane synoviale, par les débris du cartilage et/ou les microcristaux libérés dans la cavité synoviale, pourrait contribuer à la chondrolyse, avec libération de MMPs, de cytokines telles que l'IL-1 et de dérivés radicalaires de l'oxygène. De même les altérations de l'os sous-chondral contribuent également à pérenniser la maladie. 
Si le primum movens de l'arthrose n'est pas clairement établi, deux grands facteurs étiologiques semblent intimement liés à l'évolution de l'arthrose :

D'une part des facteurs mécaniques, et d'autre part des facteurs inflammatoires

\section{Facteurs mécaniques}

L'arthrose est sans doute initiée sous l'influence de plusieurs facteurs de risque combinés à une susceptibilité propre du cartilage à développer une arthrose.

Le stress mécanique qui peut être en tension, compression, cisaillement ou étirement agit donc à deux niveaux : directement sur le chondrocyte, ou sur la structure physique du cartilage (Figure 8).

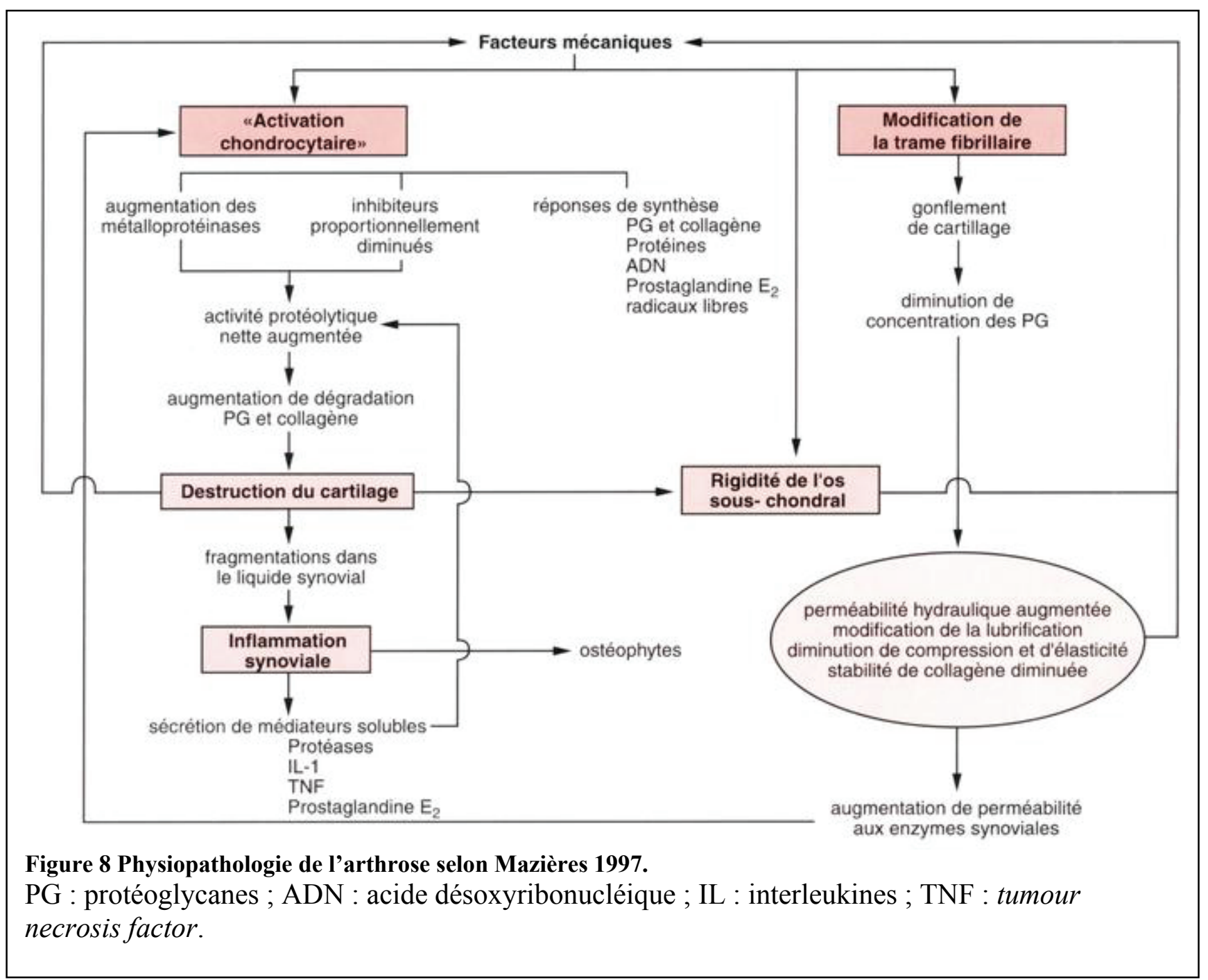

- $\quad$ sur le chondrocyte

Ce stress mécanique va aboutir au processus décrit plus haut en agissant directement sur le chondrocyte qui est une cellule qui est sensible aux contraintes mécaniques (Figure 8, partie de gauche). En réalité, le stimulus mécanique «anormal» peut être transmis au chondrocyte, 
puis être traduit en un signal qui l'engage à modifier son comportement, par l'intermédiaire de mécanorécepteurs membranaires ( $\alpha 5 \beta 1$ intégrines) (Chowdhury et coll. 2004) ou de canaux ioniques à calcium (Kono et coll. 2006). Il agit ensuite sur l'expression de différentes protéines comme des cytokines IL-1 $\beta$, le TNF- $\alpha$, des aggrécanases, et des métalloprotéases comme la MMP-3, ou la MMP-9 (Fujisawa et coll. 1999, Millward-Sadler et coll. 2000, Salter et coll. 2004).

Un stress mécanique cyclique appliqué sur des chondrocytes articulaires en cultures induit une augmentation de la sécrétion de l'IL-1 $\beta$, et la production de dérivés radicalaires de l'oxygène aboutissant à la dépolymérisation de l'acide hyaluronique (hyaluronane) (Yamazaki et coll. 2003). Cette cascade de signalisation emprunte entre autre la voie NF-кB (Agarwal et coll. 2004).

D'autres contraintes mécaniques peuvent au contraire être anabolisantes, notamment les contraintes continues en compression sur explant de cartilage, et agissent directement sur la régulation génique du collagène de type II via un facteur de transcription $\mathrm{Sp} 1$ (Xie et coll. 2006).

- Sur la structure physique du cartilage et de l'os sous chondral

Le stress mécanique peut agir directement sur la structure physique du cartilage au niveau de la trame fibrillaire et de l'os sous chondral (Figure 8, partie de droite). Des pressions anormales sur des fibres fragilisées peuvent rompre le filet collagénique par places, permettre une expansion anormale des protéoglycanes et donc une hyperhydratation du cartilage. $\mathrm{Ce}$ cartilage hyperhydraté va perdre ses caractéristiques biomécaniques.

La teneur en acide hyaluronique va diminuer, les agrégats de protéoglycanes se dépolymérisent, la taille des monomères eux-mêmes diminue. L'élasticité du tissu cartilagineux diminue ; il va moins bien amortir les pressions sur l'os sous-chondral qui réagit en se condensant et en développant une ostéophytose réactionnelle.

\section{Facteurs inflammatoires}

On connaît peu le mécanisme intime de l'activation métabolique, médié par l'IL-1, ou l'oxyde nitrique (NO), mais ses conséquences sont en revanche de mieux en mieux décrites. Le chondrocyte activé synthétise plus de collagène et de protéoglycanes (PG). Les radicaux libres aussi sécrétés, vont favoriser la dépolymérisation des PG, poursuivre la fragmentation du collagène scindé naturellement par la collagénase-1 (MMP-1) et favoriser la libération de prostaglandines qui vont altérer elles aussi les PG. 
La concentration du tissu en collagène et en PG diminue progressivement, traduisant un équilibre métabolique négative. Ce catabolisme des éléments de la matrice est principalement le fait d'enzymes dégradatives, les métalloprotéinases [1a MMP-1, la stromélysine (MMP-3) mais aussi la collagénase-3(MMP-13)]. Parallèlement des protéases acides dégradent aussi les composants matriciels dans la cellule et l'atmosphère péri cellulaire, là où le $\mathrm{pH}$ est acide. Dans l'articulation arthrosique, il y a production d'une véritable «soupe cytokinique » pro et anti inflammatoire et de facteurs de croissances synergiques ou antagonistes (Martel-Pelletier et coll. 1999) (Tableau1). Ces cytokines peuvent agir alors de 3 façons, soit sur un mode autocrine sur le chondrocyte, soit sur un mode paracrine dans le tissu, soit enfin sur un mode juxtacrine où la cytokine reste attachée à la membrane et peut agir sur les récepteurs cellulaires d'une cellule voisine.

Les principales cytokines impliquées sont l'IL1et surtout son isoforme $\beta$ et le TNF- $\alpha$ :

- L'interleukine 1

C'est probablement la cytokine la plus importante dans la genèse de l'arthrose (Pelletier et coll. 1989). De nombreux auteurs ont démontré une augmentation de sa concentration dans le liquide synovial issu d'articulation arthrosique (Takahashi et coll. 1998, Kubota et coll. 1997, 1998). Elle est produite par le chondrocyte lui-même mais aussi par les synoviocytes notamment en apoptose.

Cette cytokine va en effet induire une diminution de synthèse des PG et du collagène de types II ,IX, XI mais va aussi provoquer une augmentation de production de MMP-1, et MMP-13 (Reunanen et coll. 1998, Barchowsky et coll. 2000, Mengshol et coll. 2000), d'aggrécanases, et de médiateurs de l'inflammation tels que les radicaux libres, le NO et de la prostaglandine $\mathrm{E}_{2}$ (Benton et coll. 1988, Gowen et coll. 1984). 
Tableau 1 Cytokines et facteurs de croissance de l'articulation arthrosique : activités potentielles et origines (WESTACOTT, 1996, Mazières 1997)

\begin{tabular}{|c|c|c|c|}
\hline Cytokine & Activité principale & \multicolumn{2}{|c|}{ Cellules productrices } \\
\hline \multicolumn{4}{|c|}{ Activité anabolique } \\
\hline TGF ${ }^{\beta}$ & $\begin{array}{l}\text { Stimule la production des composants de la matrice } \\
\text { Probable stimulation de la réplication ostéoclastique } \\
\text { Stimule la production des composants de la matrice } \\
\text { Peut induire la production d'IL-Ira par le macrophage }\end{array}$ & 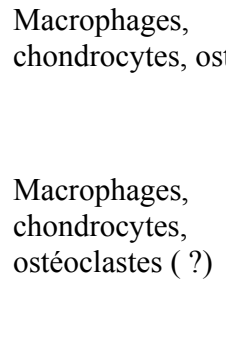 & $\begin{array}{l}\text { blastes (?), } \\
\text { astes } \\
\text { fibroblastes, } \\
\text { ostéoblastes, }\end{array}$ \\
\hline \multicolumn{4}{|c|}{ Activité catabolique } \\
\hline IL-1 & $\begin{array}{l}\text { Puissant inducteur de la dégradation du cartilage et de la } \\
\text { résorption osseuse. Inhibe la synthèse des PG }\end{array}$ & $\begin{array}{l}\text { Macrophages, } \\
\text { chondrocytes, } \\
\text { ostéoclastes (?) }\end{array}$ & $\begin{array}{l}\text { fibroblastes, } \\
\text { ostéoblastes, }\end{array}$ \\
\hline TNF & Même activité que l'IL-1, mais moins puissante & $\begin{array}{l}\text { Macrophages, } \\
\text { chondrocytes }\end{array}$ & fibroblastes, \\
\hline LIF & $\begin{array}{l}\text { Probable destruction du cartilage. Sa production par les } \\
\text { fibroblastes synoviaux est augmentée par l'IL-1 et le TNF }\end{array}$ & $\begin{array}{l}\text { Macrophages, } \\
\text { chondrocytes }\end{array}$ & fibroblastes \\
\hline
\end{tabular}

Modulateurs de l'activité anabolique et catabolique

\begin{tabular}{|c|c|c|}
\hline IL-4 & $\begin{array}{l}\text { Réduit la sécrétion monocytaire de IL-1, IL- } 6 \text {, TNF. Diminue } \\
\text { les récepteurs TGF } \beta\end{array}$ & $\begin{array}{l}\text { Macrophages (?), lymphocytes } \\
\text { TH2 (?) }\end{array}$ \\
\hline IL-6 & Incertain & $\begin{array}{ll}\text { Macrophages, } & \text { fibroblastes, } \\
\text { chondrocytes, } & \text { ostéoblastes, } \\
\text { ostéoclastes (?) } & \end{array}$ \\
\hline IL-8 & $\begin{array}{l}\text { Chimiotactisme du neutrophile. Stimule la production d'anions } \\
\text { superoxydes par les neutrophiles }\end{array}$ & $\begin{array}{l}\text { Macrophages, fibroblastes, } \\
\text { chondrocytes, ostéoblastes }\end{array}$ \\
\hline IRAP & Empêche la liaison de l'IL-1 à ses récepteurs & Macrophages \\
\hline bFGF & $\begin{array}{l}\text { Potentialise la libération de protéases induite par l'IL-1. Peut } \\
\text { augmenter l'expression des récepteurs du TNF }\end{array}$ & Macrophages, chondrocytes \\
\hline GM-CSF & $\begin{array}{l}\text { Probable activateur principal des macrophages et autres } \\
\text { cellules. Module l'expression des récepteurs des cytokines }\end{array}$ & $\begin{array}{l}\text { Macrophages, fibroblastes, } \\
\text { chondrocytes, ostéoblastes }\end{array}$ \\
\hline IFN' & $\begin{array}{l}\text { Présence discutée dans l'articulation arthrosique. Pourrait } \\
\text { augmenter les récepteurs du TNF }\end{array}$ & Fibroblastes, chondrocytes \\
\hline MCP & $\begin{array}{l}\text { Chimiotactisme du monocyte. Régule l'expression des } \\
\text { molécules d'adhésion et la sécrétion des cytokines }\end{array}$ & Fibroblastes, chondrocytes \\
\hline PDGF & $\begin{array}{l}\text { Peut augmenter la production par les synoviocytes des } \\
\text { prostaglandines induites par l'IL-1 }\end{array}$ & Macrophages \\
\hline $\begin{array}{l}\text { Récepteurs } \\
\text { solubles }\end{array}$ & $\begin{array}{l}\text { Décrits pour l'IL-1, le TNF, l'IL-6 et probablement la plupart } \\
\text { des cytokines. On pense qu'ils inactivent les cytokines en } \\
\text { formant un complexe avec elles }\end{array}$ & Cellules variées \\
\hline
\end{tabular}

IGF : insulin-like growth factor; TGF : transforming growth factor, IL- (1 à 8$)$ : interleukine-(1 à 8$)$; PG : protéoglycanes ; TNF : tumour necrosis factor ; LIF : leukemia inhibitory factor ; IRAP : interleukine receptor antagonist protein ; bFGF : basic fibroblast growth factor; GM-CSF : granulocyte-macrophage colony-stimulating factor ; IFN : interféron gamma ; MCP : macrophage chemotactic protein ; PDGF : platelet-derived growth factor. 
En parallèle, elle va augmenter l'expression du collagène de type I. Cette régulation se fait par l'intermédiaire de voies de signalisation classiques telles que NF- $\kappa \mathrm{B}$, « mitogen-activated protein kinase » $(\mathrm{MAPK})$ « activator protein-1» (AP-1), et « extracellular regulated kinase » ERK (Vincenti et coll. 2001, Martin et coll. 2003, Luciani et coll. 2002).

L'IL-1 stimule aussi l'expression de l'iNOS («inducible nitric oxide synthase ») qui augmente la sécrétion de NO (Stadler et coll. 1991), ainsi que la transcription de la cyclooxygénase-2 COX-2.

L'IL-1 se fixe sur des récepteurs membranaires spécifiques du chondrocyte (IL-1R) (Slack et coll.1993). Le chondrocyte normal présente 2500 de ces récepteurs à sa surface.

Le chondrocyte arthrosique voit ce chiffre multiplié par deux. Ces récepteurs ont la même affinité pour l'IL-1 et une saturation de seulement $5 \%$ par l'IL-1 suffit à induire une augmentation de synthèse de MMP-1 (Martel-Pelletier et coll. 1992).

L'IL-1 peut même induire la mort cellulaire des chondrocytes par dérégulation de la production d'énergie mitochondriale à travers la formation de peroxynitrite $\mathrm{ONOO}^{-}$ (Yasuhara et coll. 2005). Son action est aussi influencée par les conditions d'oxygénation du cartilage; ainsi in vitro, en conditions d'hypoxie (moins de 5\% d' $\mathrm{O}_{2}$ ) ses effets sont multipliés par rapport aux conditions de normoxie $\left(21 \% \mathrm{~d}^{\prime} \mathrm{O}_{2}\right)$ (Martin et coll. 2004, MathyHartert et coll. 2005).

Son influence sur la transcription de la collagénase-1 dans le chondrocyte, peut être inhibée par d'autres molécules comme les «Peroxisome Proliferator-Activated Receptor- $\gamma$ ou $\alpha$ » (PPAR- $\gamma$ ou PPAR- $\alpha$ ).

- Le «tumor necrosis factor- $\alpha »(\mathrm{TNF}-\alpha)$

Le TNF a les mêmes propriétés et agit en synergie avec l'IL-1 avec une puissance 100 à 1000 fois moindre en terme d'activité métabolique dans l'arthrose.

- Les autres cytokines et facteurs de croissance (Tableau 1, Figure 9)

L'Il-6 et l'interféron $\gamma$ (IFN $\gamma$ ) ont une action antagoniste en inhibant partiellement l'action de l'IL-1 et du TNF- $\alpha$. Mais parfois, ces cytokines ont aussi un rôle plus ambigu. Ainsi, l'IL-6 produite sous l'effet de l'IL-1 stimule la synthèse d'inhibiteurs des MMPs (les TIMPs), de l'IL-1ra (récepteur soluble de 1'IL-1), et du récepteur soluble du TNF- $\alpha$ (cytokine pro anabolique), mais en parallèle peut aussi potentialiser l'effet de l'IL-1 $\beta$ sur l'activité des collagénases lorsqu'il est lié à son récepteur soluble. 
Les facteurs de croissance les plus importants pour le cartilage sont l'hormone de croissance (GH : «growth hormone »), «l'insulin-like growth factor 1 »(GG-1), le «fibroblast growth factor » (FGF) et le «transforming growth factor » (TGF). Ils favorisent la prolifération chondrocytaire (Osborne et coll. 1989), et la synthèse de PG.

L'IGF-1 qui stimule aussi la synthèse de collagène est diminué dans l'arthrose (Denko et coll. 1990). Le rôle de ces facteurs de croissance est encore mal connu mais un schéma de régulation du métabolisme du cartilage par les cytokines est proposé (Figure 9), qui montre bien la complexité des interactions et des influences. En effet tous ces mécanismes, s'intriquent et interagissent les uns sur les autres en une véritable autocrinie.

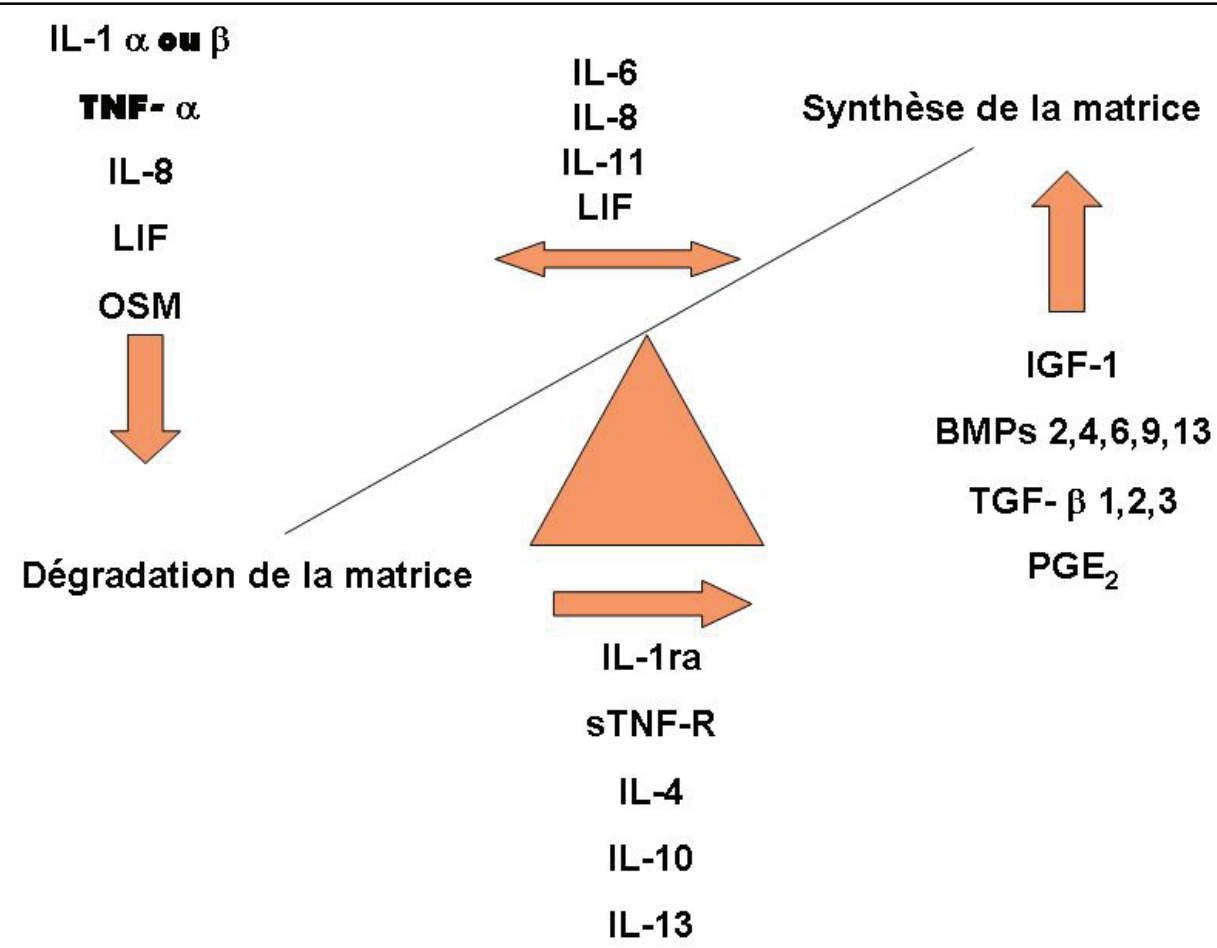

Figure 9 Equilibre des cytokines et des facteurs de croissance en fonction de leurs modes d'action

Ainsi, des produits de dégradation de la matrice et des substances solubles (cytokines) vont être libérés dans le liquide synovial et phagocytés par les cellules de la synoviale. L'inflammation de la synoviale dans l'arthrose est moins constante et moins importante que dans la polyarthrite rhumatoïde mais elle a les mêmes conséquences : macrophages, synoviocytes et fibroblastes vont, à leur tour, produire radicaux libres, prostaglandine $\mathrm{E}_{2}$, IL1, MMP1 et MMP3 qui vont venir renforcer la destruction du cartilage. 


\section{I-B Les dérivés réactifs de l'oxygène :}

\section{I-B-1 Généralités :}

Les dérivés réactifs de l'oxygène (ROS) sont des composés extrêmement réactifs incluant l'anion superoxyde $\left(\mathrm{O}_{2}{ }^{-}\right)$, le radical hydroxyle $\left(\mathrm{OH}^{\circ}\right)$ et le peroxyde d'hydrogène $\left(\mathrm{H}_{2} \mathrm{O}_{2}\right)$. Ces éléments existent de manière constitutive et sont ubiquitaires dans les cellules. Leur taux est régulé par des systèmes antagonistes de génération et de dégradation dits antioxydants. Les ROS sont considérés comme néfastes pour les cellules. En effet, lors d'un stress oxydatif où leur taux augmente au-delà des valeurs physiologiques, des phénomènes de mort cellulaire sont observés. Ils sont également décrits dans les mécanismes de vieillissement cellulaire et de cancer. La mort cellulaire constatée résulte de l'extrême réactivité de ces composés qui sont responsables de réactions de lipido-peroxydation qui fragilisent la membrane plasmique entraînant la cellule vers la voie nécrotique. Ils agissent aussi au niveau de l'ADN en l'endommageant, orientant ainsi la cellule vers la voie apoptotique. Ils modifient également les protéines et leur activité en les oxydant.

Les ROS connaissent un regain d'intérêt depuis quelques années. En effet, la génération des ROS ne survient pas seulement lors du stress oxydatif avec les conséquences dévastatrices que l'on connaît, mais également de façon mesurée et physiologique lorsque ces radicaux libres sont produits en faible quantité.

Dans ces conditions, les ROS pourraient être impliqués dans une multitude de voies de signalisation aboutissant aux phénomènes de prolifération et de différenciation cellulaire

\section{I-B.2 Production des Espèces Réactives de l'Oxygène :}

En réponse à un stimulus inflammatoire, la NADPH oxydase est activée et catalyse le transfert d'électrons depuis le donneur (NADPH) vers l'accepteur (oxygène moléculaire) permettant la production d'ions superoxyde :

$\mathrm{NADPH}+2 \mathrm{O}_{2} \rightarrow \mathrm{NADP}^{+}+\mathbf{H}^{+}+\mathbf{2 \mathrm { O } _ { 2 }}{ }^{\bullet-}$

Ce radical superoxyde qui présente une certaine toxicité dismute spontanément ou par action de la superoxyde dismutase (SOD) qui catalyse la dismutation : 
(SOD)

$2 \mathbf{H}^{+}+\mathbf{O}_{2}^{\bullet-}+\mathbf{O}_{2}^{\bullet-} \rightarrow \mathbf{H}_{2} \mathbf{O}_{2}+\mathbf{O}_{2}$

La molécule de peroxyde d'hydrogène $\left(\mathrm{H}_{2} \mathrm{O}_{2}\right)$ ainsi formée est un intermédiaire réduit de l'oxygène qui est modérément toxique. Sa concentration est régulée dans les neutrophiles par des enzymes telles que la catalase (présente dans les peroxysomes) et les glutathion peroxydases (essentiellement localisées dans le cytosol). La catalase accélère la réduction de l' $\mathrm{H}_{2} \mathrm{O}_{2}$ en eau (1) tandis que la glutathion peroxydase accélère la réaction d'oxydation du glutathion par l'eau oxygénée (2):

$$
\begin{aligned}
& \mathrm{H}_{2} \mathrm{O}_{2}+\mathrm{H}_{2} \mathrm{O}_{2} \rightarrow 2 \mathrm{H}_{2} \mathrm{O}+\mathrm{O}_{2} \\
& \mathrm{H}_{2} \mathrm{O}_{2}+2 \mathrm{GSH} \rightarrow 2 \mathrm{H}_{2} \mathrm{O}+\mathrm{GSSG}
\end{aligned}
$$

La toxicité du peroxyde d'hydrogène résulte de sa capacité à générer le radical hydroxyle $\left({ }^{\bullet} \mathrm{OH}\right)$ en présence de cations métalliques tels que le fer $\left(\mathrm{Fe}^{2+}\right)$ par la réaction dite de Fenton :

\section{$\mathrm{H}_{2} \mathrm{O}_{2}+\mathrm{Fe}^{2+} \rightarrow{ }^{\bullet} \mathrm{OH}+\mathrm{Fe}^{3+}+{ }^{-} \mathrm{OH}$ (réaction de Fenton)}

Le peroxyde d'hydrogène $\left(\mathrm{H}_{2} \mathrm{O}_{2}\right)$ peut également être transformé en acide hypochloreux ( $\mathrm{HOCl})$ (3), en présence de la myéloperoxydase (MPO) contenue dans les granules azurophiles des neutrophiles. $\mathrm{HOCl}$ est ensuite métabolisé en ion hypochlorite $\left(\mathrm{OCl}^{-}\right)$et en chlore :

$\mathrm{H}_{2} \mathrm{O}_{2}+\mathrm{Cl}^{-} \rightarrow \mathrm{H}_{2} \mathrm{O}+\mathrm{ClO}^{-}(3)$

(MPO)

L'acide hypochloreux $(\mathrm{HOCl})$ est extrêmement toxique de part sa grande réactivité vis à vis des amines pour donner des chloramines (4):

$\mathrm{HOCl}+\mathrm{RNH}_{2} \rightarrow \mathrm{RNHCl}+\mathrm{H}_{2} \mathrm{O}$ (4)

\section{I-B-3 Régulation du taux des ROS :}

La régulation du taux des ROS dépend de l'équilibre entre deux systèmes antagonistes : la production et la dégradation des radicaux libres dans le but de limiter la 
quantité de ROS et de la maintenir à un niveau tolérable pour la cellule. Des enzymes comme la superoxyde dismutase réduisent l'ion superoxyde et le peroxyde d'hydrogène à son tour peut être réduit en $\mathrm{H}_{2} \mathrm{O}$ par la catalase et la glutathion peroxydase. Des systèmes de piégeage (la thiorédoxine, la vitamine $\mathrm{A}, \mathrm{C}$ et $\mathrm{E}$, l'urate et l'ubiquinone) des ROS participent aussi à la régulation.

Les ROS sont synthétisés par différentes voies :

La mitochondrie par un shunt de ses électrons va convertir $1^{\prime} \mathrm{O}_{2}$ en $\mathrm{O}_{2}{ }^{-}$. La proportion des électrons ne représente que 1 à $2 \%$ de ceux mis en jeux dans la chaîne respiratoire.

Le système hypoxanthine /xanthine oxidase, ainsi que la lipoxygénase, la cyclooxygénase, la gamma-glutamyl transpeptidase et le cytochrome P450.

La source de ROS la plus importante est représentée par le complexe multi-protéique membranaire de la NADPH oxydase (Figure 10). Les NAD(P)H oxydases appelées aussi $\mathrm{Nox}_{\mathrm{s}}$ constituent une famille de protéines dont la plus connue est Nox2 identifiée dans les cellules phagocytaires comme le neutrophile, le macrophage et l'éosinophile. Le neutrophile utilise ce processus de fabrication de ROS pour lutter contre les agents pathogènes. Au cours de la phagocytose, on assiste à une production massive des espèces dérivées de l'oxygène, appelée «explosion respiratoire », par le complexe NADPH oxydase, dans le phagosome responsable de la destruction de l'agent étranger.

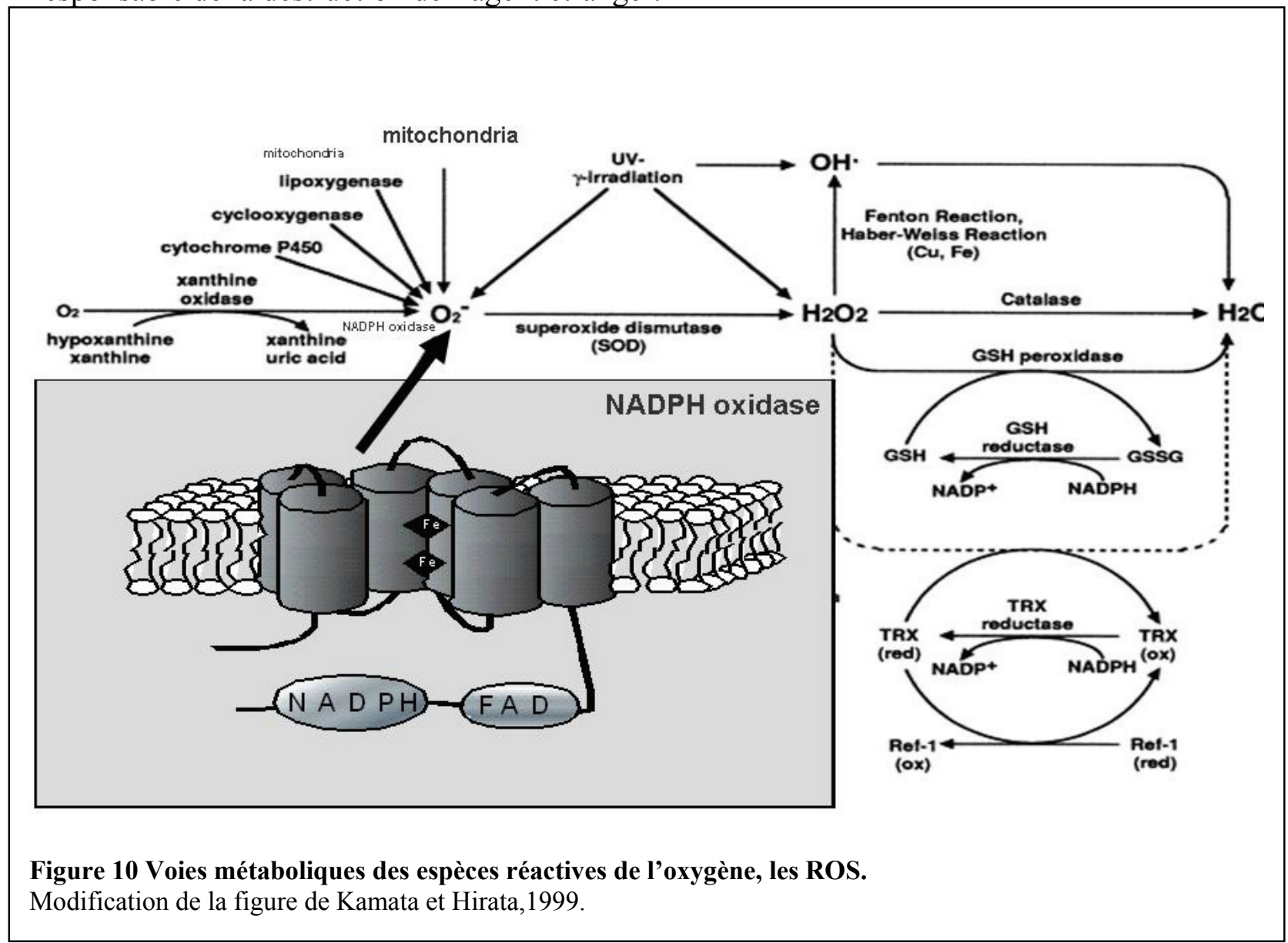




\section{I-C La famille des $N A D(P) H$ oxydases :}

\section{I-C-1 La famille des NAD(P)H oxydases des cellules phagocytaires :}

\section{I-C-1-a Les facteurs membranaires :}

La NAD $(\mathrm{P}) \mathrm{H}$ oxydase des cellules phagocytaires est un élément majeur de la réponse immunitaire non spécifique de l'organisme à l'origine d'une cascade de réactions enzymatiques amenant à la destruction des agents pathogènes (Morel et coll.1991). Cette enzyme est un complexe multimérique dissocié dans les cellules au repos. Il s'assemble en réponse à un stimulus inflammatoire (Figure 11). Tout d'abord, la phospholipase C (PLC) membranaire est activée permettant ainsi le clivage du phosphatidyl inositol 4-5 bisphosphate $\left(\mathrm{PIP}_{2}\right)$ en diacylglycérol (DAG) et inositol trisphosphate $\left(\mathrm{IP}_{3}\right)$. Ainsi formé, l'IP $\mathrm{I}_{3}$ stimule le relargage du calcium contenu dans les vésicules de stockage intracellulaire ce qui permet, entre autres, l'activation de la phospholipase A2 (PLA2) et de la protéine kinase C (PKC) cytosolique. En parallèle, une phospholipase D membranaire déphosphoryle l'acide phosphatidique (PA) en DAG qui entretient l'activation de la PKC. Cette dernière va permettre le rassemblement des composants du complexe de la $\mathrm{NAD}(\mathrm{P}) \mathrm{H}$ oxydase en initiant la phosphorylation de la protéine $\mathrm{p} 47^{\text {phox }}$ cytosolique qui migrera à la membrane plasmique (Nauseef et coll. 1990). L'activation de la NAD(P)H oxydase peut être également obtenue «artificiellement» avec la stimulation de la PKC qui court-circuite ainsi toutes les voies intermédiaires. Dans ce cas, l'agent activateur le plus utilisé est un ester de phorbol, le Phorbol Myristate Acétate (PMA).

La NAD(P)H oxydase est un complexe multimérique dissocié dans les cellules au repos. Il est constitué d'un cœur membranaire rèdox, le cytochrome $b_{558}$, et de facteurs cytosoliques $\mathrm{p} 47^{\text {phox }}, \mathrm{p} 67^{\text {phox }}$ et $\mathrm{p} 40^{\text {phox }}$ ainsi que de la protéine $\mathrm{G}$ monomérique Rac. La formation d'un trimère, constitué de $\mathrm{p} 47^{\text {phox }}, \mathrm{p} 67^{\text {phox }}$ et $\mathrm{p} 40^{\text {phox }}$, a été mise en évidence dans les cellules au repos; trimère dans lequel $\mathrm{p} 67^{\text {phox }}$ constituerait le pont de liaison entre les deux autres protéines. Il s'agirait d'un stade de pré-activation de la $\mathrm{NAD}(\mathrm{P}) \mathrm{H}$ oxydase (Lapouge et coll.2002) (Figure 11 et 12). 


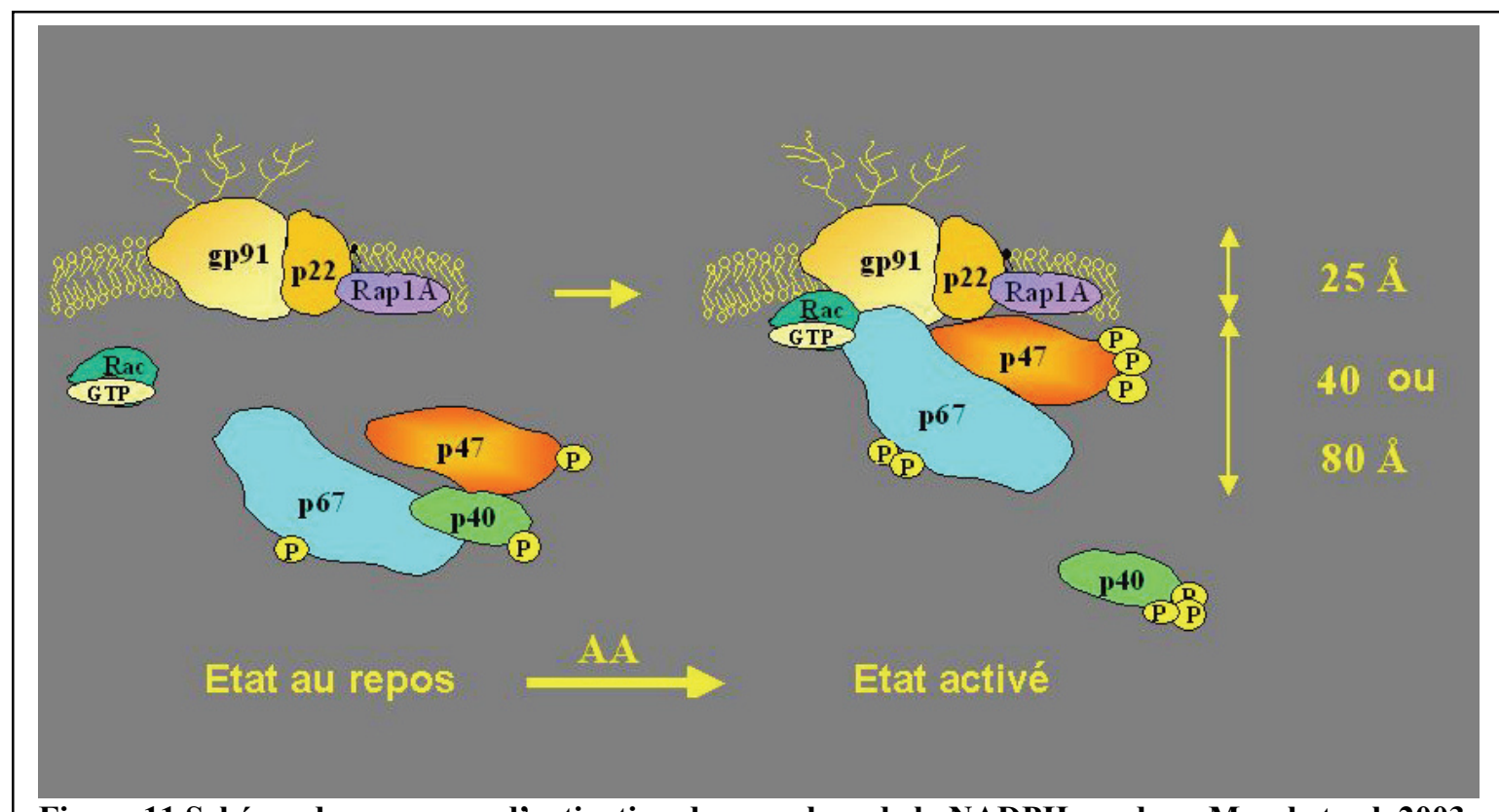

Figure 11 Schéma du processus d'activation du complexe de la NADPH oxydase. Morel et col. 2003

L'activation de la NAD(P)H oxydase passe par la translocation des protéines $\mathrm{p} 47^{\text {phox }}, \mathrm{p} 67^{\text {phox }}$ et $\mathrm{p} 40^{\text {phox }}$ associées dans le cytosol selon un rapport stœchiométrique de $1: 1: 1$ (Groemping et coll. 2005) indépendamment de la protéine G monomérique Rac $1 / 2$ qui migre également jusqu'au cytochrome $b_{558}$ membranaire (Figure 11 et 12). Une autre protéine G, Rap1A, présente dans la membrane plasmique, pourrait intervenir dans la régulation de l'activité oxydase.

L'importance fonctionnelle de ce complexe est mise en évidence en pathologie humaine. Un défaut génétique de l'un des constituants du complexe oxydase, entraînant un dysfonctionnement de la $\mathrm{NAD}(\mathrm{P}) \mathrm{H}$ oxydase, est à l'origine d'une maladie familiale, la granulomatose septique chronique (CGD). L'organisme de ces patients est incapable de détruire les micro-organismes phagocytés, soulignant ainsi le rôle essentiel joué par les ROS dans la bactéricidie. 


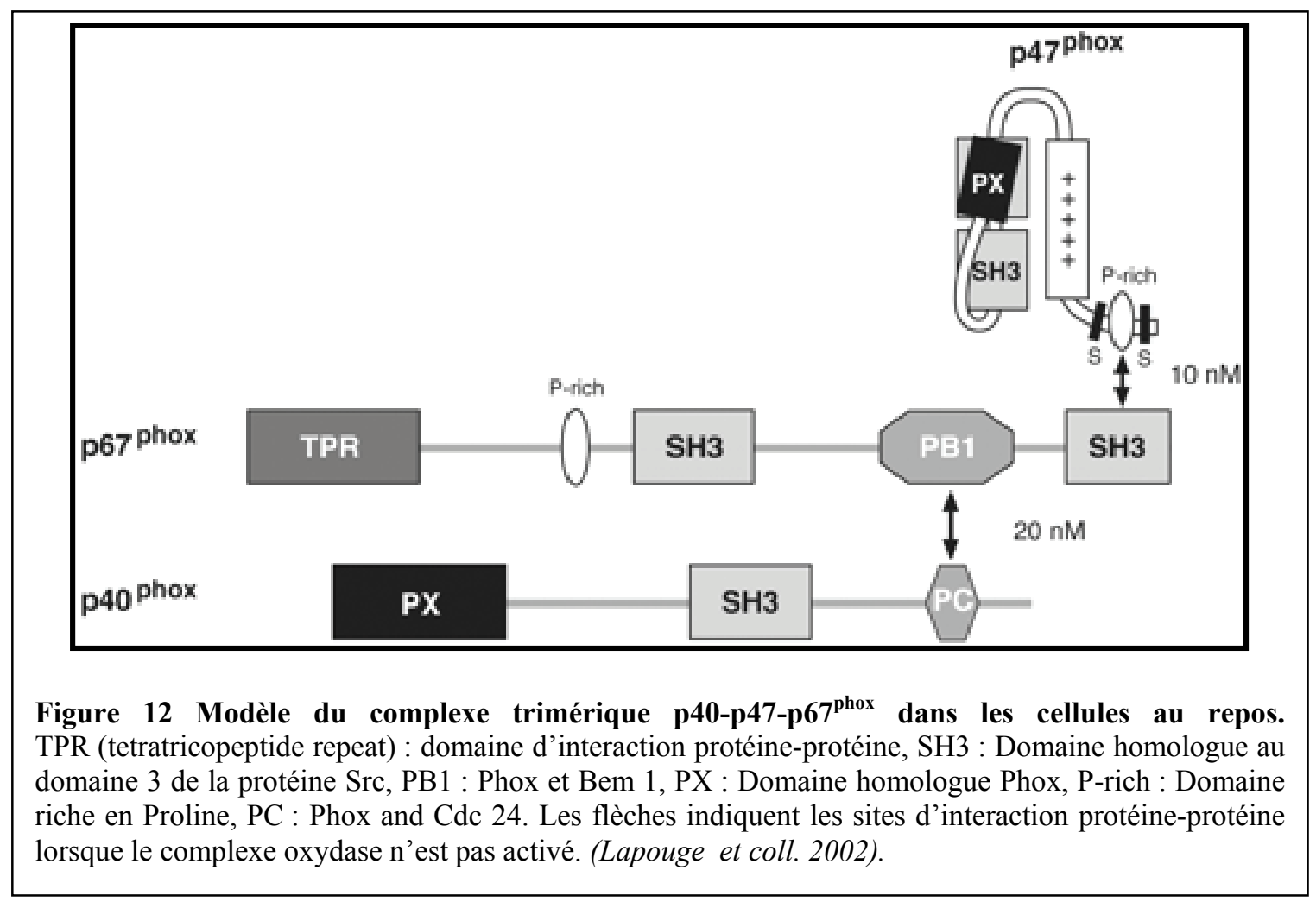

\section{Le cytochrome $b_{558}$ :}

Le cytochrome $b_{558}$ a été identifié pour la première fois par Segal au niveau des vacuoles de phagocytose des granulocytes humains (Segal et coll. 1978). Il s'agit d'un hétérodimère transmembranaire constitué de deux sous-unités, $\alpha$ et $\beta$, dont les masses moléculaires respectives sont de $22 \mathrm{kDa}$ (p22phox) et $91 \mathrm{kDa}$ (gp91phox). Leur rapport stœchiométrique est de 1:1 (Huang et coll. 1995, Wallach et coll. 1996). Le cytochrome $b_{558}$ est retrouvé principalement $(80 \%)$ dans la membrane des granules spécifiques et des granules tertiaires riches en gélatinase qui fusionnent avec la membrane plasmique au niveau du site de formation du phagosome lors de la stimulation cellulaire (Borregaard et coll. 1983, Morel et coll. 1985). Environ $20 \%$ du cytochrome $b_{558}$ est présent au niveau de la membrane plasmique. Dans cette membrane, il pourrait être localisé dans des micro-domaines enrichis en cholestérol, les « radeaux lipidiques » (Shao et coll. 2003, Vilhardt et coll. 2004).

$$
\operatorname{gp91}^{\text {phox }}(\text { Nox 2): }
$$

La sous-unité $\beta$ du cytochrome $b_{558}$, constituée de 570 acides aminés, correspond à la protéine gp91 ${ }^{\text {phox }}$ et depuis peu de temps à Nox 2 d'après la nomenclature proposée par Lambeth 
(Lambeth et coll. 2002). Le gène CYBB codant pour cette protéine membranaire est situé sur le bras court du chromosome X (Xp21.1) (Royer-Pokora et coll. 1986, Dinauer et coll. 1987, 1990). Nox 2 est une glycoprotéine de $91 \mathrm{kDa}$ synthétisée d'abord sous la forme précurseur de $65 \mathrm{kDa}$ glycosylée uniquement avec des résidus mannose (Porter et coll. 1996, Yu et coll. 1997) mais portant, à maturation, 55 dérivés glucidiques ( $\mathrm{N}$-acétyl glucosamine et galactose en majorité) sur 3 résidus Asparagine : $\operatorname{Asn}^{131}$, $\operatorname{Asn}^{148}$ et $\operatorname{Asn}^{239}$ (Harper et coll.1985, Wallach et coll. 1997, Yu et coll. 1999). Elle possède également six passages trans-membranaires coordinatrices de deux hèmes différents, de potentiels redox respectifs $-225 \mathrm{mV}$ et $-265 \mathrm{mV}$ (Cross et coll. 1995; Biberstine-Kinkade et coll. 2001). Nox 2 est la sous-unité du cytochrome $b_{558}$ où l'on trouve tous les éléments redox essentiels au transport des électrons du NAD $(\mathrm{P}) \mathrm{H}$ vers l'oxygène moléculaire (Doussiere et coll.1986, 1995, Ravel et coll. 1991). En effet, Segal a démontré l'importance de la partie C-terminale de la protéine qui porte les sites de liaison du FAD et de quatre régions potentielles de fixation du NAD(P)H (Segal et coll. 1992) :

- Une région riche en glycine qui formerait des liaisons hydrogène avec la partie pyrophosphate du NADPH.

- Un domaine contenant une tyrosine très conservée qui formerait une liaison hydrogène avec le ribose du NAD(P)H.

- La séquence qui formerait une liaison hydrogène avec l'adénine du NAD(P)H.

- Un double motif Cys-Gly qui lierait le nicotinamide du NAD(P)H (Rotrosen et coll. 1992, Sumimoto et coll. 1992, Vignais et coll. 2002).

Certaines régions cytosoliques de la protéine gp91 ${ }^{\text {phox }}$ sont également des sites potentiels de liaison avec les facteurs cytosoliques tels que p47 $7^{\text {phox. }}$ (Rotrosen et coll. 1990, Kleinberg et coll. 1992, Leusen et coll. 1994, De Leo et coll. 1995, Park et coll. 1997).

$$
\text { p22 }{ }^{\text {phox }} \text { : }
$$

La protéine $\mathrm{p} 22^{\text {phox }}$ est constituée de 195 acides aminés et correspond à la plus petite des deux sous-unités du cytochrome $b_{558}$. Elle est codée par le gène CYBA localisé au niveau du chromosome 16 (16q24) (Dinauer et coll. 1990). Son profil d'hydrophobicité suggère la présence de deux hélices trans-membranaires mais sa topologie reste encore méconnue. $\mathrm{Au}$ niveau structural, Leto a mis en évidence une région riche en proline sur la partie C-terminale de $\mathrm{p} 22^{\text {phox }}$ susceptible d'interagir avec la protéine cytosolique $\mathrm{p} 47^{\text {phox }}$ au cours de l'activation (Leto et coll. 1994, Sumimoto et coll. 1996). La protéine $\mathrm{p} 22^{\text {phox }}$ est également le point d'ancrage du facteur cytosolique $\mathrm{p} 67^{\text {phox }}$. L'affinité de $\mathrm{p} 67^{\text {phox }}$ pour $\mathrm{p} 22^{\text {phox }}$ est toutefois moins 
grande que celle de $\mathrm{p} 47^{\text {phox }}$ pour la sous-unité $\alpha$ du cytochrome $b_{558}$ (Dahan et coll. 2002). L'association de $\mathrm{p} 22^{\text {phox }}$ avec la sous-unité $\beta$ s'effectue après la traduction mais avant la modification de gp65 (protéine précurseur de gp91 ${ }^{\text {phox }}$ ) dans 1'appareil de Golgi. Le rôle de $\mathrm{p} 22^{\text {phox }}$ n'est pas encore bien défini mais il apparaît clairement que cette protéine est indispensable pour la stabilité du cytochrome $b_{558}$ : l'expression de la sous-unité $\beta$ mature (glycosylée) n'est possible qu'en sa présence (Yu et coll. 1997).

\section{I-C-1-b Les facteurs cytosoliques :}

$$
\text { p47 } 7^{\text {phox }} \text { : }
$$

P47 $7^{\text {phox }}$ est codée par le gène NCF1 (Neutrophil Cytosolic Factor 1) localisé sur le chromosome 7 (7q11.23). Cette protéine est constituée de 390 acides aminés (Lomax et coll. 1989). Dans les cellules au repos, la protéine $\mathrm{p} 47^{\text {phox }}$ est repliée sur elle-même dans une conformation dite «auto-inhibitrice». (Sumimoto et coll. 1994; De Leo et coll. 1995; De Mendez et coll. 1996, Ago et coll. 2003). Lors de l'activation de la NADPH oxydase, la protéine $\mathrm{p} 47^{\text {phox }}$ fait l'objet, en premier lieu, d'une série de phosphorylations induites par des protéines kinases dont la protéine kinase C (Segal et coll. 1985, El Benna et coll.1994, Fontayne et coll. 2002).

Il a été démontré in vitro, que $\mathrm{p} 47^{\text {phox }}$ n'était pas indispensable à l'activation de la NAD(P)H oxydase et donc à la production d'anions superoxyde (Koshkin et coll. 1996, Freeman et coll. 1996). Son absence peut être compensée par l'augmentation de la concentration protéique de p $67^{\text {phox }}$. La protéine $\mathrm{p} 47^{\text {phox }}$ apparaît donc comme une protéine régulatrice de la $\mathrm{NAD}(\mathrm{P}) \mathrm{H}$ oxydase agissant comme une protéine adaptatrice nécessaire in vivo au bon positionnement des différents facteurs cytosoliques lors de leur translocation membranaire au cours de l'activation de l'enzyme. Ceci a notamment été confirmé dans une expérience de reconstitution de l'activité $\mathrm{NAD}(\mathrm{P}) \mathrm{H}$ oxydase en milieu acellulaire dans laquelle il a été observé que $\mathrm{p} 47^{\text {phox }}$ augmentait l'affinité de $\mathrm{p} 67^{\text {phox }}$ pour le cytochrome $b_{558}$ (Paclet et coll. 2000).

$$
\text { p67 } 7^{\text {phox }} \text { : }
$$

La protéine $\mathrm{p} 67^{\mathrm{phox}}$, dont le gène est localisé sur le chromosome 1 (1q25), est constituée de 526 acides aminés (Sumimoto et coll. 1996, Groemping et coll. 2005) . 
La protéine $\mathrm{p} 67^{\text {phox }}$ contient un site de liaison de la protéine Rac (Koga et coll. 1999), et peut interargir avec $\mathrm{p} 40^{\text {phox }}$ (Ito et coll. 2001). La protéine $\mathrm{p} 67^{\text {phox }}$ contiendrait également le site catalytique de liaison avec le $\mathrm{NAD}(\mathrm{P}) \mathrm{H}$. Comme $\mathrm{p} 47^{\text {phox }}$, cette protéine est aussi phosphorylable au cours de l'activation de la NADPH oxydase (El Benna et coll. 1997). Par ailleurs, la reconstitution de l'activité oxydase in vitro requiert la présence de $\mathrm{p} 67^{\text {phox }}$ (Vergnaud et coll. 2000). Toutefois, des formes tronquées de la protéine ont été utilisées pour ce type de reconstitution et ont montré que seules les 210 premiers acides aminés étaient indispensables (Han et coll. 1998, Nisimoto et coll. 2004). La partie fonctionnelle de $\mathrm{p} 67^{\text {phox }}$ correspond donc au fragment N-terminal. Aussi, la plupart des cas de CGD liés à une déficience de $\mathrm{p} 67^{\text {phox }}$ ont révélé des mutations au niveau de cette région $\mathrm{N}$-terminale (Cross et coll. 2000, Grizot et coll. 2001, Roos et coll. 2003).

$$
\text { p40 }{ }^{\text {phox }} \text { : }
$$

Le gène codant pour $\mathrm{p} 40^{\text {phox }}$ est situé sur le chromosome 22 (22q13.1). Cette protéine de 339 acides aminés est certainement celle dont le rôle est le plus controversé à l'heure actuelle. Il a été démontré qu'elle interagissait avec p6 $7^{\text {phox }}$ (Tsunawaki et coll. 1996) et aurait une affinité pour la région riche en proline de $\mathrm{p} 47^{\text {phox }}$ (Grizot et coll. 2001). Le rôle que peut jouer $\mathrm{p} 40^{\text {phox }}$ au cours de l'activation de la NAD(P)H oxydase n'est pas encore clairement défini. En effet, après phosphorylation de $\mathrm{p} 40^{\text {phox }}$, il a été démontré que $\mathrm{p} 40^{\text {phox }}$ pouvait jouer un rôle significatif au cours de l'activation du complexe (Fuchs et coll. 1997, Bouin et coll. 1998, Someya et coll. 1999). Cross (Cross et coll. 2000) a notamment mis en évidence que cette protéine permettait d'augmenter l'affinité de $\mathrm{p} 47^{\text {phox }}$ pour le cytochrome $b_{558}$ tandis que Kuribayashi (Kuribayashi et coll. 2002) a montré l'intérêt de $\mathrm{p} 40^{\text {phox }}$ dans la translocation des facteurs cytosoliques $\mathrm{p} 47^{\text {phox }}$ et $\mathrm{p} 67^{\text {phox }}$. En revanche, d'après Sathyamoorthy et coll. (Sathyamoorthy et coll. 1997) et Lopes et coll. (Lopes et coll. 2004), la protéine p40 phox phosphorylée semblerait inhiber l'activité oxydase reconstituée in vitro.

\section{Protéine G monomérique : Rac :}

Contrairement aux autres protéines cytosoliques, Rac peut migrer et interagir indépendamment des autres facteurs cytosoliques avec la membrane plasmique. Trois isoformes ont été identifiées : Rac 1 (Abo et coll. 1991), Rac 2 (Knaus et coll. 1991), qui est l'isoforme prédominante dans les neutrophiles, et Rac 3 (Haataja et coll. 1997). Elles 
présentent $92 \%$ d'homologie sur les 192 acides aminés qui les constituent. Dans le cytosol des cellules non stimulées, Rac est associée à une molécule inhibitrice, RhoGDI (GDP Dissociation Inhibitor), qui la maintient dans sa forme inactive (Pick et coll. 1993). A la suite d'un stimulus, Rac se dissocie de RhoGDI ce qui lui permet de migrer jusqu'à la membrane et d'interagir avec p67 $7^{\text {phox }}$ (Heyworth et coll. 1994, Koga et coll. 1999, Takai et coll. 2001). L'échange du GDP en GTP est catalysé par la protéine GEF (GDP / GTP Exchange Factor).

\section{La protéine membranaire : $\operatorname{Rap} 1 \mathrm{~A}$}

L'intervention de Rap1A dans l'activation de la NAD(P)H oxydase a été mise en évidence fortuitement lors de la purification du cytochrome $b_{558}$ (Quinn et coll. 1989, 1992). Elle s'active indépendamment du complexe oxydase mais son rôle exact est encore méconnu (Vignais et coll. 2002, Quinn et coll. 2004). Elle interviendrait dans la régulation de l'activité oxydase (Maly et coll. 1994; Gabig et coll. 1995). Rap1A se lie spécifiquement au cytochrome $b_{558}$ selon une stœchiométrie de 1:1. Dans les neutrophiles, elle est phosphorylable sur sa partie C-terminale (résidu Ser $^{180}$ ) par la protéine kinase PKA (Quilliam et coll. 1991). Sa phosphorylation induit la rupture de l'interaction avec le cytochrome $b_{558}$ (Bokoch et coll. 1991) et pourrait ainsi réguler la désactivation de la NADPH oxydase.

\section{I-C-2. La famille des NADPH Oxydases des cellules non phagocytaires :}

Au cours de ces 5 dernières années, la famille des Nox s'est agrandie avec la mise en évidence de nouveaux membres dans les cellules dites non-phagocytaires (qui ne participent pas directement à la bactéricidie).

Il existe donc actuellement 7 membres identifiés Nox1, Nox2, Nox3, Nox4 et Nox5, ainsi que deux Duox : Duox1 et 2 (Krause et coll.2004).

\section{- Nox1 (Figure 13)}

Nox 1 , protéine de 564 acides aminés fut la première découverte et séquencée à partir d'ADNc du côlon par l'équipe de Lambeth. Elle possède 56\% d'identité avec gp91 ${ }^{\text {-phox }}$. Nox1 a été signalée aussi dans l'estomac de porc de Guinée (Banfi et coll. 2000), l'utérus et la prostate (Banfi et coll. 2000 Suh et coll. 1999). Elle jouerait un rôle dans la défense anti bactérienne au niveau du côlon, dans la différenciation de l'épithélium colique (Krause et coll. 2004), et plus 
généralement interviendrait dans l'hypertrophie et la prolifération cellulaire (Geiszt et coll. 2004)

Nox1 semble intervenir dans la différenciation neuronale (Ibi et coll. 2001). Par ailleurs Nox1 semble avoir une expression inductible dans le muscle lisse de l'aorte (Suh et coll. 1999) et jouerait un rôle dans la régulation de la pression sanguine (Gavazzi et coll. 2006).

\section{Nox1, Nox2 (gp91 phox), Nox3, Nox4:}

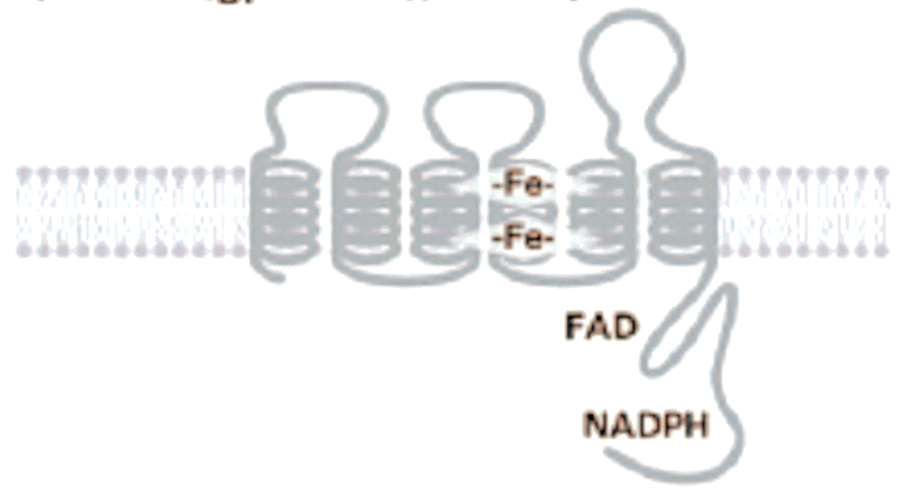

Nox 5:

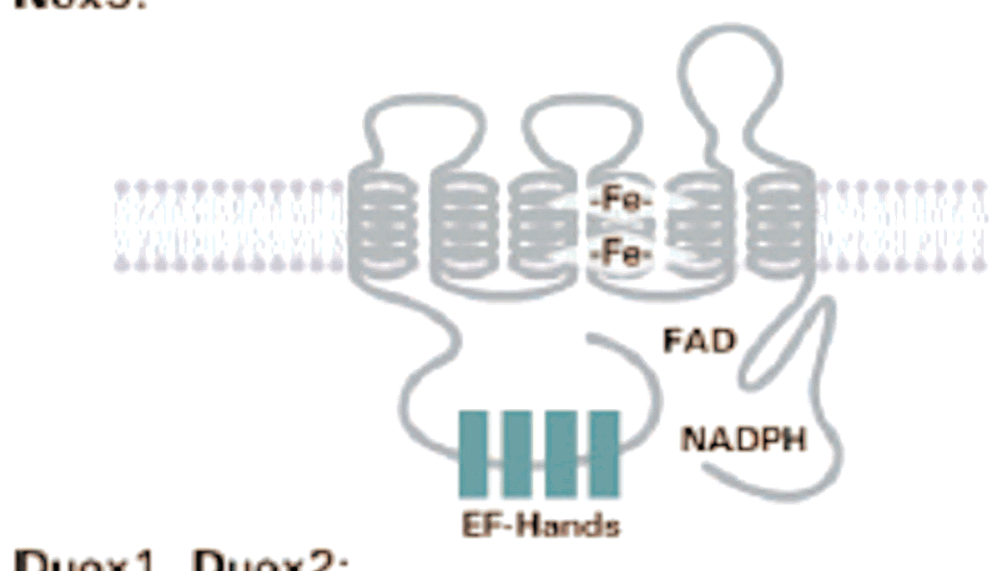

\section{Duox1, Duox2:}

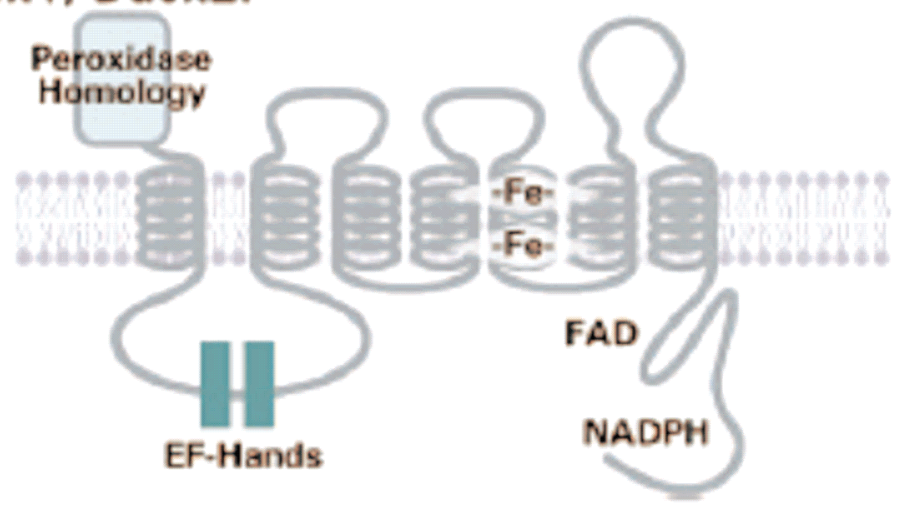

Figure 13 Structure tridimensionnelle prédite des Noxs. Le squelette de 6 passages transmembranaires hydrophobique et les régions de fixation du NADPH et du FAD sont conservés pour toutes les Nox . Nox5 possède en plus 4 motifs EF-Hand capables de fixer le calcium en N-terminal. Et les Duox 1 et 2 ont deux motifs EF-Hand capables de fixer le calcium et un domaine homologue peroxydase extra cellulaire (selon Geistz et coll. 2004). 
Par la suite, d'autres Nox $_{\mathrm{s}}$ furent identifiées :

- Nox3 (Figure 13)

Nox3, protéine de 568 acides aminés a été isolée à partir du rein fœtal et a été retrouvée en fait essentiellement dans l'oreille interne, et plus particulièrement dans le système vestibulaire et auditif. Elle intervient dans l'équilibre et la formation de l'oreille interne (Banfi et coll. 2004, Paffenholz et coll. 2004). Nox3 possède 58\% d'identité avec gp91 ${ }^{\text {-phox }}$. On retrouve une expression transcriptionnelle de cette Nox aussi bien dans le foie que le poumon ou la rate (Kikuchi et coll. 2000). Son activité oxydase semble liée à la présence de p22 ${ }^{\text {phox }}$ (Ueno et coll. 2005).

- Nox4 (Figure 13)

Nox4 à été caractérisée initialement à partir du tissu adulte de rein (son premier nom a été renox) (Geizst et coll. 2000, Shiose et coll. 2001). C'est une protéine de 578 acides aminés, avec une identité proche de $58 \%$ avec gp91 $1^{\text {-phox }}$. On la retrouve dans le rein mais aussi dans beaucoup d'autres cellules comme les cellules endothéliales, les cellules musculaires lisses, les cellules cardiaques, pancréatiques, les cellules du placenta, du muscle strié, des ovaires, des testicules, dans les ostéoclastes et la famille des fibroblastes et des astrocytes (Krause et coll. 2004). Récemment Kuroda et coll. ont mis en évidence la présence de Nox4 uniquement dans le noyau des cellules endothéliales de veines ombilicales mais, pour les autres cellules, cela reste à déterminer (Kuroda et coll. 2005). Protéine à multiples fonctions dans le rein, Nox4 aurait un rôle de détecteur d'oxygène "oxygen sensing» et de régulateur de la sécrétion d'érythropoïétine (Geiszt et coll. 2000, Shiose et coll. 2001). Nox4 pourrait intervenir aussi dans la régulation de la prolifération cellulaire. Nox4 semble être aussi, au niveau rénal, la principale source de radical oxydant dans les premières étapes du diabète entraînant une hypertrophie et une surexpression de fibronectine prèmices d'une fibrose rénale, qui est une redoutable complication de cette pathologie (Gorin et coll. 2005, Geiszt et coll. 2004, Lassegue et coll. 2003). Nox 4 interviendrait dans la défense anti bactérienne au niveau rénal en libérant les radicaux oxydants dans l'urine. Au niveau extra rénal, Li et coll. ont mis à la lumière le rôle de Nox4 dans la différenciation cardiaque au stade embryonnaire ( $\mathrm{Li}$ et coll. 2006), de même Nox4 interviendrait dans la résorption osseuse au niveau des ostéoclastes (Yang et coll. 2001), et dans le métabolisme de l'insuline (Mahadev et coll. 2004). Le rôle de Nox4 a été associé à la différenciation des fibroblastes en myo fibroblastes en présence de TGF- $\beta$ (Cucoranu et coll. 2005). Gorin et coll. suggèrent que Nox4 est stimulée en réponse à l'angiotensine II (Gorin et coll. 2004). 
- Nox5 (Figure 13)

Nox5 est une enzyme sensible au calcium et retrouvée dans les cellules de la rate et des spermatozoïdes (Banfi et coll. 2001) ; elle n'a que 27\% d'homologie avec Nox2. C'est une protéine de 737 acides aminés qui possède en plus 4 motifs «EF-Hand» de liaison du calcium en N-terminal. (figure15). Son rôle semble lié à la maturation des spermatozoïdes et à la prolifération cellulaire dans la rate.

- Les Duox (Duox1 et Duox2)

Initialement appelé thyroïde oxydase (Thox ou Tox), ces enzymes sont isolées dans les glandes du tractus gastro intestinal et la glande thyroïde pour Duox 2 et dans l'épithélium respiratoire et la thyroïde pour Duox1. Elles ont un domaine d'homologie avec la peroxydase du côté $\mathrm{N}$ terminal et en position extra cellulaire (figure 17). Elles ont 1551 et 1548 acides aminés respectivement pour Duox 1 et Duox 2 et ont $83 \%$ d'homologie avec Nox2. Elles sont également sensibles au calcium (Geiszt et coll. 2004). Ces deux enzymes sont impliquées dans la synthèse des hormones thyroïdiennes mais aussi dans la défense au niveau des épithéliums. Toutes ces protéines ont une structure tridimensionnelle prédite très similaire, elles possèdent toutes six passages transmembranaires et une «queue cytosolique » en C-terminal contenant des régions de fixation du FAD et du NADPH. Seule, Nox5 se différencie avec quatre motifs EF-hand en N-terminal, motifs capables de fixer le calcium, ainsi que les Duox 1 et 2 qui ont deux motifs EF-Hand capables de fixer le calcium et un domaine homologue de type peroxydase au niveau extra cellulaire.

Ces protéines sont bien conservées au cours de l'évolution puisque des homologues sont retrouvés chez la plante A. thaliana; D. melanogaster, C. elegans et l'amibe Dictyostelium (Lambeth et coll. 2000). Chez A. thaliana, les ROS produits par 1'homologue (RHD2) contrôlent la croissance cellulaire des racines en permettant l'activation de canaux à calcium (Foreman et coll. 2003). Chez les plantes, il existe plus d'une dizaine d'isoformes. Chez $C$. elegans, une NADPH oxydase semble impliquée dans la formation d'une cuticule stable puisque qu'une inhibition de sa synthèse par l'emploi d'ARN interférent conduit à l'absence de points de contacts entre les différentes couches de cette cuticule. Bernard Lardy a mis en évidence les homologues DdNoxA, DdNoxB et DdNoxC chez Dictyostelium discoideum (Lardy et coll. 2005). Leur invalidation conduit à une anomalie de développement majeur, aboutissant à un phénotype de différenciation arrêté précocement. Chez l'homme, le rôle des différentes $\mathrm{Nox}_{\mathrm{s}}$, mis à part celui de Nox2, commence juste à se dévoiler et reste l'objet de nombreux travaux de recherche qui commencent à impliquer les Nox $_{\mathrm{s}}$ dans des pathologies aussi importantes que le diabète, l'athérosclérose, l'hypertension artérielle et le cancer. 
I-C-2-a Régulation de la production des ions superoxyde par les Nox $_{s}$ non phagocytaires :

Contrairement aux complexes oxydases des cellules phagocytaires, les Nox $_{\mathrm{s}}$ retrouvées dans les cellules non phagocytaires ne produisent que de faibles quantités d'ions superoxyde. Ces activités ont été mesurées pour les protéines Nox1, Nox4 et Nox5, mais la plupart des expériences ont été réalisées sur des cellules surexprimant ces protéines.

La transfection de Nox1 dans les cellules NIH3T3 aboutit à une production de ROS à un niveau 10 fois inférieur à celui de Nox2 des neutrophiles (Suh et coll. 1999). De même, Nox4 exprimée dans les cellules HEK génère 10 fois moins de ROS que les neutrophiles (Shiose et coll. 2001). De plus, ces protéines ne semblent pas sensibles aux activateurs classiquement utilisés pour Nox2 comme l'acide arachidonique et le phorbol myristate acétate (Geiszt et coll. 2000, Shiose et coll. 2001, Banfi et coll. 2003).

\section{I-C-2-b Rôle potentiel des Nox dans certaines voies de signalisation :}

a) Il a été démontré durant ces dix dernières années que les ROS stimulaient l'activité des MAP (Mitogen-Activated protein) Kinases. Cette voie de signalisation est composée par 3 principaux sous groupes : ERK 1/2 (Extracellular Regulated Kinase) ; JNK (c-Jun N-terminal Kinase) et $\mathrm{p} 38$. Les ROS ont été décrits comme activateurs directs de l'oncogène $\mathrm{p} 21^{\text {Ras }}$ qui est une protéine clé de cette voie de signalisation (Lander et coll. 1995). La PKC (Protein Kinase C) une autre protéine clé est aussi sujette à une régulation redox stimulée par $\mathrm{H}_{2} \mathrm{O}_{2}$.

Ainsi, Nox1 participe au processus aboutissant à la phosphorylation des protéines p38MAPK et Akt/PKB après stimulation des cellules musculaires lisses des vaisseaux par le PDGF ou l'angiotensine II. L'expression d'un ARN anti-sens de Nox1 inhibe la phosphorylation de ces deux protéines (Lassegue et coll. 2001). L'expression d'un ARN anti-sens de p22 ${ }^{\text {phox }}$, la surexpression de la catalase ainsi que l'utilisation du diphénylène iodonium (inhibiteur de la NAD(P)H oxydase) inhibent également la phosphorylation des MAPKs (p38MAPK et JNK). D'autres auteurs rapportent que la synthèse protéique, induite par l'angiotensine II passant par la voie de signalisation cellulaire Akt/protéine kinase B dans les cellules mésangiales, serait médiée par Nox4. L'utilisation d'ARN anti-sens de Nox4 inhibe cette voie (Gorin et coll. 2004). 
b) Le facteur de transcription $\mathrm{NF}-\kappa \mathrm{B}$ régule un grand nombre de gènes qui maintiennent une résistance cellulaire au stress, participent au contrôle de l'apoptose et à la régulation de la réponse immune. Les ROS activent NF- $\kappa \mathrm{B}$ dans beaucoup de types cellulaires, à l'inverse les antioxydants diminuent son activité. Un résidu cystéine en position 62, impliqué dans la liaison de ce facteur de transcription à l'ADN, a été décrit comme pouvant être régulé par un système redox (Matthews et coll. 1992). Pour être actif, NF-кB

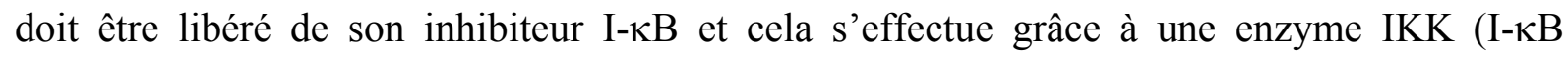
Kinase) protéine kinase. L'activité de cette enzyme est régulée par des protéines kinases de la voie JNK et p38, sensibles aux ROS.

c) L'état redox de la cellule pourrait agir comme senseur de l'oxygène. En 1993, Wang et Semanza ont mis en évidence l'existence d'un facteur de transcription appelé HIF-1 («Hypoxia Inducible Factor 1») capable d'augmenter l'expression de 1'EPO (Erythropoïétine) (Wang et coll. 1993). Cette protéine contrôle l'expression d'une soixantaine de gènes d'adaptation au manque d'oxygène. Une régulation par les ROS de HIF-1 a été proposée depuis quelques années (Salceda et coll. 1997, Haddad et coll. 2001). Il semblerait que la production intracellulaire continue des ions superoxyde $\mathrm{O}_{2}{ }^{-}$agirait en favorisant la dégradation de HIF-1. Ces mêmes auteurs montrent également que $1^{\prime} \mathrm{O}_{2}{ }^{-}$augmente l'activité protéolytique du système ubiquitine-protéasome, responsable de la dégradation de HIF-1 en normoxie. La transfection d'un ARN anti-sens de $\mathrm{p} 22^{\text {phox }}$, dans les cellules musculaires lisses vasculaires, inhibe l'accumulation de HIF-1 induite par la thrombine (Gorlach et coll. 2001). Parmi les systèmes de génération des ROS dans le rein, les NAD $(\mathrm{P}) \mathrm{H}$ oxydases semblent être la source de production la plus importante ( $\mathrm{Li}$ et coll. 2002). Nox4 a été identifiée comme la $\mathrm{NAD}(\mathrm{P}) \mathrm{H}$ oxydase caractéristique du rein, haut lieu de synthèse de l'EPO en réponse à l'hypoxie. Du fait de cette localisation, Nox4 a été proposée comme un bon candidat pour « l'oxygène sensing » dans le rein.

Comme on le voit, un certain nombre d'hypothèses ont été avancées pour définir le rôle de ces nouvelles isoformes, les $\mathrm{Nox}_{\mathrm{s}}$, dans l'organisme. La vérification de ces hypothèses pourrait permettre une meilleure compréhension de leur fonction dans les pathologies telles que l'hypertension, l'athérosclérose et le diabète et l'arthrose (Lassegue et coll. 2003, Meyer et coll. 2000, Baynes et coll. 1991). 


\section{I-C-2-c Facteurs potentiellement associés aux protéines Nox $\mathbf{s}_{\mathbf{s}}$ non phagocytaire :}

A 1'instar de Nox2 dont les partenaires protéiques composant le complexe oxydase sont bien caractérisés et abondamment étudiés, peu de choses sont connues sur les autres protéines Nox.

L'activité de Nox1 peut être augmentée en présence de facteurs cytosoliques p $47^{\text {phox }}$ et p6 $7^{\text {phox }}$. Par contre, ces protéines n'ont aucun effet sur l'activité de Nox4. Récemment, des homologues de $\mathrm{p} 47^{\text {phox }}$ et de $\mathrm{p} 67^{\text {phox }}$ dénommés respectivement $\mathrm{p} 41^{\text {nox }}$ ou NOXO1 (Nox Organizer 1) et p51 nox ou NOXA1 (Nox Activator 1) ont été mis en évidence dans les cellules épithéliales du côlon (Geiszt et coll. 2003a, Banfi et coll. 2003). Ces protéines co-exprimées avec Nox1 augmentent l'activité oxydase de Nox1 de manière stimuli-indépendante contrairement à $\mathrm{p} 47^{\text {phox }}$ et $\mathrm{p} 67^{\text {phox }} ; \mathrm{p} 22^{\text {phox }}$ semble être indispensable à l'activité oxydase de Nox1 dans les cellules musculaires lisses vasculaires (Viedt et coll. 2000).

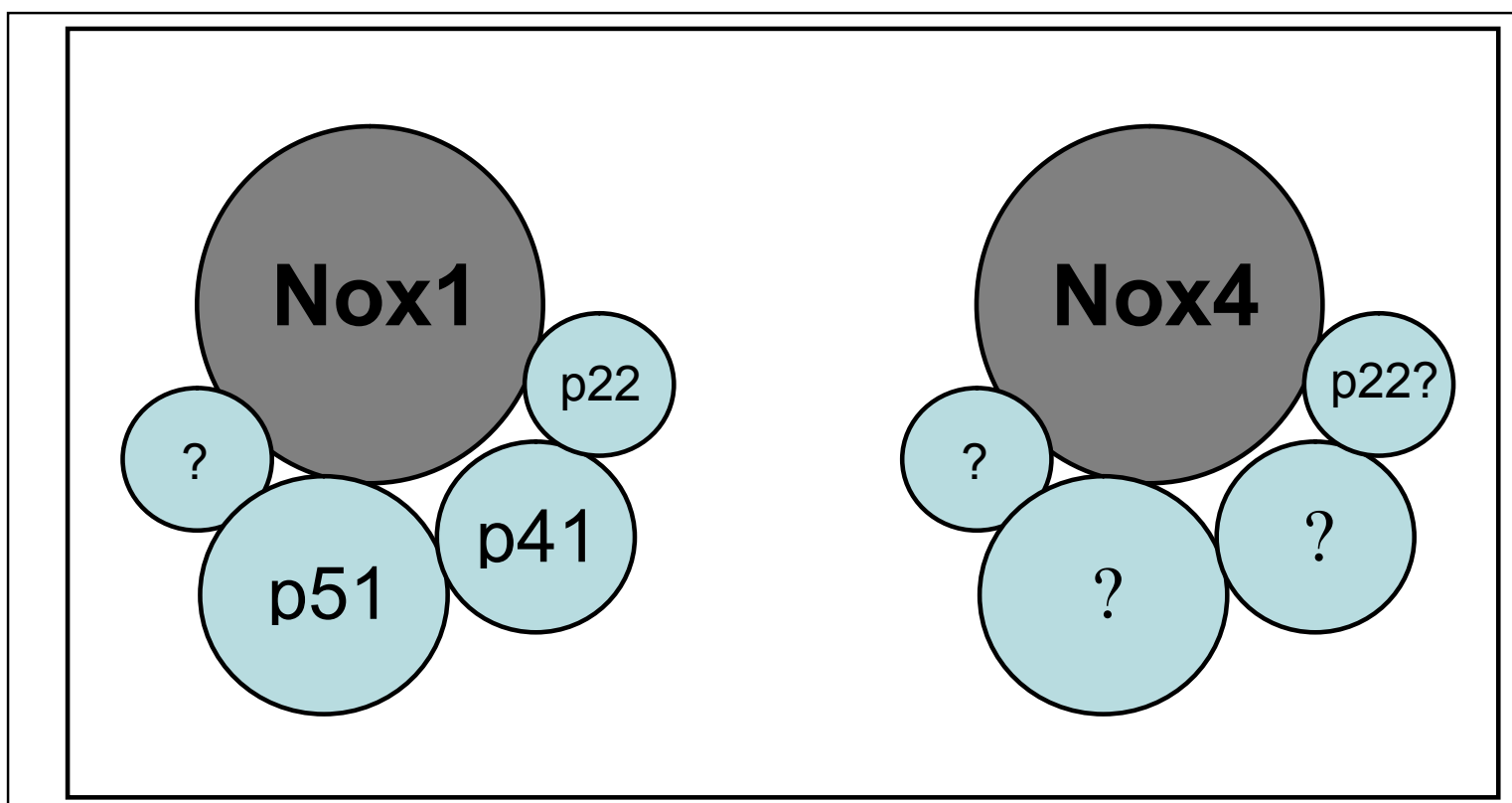

Figure 14 Partenaires potentiels de Nox1 et de Nox4.

L'association de $\mathrm{p} 22^{\text {phox }}$ et de Nox4 reste par contre encore incertaine (Figure 14). Contrairement à Nox 2 qui ne peut être exprimée qu'en présence de $\mathrm{p} 22^{\text {phox }}$, dans les cellules MIMCD3 (tube collecteur du rein de souris), Nox4 est exprimée alors que p22 $2^{\text {phox }}$ ne l'est pas (Geiszt et coll. 2000). Par ailleurs, la présence de Nox4 et $\mathrm{p} 22^{\text {phox }}$ dans les mélanomes semble être nécessaire à l'augmentation de la quantité de ROS produite et à la prolifération cellulaire. Ces deux phénomènes sont inhibés, non seulement par l'expression d'ARN anti-sens de Nox4 
mais aussi de $\mathrm{p} 22^{\text {phox }}$ (Brar et coll. 2002). Ceci suggère la possibilité d'un complexe Nox $4 /$ p2 $2^{\text {phox }}$. Cette hypothèse est appuyée par le fait que l'on observe une augmentation concomitante des deux protéines notamment au cours du diabète dans les cellules épithéliales du rein (Etoh et coll. 2003). De plus, récemment, une co-localisation cellulaire entre Nox4 et p2 $2^{\text {phox }}$ a été décrite au niveau des points d'adhésion focaux par immunofluorescence (Hilenski et coll. 2004) dans les cellules musculaires lisses des vaisseaux. Un travail récent (Ago et coll. 2004) montre que la transfection d'ARN anti-sens de p22 $2^{\text {phox }}$ entraîne la même inhibition sur la production de ROS dans les cellules endothéliales que celle induite par l'antisens Nox4.

\section{I-D Les métalloprotéases Matricielles :}

\section{I-D-1 Généralités :}

Parmi les enzymes capables de dégrader une protéine, on distingue les exopeptidases (leur rôle dans la dégradation de la MEC est mal connu) et les endopeptidases qui sont capables de rompre une liaison peptidique entre deux résidus acides aminés (Werb et coll. 1993). Au sein des endopeptidases, on distingue : les protéases à Aspartate, à Cystéine, à Sérine et les métalloprotéases.

Depuis la découverte en 1962 d'une collagénase impliquée dans la morphogenèse de la queue de têtard (Gross et coll. 1962), beaucoup de protéases du même type ont été découvertes dans des organismes aussi variés que la drosophile, l'hydre ou l'Homme. Ces endopeptidases dépendantes du zinc et du calcium, appelées Métalloprotéases Matricielles (MMPs), sont aujourd'hui au nombre de 24 chez l'humain. Elles appartiennent à la superfamille des metzincines qui comprend cinq familles de protéines: les serralysines, les astacines, les reprolysines (comprenant les adamalysines ou ADAMs), les MMPs et plus récemment une autolysine bactérienne. Parmi les 30 familles de métalloprotéases connues, les métalloprotéases matricielles sont les principaux protagonistes de la protéolyse matricielle. Actuellement les 24 MMPs identifiées se répartissent en 5 sous-classes établies principalement selon leur structure et la spécificité de leur substrat (Nagase, et coll. 1997, 1999).

Les métalloprotéases (MMPs) forment une famille d'enzymes qui sont sécrétées principalement par les cellules participant à la réaction inflammatoire (pour revue Gaudin et 
coll. 1998) mais aussi par d'autres types de cellules résidentes (cellules tumorales, fibroblastes, chondrocytes...). Ces enzymes sont synthétisées sous une forme latente inactive (pro enzyme) qui est activée in vivo par d'autres protéases, des substances radicalaires et in vitro par des composés de types organomercuriels, des détergents, par la chaleur.....

L'activité de ces enzymes est contrôlée par des inhibiteurs spécifiques tissulaires les TIMPs (Gomez, et coll. 1997). Il en existe actuellement quatre qui sont glycosylés ou non, libres ou fixés à la MEC par un mécanisme de crinopexie.

Il existe trois niveaux de régulation des MMPs. Tout d'abord lors de l'expression du gène (au niveau intracellulaire), ensuite dans le contrôle de leur activité par synthèse sous une forme inactive et activation du proenzyme (au niveau extracellulaire), et enfin par une compartimentation subcellulaire précise soit dans des granules de sécrétion, soit par une fixation à la membrane plasmique ou aux constituants de la MEC. L'expression des MMPs est aussi régulée par différents médiateurs (GF, cytokines, hormones) induisant la fixation de facteurs de transcription sur leurs régions promotrices.

- La Famille des MMPs.

Les MMPs ont des points communs :

1 - une organisation en domaines conservés.

2 - dégradation d'au moins un constituant de la MEC.

3 - présence d'atome de zinc au niveau du site actif.

4 - synthèse sous la forme d'un proenzyme inactif.

5 - activité à $\mathrm{pH}$ neutre

6 - inhibition par les TIMPs 
Les différentes familles de MMPs :

Tableau 2 Famille des MMPs humaines (d'après Nagase et coll. 1997 \& 1999et actualisé septembre 2006)

\begin{tabular}{|c|c|c|c|}
\hline MMP & $\begin{array}{c}\text { Enzyme } \\
\text { nomenclature }\end{array}$ & $\begin{array}{c}\text { PM (kDa) } \\
\text { latent/actif }\end{array}$ & Substrats connus MEC \\
\hline 1 & $\begin{array}{r}\text { Collagénase } \\
\text { interstitielle } \\
\text { (EC 3.4.24.7) } \\
\end{array}$ & $55-45$ & $\begin{array}{l}\text { Coll. I, II, III, VII, VIII, X, } \alpha 1 \text {-antitrypsine, caséine, } \\
\alpha 2 \text {-macroglobuline, aggrécanes, versicane, } \\
\text { MMP-2,-9, L-sélectine }\end{array}$ \\
\hline 8 & $\begin{array}{c}\text { Collagénase } \\
\text { neutrophile } \\
\text { (EC 3.4.24.34) }\end{array}$ & $75-58$ & $\begin{array}{l}\text { Coll. I, II, III, V, VII, VIII, X, XI, aggrécanes, élastine, } \\
\text { fibronectine, gélatine, laminine }\end{array}$ \\
\hline 13 & Collagénase- 3 & $60-48$ & Coll. I, II, III, IV, gélatine, ténascine, perlécane, aggrécanes \\
\hline 18 & Collagénase-4 & $70-53$ & Coll. I \\
\hline 2 & $\begin{array}{r}\text { Gélatinase A } \\
\text { (EC 3.4.24.24) }\end{array}$ & $72-66$ & $\begin{array}{l}\text { Coll. I, II, III, IV, V, VII, IX, X, gélatine, aggrécanes, laminine, } \\
\text { fibronectine, élastine, MMP- } 9,-13\end{array}$ \\
\hline 9 & $\begin{array}{r}\text { Gélatinase B } \\
\text { (EC 3.4.24.25) }\end{array}$ & $92-86$ & $\begin{array}{c}\text { Coll. IV, V, VII, X, XIV, gélatine, élastine, fibronectine } \\
\alpha 1 \text {-antitrypsine, proTNF- } \alpha\end{array}$ \\
\hline 3 & $\begin{array}{l}\text { Stromélysine } 1 \\
\text { (EC 3.4.24.17) }\end{array}$ & $57-45$ & $\begin{array}{c}\text { Protéoglycanes, coll. II, III, IV, IX, X, XI, aggrécanes, gélatine, } \\
\text { élastine, laminine, caséine, } \alpha 2 \text {-macro., MMP-1, }-7,-8,-9,-13 \text {, } \\
\text { proTNF- } \alpha\end{array}$ \\
\hline 10 & $\begin{array}{l}\text { Stromélysine } 2 \\
\text { (EC 3.4.24.22) }\end{array}$ & $57-44$ & $\begin{array}{c}\text { Aggrécanes, fibronectine, laminine, coll.III, IV, V, } \\
\text { gélatine, caséine, MMP- } 1,-8\end{array}$ \\
\hline 11 & Stromélysine 3 & $51-44$ & $\alpha 1$-antitrypsine, aggrécanes, fibronectine, laminine \\
\hline 14 & $\begin{array}{c}\text { MT1-MMP } \\
\text { Métalloprotéase } \\
\text { membranaire 1 }\end{array}$ & $66-56$ & $\begin{array}{l}\text { Coll. I, II, III, gélatine, aggrécanes, caséine, élastine, fibronectine, } \\
\text { laminine, vitronectine, MMP-2, -13, proTNF- } \alpha\end{array}$ \\
\hline 15 & $\begin{array}{l}\text { MT2-MMP } \\
\text { Métalloprotéase } \\
\text { membranaire } 2\end{array}$ & $72-60$ & MMP-2, gélatine, fibronectine, ténascine, laminine \\
\hline 16 & $\begin{array}{l}\text { MT3-MMP } \\
\text { Métalloprotéase } \\
\text { membranaire } 3 \\
\end{array}$ & $64-52$ & MMP-2, caséine, gélatine \\
\hline 17 & $\begin{array}{l}\text { MT4-MMP } \\
\text { Métalloprotéase } \\
\text { membranaire } 4\end{array}$ & $57-53$ & Fibrine, gélatine \\
\hline 24 & $\begin{array}{l}\text { MT5-MMP } \\
\text { Métalloprotéase } \\
\text { membranaire }\end{array}$ & $?-62$ & \\
\hline 25 & $\begin{array}{l}\text { MT6-MMP } \\
\text { Métalloprotéase } \\
\text { membranaire }\end{array}$ & & Coll. IV, gélatine, fibronectine, laminine-1 \\
\hline 7 & $\begin{array}{c}\text { Matrilysine } \\
\text { (EC 3.4.24.23) }\end{array}$ & $28-19$ & $\begin{array}{l}\text { Coll. IV, X, aggrécanes, gélatine, élastine, laminine, } \alpha 1- \\
\text { antitrypsine, fibronectine, MMP- } 1,-2,-9\end{array}$ \\
\hline 12 & $\begin{array}{l}\text { Métalloélastase } \\
\text { (EC 3.4.24.65) }\end{array}$ & $54-45 / 22$ & $\begin{array}{c}\text { Elastine, fibronectine, caséine, gélatine, } \\
\alpha 1 \text {-antitrypsine, coll.IV, laminine, proTNF- } \alpha\end{array}$ \\
\hline 19 & RASI-1 & $54-45$ & $\begin{array}{l}\text { Coll. IV, gélatine, aggrécanes, laminine, } \\
\text { fibronectine, COMP }\end{array}$ \\
\hline 20 & Enamélysine & $54-22$ & Amélogénine, COMP, aggrécanes \\
\hline 23 & CA-MMP & 44 & \\
\hline 26 & Matrilysine-2 & $28-19$ & Coll. IV, gélatine, fibronectine \\
\hline 28 & Epilysine & & \\
\hline CMMP & Chicken MMP & $51-42$ & Caséine, gélatine \\
\hline XMMP & Xénopus MMP & & Caséine, gélatine \\
\hline
\end{tabular}


Les MMPs sont réparties en cinq classes qui sont déterminées principalement par la spécificité de leurs substrats.

- Les 4 collagénases (MMP-1, MMP-8, MMP-13, MMP-18): elles transforment le collagène fibrillaire (collagène de type I, II, III) en collagène dénaturé (gélatine) pouvant alors être digéré par les gélatinases.

- Les 2 gélatinases (gélatinase A ou MMP-2, gélatinase B ou MMP-9) : comme indiqué précédemment leur substrat principal est le collagène non fibrillaire (gélatine).

- Les 3 stromélysines (MMP-3, MMP-10 et MMP-11) : leur spectre protéolytique est plus étendu et inclut de nombreuses glycoprotéines et des protéoglycanes.

- Les 6 métalloprotéases membranaires (MMP-14, MMP-15, MMP-16, MMP-17, MMP-24, MMP-25) : en plus de leur rôle dans la dégradation de la MEC, ces enzymes interviennent dans l'activation des autres MMPs, principalement la MMP-2.

- Enfin la dernière classe est constituée de 10 MMPs encore imparfaitement caractérisées et/ou ne pouvant appartenir à aucune des catégories précédemment définies.

\section{I-D-1-a La structure des MMPs :}

Les MMPs possèdent une caractéristique propre aux metzincines. Elles sont organisées au niveau de leur séquence primaire en domaines dont trois sont présents chez tous les représentants de la famille et qui sont le pré-domaine, le pro-domaine et le domaine catalytique (Figure. 15) :

- Le pré-domaine, n'est autre qu'un peptide signal de 20 acides aminés situé en Nterminal, qui est nécessaire à l'acheminement de la protéine jusqu'à la surface cellulaire et est éliminé après sa sécrétion ou son ancrage membranaire.

- Le pro-domaine constitué de 80 résidus environ, maintient la MMP sous une forme latente (zymogène) par la présence d'une cystéine réagissant avec l'atome de zinc catalytique (Figure. 15).

- Le domaine catalytique de 110 acides aminés contient les acides aminés fixant le zinc

- Et enfin en C-terminal une région d'environ 200 acides aminés présentant de nombreuses similitudes avec l'hémopexine ou la vitronectine et responsable d'une certaine spécificité de substrat pour les collagénases, et de la liaison des TIMPs aux 
gélatinases. A part la matrilysine (MMP-7) et la matrilysine-2 (MMP-26), toutes les MMPs possèdent un quatrième domaine.

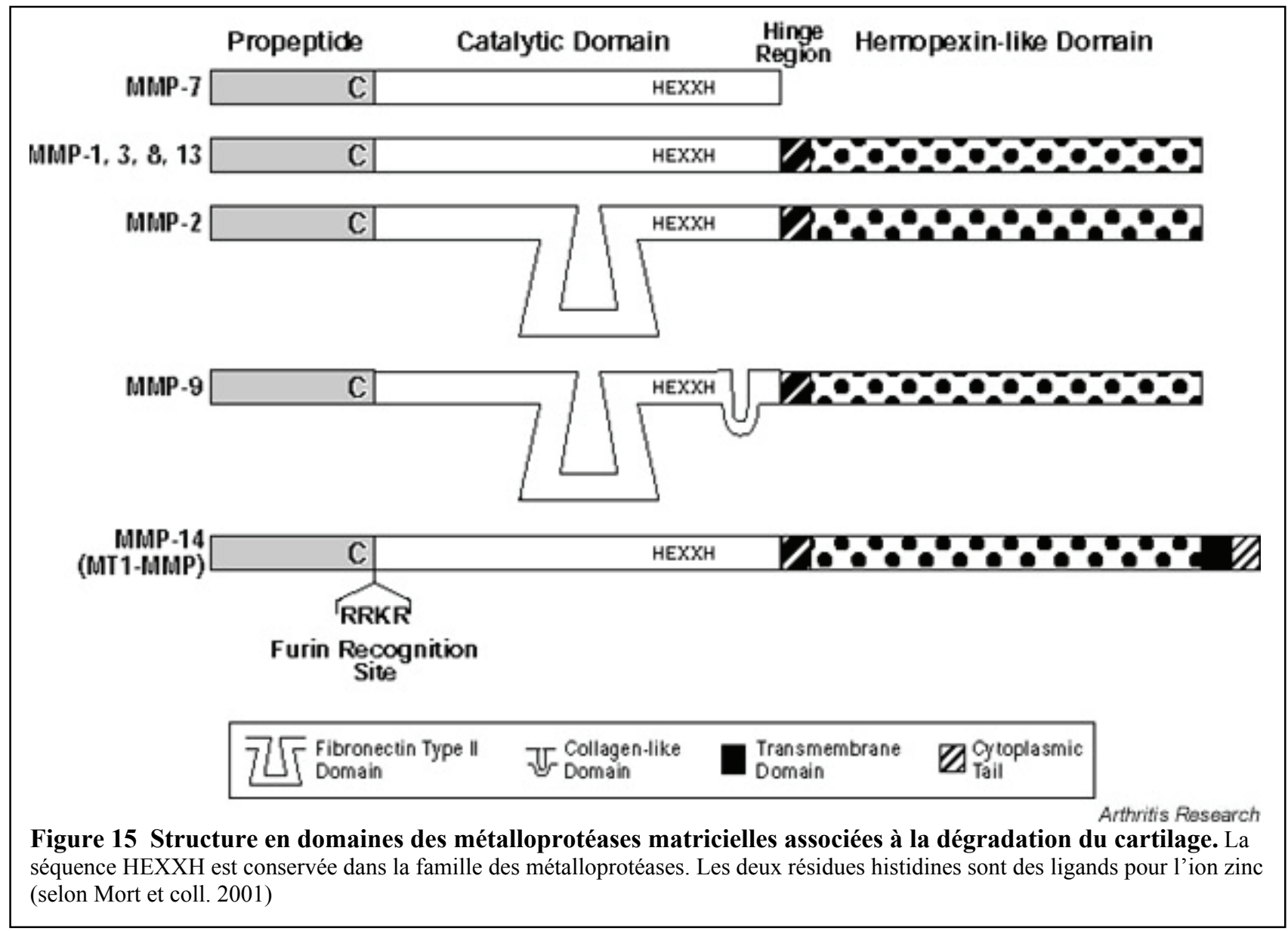

Les MMPs possèdent de plus, deux séquences consensus :

- la première située dans le propeptide (PRCGVPD) contient un résidu cystéine permettant une synthèse de l'enzyme sous une forme latente. Celle-ci se lie à l'atome de zinc du site catalytique tel un quatrième ligand (en plus des trois histidines du site catalytique) et empêche la liaison d'un substrat en excluant les molécules d' $\mathrm{H}_{2} \mathrm{O}$. La modification de la conformation du pro-domaine ou son clivage protéolytique rompt cette liaison cystéine-zinc et permet le remplacement du groupe thiol par l'eau. C'est ce qu'on appelle le "cystein-switch". L'enzyme est alors capable de cliver totalement son propeptide de manière autocatalytique et devient complètement active.

- La seconde séquence consensus hautement conservée est constituée de 11 acides aminés contenant trois histidines qui lient un atome de zinc dans le site catalytique et une méthionine située dix résidus en aval permettant le repliement du domaine catalytique sous la forme d'une poche. Ce motif protéique de liaison au zinc est 
composé de la façon suivante HEBXHXBGBXHZ où l'histidine (H), l'acide glutamique $(\mathrm{E})$, et la glycine $(\mathrm{G})$ sont constants, le $\mathrm{B}$ correspond à un résidu hydrophobe, $\mathrm{X}$ varie et $\mathrm{Z}$ est spécifique de chaque famille de protéases, soit une sérine chez presque toutes les MMPs.

Sur cette structure de base se greffent des motifs additionnels comme un motif répétitif identique à la fibronectine II pour les gélatinases, la MMP-9 (gélatinase B) ayant en plus une portion de séquence similaire à la chaîne $\alpha 2$ du collagène de type $V$. On trouve du coté $\mathrm{C}$ terminal une séquence de 60 résidus d'acides aminés permettant un ancrage membranaire pour certaines formes de MMPs membranaires (MMP-14, 15, 16, 17, 24, 25). La MMP-23 possède de plus en position C-Ter, une région riche en cystéine suivie d'un domaine homologue au récepteur de type II à l'IL-1. Enfin une dernière séquence de type RXKR est présente chez certaines MMPs (MMP-11, MT-MMPs, MMP-20, MMP28...) entre le prodomaine et le domaine catalytique : il s'agit du site de coupure de la furine, protéase à sèrine de la famille des convertases, ce qui permet une activation intra cellulaire de ces MMPs.

\section{I-D-1-b Régulation des MMPs :}

Les MMPs sont régulées à plusieurs niveaux incluant la transcription, l'activation des formes zymogènes, l'inhibition de l'activité par des protéines extracellulaires spécifiques ou non, et une inactivation par internalisation par endocytose.

Le mécanisme aboutissant à l'activation des MMPs sont de trois types :

- Le plus courant, concernant la majorité des MMPs, consiste en une activation de l'enzyme en deux étapes au niveau extracellulaire aboutissant après une modification conformationnelle de la molécule et le clivage de la liaison zinc-cystéine à une élimination du propeptide.

- Le second, restreint aux MMPs membranaires, (MMP-14, MMP-20, MMP-23, MMP28) utilise pour une activation intracellulaire des convertases de type furine. (Kang et coll. 2002, Sato et coll. 1996).

- Enfin le troisième mécanisme concernant uniquement la MMP-2 et la MMP-13 fait intervenir une metalloprotéase membranaire et le TIMP-2 (Nagase et coll. 1997). 
Une fois activées, les MMPs sont inactivées selon des mécanismes précis par différentes protéines comme l'a2-macroglobuline ou la protéine RECK (REversion inducing Cysteine rich protein with Kazal motifs) (Somerville et coll., 2003), mais les principaux inhibiteurs restent spécifiques et sont les quatre TIMPs. En effet, quatre inhibiteurs tissulaires des métalloprotéases matricielles ont été définis chez les mammifères. Ils possèdent des caractéristiques de base communes mais des différences ont été observées dans leur structure, leurs propriétés biochimiques ou encore dans leur profil d'expression. Chaque TIMP a donc un rôle particulier in vivo.

\section{I-D-1-c. Activités des MMPs :}

La famille des MMPs est capable dans son ensemble de dégrader, à $\mathrm{pH}$ physiologique, la totalité des composants de la matrice extracellulaire ou de la membrane basale bien que chaque MMP possède son propre éventail de substrats. Cependant les MMPs peuvent aussi dégrader d'autres protéines non matricielles comme des facteurs de croissance ou de liaison aux facteurs de croissance, des cytokines, ou encore des récepteurs d'adhésion ou de mort cellulaire voire d'autres protéases modifiant ainsi leur activité. Elles ont ainsi pour cible des inhibiteurs de protéases (serpines), des protéines impliquées dans l'apoptose (TNF $\alpha$, Fas L), des facteurs de croissance (VEGF, TGF- $\beta \ldots . .$. ), et leurs récepteurs (FGF-R1), ou encore des molécules d'adhésions (CD44, E-Cadhérine....)

A travers leurs activités protéolytiques les MMPs influencent le phénotype cellulaire en permettant la libération de facteurs de croissance contenus dans la MEC mais aussi la génération de fragments ayant des propriétés de type cytokinique appelés les matrikines (Maquart et coll. 2005) Il a été montré que certaines MMPs clivent le $\beta$-dystroglycane (Yamada et coll. 2001) ou le syndecan (Endo et coll. 2003).

A travers leurs activités variées, les MMPs sont impliquées dans de multiples mécanismes physiologiques (angiogenèse, cicatrisation, embryogenèse) et dans de nombreuses pathologies comme par exemple les maladies auto-immunes, inflammatoires, ou tumorales, etc.

\section{I-D-2 La protéolyse matricielle focalisée :}

La matrice extracellulaire, en continuel renouvellement, est le siège de trois phénomènes qui coexistent : l'assemblage, le remodelage, le dépôt de substance fondamentale qui peut parfois se faire en excès (Basbaum et coll. 1996). Le remodelage matriciel est sous la 
dépendance de 3 familles d'enzymes qui sont les MMPs, les protéases à sérine [en particulier l'u-PA (activateur du plasminogène de type urokinase), le t-PA (activateur du plasminogène de type tissulaire), la plasmine, l'élastase des polynucléaires neutrophiles (Gaudin et coll. 1997)] et les protéases à cystéine (cathepsines B et L). Les inhibiteurs impliqués dans le contrôle du remodelage matriciel sont l' $\alpha 2$-macroglobuline, les inhibiteurs de l'activateur du plasminogène de type 1 et 2 (PAI-1 et PAI-2), et les TIMPs.

De façon très récente, de nouveaux acteurs ont été impliqués dans la dégradation du tissu conjonctif en particulier du cartilage. On pensait en effet que seules les MMPs pouvaient dégrader ces agrécanes. Or, d'autres enzymes du groupe des métalloprotéases, de la famille des ADAMTs «a disintegrin and metalloproteinase with thrombospondin motifs », les aggrécanases, sont impliquées. Il existe à l'heure actuelle 5 sous-types d'ADAMTs exprimés dans le tissu cartilagineux, leur nombre et leurs rôles respectifs restant encore à préciser. Les stratégies thérapeutiques devront les prendre en considération (Pujol et coll. 1998).

La protéolyse matricielle focalisée dépend : de la compartimentation des enzymes protéolytiques (Werb et coll. 1997), de l'inactivation des inhibiteurs par les dérivés radicalaires de l'oxygène (Vissers et coll. 1988), de la liaison étroite des enzymes à leurs substrats (Kolev et coll. 1994) et des phénomènes d'activation protéolytique membranaire (Basbaum et coll. 1996).

\section{I-D-3 La collagénase 1 MMP-1}

La MMP-1 ou collagénase interstitielle est la première MMP identifiée en 1962 chez le têtard (Gross et coll 1962) et fait maintenant partie de la sous-famille des collagénases qui comportent actuellement 4 membres (MMP-1, MMP-8 ou collagénase neutrophile, MMP-13 ou collagénase-3, et MMP-18 identifiée chez le Xénope). Synthétisée par les fibroblastes, les cellules endothéliales, les kératinocytes ou encore les chondrocytes, elle clive principalement les collagènes fibrillaires (I, II et III) avec une affinité préférentielle pour le collagène III. Sa structure primaire est constituée des 4 domaines conservés précédemment décrits (séquence signal, propeptide, domaine catalytique et domaine C-Terminal), correspondant à une masse moléculaire de $55 \mathrm{kDa}$ sous sa forme inactive et $45 \mathrm{kDa}$ après activation.

$\mathrm{Du}$ fait de son activité protéolytique essentiellement ciblée sur les collagènes fibrillaires, la MMP-1 est impliquée dans la première étape du remodelage matriciel. Une modification de son expression et/ou activation se trouve associée à plusieurs processus physiologiques tels 
que la cicatrisation (Ravanti et coll 2000), le remodelage utérin ou l'embryogenèse, ainsi qu'à de nombreuses pathologies comme l'hépatite C (Leroy et coll 2004), la rectocolite hémorragique (Wang et coll 2006) et la maladie de Crohn (Warnaar et coll 2006), l'athérosclérose (Montero et coll 2006) ou encore la plupart des cancers, où il a été montré une corrélation entre la surexpression de MMP-1 et un mauvais pronostic de survie (Westermarck et coll 1999). Au niveau rhumatologique, la MMP-1 est une des principales MMPs responsable de la protéolyse matricelle survenant dans l'arthrose. Elle est située essentiellement sur les couches les plus superficielles du cartilage. Il exite après un stress cytokinique par IL-1, une augmentation d'expression de cette mètalloprotéase entre 8 heures et 24 heures puis une décroissance d'expression à partir de la $48^{\text {éme }}$ heure (Koshy et coll. 2002)

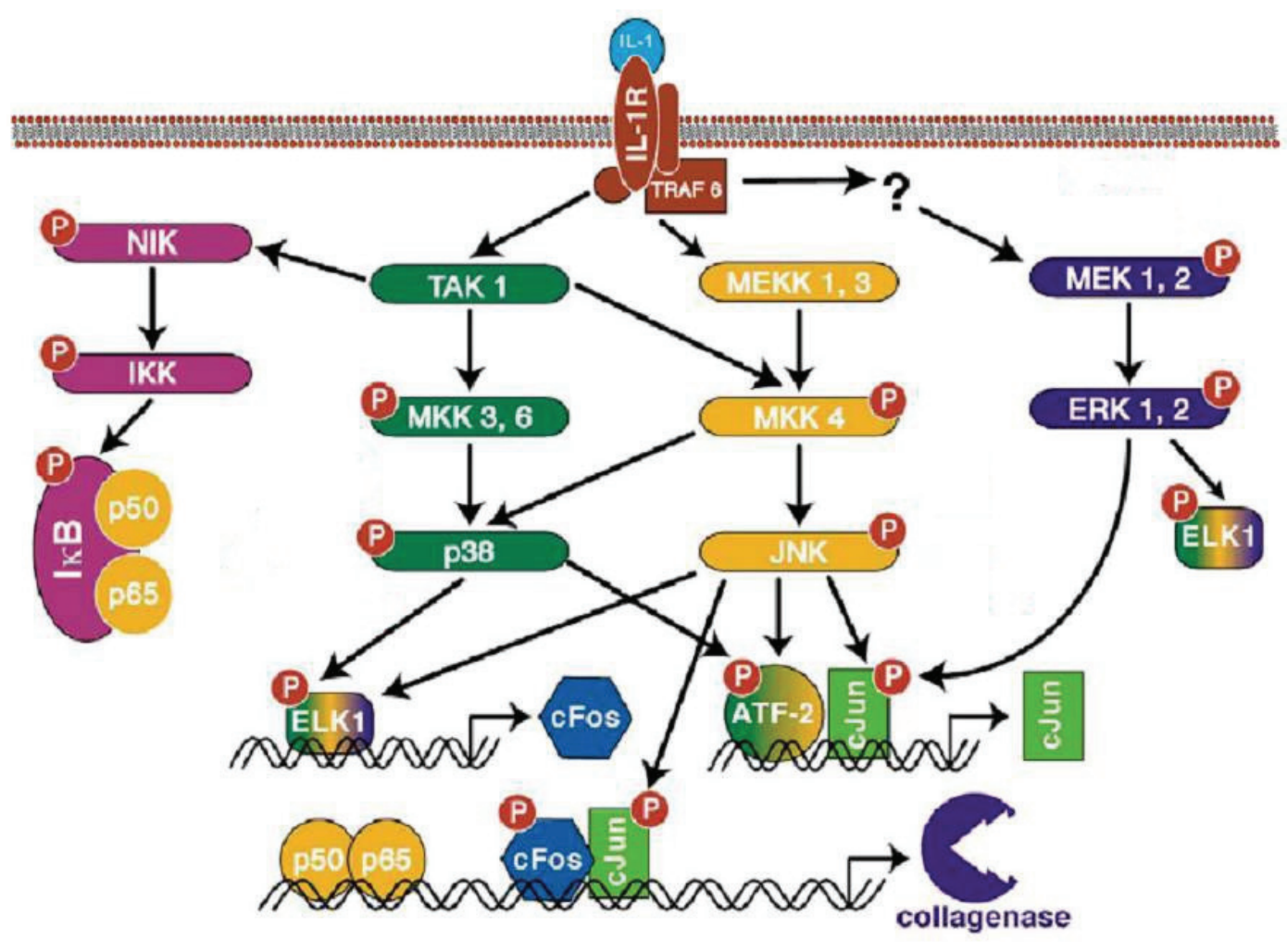

Figure 16 Principales voies de signalisation régulant la transcription de la collagénase dans les chondrocytes après une stimulation par l'IL-1 (Burrage et coll. 2006).

Sa régulation est sous la dépendance de deux cytokines (l'interleukine -1 et le TNF- $\alpha$ ). La séquence promotrice de la MMP-1 contient plusieurs sites de fixation de facteurs de transcription comme des sites AP1, fixant les dimères oncogéniques c-fos / c-jun, ou encore le site de fixation des sous unités de iкB (P50et P65) ou PEA3 pour les facteurs c-ets (Pardo et 
coll. 2005). L'interleukine -1 et le TNF- $\alpha$ régulent l'expression de cette collagénase -1 à travers des voies de signalisation comme la voie MAPKS ou NF-kB, ou encore AP1 (cf figure 16)

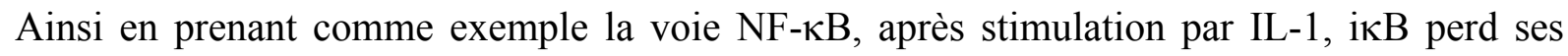
sous unités P50 et P65 qui sont dans le noyau où ils rejoignent leur site de fixation sur le gène promoteur (séquence consensus GGGACTTTCC) de MMP-1 activant la transcription.

\section{I-E Les ROS, les chondrocytes et l'arthrose :}

\section{I-E-1 Le stress oxydatif :}

Les dérivés radicalaires de l'oxygène ont une place importante en conditions physiologiques dans la régulation d'un grand nombre de fonctions basales dans le chondrocyte comme l'activation, la prolifération et la régulation de l'homéostasie du cartilage.

Lorsque la production de ROS excède la capacité anti oxydante de la cellule, le stress oxydatif apparait au sein de la cellule et du cartilage entraînant des changements structurels et de fonction (Henrotin et coll. 2005).

De nombreux auteurs ont impliqué le stress oxydatif dans la physiopathologie de l'arthrose. Ils ont souligné son impact direct sur le catabolisme du cartilage articulaire (Tiku et coll.1998, Loeser et coll. 2002), mais aussi sur le vieillissement du cartilage via notamment la peroxydation des lipides et l'oxydation des collagènes cartilagineux (Stadler et coll. 1991, Del Carlo et coll.2002, Tiku et coll.2000).

Ainsi dans des cultures de chondrocytes bovins, les LDL oxydées (low density lipoprotein) augmentent la production intra cellulaire de ROS en se fixant sur des récepteurs spécifiques les « oxLDL receptor-1 »(LOX-1) (Nishimura et coll. 2004).

Les chondrocytes articulaires produisent activement et de manière endogène (Figure 17) les différents membres des dérivés radicalaires de l'oxygène tel que l'ion superoxyde $\left(\mathrm{O}_{2}{ }^{-}\right)$ (Hiran et coll. 1997), le monoxyde d'azote (NO) via l'activation d'une NO synthase (NOS). (Stefanovic-Racic et coll. 1996, Mazzetti et coll.2001).

Le chondrocyte exprime d'ailleurs, deux des trois isoformes de la NO synthase (NOS), une constitutive (eNos ou NOS3) et une inductible (iNos ou NOS2). 
L'expression de cette enzyme est régulée positivement au niveau génique, à la fois par des facteurs mécaniques (en compression statique ou intermittente et en étirement), et aussi par des cytokines (IL-1 $\beta$, IL-17, TNF- $\alpha$, IFN $\gamma$ ) et des lipopolysacharrides (LPS).

Inversement, son expression est régulée négativement par le TGF- $\beta$, l'IL-4, l'IL-6, l'IL-10, l'IL-13 et l'oncostatine.

$\mathrm{L}^{\prime} \mathrm{O}_{2}{ }^{-}$et le $\mathrm{NO}$ génèrent ensuite du peroxyde d'hydrogène $\left(\mathrm{H}_{2} \mathrm{O}_{2}\right)$ et du peroxynitrite $\left(\mathrm{ONOO}^{-}\right)$(Distler et coll.2004). En présence de Fer $\left(\mathrm{Fe}^{2+}\right)$, et avec de $\mathrm{l}^{\prime} \mathrm{H}_{2} \mathrm{O}_{2}$ le chondrocyte produit aussi des radicaux hydroxyle $(\mathrm{OH})$, à travers la réaction de Haber-Weiss (Tiku et coll.1990) (figure 17).

Le NO possède des fonctions physiologiques et des propriétés pro inflammatoires et cytotoxiques. Ainsi au niveau du cartilage il stimule la production de cytokines pro inflammatoires comme l'IL-1 $\beta$, le TNF- $\alpha$ et même des MMPs, tandis qu'il inhibe la synthèse des protéoglycanes.

Le chondrocyte synthétise de la myèloperoxydase notamment dans l'arthrose, suggérant qu'il a la capacité également de produire de l'acide hypochloreux ( $\mathrm{HOCl})$ (Attur et coll. 2002).

Cette possibilité qu'ont les chondrocytes à produire des radicaux oxydants est liée à la présence d'un complexe NAD(P)H oxydase. Moulton en 1997 et 1998 ainsi que Hiran en 1997 ont émis l'hypothèse que l'isoforme gp91 ${ }^{\text {phox }}$ du complexe NAD(P)H oxydase appelé Nox2 qui était présent dans ces chondrocytes était l'isoforme responsable de cette production de radicaux oxydants (Moulton et coll. 1997, 1998, Hiran et coll.1997). L'IL-1 $\beta$ augmente d'ailleurs l'expression de l'unité gp91 ${ }^{\text {phox }}$ du complexe NAD(P)H oxidase Nox2, et de la NO synthase inductible dans une lignée immortalisée de chondrocytes nommée ATDC5 (Yasuhara et coll. 2005.

Cependant HIRAN en 1997 montrait aussi qu'un ester de phorbol le Phorbol Myristate Acétate (le PMA, qui est un activateur préferentiel de Nox2) n'activait pas la production de ces ROS pouvant faire penser que Nox2 n'ètait peut-être pas l'isoforme responsable (Hiran et coll.1997). D'autres auteurs comme Henrotin prouvaient en parallèle le contraire (Henrotin et coll. 1993)

La question reste ouverte et nous allons essayer d'y apporter une réponse par la suite.

Les dérivés radicalaires de l'oxygène sont produits par le chondrocyte sous l'influence de stress mécaniques et cytokiniques. In vitro, sous l'effet de contraintes mécaniques, des chondrocytes en culture peuvent produire des ROS mesurés par 
chimioluminescence.(Yamazaki et coll. 2003). D'autres cytokines comme le TNF- $\alpha$, ou l'IL$1 \beta$ peuvent aussi stimuler la production de ROS (Clancy et coll. 2001).

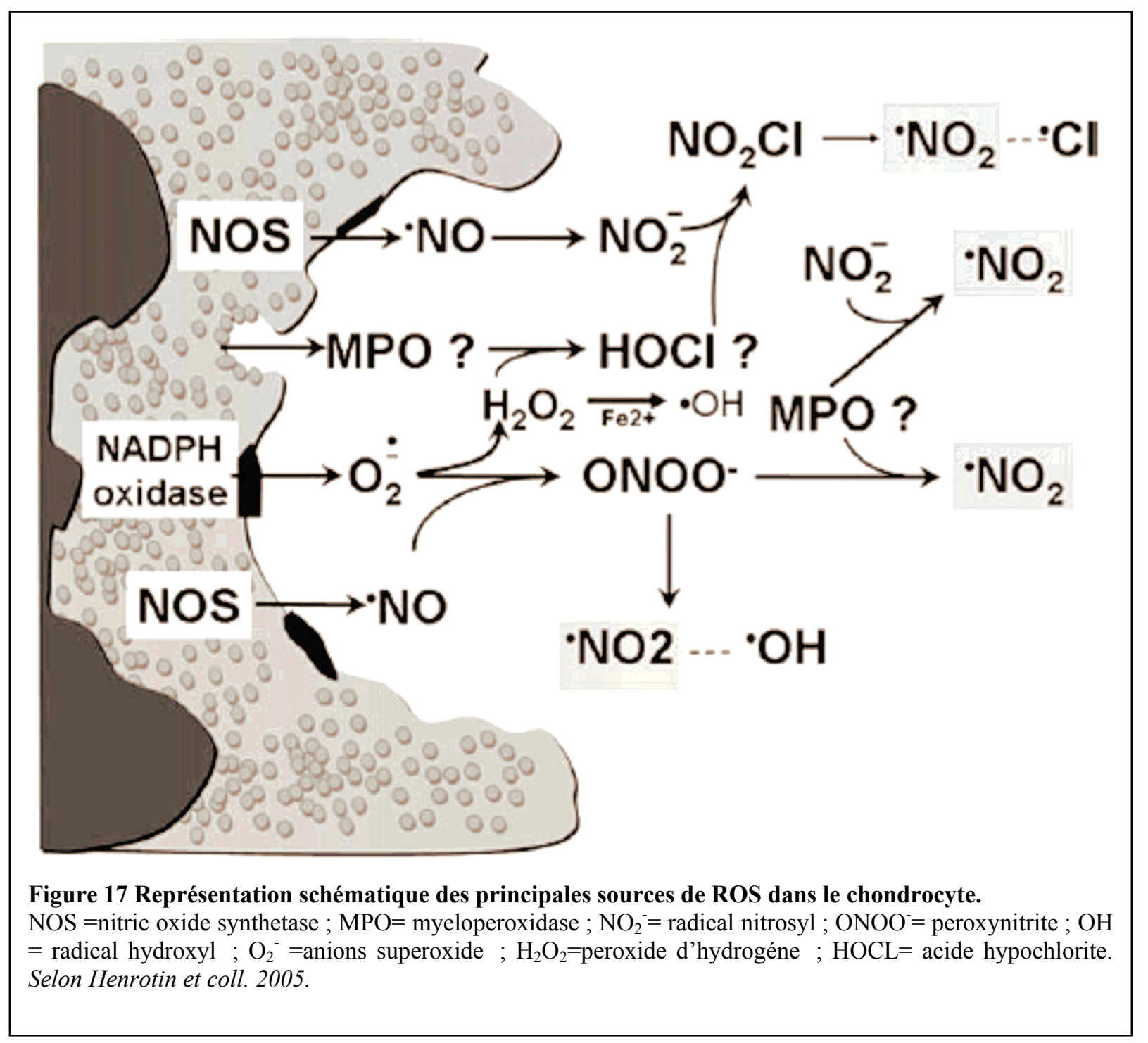

Les radicaux oxydants jouent un rôle dans la physiopathologie de 1'arthrose de différentes manières, soit directement en dégradant la matrice, soit indirectement en inhibant la synthèse, et enfin en régulant l'apoptose des cellules et des différents acteurs impliqués (cytokines, enzymes protéolytiques etc.).

\section{I-E-2 Les ROS et la mort cellulaire des chondrocytes :}

Dans l'arthrose, la mort cellulaire des chondrocytes est maintenant reconnue par tous (cf. chapitre ci-dessus). 
Les ROS induits par le stress mécanique provoquent l'apoptose des cellules via l'activation de la voie de la caspase-3 (Toussaint et coll. 2000, Dumont et coll.2000) et la voie des protéines kinases C $\beta 1$ PKC- $\beta 1$ (Del Carlo et coll. 2006). $\mathrm{L}^{\prime} \mathrm{O}_{2}{ }^{-}$et $\mathrm{ONOO}^{-}$sont les premiers acteurs qui jouent un rôle clé dans ce mécanisme d'apoptose : ils entrainent ainsi des lésions irréversibles du matériel nucléaire et mitochondrial entraînant sénescence et apoptose des chondrocytes (Martin et coll. 2004). Le NO est l'autre acteur clé : il peut être en effet responsable d'apoptose des chondrocytes dans certaines conditions et avoir une action anti apoptotique dans d'autres, en fonction notamment de la présence ou non d'autres dérivés radicalaires ( Del Carlo et coll. 2002).

\section{I-E-3 Les ROS et la protéolyse matricielle du cartilage :}

Les ROS agissent à différents niveaux sur le catabolisme du cartilage

- Protéolyse matricielle directe

Les ROS participent directement à la dégradation des collagènes (notamment le radical hydroxyle $\mathrm{OH}$ ), des aggrécanes de la matrice cartilagineuse (Tiku et coll.1999), et à la dépolymérisation de l'acide hyaluronique (notamment $\mathrm{HOCl}$ ) (Yamazaki et coll.2003). Les ROS augmentent l'expression d'un certains nombre de métalloprotéases matricielles comme la MMP-1, MMP-3, MMP-9, MMP-13 (Lo et coll. 1995). HOCl active directement les proenzymes non actives comme la MMP-8 (Burkhardt et coll. 1986). Il diminue l'expression du TIMP-1, ainsi que les inhibiteurs d'autres protéases comme l' $\alpha 2$-macroglobuline et l' $\alpha 1$ anti protéinase (Michaelis et coll. 1992, Shabani et coll. 1998)

- Inhibition de la synthèse matricielle

Les ROS limitent la respiration mitochondriale du chondrocyte entraînant une baisse de la sécrétion de PG et de collagène (Johnson et coll. 2000). Le NO joue aussi un rôle dans l'inhibition de la synthèse des aggrécanes sur des cultures de chondrocytes de lapins incubés avec de l'IL-1 $\beta$. Il joue aussi un rôle en bloquant directement les premiers stades de la synthèse des GAG et du collagène de type II. L'ONOO$^{-}$inhibe directement la synthèse des aggrécanes de la matrice. Les ROS peuvent aussi faire perdre la sensibilité des chondrocytes à certains facteurs de croissance pro-anaboliques. Ainsi, in vitro, l'OONO' et le $\mathrm{NO}^{-}$inhibent d'une manière réversible et avec un effet dose, la synthèse de PG engendrée par IGF-1 
(insuline-like growth factor) (Studer et coll. 2000, 2004). L'action du TGF- $\beta$ semble être modulée de la même manière par les ROS dans les chondrocytes (Ayache et coll. 2002).

Les ROS régulent également la production chondrocytaire d'IL-1 $\beta$, de prostaglandine E2 (PGE2) et de NO par un phénomène de rétrocontrôle (Mendes et coll. 2003, Mathy-Hartert et coll. 2002). Le NO inhibe la migration des chondrocytes en agissant sur l'actine de leur cytosquelette, et bloque ainsi l'èventuelle réparation du cartilage (Frenkel et coll. 1996). Les ROS pourraient aussi selon Li, avoir un rôle anti inflammatoire: $1^{\prime} \mathrm{H}_{2} \mathrm{O}_{2}$ par exemple, intervient dans la régulation positive de l'expression du TIMP-3 induit par le TGF- $\beta$ dans les chondrocytes bovins ( $\mathrm{Li}$ et coll.2004). Les ROS induisent aussi, une régulation négative sur un certain nombre de gènes pro inflammatoires comme les Cox-2 ou l'iNOS (Mathy-Hartert et coll. 2003,). In vitro, après stimulation des chondrocytes en culture par IL-1 $\beta$, le NO inhibe l'augmentation d'expression d'éléments pro inflammatoires comme l'IL-6, l'IL-8 et la prostaglandine E2 et limite ainsi la réaction inflammatoire (Henrotin et coll. 1998).

\section{I-E-4 Les ROS et la signalisation intra cellulaire dans le chondrocyte :}

Il semble clairement démontré qu'au décours de la stimulation de récepteurs type tyrosine kinase ou au décours d'une contrainte pro inflammatoire (IL- $1 \beta$ ou TNF- $\alpha$ ou, l'IFN- $\gamma-$ ), il y a une production de ROS. Ces radicaux oxydants agissent alors comme des messagers secondaires impliqués dans la régulation génique d'un certain nombre de protéines comme entre autres, les cytokines, les MMPs, les molécules d'adhésions et les protéines de la matrice (Van Lent et coll. 2005).

Ainsi ils activent les voies de signalisation MAPK incluant les cascades ERK Jun-NH2 et p38MAPK, aboutissant dans l'arthrose à la régulation négative de l'expression de protéines comme le collagène et les agrécanes et à l'augmentation de la sécrétion d'enzymes catalytiques comme les MMPs (figure 18).

Ils agissent aussi directement en modulant des facteurs de transcription de certains gènes à

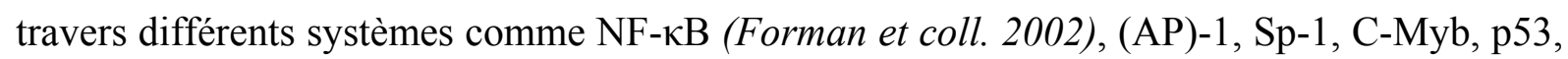
(egr)-1et HIF-1 $\alpha$.

Ainsi l'IL-1 $\beta$ engendre la production de ROS à l'origine d'une régulation de gène via l'activation de différentes voies de signalisation, c-fos, NF-kappaB, (AP)-1 (Mendes et coll. 2001) aboutissant à la sécrétion de la collagénase-1 (MMP-1) (Lo et coll. 1995, 1996, 1998), 
mais aussi de la MMP-13 (Mengshol et coll.2000, Barchowsky et coll. 2000, Reunanen et coll. 1998, Liacini et coll. 2002, Martin et coll.2003, 2004 , Vincenti et coll. 2001)

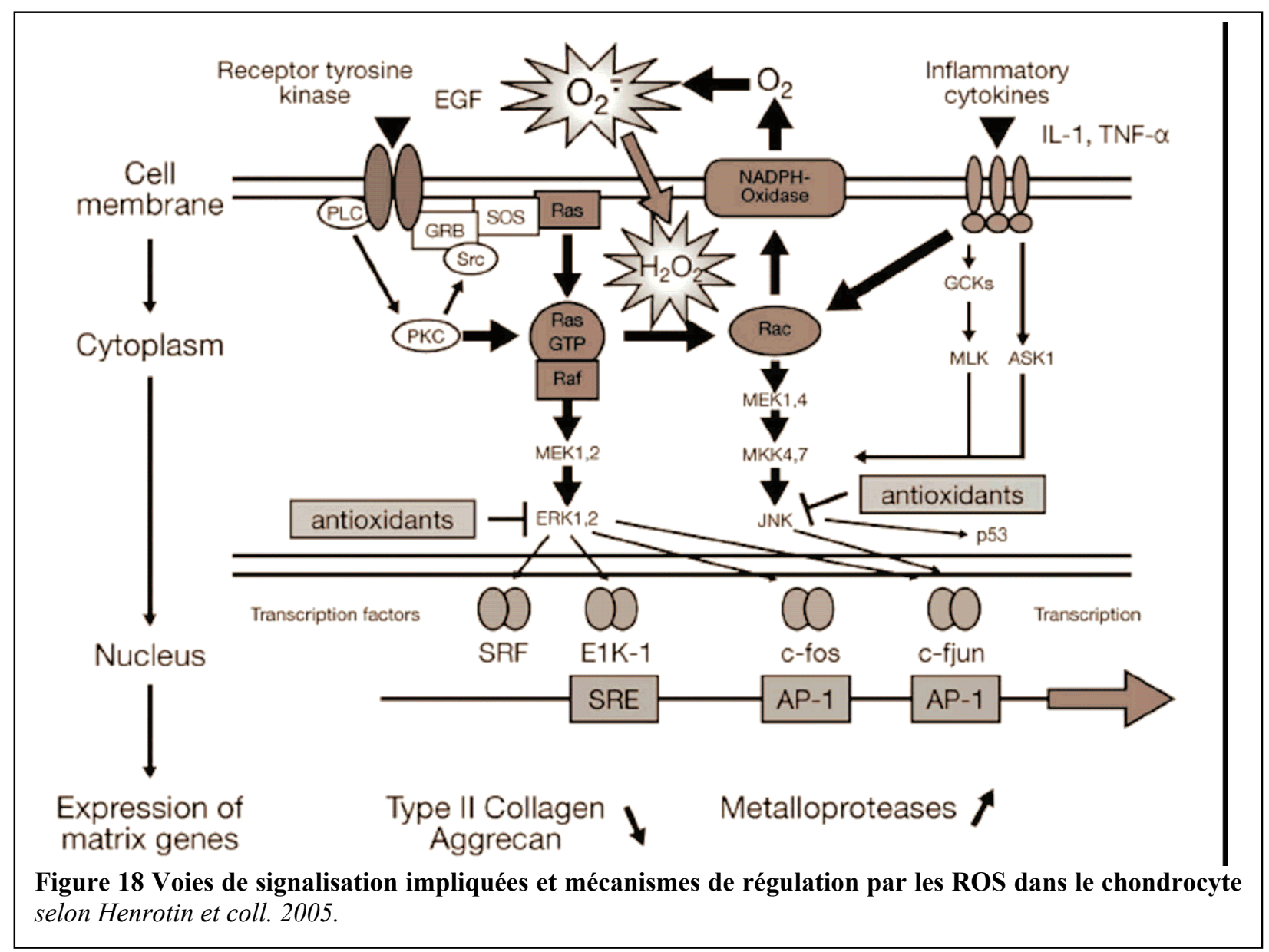

\section{I-E-5 Systèmes anti oxydants dans le cartilage :}

Pour prévenir la toxicité des dérivés radicalaires de l'oxygène, un système anti oxydant coexiste qui en condition d'homéostasie contrôle le stress oxydatif.

Les principaux acteurs de ce système anti oxydant décrit dans le chondrocyte sont la SOD, la catalase, la GPX (gluthation peroxydase) et le peroxiredoxine-5 PRDX5 (un membre d'une nouvelle famille de peroxydases) (Wang et coll. 2002). Ces acteurs anti oxydants sont eux aussi régulés par les différents éléments déjà cités comme les cytokines mais aussi les contraintes mécaniques. Ils permettent de contenir le stress oxydatif jusqu'aux limites de leurs capacités engendrant alors l'explosion oxydative et les conséquences que nous venons de décrire. 
L'arthrose est une pathologie très fréquente qui est caractérisée par la dégénérescence progressive du cartilage.

Le chondrocyte est la cellule clé du tissu cartilagineux. Il est impliqué dans l'homéostasie de la matrice extra cellulaire qui l'entoure.

La physiopathologie de l'arthrose implique une protéolyse matricielle où le stress oxydatif est un acteur clé devant le rôle prépondérant que semblent jouer les dérivés radicalaires de l'oxygène. Les NADPH oxydases, Nox, sont les principaux médiateurs de la production des espèces réactives de l'oxygène.

La protéolyse matricielle est principalement médiée par les métalloprotèases et notamment la MMP-1.

Il a été montré il y a quelques années que certains des facteurs de transcription pouvaient être induits par les dérivés radicalaires de l'oxygène (ROS), notamment NF- $\kappa \mathrm{B}$, aboutissant ainsi à la synthèse de MMP-1 (Kheradmand et coll. 1998).

Depuis, la régulation par les ROS de l'expression de la MMP-1 a été caractérisée dans certains types cellulaires comme les monocytes en présence de LPS (Lu et coll. 2005), les cellules musculaires lisses stimulées par de l'angiotensine II et plus récemment par les chondrocytes (Lo et coll. 1995, 1996, 1998). 
Nous nous proposons dans ce travail de montrer que le chondrocyte est capable dans des conditions particulières de sècréter des dérivés radicalaires de l'oxygène et que ceux-ci sont impliqués dans la régulation de l'expression d'enzymes protéolytiques particulièrement impliquées dans la dégradation cartilagineuse aboutissant à l'arthrose. Nous allons donc évaluer de manière exhaustive toutes les isoformes du complexe $\mathrm{NAD}(\mathrm{P}) \mathrm{H}$ oxydase présentes dans le chondrocyte, afin de mettre en évidence celle responsable de la production de ces ROS impliqués dans la régulation de l'expression d'un des acteurs le plus important dans l'arthrose la MMP-1.

Des lignées de chondrocytes disponibles dans le laboratoire (ayant démontré leur intérêt dans l'étude de la physiologie des chondrocytes dans le cartilage) et une expertise du groupe de travail (reconnue dans le domaine de la protéolyse matricielle et du stress oxydatif) ont contribué à la faisabilité de ce travail. 
MATERIEL ET METHODES 


\section{MATERIEL ET METHODES :}

\section{II-A Cultures cellulaires :}

\section{II-A-1 Les lignées de chondrocytes immortalisés par le virus SV40 :}

Les chondrocytes issus de lignées immortalisés par le virus SV40 (C-20/A4, C28/I2, T/C28a2), dons du Dr M.B. Goldring (Harvard Institutes of Medicine, Boston) (Goldring, et coll. 1994), sont cultivés en mono couche adhérente en DMEM (30 ml/ boîtes de $\left.75 \mathrm{~cm}^{2}\right)$, SVF $10 \%$, L glutamine $2 \mathrm{mM}$, pénicilline $(100 \mathrm{U} / \mathrm{ml})$ et streptomycine $(50 \mu \mathrm{g} / \mathrm{ml})$ à $37^{\circ} \mathrm{C}$ en atmosphère humide contenant $5 \%$ de $\mathrm{CO}_{2}$ avec des passages bi-hebdomadaires après trypsinisation. Cette étape est réalisée après deux lavages en EBSS sans SVF : $6 \mathrm{ml}$ de trypsine-EDTA $(0,25 \%)$ sont ajoutés par boîte de $75 \mathrm{~cm}^{2}$ puis les boîtes sont incubées à température ambiante pendant 5 minutes avec un contrôle à vue du décollement des cellules au microscope. La trypsine est alors inhibée par du milieu DMEM/10\% SVF, puis $50 \%$ des cellules sont prélevées pour l'ensemencement d'une nouvelle boîte de $75 \mathrm{~cm}^{2}$ ou pour une utilisation immédiate dans une expérimentation. Les lignées C20/A4 et T/C28a2 sont confluentes tous les 5-6 jours et la lignée C28/I2 est confluente tous les 6-7 jours.

Ces lignées de chondrocytes gardent un phénotype chondrocytaire en culture et elles sont validées pour l'étude et la recherche sur la physiopathologie de la dégénérescence cartilagineuse, notamment dans l'arthrose (Goldring et coll. 2004) (Figure 19).

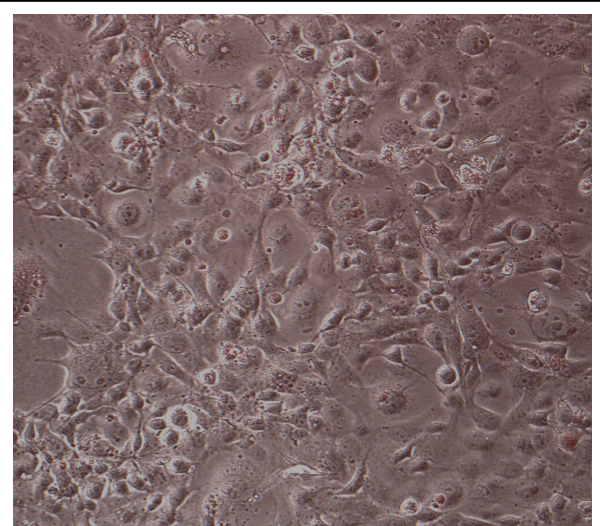

Figure 19 Chondrocyte C-20/A4 en culture (photographie microscopie optique $x$ 250) 


\section{II-A-2- Obtention des lymphocytes B immortalisés par le virus Epstein-Barr (cellules contrôles) :}

\section{II-A-2-a Obtention des cellules :}

Les lymphocytes $\mathrm{B}$ sont préparés à partir du sang périphérique prélevé sur tube hépariné. Le sang est centrifugé à $700 \mathrm{~g}, 10 \mathrm{~min}$ à $20^{\circ} \mathrm{C}$ pour éliminer le plasma. Le culot cellulaire est resuspendu dans 2 volumes de milieu de culture (RPMI 1640, L-Glutamine $2 \mathrm{mM}$, Penicilline $100 \mathrm{U} / \mathrm{ml}$, Streptomycine $50 \mu \mathrm{g} / \mathrm{ml}$ ). Le sang dilué est déposé délicatement sur 1 volume de Ficoll-hypaque $(\mathrm{d}=1,077)$ puis centrifugé à $500 \mathrm{~g}, 20 \mathrm{~min}$ à $20^{\circ} \mathrm{C}$. L'anneau lymphomonocytaire est récupéré, lavé deux fois dans du RPMI 1640, puis numéré. Après centrifugation à $350 \mathrm{~g}, 8 \mathrm{~min}$ à $20^{\circ} \mathrm{C}$, le culot cellulaire est resuspendu dans le milieu de culture complémenté par $20 \%$ de SVF et ajusté à $10^{6}$ cellules $/ \mathrm{ml}$.

\section{II-A-2-b Immortalisation des cellules et entretien :}

(Pour revue Seigneurin et coll. 1988)

L'anneau lympho-monocytaire est déposé dans un flacon de culture de $25 \mathrm{~cm}^{2}$ (Falcon ${ }^{\circledR}$ ) sur une monocouche adhérente de fibroblastes MRC5 (cellules nourricières) préalablement irradiés (blocage de la prolifération). $1 \mathrm{ml}$ d'une suspension du virus d'Epstein-Barr (souche B-95; $10^{8}$ copies d'ADN/ml soit $10^{4}$ unités tranformantes $/ \mathrm{ml}$ ) est ajouté en présence de $1 \mu \mathrm{g}$ de Ciclosporine A (inhibiteur des cellules $\mathrm{T}$ qui facilite l'établissement des lignées lymphoblastoïdes). Les lymphocytes $\mathrm{B}$ sont ensuite incubés à $37^{\circ} \mathrm{C}$ en atmosphère humide contenant $5 \%$ de $\mathrm{CO}_{2}$. Le milieu de culture complémenté par $20 \%$ de SVF est changé deux fois par semaine. Dès la formation d'amas lymphocytaires (7 à 20 jours), les cultures cellulaires sont divisées et changées de milieu afin de conserver une concentration de 0,5 à 1,5.10 ${ }^{6}$ lymphocytes par ml. Par la suite des changements bihebdomadaires de milieu de culture (RPMI 1640 supplémenté en L-Glutamine $2 \mathrm{mM}$ et pénicilline $(100 \mathrm{U} / \mathrm{ml})$ et de la streptomycine $(50 \mu \mathrm{g} / \mathrm{ml})$ et ne contenant plus que $10 \%$ de SVF sont effectués. Avant toute expérimentation, Les LB-EBV sont récupérés par centrifugation à $350 \mathrm{~g}, 5 \min$ à $4^{\circ} \mathrm{C}$, lavés 2 fois dans du $\mathrm{PBS}^{(-)}$, puis le culot est ajusté dans ce même tampon à $10^{8} \mathrm{LB}-\mathrm{EBV} / \mathrm{ml}$ (CohenTanugi et coll., 1991). 


\section{II-A-3 Obtention des polynucléaires neutrophiles à partir de sang vieilli ou "buffy coat" :}

Les polynucléaires neutrophiles sont préparés à partir de poches de sang provenant de l'Etablissement Français du Sang (EFS) de Grenoble. Le sang est prélevé sur citrate de sodium, conservé une nuit à $4^{\circ} \mathrm{C}$. Le lendemain les cellules sont purifiées selon la méthode décrite par Morel et coll. (1992). Trois volumes de "buffy coat" sont mélangés à un volume d'anticoagulant (Glucose $44 \mathrm{mM}$, Acide citrique $120 \mathrm{mM}, \mathrm{NaCl} 0,9 \%, \mathrm{pH} 6,5$ ) et centrifugés à $800 \mathrm{~g}, 5 \mathrm{~min}$ à $20^{\circ} \mathrm{C}$. Après élimination du surnageant (plasma, plaquettes), $8 \mathrm{ml}$ de la couche supérieure du culot enrichie en globules blancs sont prélevés et resuspendus dans $22 \mathrm{ml}$ de PBS (NaCl 137 mM, KCl 2,7 mM, KH $\mathrm{PO}_{4} 1,5$ mM, Na $\mathrm{HPO}_{4} 8 \mathrm{mM}, \mathrm{pH}$ 7,3) contenant 300 UI d'héparine. Le mélange est déposé délicatement sur un gradient de Ficoll-Hypaque $(\mathrm{d}=1,077)$ contenant du citrate de sodium $0,15 \%(\mathrm{p} / \mathrm{v})$, puis centrifugé à $500 \mathrm{~g}, 30 \min$ à $20^{\circ} \mathrm{C}$. Le culot, contenant les globules rouges et les polynucléaires neutrophiles (PMNs), est remis en suspension dans une solution saline $\left(\mathrm{NaCl} 2,74 \mathrm{mM}, \mathrm{CaCl}_{2} 18,16 \mathrm{mM}, \mathrm{H}_{2} \mathrm{O}\right.$ qsp 1 litre) pour éliminer les globules rouges, puis centrifugé à $300 \mathrm{~g}, 8 \mathrm{~min}$ à $4^{\circ} \mathrm{C}$. Les quelques globules rouges résiduels sont éliminés lors d'une incubation de $20 \mathrm{~min}$ à $4^{\circ} \mathrm{C}$ dans le tampon de lyse hypotonique $\left(\mathrm{NH}_{4} \mathrm{Cl} 155 \mathrm{mM}, \mathrm{KHCO}_{3} 10 \mathrm{mM}\right.$, EGTA 0,1 mM, pH 7,4) suivi d'une centrifugation de $300 \mathrm{~g}, 8 \mathrm{~min}$ à $4^{\circ} \mathrm{C}$. Les PMNs sont lavés 2 fois dans la même solution saline puis resuspendus en PBS à raison de $10^{8}$ cellules $/ \mathrm{ml}$.

\section{II-A-4 Congélation et décongélation des différentes lignées cellulaires :}

Les différentes lignées cellulaires immortalisées sont numérées puis ajustées à $10^{7}$ cellules $/ \mathrm{ml}$ en SVF contenant $10 \%(\mathrm{v} / \mathrm{v})$ de DMSO, et enfin congelées de manière progressive $(2 \mathrm{~h}$ à $+4^{\circ} \mathrm{C}, 12 \mathrm{~h}$ à $-20^{\circ} \mathrm{C}, 24 \mathrm{~h}$ à $-80^{\circ} \mathrm{C}$ ). Elles sont conservées dans l'azote liquide par fraction de 1 $\mathrm{ml}$. La décongélation se fait par passage direct du cryotube de l'azote liquide en bain-marie à $37^{\circ} \mathrm{C}$. Les cellules sont immédiatement lavées 2 fois dans le milieu de culture adéquat, reprises dans $6 \mathrm{ml} \mathrm{du}$ milieu précédent contenant 20\% de SVF et mises en culture en monocouche dans des boîtes de $25 \mathrm{~cm}^{2}$. Le milieu est changé le lendemain puis les cellules 
sont cultivées selon les conditions classiques après un passage en boîte de $50 \mathrm{~cm}^{3}$. Le milieu alors est changé 2 fois par semaine.

\section{II-B Méthodes biochimiques :}

\section{II-B-1 Préparation de membranes et de cytosol :}

Les polynucléaires neutrophiles, les chondrocytes ou les LB-EBV ajustés à $10^{8}$ cellules $/ \mathrm{ml}$ dans la solution de $\mathrm{PBS}^{(-)}$sont traités par le DFP (diisopropyl fluorophosphate) à une concentration finale de $3 \mathrm{mM}$, pendant $10 \mathrm{~min}$ à $4^{\circ} \mathrm{C}$. Les cellules sont ensuite centrifugées à $500 \mathrm{~g}, 10 \mathrm{~min}$ à $4^{\circ} \mathrm{C}$, puis sont remises en suspension à $2.10^{9}$ cellules $/ \mathrm{ml}$ dans du $\mathrm{PBS}^{(-)}$ contenant un mélange d'inhibiteurs de protéases (TLCK $10 \mu \mathrm{M}$, PMSF $1 \mathrm{mM}$, leupeptine 1,8 $\mu \mathrm{M}$ et pepstatine 1,5 $\mu \mathrm{M}$ ) et de l'EGTA 1,25 mM. La suspension cellulaire est passée aux ultrasons 3 fois pendant 10 secondes à 40 watts avec des intervalles de refroidissement de 1 min dans la glace. L'homogénat cellulaire est centrifugé à $1000 \mathrm{~g}$ pendant $15 \mathrm{~min}$ à $4^{\circ} \mathrm{C}$. Le surnageant est prélevé et soumis à une ultracentrifugation à $200000 \mathrm{~g}$ pendant 1 heure à $4^{\circ} \mathrm{C}$. Le surnageant de l'ultracentrifugation correspondant au cytosol est filtré sur une membrane de $0,22 \mu \mathrm{m}$. La quantité de protéines est dosée selon la méthode de Bradford. Le cytosol est ensuite aliquoté et conservé à $-80^{\circ} \mathrm{C}$.

Le culot membranaire est lavé, remis en suspension dans du $\mathrm{PBS}^{(-)}$et soumis aux ultrasons brièvement ( 2 fois 5 secondes à 40 watts). La concentration protéique est déterminée par la méthode de Bradford, puis ajustée à $3 \mathrm{mg} / \mathrm{ml}$. La suspension membranaire est conservée à (-) $80^{\circ} \mathrm{C}$ par fractions aliquotées.

\section{II-B-2 Mesure de l'activité de la NADPH oxydase :}

L'activité NADPH oxydase peut être mesurée sur cellules entières après stimulation (PMA, fMLP ou zymosan opsonisé) ou après reconstitution en système acellulaire homologue ou hétérologue. L'activité est exprimée en nmoles $\mathrm{O}_{2}{ }^{-}$par minute et en se référant soit à un nombre de cellules données soit à une quantité donnée de protéines membranaires. 


\section{II-B-2-a Mesure de la production de $\mathrm{H}_{2} \mathrm{O}_{2}$ par luminescence :}

C'est une technique qui mesure la production totale d' $\mathrm{H}_{2} \mathrm{O}_{2}$, dans laquelle la lumière émise est le résultat d'une réaction de chimioluminescence ; une molécule dans un état stable recevant une énergie chimique exergonique (action d'agents chimiques ou d'enzymes sur des molécules organiques) passe à l'état excité, le retour à l'état fondamental se traduit par une émission de lumière dont l'intensité peut être mesurée. Ces molécules de type hydrazide (luminol, isoluminol) sont révélées lors d'une réaction où intervient un peroxyde $\left(\mathrm{H}_{2} \mathrm{O}_{2}\right.$, perborate) et une enzyme (peroxydase, catalase). Il y a formation d'un dérivé aminophtalate excité qui en repassant à une forme stable émet un rayonnement lumineux à $430 \mathrm{~nm}$.

\section{Luminol $+\mathrm{H}_{2} \mathrm{O}_{2}=$ acide aminophtalique $+\mathrm{N}_{2}+$ Lumière}

$5 \times 10^{5}$ cellules (chondrocytes ou LB-EBV) dans $50 \mu 1$ de PBS $^{(-)}$sont incubées avec $200 \mu 1$ de milieu commun contenant $25 \mu \mathrm{l}$ de Glucose $0,8 \mathrm{M}, 10 \mu \mathrm{l}$ de Luminol $2 \mathrm{mM}, 20 \mu 1$ d'HRPO $500 \mathrm{U} / \mathrm{ml}$ et $945 \mu 1$ de $\operatorname{PBS}^{(-)}$pendant 1 minute à $37^{\circ} \mathrm{C}$ dans le luminomètre (Luminoscan ${ }^{\circledR}$ Labsystem). La réaction est initiée par l'addition de $10 \mu \mathrm{l}$ de PMA à $(2 \mu \mathrm{g} / \mathrm{ml})$ ou de $10 \mu \mathrm{l}$ de ionomycine $(2.5 \mu \mathrm{M})$. L'émission de photons est suivie pendant 1 heure avec 1 mesure toutes les 30 secondes (500 itérations par mesure).

\section{II-B-2-b Système de reconstitution acellulaire hétérologue : mesure de la production de $\mathrm{O}_{2}^{-}$par la réduction du cytochrome $c$ :}

L'activité NADPH oxydase peut être reconstituée en milieu acellulaire (Heynemann et coll. 1984, Bromberg et coll. 1984) en incubant une fraction membranaire contenant le cytochrome $b_{558}$ avec le cytosol contenant les facteurs cytosoliques de l'oxydase.

L'activation de la $\mathrm{NAD}(\mathrm{P}) \mathrm{H}$ oxydase en système acellulaire nécessite l'incubation de membranes plasmiques de chondrocytes (contenant le cytochrome $b_{558}$ ) avec du cytosol de PMNs (contenant les facteurs d'activation de la NAD(P)H oxydase), du GTP, du magnésium, et un agent amphiphile un acide gras à longue chaîne polyinsaturée (acide arachidonique) ou le dodécyl sulfate de sodium (SDS) dont la quantité ajoutée dépend des quantités de protéines présentes dans la fraction membranaire et dans la fraction cytosolique (Pilloud-Dagher et coll., 1989 ; Cohen-Tanugi et coll., 1991). 
Système composé de membranes et de cytosol :

a) Préparation du milieu de pré-incubation.

Le milieu de pré-incubation est préparé pour 10 essais en mélangeant les constituants suivants :

\begin{tabular}{ll}
\hline Constituants & Quantité \\
\hline membranes plasmiques & $300 \mu \mathrm{g}$ \\
Cytosol PMN & $3 \mathrm{mg}$ \\
MgCl2 50 mM & $100 \mu \mathrm{l}$ \\
GTP $\gamma-\mathbf{S} 2 \mathbf{~ m M}$ & $20 \mu \mathrm{l}$ \\
PBS $^{-}$qsp 1 ml & $1000 \mu \mathrm{l}$ \\
\hline
\end{tabular}

Des aliquots de $100 \mu 1$ sont conservés dans la glace jusqu'à utilisation.

b) Détermination de l'optimum d'acide arachidonique.

La réduction du NBT est habituellement utilisée pour déterminer la quantité optimale d'acide arachidonique nécessaire pour obtenir une activation maximale de l'oxydase [avec un coefficient d'extinction molaire du $\left.\operatorname{NBT}(\varepsilon N B T)=15 \mathrm{mM}^{-1} \mathrm{~cm}^{-1}\right]$. Des concentrations croissantes d'acide arachidonique (0 à 100 nmoles) sont ajoutées à $100 \mu 1$ du milieu de préincubation et, après agitation vigoureuse le mélange est incubé $10 \mathrm{~min}$ à température ambiante. L'ensemble est transféré dans une cuve de spectrophotomètre contenant les constituants suivants :

\begin{tabular}{ccc}
\hline Composants & Quantité / cuve & $\begin{array}{c}\text { Concentration } \\
\text { finale }\end{array}$ \\
\hline NBT 100 $\boldsymbol{\mu M}$ & $10 \mu \mathrm{l}$ & $1 \mu \mathrm{M}$ \\
NADPH $10 \mathrm{mM}$ & $15 \mu \mathrm{l}$ & $0,5 \mathrm{mM}$ \\
PBS $^{-}$qsp $1 \mathrm{ml}$ & $900 \mu \mathrm{l}$ & \\
\hline
\end{tabular}

Le mélange réactionnel est incubé 2 min à température ambiante. La réaction est arrêtée par $50 \mu 1$ de SDS $10 \%$ p/v. La lecture de l'absorbance à $550 \mathrm{~nm}$ permet de suivre la réduction du NBT par les $\mathrm{O}_{2}^{-}$produits (Figure 20). 


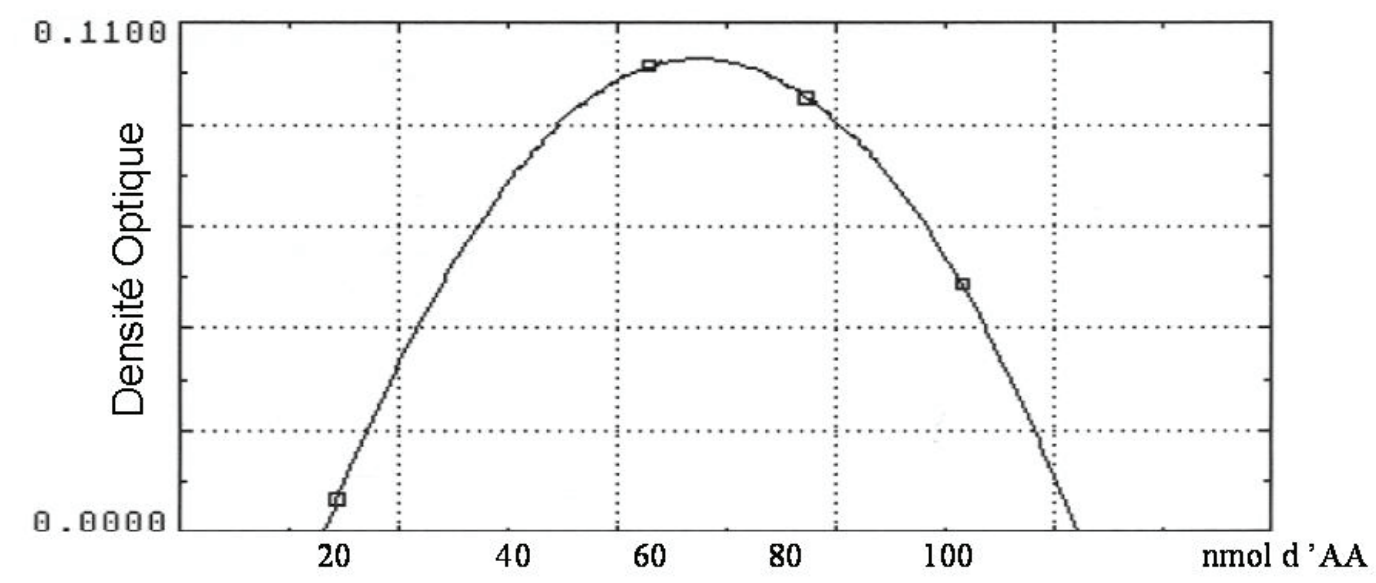

Figure 20 Détermination de la concentration optimale d'Acide Arachidonique (AA) à utiliser pour la mesure de l'activité $\mathbf{N A D}) \boldsymbol{P}) \boldsymbol{H}$ oxydase in vitro, par réduction du NBT en présence d'acide arachidonique, pour le système membranes de chondrocytes et cytosol de PMNs.

c) Mesure de la production d' $\mathrm{O}_{2}^{-}$par la réduction du cytochrome c.

Les ions superoxyde produits sont détectés par leur capacité à réduire le cytochrome $c$ se traduisant par une augmentation de l'absorption à une longueur d'onde $\lambda=550 \mathrm{~nm}$ (Coefficient d'extinction molaire du cytochrome $c \varepsilon_{550}=21,1 \mathrm{mM}^{-1} \cdot \mathrm{cm}^{-1}$ ). Des fractions de $100 \mu \mathrm{l}$ du milieu de pré-incubation activé par la quantité optimale d'acide arachidonique préalablement déterminée, sont placées dans une cuve de spectrophotomètre contenant le tampon PBS $^{-}\left(\mathrm{QSP}^{1 \mathrm{ml})}\right.$ supplémenté par du cytochrome $c(100 \mu \mathrm{M})$. La réaction est initiée par l'addition de $15 \mu \mathrm{l}$ de NADPH $(10 \mathrm{mM})$. La production d'ions $\mathrm{O}_{2}^{-}$est suivie par la réduction du cytochrome $c$ à $550 \mathrm{~nm}$, pendant quelques minutes. La réduction du cytochrome $c$ est ensuite stoppée par l'addition de $50 \mu \mathrm{l}$ de superoxyde dismutase (SOD) à $1 \mathrm{mg} / \mathrm{ml}$ (3000 $\mathrm{U} / \mathrm{ml})$.

L'activité oxydase est donc déterminée indirectement par la mesure de la réduction du cytochrome $c$ et la cinétique d'activation de l'enzyme est suivie par spectrophotométrie. Seule 
la réduction du cytochrome $c$ sensible à la superoxyde dismutase (enzyme dismutant les ions superoxyde $\mathrm{O}_{2}{ }^{-}$en $\mathrm{H}_{2} \mathrm{O}_{2}$ ) ajoutée dans la cuve pour arrêter la réaction, sera prise en compte.

Pour objectiver la part de la cytochrome oxydase mitochondriale nous inhibons dans certaines expériences la respiration mitochondriale en rajoutant $0,5 \mathrm{mM}$ finale de cyanure de potassium dans la cuve spectrophotométrique.

L'activité oxydase est exprimée en : $\mathrm{nmol}_{2}^{-}$produits / $\mathrm{min} / \mathrm{mg}$ de protéines membranaires. Remarque :

1) Réduction du cytochrome $\mathrm{c}: \mathrm{O}_{2}{ }^{-}+$cyt.c $\mathrm{c}^{3+} \rightarrow$ cyt.c $\mathrm{c}^{2+}+\mathrm{O}_{2}$

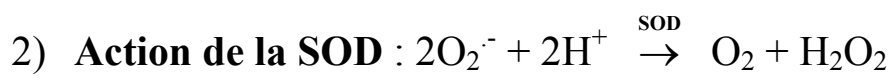

\section{II-B-3 Méthode d'analyse des différentes protéines :}

\section{II-B-3-a Analyse protéique par Western blot :}

\section{Préparation des échantillons :}

Les protéines sont dénaturées en présence de SDS, et la structure tertiaire est dissociée en chaînes polypeptidiques par le $\beta$-mercaptoéthanol : le $\beta$-mercaptoéthanol réduit les ponts disulfure intra et interchaînes. L'échantillon protéique (1 à $1000 \mu \mathrm{g}$ de protéines) est dilué au $1 / 10^{\text {ème }}$ dans le "Sample Buffer" $10 \mathrm{X}$, puis incubé à $60^{\circ} \mathrm{C}$ pendant 60 minutes en présence de $\beta$-mercaptoéthanol 2,5\%(v/v).

\section{Electrophorèse en gel d'acrylamide en présence de SDS :}

(Laemmli et Favre, 1973)

Les protéines chargées négativement par le SDS, sont séparées en fonction de leur taille moléculaire à travers un gel de séparation constitué d'un réseau d'acrylamide, sous l'action d'un champ électrique. 
Tableau 3 : Préparation des gels de SDS-PAGE.

\begin{tabular}{|l|lll|}
\cline { 2 - 4 } \multicolumn{1}{c|}{} & $8 \%$ & $10 \%$ & $11 \%$ \\
\hline Tris-HCl 1,5 M, pH 8,9 & $9,0 \mathrm{ml}$ & $9,0 \mathrm{ml}$ & $9,0 \mathrm{ml}$ \\
\hline H2O distillée & $19,2 \mathrm{ml}$ & $17,4 \mathrm{ml}$ & $16,5 \mathrm{ml}$ \\
\hline Acrylamide $40 \%$ / Bis acrylamide & $7,2 \mathrm{ml}$ & $9,0 \mathrm{ml}$ & $9,9 \mathrm{ml}$ \\
\hline SDS $10 \%$ & $360 \mu \mathrm{l}$ & $360 \mu \mathrm{l}$ & $360 \mu \mathrm{l}$ \\
\hline Persulfate d'ammonium $10 \%$ & $225 \mu \mathrm{l}$ & $225 \mu \mathrm{l}$ & $225 \mu \mathrm{l}$ \\
\hline TEMED & $37,5 \mu \mathrm{l}$ & $37,5 \mu \mathrm{l}$ & $37,5 \mu \mathrm{l}$ \\
\hline
\end{tabular}

Un gel de concentration est coulé en surface du gel de séparation (4,52 $\mathrm{ml}$ d'acrylamide $11 \%$ /Bis acrylamide (v/v) ; $5 \mathrm{ml}$ de Tris- $\mathrm{HCl} 0,25 \mathrm{M}$, pH 6,8, SDS 0,2 \% 0,5 ml de persulfate d'ammonium $15 \mathrm{mg} / \mathrm{ml}$; $20 \mu \mathrm{l}$ TEMED). Le gel est placé dans une cuve d'électrophorèse contenant le tampon de migration (Tris $25 \mathrm{mM}$, glycine $192 \mathrm{mM}$, SDS 0,1\% (p/v), pH 8,8). Les échantillons sont déposés dans les puits du gel de concentration. L'intensité électrique est maintenue constante $(30 \mathrm{~mA})$ lors de la migration des protéines qui vont migrer de la cathode vers l'anode.

\section{Electrotransfert des protéines sur nitrocellulose :}

Les protéines séparées en gel d'acrylamide sont transférées sur une membrane de nitrocellulose par un système semi-sec. Le gel d'électrophorèse est incubé quelques minutes dans le tampon de transfert semi-sec (Tris $25 \mathrm{mM}$, glycine $129 \mathrm{mM}$, SDS 0,01\% (p/v), méthanol 10\% (v/v), pH 8,3). La feuille de nitrocellulose (porosité : 0,2 $\mu \mathrm{m}$ ) est rincée dans le même tampon. Le sandwich est réalisé entre 2 électrodes de graphite (LKB, electrophoretic transfert kit) de la façon suivante : anode, 3 feuilles de papier whatman $n^{\circ} 3$ imbibées du tampon de transfert semi-sec, la feuille de nitrocellulose, le gel, 3 feuilles de papier whatman $\mathrm{n}^{\circ} 3$, et la cathode. Les protéines chargées négativement en présence de SDS migrent vers l'anode sous l'action d'un champ électrique imposé $\left(1 \mathrm{~mA} / \mathrm{cm}^{2}\right.$ de gel à transférer; Towbin et coll. 1979). L'électrotransfert est réalisé pendant 2 heures 30 min pour les gels de 1,5 mm d'épaisseur et 1 heure $15 \mathrm{~min}$ pour les gels de $0,75 \mathrm{~mm}$ d'épaisseur. 


\section{Immunodétection par anticorps couplés à la peroxydase :}

Les sites libres de la membrane de nitrocellulose, sont saturés pendant une heure à température ambiante, dans du tampon TBS (Tris-HCl $50 \mathrm{mM}, \mathrm{NaCl} 150 \mathrm{mM}, \mathrm{pH} 7,5$ ) contenant du Tween $20(0,05 \%, \mathrm{p} / \mathrm{v})$ et 1\% de lait déshydratée "Régilait". La membrane est ensuite lavée pendant 1 heure dans ce même tampon sans lait déshydratée "Régilait". Elle est ensuite incubée pendant 1 heure à température ambiante avec un anticorps de souris ou de lapin spécifique de la protéine à identifier dilué dans le tampon TBS additionné de Tween 20 $(0,05 \%, \mathrm{p} / \mathrm{v})$. La membrane de nitrocellulose est lavée dans le tampon TBS-Tween 20 0,05\%, 3 fois, avant d'être incubée en présence d'un anticorps couplé à la peroxydase, anti-IgG de souris ou de lapin, suivi d'une révélation par chimioluminescence ; le réactif de détection ECL, le luminol (ECL $®$, Amersham) est oxydé par la peroxydase. La membrane est incubée pendant une minute avec le réactif ECL, avant d'être emballée dans un film plastique de type "Saran". La réaction de chimioluminescence est assurée par l'oxydation du luminol par la peroxydase, en présence d'un peroxyde et d'un catalyseur chimique comme le phénol. La membrane de nitrocellulose est ensuite placée dans une cassette, la face protéique contre le film de détection. Le temps d'exposition varie de 10 secondes à 5 minutes suivant le taux de luminescence. Le film est ensuite développé de façon classique à l'aide d'un révélateur. Elle permet de révéler des quantités très faibles d'antigène sur la membrane de nitrocellulose, inférieures à 1 pg de protéine( quantité révélée variable en fonction aussi du type d'anticorps primaires)

\section{II-B-3-b Méthode de dosage des protéines :}

(Bradford, 1976)

Le réactif de Bradford (Bio-Rad protein Assay ${ }^{\circledR}$ ) permet un dosage rapide (incubation de 5 min) des protéines même en présence de glycérol, de Triton X-100 0,1\%, de SDS 0,1\%, ou d'une forte concentration saline. Un changement du maximum d'absorption de la lumière de $435 \mathrm{~nm}$ à $595 \mathrm{~nm}$ est observé après la fixation du réactif (solution acide de bleu de Coomassie G-250) à la protéine. L'absorbance à $595 \mathrm{~nm}$ est proportionnelle à la concentration protéique. L'échantillon à doser $(100 \mu \mathrm{l})$ est incubé avec le réactif de Bradford $(2 \mathrm{ml})$ pendant $5 \mathrm{~min}$ à température ambiante. L'absorbance à $595 \mathrm{~nm}$ est lue contre un blanc. Une gamme 
d'étalonnage est réalisée avec de l'albumine de sérum bovin (BSA) dans le tampon de l'échantillon.

\section{II-B-3-c Spectres différentiels redox du cytochrome $b_{558}$ des 3 lignées de chondrocytes et de PMNs humains :}

Le spectre d'absorption d'un cytochrome permet de l'identifier et de le quantifier (le composé qui absorbe la lumière dans les cytochromes est l'hème).

Les spectres d'absorption du cytochrome $b_{558}$ ont été réalisés à l'aide d'un spectrophotomètre monofaisceau (Beckman DU 640) équipé d'un portoir de microcuves de $50 \mu$ (trajet optique de $1 \mathrm{~cm}$ ). Le spectre d'absorption de la fraction oxydée est lu de 400 à $650 \mathrm{~nm}$, puis il est mémorisé. Cette fraction est ensuite réduite par l'addition de quelques grains de dithionite de sodium. Le spectre de la fraction réduite est lu de 400 à $650 \mathrm{~nm}$, et automatiquement, le spectre différentiel rédox, correspondant à la différence entre le spectre de la fraction réduite et celui de la fraction oxydée, est calculé. Le spectre différentiel rédox est propre à un cytochrome donné. Il montre trois bandes d'absorption caractéristiques : $\alpha, \beta, \gamma$. Le spectre différentiel du cytochrome $b_{558}$ (Figure 21) présente trois pics d'absorption à des longueurs d'onde correspondant à $558 \mathrm{~nm}(\alpha), 530 \mathrm{~nm}(\beta)$ et $426 \mathrm{~nm}(\gamma)$ avec des coefficients d'extinction molaire :

$$
\varepsilon_{558}=21,6 \mathrm{mM}^{-1} \cdot \mathrm{cm}^{-1}, \varepsilon_{426}=106 \mathrm{mM}^{-1} \cdot \mathrm{cm}^{-1} .
$$

Le spectre absolu du cytochrome $b_{558}$ oxydé présente une absorption caractéristique à $414 \mathrm{~nm}$ avec un coefficient d'extinction molaire $\varepsilon_{414}=58,3 \mathrm{mM}^{-1} \cdot \mathrm{cm}^{-1}$.

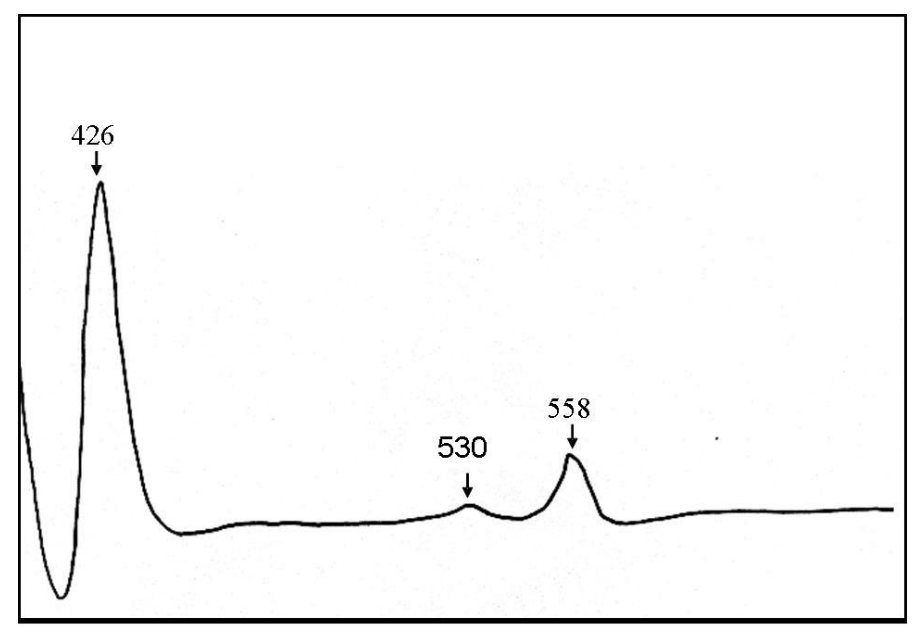

Figure 21 Spectre rédox du cytochrome $b_{558}$ purifié à partir de PMN 
La loi de Beer-Lambert établit un lien entre l'absorbance d'un composé à une longueur d'onde définie et sa concentration dans la cuve :

$$
\mathbf{A}=\text { ع.l.c }
$$

Avec A : absorbance à la longueur d'onde $\lambda$

$1:$ trajet optique en $\mathrm{cm}$ (égal à $1 \mathrm{~cm}$ dans notre cas)

$\mathrm{c}:$ concentration du composé absorbant à la longueur d'onde $\lambda(\mathrm{mM})$

$\varepsilon$ : coefficient d'extinction molaire $\left(\mathrm{mM}^{-1} \cdot \mathrm{cm}^{-1}\right)$ à la longueur d'onde $\lambda$.

Cette relation permet de calculer la concentration en hème dans la cuve spectrophotométrique.

\section{II-C Méthode d'analyse des MMPs :}

\section{II-C-1 Méthode ELISA de dosage de la pro MMP-1 :}

Le dosage de la concentration de la collagénase 1 sous sa forme latente (proMMP-1) est effectué par une technique ELISA (Laboratoire R\&D Systems). Les résultats sont exprimés en $\mathrm{ng} / \mathrm{g}$ de protéines du surnageant à T23h (déterminé par un dosage selon la technique de Bradford). Le dosage ELISA est réalisé en fonction des recommandations du laboratoire fabricant du kit ELISA en ayant réalisé une gamme d'étalonnage au préalable à partir de $100 \mu 1$ d'une solution de proMMP-1 fournie par le laboratoire (figure 22). La sensibilité de ces tests varie de 6 à $95 \mathrm{pg} / \mathrm{ml}$.

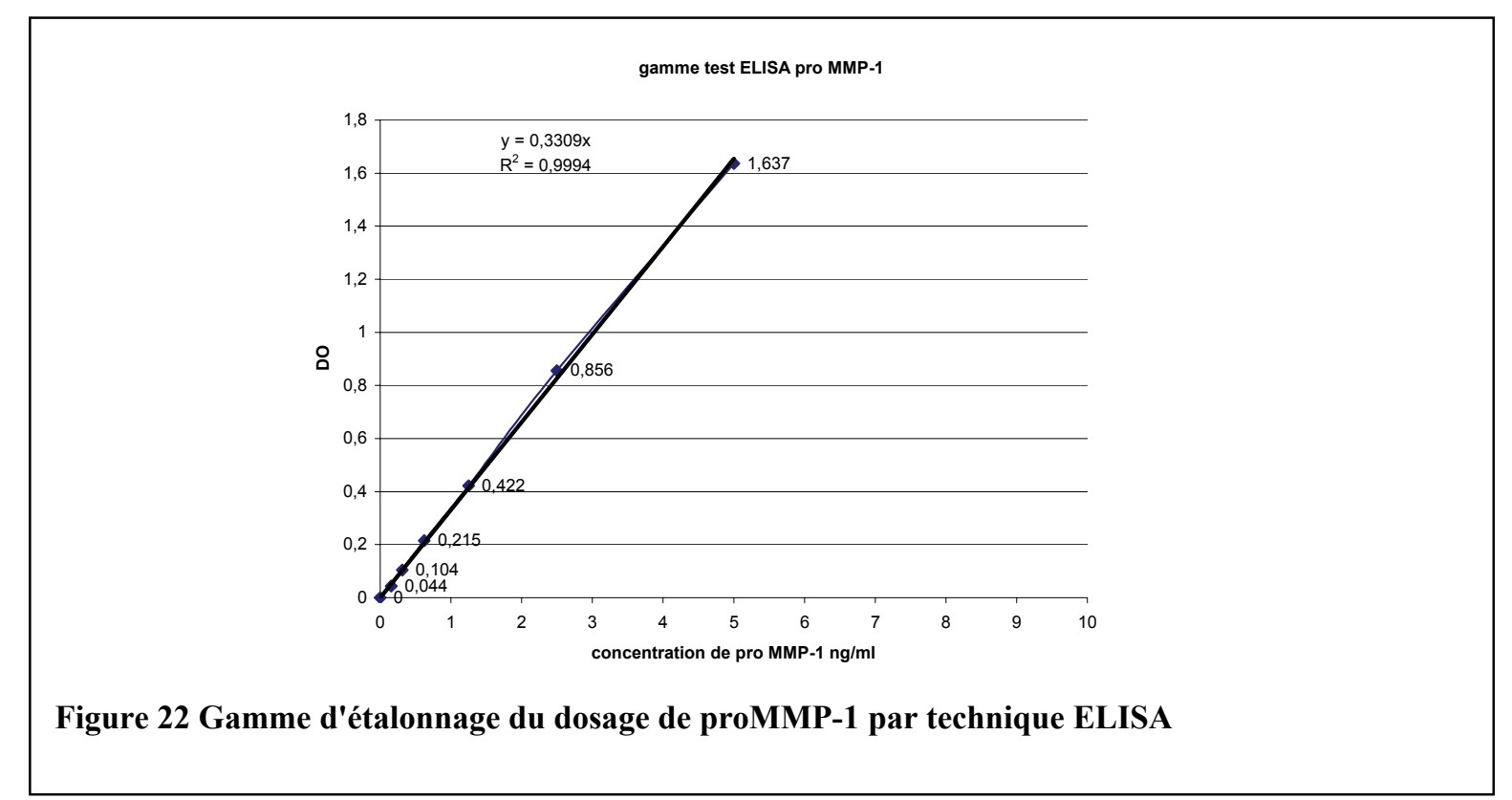




\section{II-C-2 Zymographie (MMP-2 \& MMP-9) :}

Après élimination du milieu de culture des chondrocytes natifs C-20/A4 cultivés sur des boîtes de culture de $75 \mathrm{~cm}^{2}$ en condition de confluence, les cellules sont lavées 3 fois en EBSS et cultivées sans SFV, avec ou sans une incubation avec de l'hIL-1 $\beta$ (500 pg/ml). Après $23 \mathrm{H}$ de culture, le surnageant est prélevé et congelé à $-80^{\circ} \mathrm{C}$. Le dosage de la quantité de gélatinase A (MMP-2) et de gélatinase B (MMP-9) est réalisé par zymographie.

Cette technique électrophorétique qualitative et semi-quantitative consiste en une séparation des protéines de l'échantillon testé sur un gel d'acrylamide $10 \%$ copolymérisé avec le substrat de l'enzyme recherchée, en l'occurrence ici la gélatine, incorporée à raison de $0,5 \mathrm{mg} / \mathrm{ml}$ de gel, et contenant un agent dénaturant, du SDS à la concentration finale de $0,1 \%$.

Après incubation du gel dans un tampon d'activation contenant de l'acétate 4aminophenylmercurique (APMA) et coloration au Bleu de Coomassie, l'activité enzymatique des éventuelles protéines à activité gélatinolytique est détectée par l'absence de coloration de certaines bandes du gel au niveau desquelles la gélatine aura été dégradée par l'enzyme. De plus, les progrès de la densitomètrie informatisée permettent maintenant une analyse semiquantitative par scanning de la surface et de l'intensité de ces bandes de dégradation de la gélatine. La quantification de cette activité enzymatique peut être réalisée, selon les temps d'incubation du gel, jusqu'à des quantités avoisinant 5 pg d'enzyme.

Après décongélation, le milieu de culture est resuspendu dans $50 \mu 1$ de tampon d'échantillonnage «sample buffer $X$ » ne contenant pas d'agent réducteur. Après dépôt de l'échantillon sur le zymogramme et migration à $30 \mathrm{~mA}$ constant pendant 4 heures environ, le gel est incubé pendant 30 minutes à température ambiante dans une solution de Triton X 100 $2,5 \%$ en tampon de lavage, de manière à éliminer le SDS et permettre ainsi la renaturation des MMP. Après 10 minutes dans le tampon de lavage seul, le gel est incubé pendant 18 heures environ à température ambiante dans $100 \mathrm{ml}$ de tampon d'incubation contenant $1 \mathrm{mM}$ d'APMA. Le gel est ensuite coloré au Bleu de Coomassie R250 pendant 1 heure, puis décoloré jusqu'à apparition des bandes de dégradation de la gélatine témoignant de la présence de gélatinase active, et enfin scanné à $600 \mathrm{~nm}$ sur un chromatogramme Desaga CD60.

Afin de transformer les valeurs arbitraires du scanning en quantité de MMP, une gamme de gélatinase B purifiée au laboratoire (Morel et col.1991) est réalisée (Figure 23). Seule la partie linéaire de la courbe, pour des valeurs arbitraires de scanning de 400 à 3500 environ 
correspondant à des quantités de gélatinase de 50 à 1000 pg, est exploitable. En effet, des quantités plus importantes d'enzyme provoquent un phénomène de saturation (substrat insuffisant au niveau du gel) annulant toute proportionnalité entre valeur scannée et quantité de gélatinase déposée.

\begin{tabular}{|c|c|}
\hline Sample Buffer" X & $\begin{array}{l}\text { Tris, HCI } 62,5 \text { mM; glycérol 15\%; SDS } \\
\text { 2,3\%; bleu de bromophénol } 0,001 \% \text {; } \\
\text { pH 6,8 }\end{array}$ \\
\hline Tampon d'électrophorèse & $\begin{array}{l}\text { Tris, HCI } 25 \mathrm{mM} \text {; glycine } 190 \mathrm{mM} \text {; SDS } \\
0,1 \% \text {; pH } 8,8\end{array}$ \\
\hline Tampon de lavage & $\begin{array}{l}\text { Tris, HCI } 50 \mathrm{mM} ; \mathrm{CaCI}_{2} 5 \mathrm{mM} ; \mathrm{ZnCI}_{2} 1 \mathrm{PM} \\
\mathrm{pH} 7,6\end{array}$ \\
\hline Tampon d'incubation & $\begin{array}{l}\text { Tris, HCI } 50 \mathrm{mM} ; \mathrm{CaCI}_{2} 5 \mathrm{mM} \text {; } \mathrm{ZnCI}_{2} 1 \mathrm{PM} \\
\text { Triton X } 1001 \% \text {; } \mathrm{NaN}_{3} \text { 0,02\%; APMA1mM ; pH 7,6. }\end{array}$ \\
\hline Colorant & $\begin{array}{l}\text { Bleu de Coomassie R250 0,25\%; acide } \\
\text { acétique } 10 \% \text {; éthanol } 50 \%\end{array}$ \\
\hline Décolorant rapide & Ethanol 26\%; acide acétique $7 \%$ \\
\hline
\end{tabular}

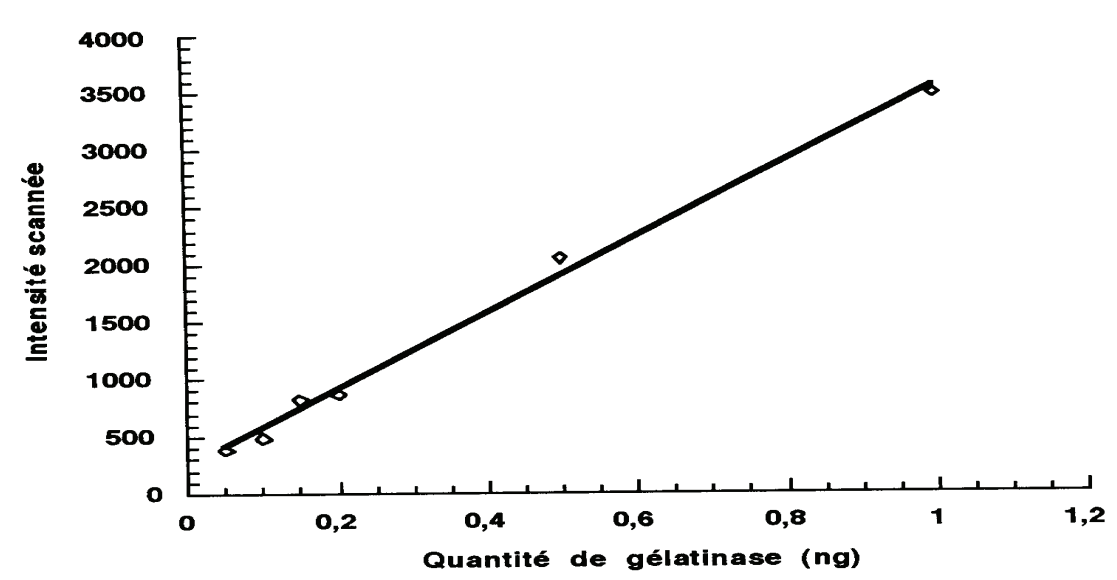

Figure 23 Gamme de gélatinase purifiée; les résultats sont représentatifs de 3 gammes d'étalonnage réalisées dans les mêmes conditions.

\section{II-D Test de viabilité dosage de la LDH :}

Les LDH sont dosés par un automate HITACHI 911 utilisant une technique automatisée spectrophotométrique par mesure à $340 \mathrm{~nm}$ de l'oxydation du NADH en NAD en présence de pyruvate.

\section{II-E Méthodes de biologie moléculaire :}

L'ensemble des techniques classiques de biologie moléculaire sont décrites dans les manuels de laboratoire (Sambrook et coll.1989, Ausubel et coll. 1992). 


\section{II-E-1 Préparation des acides nucléiques :}

\section{II-E-1-a Préparation des ARN totaux :}

Les cellules, après lavage dans du $\mathrm{PBS}^{-}$, sont suspendues à raison de $10^{8}$ cellules maximum $/ \mathrm{ml}$, dans du TRIzol ${ }^{\circledR}$ (Gibco-BRL), solution composée à 50\% par du phénol et contenant un agent dissociant, le thiocyanate de guanidium nécessaire pour détruire les structures cellulaires et inactiver les RNAses endogènes (Chomczynski et coll. 1987). Après 5 à 10 min à température ambiante, 0,2 $\mathrm{ml}$ de chloroforme sont ajoutés à la préparation, laquelle est agitée vigoureusement, incubée 2-3 minutes à température ambiante puis centrifugée (12000 g, 15 min, $4^{\circ} \mathrm{C}$ ) : les $\mathrm{ARN}$ totaux sont isolés dans la phase aqueuse supérieure alors que l'ADN et les protéines sont retrouvés au niveau de l'anneau blanchâtre intermédiaire séparant la phase aqueuse du culot de phénol. Les $\mathrm{ARN}$, transférés proprement dans un tube stérile, sont précipités par 0,5 $\mathrm{ml}$ d'isopropanol pendant $10 \mathrm{~min}$ à température ambiante. Le culot récupéré après $10 \mathrm{~min}$ de centrifugation à $12000 \mathrm{~g}$ et $4^{\circ} \mathrm{C}$ est lavé par $1 \mathrm{ml} \mathrm{d}$ 'éthanol $70 \%(\mathrm{v} / \mathrm{v})$; les ARN sont séchés à l'air libre, remis en suspension dans un volume pouvant varier de 34 à $54 \mu 1$ d'eau distillée stérile selon l'importance du culot. Ils sont ensuite chauffés 10 min à $65^{\circ} \mathrm{C}$ afin d'obtenir une dissolution complète. Les ARN sont conservés à $-20^{\circ} \mathrm{C}$ en éthanol $70 \%$ pendant un mois où, à $-80^{\circ} \mathrm{C}$ en eau stérile pendant un an.

\section{II-E-1-b Préparation d'ADN complémentaire :}

La réaction de transcription inverse est réalisée dans $20 \mu 1$ final de tampon de réaction (Tris 10 $\mathrm{mM}, \mathrm{KCl} 50 \mathrm{mM}, \mathrm{MgCl}_{2} 5 \mathrm{mM}$, dNTP $1 \mathrm{mM}$ chacun $\mathrm{pH}$ 8,3) contenant $5 \mu \mathrm{g}$ d'ARN, 1,6 $\mu \mathrm{g}$ d'amorce oligonucléotidique poly $(\mathrm{dT})_{15}, 20$ unités $(\mathrm{U})$ de la transcriptase inverse du rétrovirus de la myeloblastose aviaire (AMV-RT) et 20 à $50 \mathrm{U}$ d'inhibiteur de RNAses. Après 10 min d'hybridation de l'amorce avec la séquence terminale polyA des $\mathrm{ARNm}$ à $25^{\circ} \mathrm{C}$, les $\mathrm{ARNm}$ sont transcrits en ADN complémentaire $(\mathrm{ADNc})$ simple brin par l'AMV-RT pendant $1 \mathrm{~h}$ à $42^{\circ} \mathrm{C}$. La réaction est alors arrêtée par dénaturation de l'enzyme à $99^{\circ} \mathrm{C}$ pendant 5 min et les $\mathrm{ADNc}$ sont conservés à $+4^{\circ} \mathrm{C}$ jusqu'à l'étape suivante. 


\section{II-E-1-c Dosage des acides nucléiques :}

Après dilution de $4 \mu \mathrm{l}$ de la solution d'ARN ou $5 \mu \mathrm{l}$ d'ADN dans $1 \mathrm{ml}$ d'eau distillée stérile, l'absorbance est lue à 260 et $280 \mathrm{~nm}$ (représentant respectivement les acides nucléiques, et les protéines). La quantité d'ADN ou d'ARN.est calculée en appliquant les formules suivantes

$$
\begin{aligned}
& \text { D.O. } 260 \mathrm{~nm}=1 \text { pour }[\mathrm{ARN}]=40 \mu \mathrm{g} / \mathrm{ml} \\
& \text { D.O. } 260 \mathrm{~nm}=1 \text { pour }[\mathrm{ADN}]=50 \mu \mathrm{g} / \mathrm{ml}
\end{aligned}
$$

\section{II-E-1-d Electrophorèse d'ADN sur gel d'agarose :}

Après avoir fait fondre au micro-onde, de l'agarose ( 0,5 à 2,5\% p/v) dans le Tampon TAE 0,5 $\mathrm{X}$, et ajouté $0,05 \%(\mathrm{P} / \mathrm{V})$ de bromure d'éthidium, on coule le gel d'agarose. Les échantillons et les marqueurs après avoir été dilués au 1/5 dans du tampon d'échantillonnage $5 \mathrm{X}$ sont déposés dans les puits du gel d'agarose préalablement mis dans l'appareil d'électrophorèse rempli du tampon TAE 0,5 X. La migration s'effectue pendant 45 min environ sous une tension de $100 \mathrm{~V}$. Le gel est exposé aux U.V. et photographié.

\section{II-E-2 Réaction d'amplification en chaîne par la polymérase (PCR) :}

La technique d'amplification en chaîne de l'ADN permet d'obtenir des quantités importantes d'une séquence d'ADN présente en faible quantité. Le principe est le suivant (cf. Figure 24) : après dénaturation par la chaleur du double brin d'ADN, deux oligonucléotides complémentaires situés aux extrémités $5^{\prime}$ du double brin du fragment d'ADN à amplifier sont hybridés avec le fragment d'ADN à amplifier à une température particulière dite température de fusion (Tf) inférieure de $5^{\circ} \mathrm{C}$ de la température d'hybridation. La température d'hybridation (Th), ou température théorique, est fonction de la séquence nucléotidique des amorces. En pratique pour déterminer la $\mathrm{Tf}$ et la Th, on applique les formules suivantes :

$$
\begin{aligned}
& \operatorname{Th}\left({ }^{\circ} \mathrm{C}\right)=2(\mathrm{~A}+\mathrm{T})+4(\mathrm{G}+\mathrm{C}) \\
& \operatorname{Tf}\left({ }^{\circ} \mathrm{C}\right)=\mathrm{Th}-5
\end{aligned}
$$




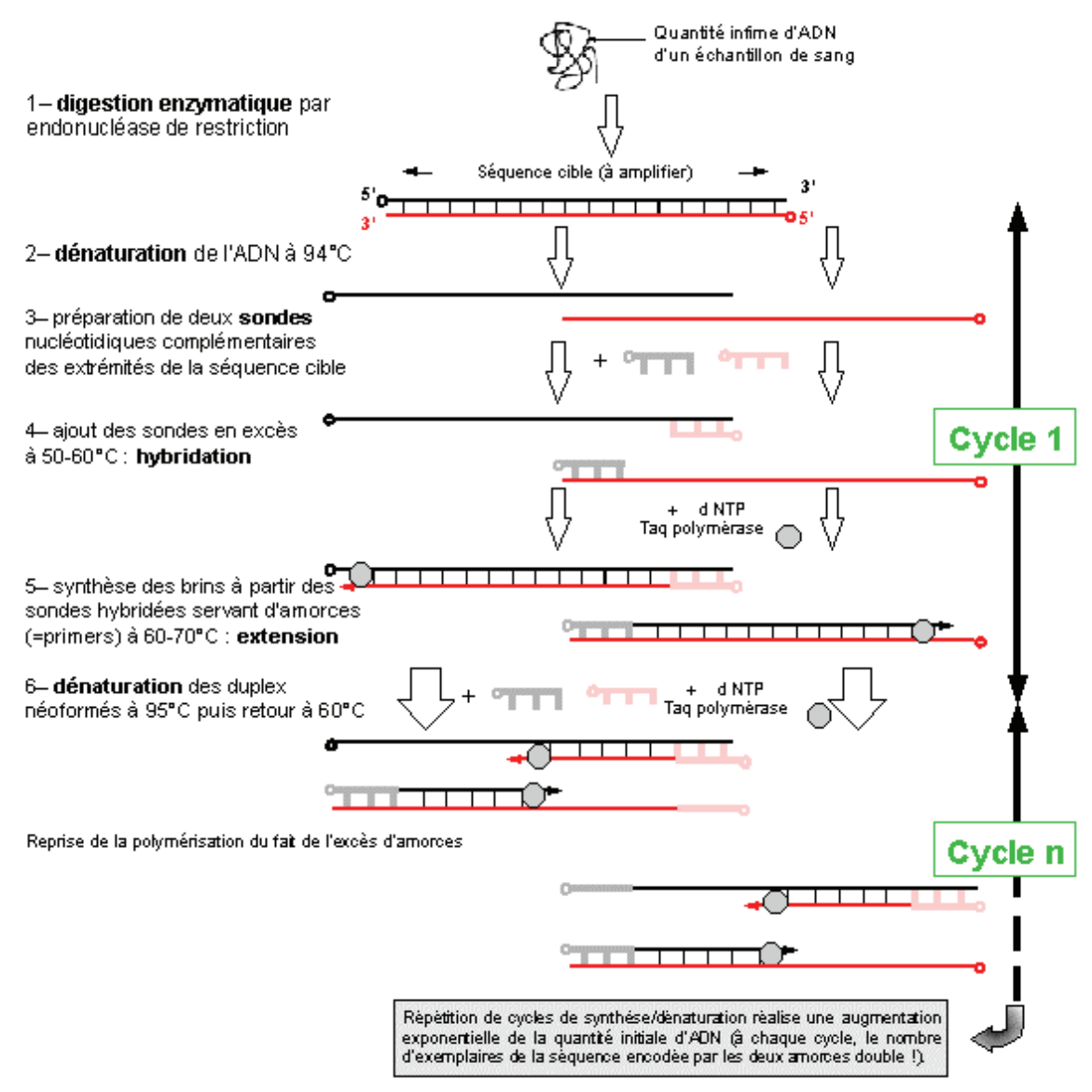

Figure 24 Principe schématique de la technique de PCR polymerase chaine reaction http://www.inrp.fr/biotic/biomol/techgen/html/schempcr.htm

Après l'étape d'hybridation, la température est amenée à $72^{\circ} \mathrm{C}$. Dans ces conditions les extrémités 3' des oligonucléotides servent d'amorces à une ADN polymérase thermostable. Chaque brin sert alors de matrice à l'enzyme qui synthétise les brins complémentaires en assemblant des désoxynucléoside-triphosphates (dATP, dCTP, dGTP, dTTP), le facteur de multiplication est de deux. Les produits issus de ce premier cycle sont ensuite dénaturés par la chaleur à $94^{\circ} \mathrm{C}$ pour séparer les deux brins. Les amorces sont de nouveau hybridées à la température Th avec les brins d'ADN provenant du premier cycle d'amplification, chaque brin servant de matrice à l'ADN polymérase. La réaction se poursuivant, le nombre de copies $\mathrm{d}^{\prime} \mathrm{ADN}$ croît de manière exponentielle et on obtient $2^{\mathrm{n}}$ fragments après $\mathrm{n}$ cycles.

La réaction de PCR est réalisée dans $100 \mu 1$ final de tampon de réaction (Tris $10 \mathrm{mM}, \mathrm{KCl} 50$ $\mathrm{mM}, \mathrm{MgCl}_{2}$ 1,5 mM, dNTP 0,2 mM chacun $\left.\mathrm{pH} 8,3\right)$ contenant 2,5 $\mu 1 \mathrm{~d}$ 'ADNc, 0,25 $\mu \mathrm{M}$ d'amorces sens et anti-sens, $2 \mu \mathrm{l}$ du mélange de dNTP $10 \mathrm{mM}$, et 2,5 U de la polymérase de la bactérie Thermus Aquaticus (Taq polymérase, Appligène). Un volume de $50 \mu$ d'huile minérale est déposé afin d'éviter toute évaporation au cours de la réaction. 
Tableau 4 Amorces oligonucléotidiques utilisées

\begin{tabular}{|c|c|c|c|}
\hline Amorces & $\begin{array}{c}\text { Taille du } \\
\text { fragment } \\
\text { amplifié (pb) } \\
\end{array}$ & Séquence (de 5' à 3') & $\begin{array}{c}\mathrm{T}^{\circ} \text { hybridation } \\
\text { optimale } \mathrm{Th}\left({ }^{\circ} \mathrm{C}\right)\end{array}$ \\
\hline $\begin{array}{l}\text { Nox1F } \\
\text { Nox1R }\end{array}$ & 248 & $\begin{array}{l}\text { F1 GTACAAATTCCAGTGTGCAGACCAC } \\
\text { R1 AGACTGGAATATCGGTGACAGCA }\end{array}$ & $58^{\circ} \mathrm{C}$ \\
\hline $\begin{array}{l}\text { gp91 } 1^{\text {phox }} \text { Nox2 F } \\
\text { gp91 }{ }^{\text {phox }} \text { Nox2 R }\end{array}$ & 624 & $\begin{array}{l}\text { F2 ATAAGCAGGAGTTTCAAGAT } \\
\text { R2GTTTTCTAGACTGAAGTTTTCCTTGTTGAAA } \\
\text { ATGAAATG }\end{array}$ & $55^{\circ} \mathrm{C}$ \\
\hline $\begin{array}{l}\text { Nox3 F } \\
\text { Nox3R }\end{array}$ & 457 & $\begin{array}{l}\text { F3ATGAACACCTCTGGGGTCAGCTGA } \\
\text { R3GGATCGGAGTCACTCCCTTCGCTG }\end{array}$ & $62 \mathrm{C}$ \\
\hline $\begin{array}{l}\text { Nox4 F } \\
\text { Nox4R } \\
\text { pour PCR quantitative* }\end{array}$ & 285 & $\begin{array}{l}\text { F4 CAGCAAGATACCGAGATG } \\
\text { R4 CTGGCTTATTGCTCCGGA } \\
\text { *F4"',CTGAATGCAGCAAGATACCGAGAT } \\
\text { *R4"' CTGGCTTATTGCTCCGGA }\end{array}$ & $\begin{array}{l}60^{\circ} \mathrm{C} \\
66^{\circ} \mathrm{C}\end{array}$ \\
\hline $\begin{array}{l}\text { Nox5 F } \\
\text { Nox5R }\end{array}$ & 236 & $\begin{array}{l}\text { F5 ATCAAGCGGCCCCCTTTTTTTCAC } \\
\text { R5CTCATTGTCACACTCCTCGAC }\end{array}$ & $60^{\circ} \mathrm{C}$ \\
\hline $\begin{array}{l}\text { p22 } 2^{\text {phox }} \mathrm{F} \\
\mathrm{p} 22^{\text {phox }} \mathrm{R}\end{array}$ & 687 & $\begin{array}{l}\text { F6 CAGTGTCCCAGCCGGGTTCGTGTC } \\
\text { R6 ATTGCAGGTGGGTGCACCTGGTGGGAG }\end{array}$ & $70^{\circ} \mathrm{C}$ \\
\hline $\begin{array}{l}\mathrm{p} 40^{\text {phox }} \mathrm{F} 2 \\
\mathrm{p} 40^{\text {phox }} \mathrm{R} 2\end{array}$ & 507 & $\begin{array}{l}\text { F7 TGGCAGCTCCGAGAGCAGAG } \\
\text { R7 GGCATCGTGTTGTAGACCCTG }\end{array}$ & $60^{\circ} \mathrm{C}$ \\
\hline $\begin{array}{l}\mathrm{p} 47^{\text {phox }} \mathrm{F} \\
\mathrm{p} 47^{\text {phox }} \mathrm{R}\end{array}$ & 180 & $\begin{array}{l}\text { F8 GAGCACTGGAGGCCACCCAGTC } \\
\text { R8 GTTTTATGGAACTCGTAGATCTCG }\end{array}$ & $70^{\circ} \mathrm{C}$ \\
\hline $\begin{array}{l}\text { p6 } 67^{\text {phox }} \mathrm{F} 2 \\
\text { p6 }\end{array}$ & 801 & $\begin{array}{l}\text { F9 TGTCTTTGTCTTGAAGAAGGGC } \\
\text { R9 GACTTCTCTCCGAGTGCTTTC }\end{array}$ & $60^{\circ} \mathrm{C}$ \\
\hline $\begin{array}{l}\text { Rac2 F } \\
\operatorname{Rac} 2 \text { R }\end{array}$ & 578 & $\begin{array}{l}\text { F10 ATGCAGGCCATCAAGTGTGT } \\
\text { R10 TAGAGGAGGCTGCAGGCG }\end{array}$ & $63^{\circ} \mathrm{C}$ \\
\hline $\begin{array}{l}\text { G3PD } \\
\text { pour PCR quantitative }\end{array}$ & 450 & $\begin{array}{l}\text { F11 GTGGTGGACCTGACCTGC } \\
\text { R11 CCCTGTTGCTGTAGCCAAATTCG }\end{array}$ & $70^{\circ} \mathrm{C}$ \\
\hline G3PD & 983 & Clontech & $72^{\circ} \mathrm{C}$ \\
\hline$\beta$-actine & 838 & Clontech & $55-65^{\circ} \mathrm{C}$ \\
\hline
\end{tabular}

Les échantillons sont soumis à 30 cycles correspondant à 1 min de dénaturation de l'ADNc à $94^{\circ} \mathrm{C}$ suivie d' 1 à 2 min d'hybridation des amorces (température variable selon la composition en bases des amorces voir tableau 3 ci-dessous et la position des amorces sur la séquence des ARNm en annexe), puis les fragments d'ADNc sont amplifiés par le mélange Taq polymérase$\mathrm{Pfu}$ à $72^{\circ} \mathrm{C}$ (la durée est fonction de la longueur du fragment à amplifier : à savoir 1 min pour 1 
$\mathrm{kb})$. L'utilisation du mélange des deux enzymes permet de limiter le risque d'introduction d'une erreur de séquence. Après 30 cycles identiques, la réaction se termine par 10 min supplémentaires d'élongation, puis est stoppée par inhibition de l'enzyme à $+4^{\circ} \mathrm{C}$. Une PCR réalisée en parallèle sur l'ADNc du gène domestique de l'actine ou de la G3PDH permet de légitimer tout résultat négatif en ce qui concerne la qualité de l'ADNc amplifié.

\section{II-E-3 Construction de plasmides exprimant les différentes isoformes de Nox4 et Nox2:}

Le plasmide d'expression de Nox4 humain est cloné pour les expériences qui suivent tandis que nous avons utilisé un plasmide d'expression de Nox2 qui est déja utilisé de maniére courante au laboratoire (Stasia et coll. 2002).

Les deux ADNc de Nox4 sont amplifiés par PCR en utilisant comme matrice une banque d'ADNc de rein humain adulte (UNI-ZAP human kidney lambda, Stratagene, Cedar Creek, USA).

Deux isoformes ont été mises en évidence (Figure 25) :

- Nox4A correspond à la forme intégrale de Nox4 habituellement décrite et répertoriée dans Genbank sous le numéro No.AF254621

- Nox4B correspond à une isoforme de Nox4 épissée du $14^{\mathrm{eme}}$ exon (répertoriée dans Genbank No.AJ704726), rendant la protéine produite non fonctionnelle par absence du premier site de fixation du FAD

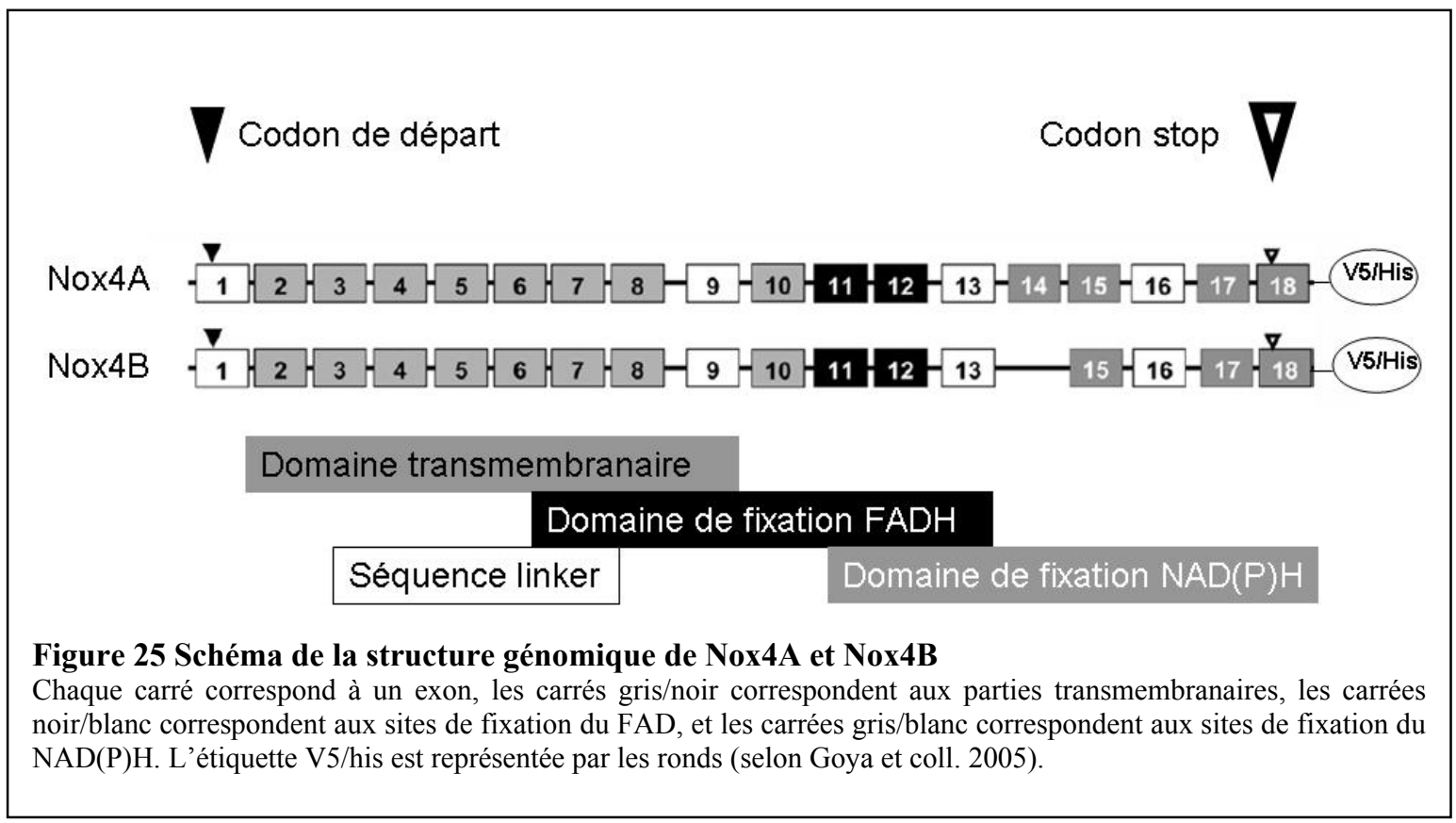


Les deux isoformes sont clonées dans un plasmide d'expression de mammifère en ajoutant en $\mathrm{N}$ terminal une étiquette V5-His. Les amorces utilisées sont les suivantes: amorces sens Nox4F4',' (5'-GTtTGgtaCCATGGCTGTGTCCTGGAGG-3') incluant un site KpnI (en caractères gras) et les amorces anti-sens Nox4 R4'

(5' GTTTACTAGTGCTGAAAGACTCTTTATTGTATTC-3'), comprenant un site de restriction Spe I (en caractères gras) sans le codon stop. Les produits de PCR purifiés sont sous-clonés dans le vecteur pCR Blunt II-TOPO conformément au protocole du fournisseur (Zero Blunt TOPO PCR cloning kit, Invitrogen). Les plasmides pCR-BluntII-TOPO contenant Nox4A ou Nox4B sont digérés par Kpn I et Spe I, et les inserts purifiés sont intégrés dans le vecteur final pEF6V5/HisB (Invitrogen) linéarisé par ces deux mêmes enzymes.

Le plasmide permettant l'expression d'un dominant-négatif de Nox4, Nox $4 \Delta$ FAD/NADPH correspondant à une protéine Nox4 délétée de la partie $\mathrm{C}$ terminale au niveau de l'acide aminé 312 (Mahadev et col 2004), est construit en utilisant l'amorce sens Nox4 F4",', et l'amorce anti-sens Nox4 R4', (5'-GTTTGCGGCCGCTCAAATGATGGTGACTGGCTTATTGC-3') contenant un site de restriction Not I (en caractères gras). Le produit de PCR purifié est digéré par Kpn I et Not I et inséré dans un vecteur pCDNA 3.1 V5/HisB vector (Invitrogen) linéarisé par ces mêmes enzymes.

La construction exprimant Nox2 dans un plasmide pEF-PGK est un don de MJ. Stasia (Stasia et coll. 2002).

Tous les inserts sont vérifiés par séquençage (Génome Express, Grenoble, France).

\section{II-E-4 RT-PCR quantitative:}

Après extraction de l'ARN des cellules d'intérêt, la réaction de transcriptase inverse est réalisée avec $2 \mu \mathrm{g}$ d'ARN, et $40 \mathrm{U}$ d'AMV-RT (cf. ci avant). Les produits de la transcriptase inverse sont dilués au dixième et $5 \mu 1$ sont alors utilisés pour la réaction de PCR quantitative. Le niveau d'expression de l'ARNm de Nox4 humain et du gène de ménage G3PDH est déterminé en utilisant les amorces spécifiques suivantes (cf. Tableau 4) :

- Pour Nox4 l'amorce sens est F4", ' et l'amorce anti-sens est R4",'

- Pour la G3PDH l'amorce sens est F11 et l'amorce anti-sens est R11 
La PCR quantitative de Nox4 et G3PDH pour chaque ADNc obtenu est réalisée dans un appareil Light Cycler 1.5 apparatus (Roche), en utilisant le kit LightCycler FastStart DNA Master plus SYBR Green I (Roche). Le principe du substrat SYBR Green utilisé est expliqué dans la figure 26. On obtient une courbe exponentielle qui est corrélée à la quantité d'ADN amplifié. Ainsi, plus il y a d'ADNc (reflet de la quantité d'ARNm) au départ de la réaction, plus la fluorescence apparaît tôt. En déterminant le moment de l'apparition de la fluorescence, on peut quantifier de manière relative le niveau d'expression des différents transcrits dans les cellules en se rapportant à celui d'un gène de ménage. La quantité d'ARNm de Nox4 mesurée est rapportée à une courbe standard établie au préalable pour chaque gène et également à celle du gène de ménage, la G3PDH.

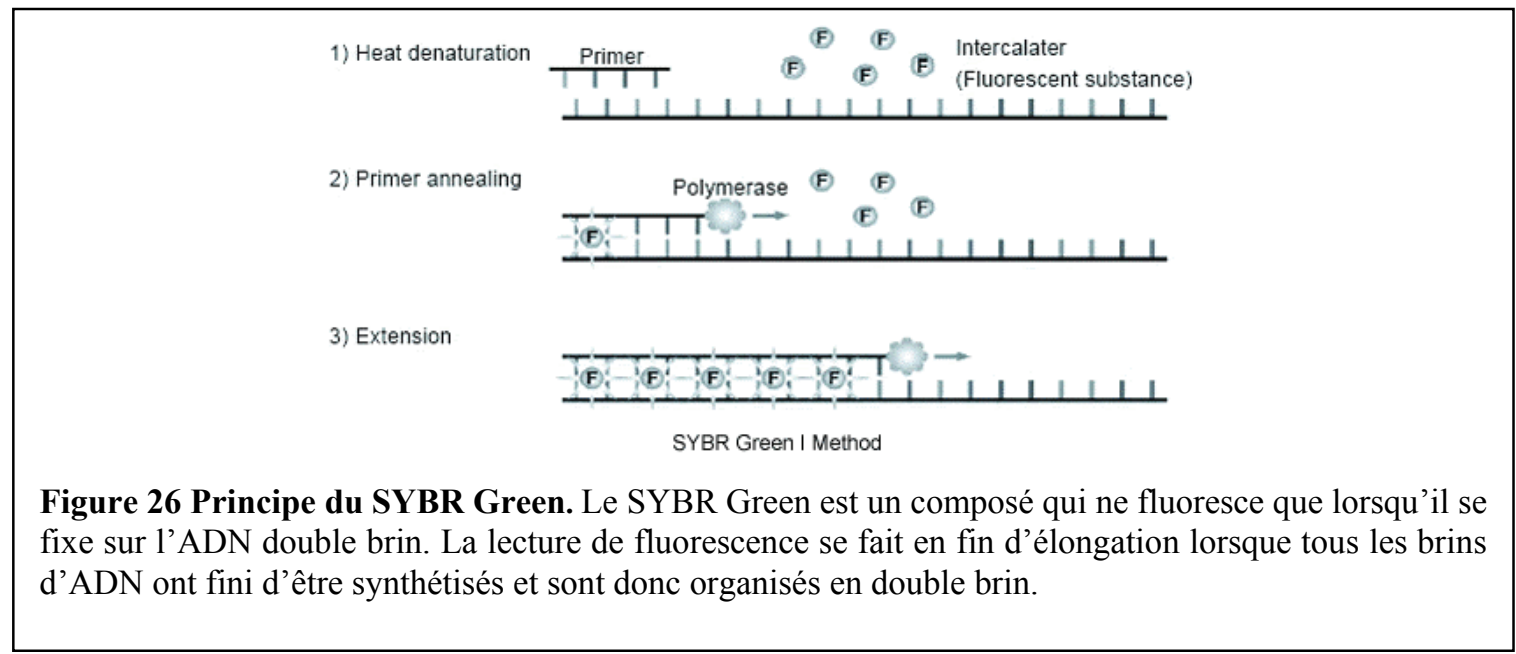

L'efficacité et la reproductibilité de la PCR pour chaque gène sont évaluées grâce aux courbes standards. L'établissement de la courbe standard se fait par dilutions successives des échantillons du dixième au millionième. Les mesures sont réalisées en 4 exemplaires. Des exemples de courbes représentant l'amplification de l'ADN à chaque cycle de PCR sont montrés sur la figure 27. Une fois les conditions de mise au point déterminées, nous avons pu alors faire la mesure avec les ARNm totaux de tous nos types cellulaires. Afin de pouvoir comparer les différentes expériences entre elles, nous avons toujours utilisé le même calibrateur interne dans chaque groupe de mesures 

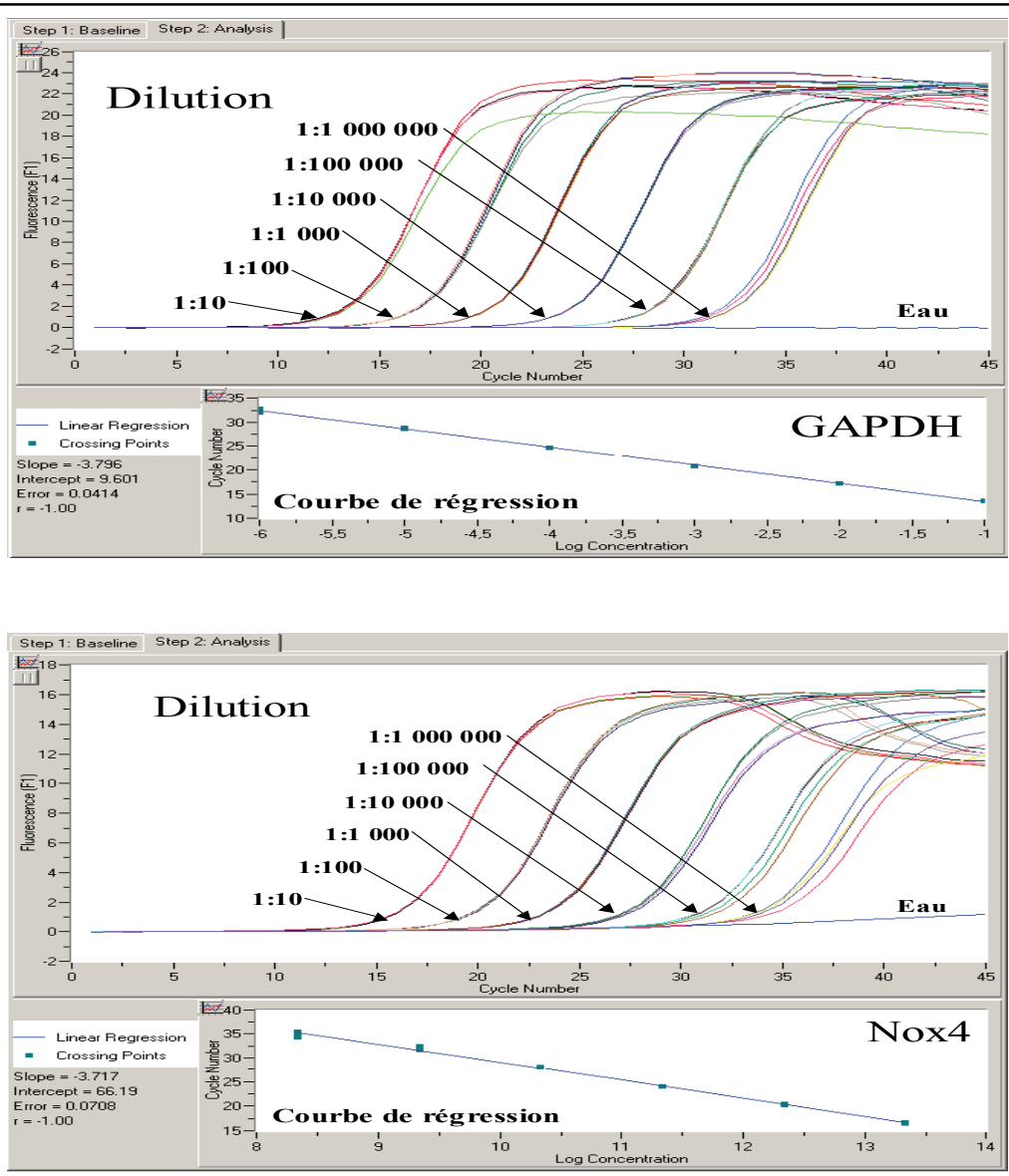

Figure 27 Courbes standards pour la GAPDH, Nox4. Les courbes sont obtenues par dilutions successives des échantillons d'ADNc. Pour chaque dilution, 4 mesures sont effectuées à chaque fois

Les conditions d'incubation ont été les suivantes :

Première phase de montée en température de $95^{\circ} \mathrm{C}$ pendant $10 \mathrm{~min}$, puis suivie par une phase de 45 cycles décomposés d'une étape de dénaturation à $95^{\circ} \mathrm{C}$ pendant $15 \mathrm{~s}$ suivie d'une étape d'hybridation à $66^{\circ} \mathrm{C}$ pendant $10 \mathrm{~s}$ pour Nox4 ou la G3PDH pour finir par une dernière étape d'extension à $72^{\circ} \mathrm{C}$ pendant $21 \mathrm{~s}$ pour Nox4, ou $10 \mathrm{~s}$ pour la G3PDH.

Les PCRs de chaque échantillon sont réalisées 4 fois par expérience qui sont elles-mêmes réalisées trois fois.

\section{II-E-5 Purification des fragments d'ADN sur gel d'agarose et séquençage :}

Nous utilisons le kit "sephaglass ${ }^{\circledR} "$ (Pharmacia). Après migration, la bande d'agarose contenant le fragment d'ADN d'intérêt est dissoute dans un tampon, auquel on ajoute $5 \mu \mathrm{lde}$ la suspension "sephaglass $\mathrm{BP}$ " à la suite de quoi une incubation de 5 min à température ambiante (billes se liant à l'ADN) est réalisée. 
Après une centrifugation à $12000 \mathrm{~g}$ de 30 secondes, le surnageant est éliminé et le précipité lavé deux fois par $80 \mu 1$ de tampon de lavage. Le culot obtenu est séché à l'air et remis en suspension dans $25 \mu \mathrm{l}$ de tampon d'élution, pour être incubé 5 min à température ambiante avec des agitations fréquentes, puis centrifugé à $12000 \mathrm{~g}$ pendant $1 \mathrm{~min}$ pour récupération du surnageant contenant l'insert d'ADN purifié qui est alors envoyé pour séquençage à la société genome-express (Meylan France).

\section{II-E-6 Méthodes de Transfection des lignées chondrocytaires :}

\section{II-E-6-aTransfection stable :}

\section{Effectene ${ }^{\circledR}$ (Qiagen) :}

Les cellules C-20/A4 sont trypsinisées et comptées. 4x10 cellules de la lignée C-20A/4 sont mises en culture en condition classique (DMEM/10\% de SVF) dans des plaques de 6 puits pour atteindre après $24 \mathrm{~h}$, une confluence de $60 \%$. Les transfections sont réalisées en suivant le protocole du kit Effectene ${ }^{\circledR}$.

Quatre $\mu \mathrm{g}$ d'ADN d'intérêt (le vecteur pEF6V5HisB codant Nox4A-V5/His ou Nox4BV5/Hi ; le vecteur pEF-PGKneo codant pour Nox2; ou enfin le plasmide codant pour la lucifèrase qui servira de témoin) sont incubés avec 3,2 $\mu \mathrm{l}$ de tampon « d'enhancer » du kit effectene. La solution est complétée à $100 \mu \mathrm{l}$ par le tampon « $\mathrm{EC} »$ du kit effectene. La solution complétée est alors homogénéisée et mise au repos 5 min à température ambiante. Puis $10 \mu \mathrm{l}$ d'effectene sont rajoutés et incubés 5 à $10 \mathrm{~min}$ à température ambiante (Figure 28); principe de la méthode de transfection). Pendant l'incubation, le milieu de culture est remplacé par $1600 \mu \mathrm{l}$ de milieu de culture frais dans les puits. On ajoute alors $600 \mu \mathrm{l}$ de $\mathrm{DMEM} / 10 \% \mathrm{SVF}$ à la solution de transfection, dont la totalité (ADN, «Enhancer » et « Effectène »et milieu) est ajoutée alors dans les puits. Après 24 heures à $37^{\circ} \mathrm{C}$ en étuve à $5 \%$ de $\mathrm{CO}_{2}$, le surnageant est remplacé par du milieu de culture classique contenant les antibiotiques de sélection (soit par $10 \mu \mathrm{g} / \mathrm{ml}$ de blasticidine pour les transfections utilisant le vecteur pEF6V5HisB, soit par $1 \mu \mathrm{g} / \mathrm{ml}$ de généticine tamponnée par $20 \mu \mathrm{l} / \mathrm{ml}$ de $\mathrm{NaOH} 5 \mathrm{~N}$ pour les transfections utilisant le vecteur pEF-PGKneo). Les lignées sont ensuite cultivées en conditions classiques prêtes à être utilisées dans les différentes expérimentations. 


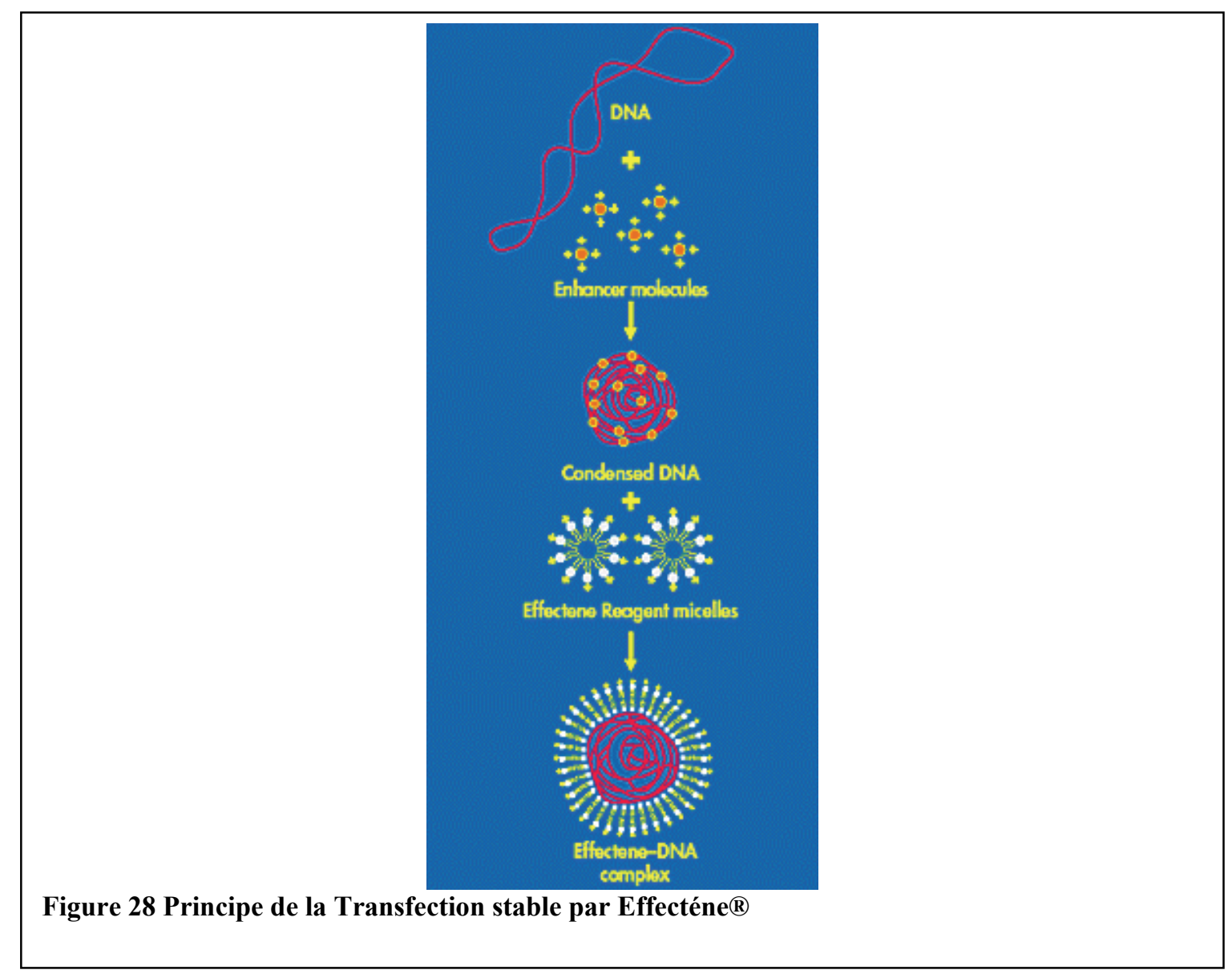

\section{II-E-6-bTransfection Transitoire :}

Les cellules C-20/A4 Nox4A-V5/His sont trypsinisées et comptées. 4x10 C-20A/4 sont mises en culture en condition classique (DMEM/10\% de SVF) dans des boîtes de $25 \mathrm{~cm}^{2}$ jusqu'à atteindre une confluence de $50 \%$.

Cinq $\mu \mathrm{g}$ du plasmide d'intérêt (le plasmide vide pCDNA 3.1 V5/His ou le plasmide pCDNA 3.1 Nox4 $\Delta$ FAD/NADPH) sont dilués dans $200 \mu \mathrm{L}$ de tampon $\mathrm{CaCl}_{2}(250 \mathrm{mM})$ et $200 \mu \mathrm{L}$ de tampon «HEPES-phosphate» (140 mM NaCl, 50 mM HEPES, 1,4 mM NaH$\left.{ }_{2} \mathrm{PO}_{4}, \mathrm{pH} 7,05\right)$. Après 60 secondes d'incubation de l'ensemble, à température ambiante, la solution de transfection ainsi constituée est ajoutée aux cellules dans $1,8 \mathrm{ml}$ de milieu de culture classique DMEM/10\% SVF. Quatre heures après, le surnageant est remplacé par du DMEM/10\% SVF frais. Quarante huit heures après la transfection, l'expérimentation de stress cytokinique hIL-1ß est réalisée directement dans les boîtes de culture en utilisant les mêmes conditions en terme de concentration d'hIL-1ß que celle décrite ci-aprés. 


\section{II-F. Mesure de l'effet du stress cytokinique $h$ IL-1 $\beta$ sur l'expression métalloprotéasique :}

\section{II-F-1 Stimulation par l'hIL1- $\beta$ sur les lignées de chondrocytes C-20/A4 :}

Après trypsinisation d'une boîte de $175 \mathrm{~cm}^{2}$ les cellules considérées sont mises en culture trois jours dans trois boîtes de $75 \mathrm{~cm}^{2}$ en conditions classiques afin d'obtenir une confluence à $90 \%$. Après trois lavages en EBSS les cellules sont incubées à $37^{\circ} \mathrm{C}$, $5 \% \mathrm{CO}_{2}$ avec le milieu de culture classique mais sans sérum de veau en présence ou non de $500 \mathrm{pg} / \mathrm{ml}$ d'IL-1ß humaine (hIL-1ß; solution à $50.000 \mathrm{U} / \mu \mathrm{l})$ pendant $23 \mathrm{~h}$ (durée et concentration d'IL-1ß humaine validée au préalable après vérification des conditions optimales de la concentration d'hIL-1ß humaine et du temps d'incubation). A T23h on prélève la totalité du milieu de culture pour doser les LDH afin de valider la viabilité des cellules durant ces $23 \mathrm{~h}$ d'incubation, doser les protéines par la méthode de Bradford, et enfin après centrifugation à $350 \mathrm{~g}$ durant 5 min à température ambiante le surnageant est aliquoté puis congelé pour dosage ELISA de la pro MMP-1.

\section{II-F-2 Impact de l'inhibition des ROS (TIRON / DPI) sur la sécrétion de la pro MMP-1 :}

Après trypsinisation d'une boîte de $175 \mathrm{~cm}^{2}$ les cellules considérées sont mises en culture trois jours dans trois boîtes de $75 \mathrm{~cm}^{2}$ en conditions classiques afin d'obtenir une confluence à $90 \%$. Après lavage trois fois en EBSS les cellules sont incubées à $37^{\circ} \mathrm{C}, 5 \% \mathrm{CO}_{2}$ avec le milieu de culture classique mais sans sérum de veau en présence ou pas de $500 \mathrm{pg} / \mathrm{ml}$ d'IL-1ß humaine (hIL-1ß) et plus ou moins en présence de $10 \mu \mathrm{M}$ DPI (inhibiteur de la NAD(P)H oxydase) ou de $5 \mathrm{mM}$ de TIRON (piégeur $\mathrm{d}^{\prime} \mathrm{O}_{2}^{-}$) pendant $23 \mathrm{~h}$

A T23h on prélève la totalité du milieu de culture pour doser les LDH afin de valider la viabilité des cellules durant ces $23 \mathrm{~h}$ d'incubation, doser les protéines par la méthode de Bradford, et enfin après centrifugation à $350 \mathrm{~g}$ durant 5 min à température ambiante le surnageant est aliquoté puis congelé pour dosage ELISA de la pro MMP-1. 


\section{II-F-3 Impact de la surexpression de Nox4 sur la sécrétion de la pro MMP-1 :}

Les mêmes expériences dans les mêmes conditions ont été réalisées avec les cellules transfectées (cf. ci avant)

\section{II-G Les anticorps utilisées}

Tableau 5 Anticorps mono clonaux et polyclonaux utilisés avec la séquence protéique de leur épitope respectif

\begin{tabular}{|c|c|c|c|c|}
\hline Anticorps & Sous-unité reconnue & Epitope & Equipe & Année \\
\hline \multicolumn{5}{|c|}{ Monoclonaux } \\
\hline 7D5 & gp91phox & ${ }^{160}$ IKNP $^{163}$ et $^{226}$ RIVRG $^{230}$ & Nakamura (Japon) & 1987 \\
\hline 54.1 & gp91phox & ${ }^{382}$ PKIAVDGP ${ }^{389}$ & $\begin{array}{c}\text { Jesaïtis } \\
\text { (Etats-Unis) }\end{array}$ & 1995 \\
\hline NL7 & gp91phox & ${ }^{498}$ EKDVITGLKQ $^{507}$ & $\begin{array}{c}\text { Jesaïtis } \\
\text { (Etats-unis) }\end{array}$ & 2003 \\
\hline 44.1 & p22phox & ${ }^{29}$ TAGRF $^{33}$ et $^{183}$ PQVNPI $^{188}$ & $\begin{array}{c}\text { Jesaïtis } \\
\text { (Etas-Unis) }\end{array}$ & 1995 \\
\hline $\begin{array}{l}\text { Penta.His } \\
N^{\circ} 34660\end{array}$ & histidine & ННННН & QIAGEN & l \\
\hline \multicolumn{5}{|c|}{ Polyclonaux } \\
\hline 504 & Nox4 & ${ }^{88}$ KVPSRRTRRLLDKSR $^{102}$ & $\begin{array}{l}\text { GREPI } \\
\text { France }\end{array}$ & 2006 \\
\hline 503 & Nox4 & ${ }^{88}$ KVPSRRTRRLLDKSR $^{102}$ & $\begin{array}{l}\text { GREPI } \\
\text { France }\end{array}$ & 2006 \\
\hline p40Nter & p40 ${ }^{\text {phox }}$ & ${ }^{1}$ MAVAQQLRAESDFEQL ${ }^{15}$ & $\begin{array}{l}\text { GREPI } \\
\text { France }\end{array}$ & 1994 \\
\hline p67Cter & p67 $7^{\text {phox }}$ & ${ }^{511}$ VEDSATTDLESTRREV ${ }^{526}$ & $\begin{array}{l}\text { GREPI } \\
\text { France } \\
\end{array}$ & 1991 \\
\hline $\begin{array}{c}\text { N19 } \\
\text { sc-7661 }\end{array}$ & p47 $7^{\text {phox }}$ & I & $\begin{array}{c}\text { Santa Cruz } \\
\text { Biotechnology, Inc. }\end{array}$ & I \\
\hline Rac & Rac1\&2 & ${ }^{120}{ }^{12 R D D K D T I E K L K E K K L T P I T Y P Q ~}{ }^{141}$ & $\begin{array}{l}\text { GREPI } \\
\text { France }\end{array}$ & 1995 \\
\hline
\end{tabular}

\section{II-H Mesure de la production de $\mathrm{O}_{2}^{-}$par oxydation du DHE par microscopie à fluorescence}

Le dihydroethidium (DHE) est une molécule ayant la propriété de s'oxyder en présence de $\mathrm{O}_{2}{ }^{-}$pour devenir de l'ethidium qui s'intercale au niveau de l'ADN des cellules. Cette molécule après une excitation à $495 \mathrm{~nm}$ émet une fluorescence rouge à $565 \mathrm{~nm}$.

Le DHE est donc un bon indicateur de la présence d' $\mathrm{O}_{2}{ }^{-}$intra cellulaire. Le niveau de production des ROS peut être apprécié et mesuré par cette méthode (Vanden et coll. 1997, Priault et coll. 2002). Certains auteurs comme Benove pensent au contraire que cette 
technique a plutôt un caractère qualitatif et non quantitatif (Benove et col.1998) et Zhao et col ont ainsi démontré en 2003 que l'ethidium n'était par le seul produit émis après oxydation du dihydroethidium par l' ${ }^{-}$rendant difficile une mesure quantitative fiable de la production de ce radical oxydant par cette technique (Zhao et coll. 2003). Nous avons donc décidé d'utiliser cette technique en suivant le protocole suivant :

Les cellules sont cultivées à $80 \%$ de confluence sur des plaques 6 puits en conditions classiques (DMEM-10\% SVF) à $37{ }^{\circ} \mathrm{C}$ et $5 \%$ de $\mathrm{CO}_{2}$. Le jour de l'expérience les chondrocytes sont lavés 2 fois avec de l'EBSS et incubés pendant 20 minutes avec $1 \mathrm{ml}$ de milieu de culture (DMEM-10\% SVF) contenant $5 \mu \mathrm{M}$ final de DHE (avec ou sans l'hIL-1 $\beta$ à $500 \mathrm{pg} / \mathrm{ml}$ ) toujours à $37{ }^{\circ} \mathrm{C}$ et $5 \%$ de $\mathrm{CO}_{2}$. Toute l'expérience se déroule dans le noir strict car le DHE est une molécule extrêmement sensible à la lumière. Dans certains puits nous avons incubé ces cellules avec en plus de la $N$-acetyl cystéine 30 nM (NAC). En effet la NAC est une molécule antioxydante qui a la propriété de piéger les $\mathrm{O}_{2}{ }^{-}$de manière non spécifique.

Après ces 20 minutes d'incubation les plaques sont lues à l'abri de la lumière sur un microscope à fluorescence Nikon éclipse TE2000-E. Les images sont enregistrées grâce à un système Nikon digital sight DS-1QM. La fluorescence du DHE est analysée en utilisant un filtre avec une longueur d'onde d'excitation à $488 \mathrm{~nm}$ et une longueur d'onde d'émission à $580 \mathrm{~nm}$. Les images sont ensuite analysées par un logiciel Lucia software. Le niveau relatif de fluorescence entre les cellules est quantifié en déterminant l'intégrale des niveaux de gris en utilisant le logiciel Lucia de Imaging Systems. L'intégrale des gris est définie comme la zone de l'intensité de chaque pixel. Un minimum de 50 cellules est analysé par expérience. Les résultats sont exprimés en unité arbitraire de fluorescence.

\section{II-J Cytométrie de flux}

\section{II-J-1 Préparation des chondrocytes}

\section{II-J-1-a Chondrocytes intacts fixés et non perméabilisés}

Les chondrocytes transfectés ou non sont cultivés à confluence (§ II.A.1). Les cellules trypsinisées sont centrifugées à $300 \mathrm{~g}$ pendant $5 \mathrm{~min}$ à température ambiante et lavées avec 15 $\mathrm{ml}$ de $\operatorname{PBS}^{(-)}$. Pour réaliser le marquage, les chondrocytes sont ajustés à $10^{7}$ cellules $/ \mathrm{ml}$ dans un tampon PBS contenant $0,2 \%(\mathrm{p} / \mathrm{v})$ de BSA et $0,5 \mathrm{mM} \mathrm{CaCl} 2$ avant fixation par du paraformaldéhyde (PFA) à $1 \%(\mathrm{p} / \mathrm{v})$ en concentration finale pendant 15 min dans la glace puis les chondrocytes sont centrifugés à $10000 \mathrm{~g}$ pendant $5 \mathrm{sec}$. à température ambiante et 
lavés avec un tampon $\operatorname{PBS}^{(-)}$. Une prise d'essai de $100 \mu 1\left(10^{6}\right.$ cellules $)$ de la suspension est déposée dans chaque tube.

Le marquage est effectué en deux étapes.

Un anticorps primaire (Ig purifiées contre la protéine d'intérêt) est incubé pendant $30 \mathrm{~min}$ dans la glace en présence des cellules intactes à raison de $5 \mu \mathrm{g} \mathrm{d}$ ' $\mathrm{Ig} / 5 \times 10^{5}$ cellules pour les Ac dirigés contre la protéine $\mathrm{p} 22^{\text {phox, }} \mathrm{gp} 91^{\text {phox }}(8 \mathrm{G} 11,54.1, \mathrm{NL} 7)$, Nox4, (503 et 504) et contre la séquence poly-histidine (his) (cf. tableau 4), ainsi que pour l'anticorps non immun servant de témoin (SIGMA).

Les cellules sont ensuite centrifugées à $13000 \mathrm{rpm}$ pendant 5 secondes à température ambiante puis le culot cellulaire est lavé avec $500 \mu 1$ de tampon PBS contenant 0,2\% (p/v) de BSA et $0,5 \mathrm{mM} \mathrm{CaCl}_{2}$.

La deuxième étape du marquage consiste à incuber, pendant 30 min dans la glace, les cellules avec $150 \mu 1$ de ce tampon contenant un anticorps secondaire dilué 200 fois. Cet anticorps est dirigé spécifiquement contre les Ig de l'espèce animale utilisée et couplé à un fluorochrome en l'occurrence, ici, de la Phycoérythrine (Beckman Coulter). Un fluorochrome étant très sensible à la lumière (extinction de la fluorescence), il est indispensable de réaliser les étapes finales du marquage à l'abri de la lumière. Afin d'éviter tout marquage non spécifique, les cellules sont une nouvelle fois lavées deux fois avec $500 \mu \mathrm{l}$ de tampon puis mises en suspension dans des tubes de $5 \mathrm{ml}$.

L'analyse des échantillons est effectuée à l'aide d'un cytomètre FacsCalibur (BectonDickinson). La source laser excite, à une longueur d'onde $\lambda=488 \mathrm{~nm}$, le fluorochrome (Phycoérythrine) qui émet, alors, de la lumière à $565 \mathrm{~nm}$ (FL2) détectée par le cytomètre.

\section{II-J-1-b Chondrocytes intacts Fixés et perméabilisés}

La suspension cellulaire de chondrocytes est ajustée à $10^{7}$ cellules / $\mathrm{ml}$ avant fixation par du paraformaldéhyde (PFA) à $1 \%(\mathrm{p} / \mathrm{v})$ en concentration finale pendant 15 min dans la glace, puis les chondrocytes sont centrifugés à $10000 \mathrm{~g}$ pendant $5 \mathrm{~s}$ à température ambiante et lavés avec un tampon PBS. Les cellules fixées sont ensuite incubées dans un tampon PBS contenant $0,2 \%(\mathrm{p} / \mathrm{v})$ de BSA, $0,5 \mathrm{mM} \mathrm{CaCl}_{2}$ et $0,01 \%(\mathrm{p} / \mathrm{v})$ de saponine pendant $10 \mathrm{~min}$ dans la glace. La saponine perméabilise les cellules en s'intercalant au niveau du cholestérol présent dans la membrane plasmique. Son action est réversible, il est donc important qu'elle soit présente tout au long de l'expérimentation. Les lavages et les incubations des différents anticorps avec les cellules s'effectueront donc dans ce même tampon contenant la saponine. Le marquage des 
cellules fixées et perméabilisées est ensuite réalisé comme il l'a été décrit au paragraphe II-J1-1-a

\section{II-K Tampons utilisés.}

Tableau 6 tampons utilisés

\begin{tabular}{|c|c|}
\hline \multicolumn{2}{|l|}{ Biochimie } \\
\hline $\begin{array}{l}\text { Milieu de culture } \\
\text { des chondrocytes }\end{array}$ & $\begin{array}{l}\text { DMEM SVF } 10 \% \text {, L-Glutamine } 2 \mathrm{mM} \text {, pénicilline streptomycine } \\
(50 \mu \mathrm{l} / \mathrm{ml})\end{array}$ \\
\hline EBSS (1X) & Earle’s Balanced Salt Solution (EBSS) (1X) \\
\hline $\begin{array}{l}\text { Milieu de culture } \\
\text { des LB-EBV }\end{array}$ & RPMI 1640, L-Glutamine $2 \mathrm{mM}$ pénicilline streptomycine $(50 \mu \mathrm{l} / \mathrm{ml})$ \\
\hline $\mathrm{PBS}^{(-)}$ & $\mathrm{NaCl} 137 \mathrm{mM}, \mathrm{KCl} 2,7 \mathrm{mM}, \mathrm{KH}_{2} \mathrm{PO}_{4} 1,5 \mathrm{mM}, \mathrm{Na}_{2} \mathrm{HPO}_{4} 8 \mathrm{mM}, \mathrm{pH} 7,3$ \\
\hline $\mathrm{PBS}^{(+)}$ & PBS $^{-}$contenant $\mathrm{CaCl}_{2} 0,9 \mathrm{mM}, \mathrm{MgCl}_{2} 0,5 \mathrm{mM}$ \\
\hline Solution Saline & $\mathrm{NaCl} 2,74 \mathrm{mM} 56 \mathrm{ml}, \mathrm{CaCl}_{2} 18,16 \mathrm{mM}$ 2,75 ml, eau qsp 1 litre \\
\hline $\begin{array}{l}\text { Tampon de lyse } \\
\text { hypotonique }\end{array}$ & $\mathrm{NH}_{4} \mathrm{Cl} 155 \mathrm{mM}, \mathrm{KHCO}_{3} 10$ mM, EGTA 0,1 mM, pH 7,4 \\
\hline $\begin{array}{l}\text { Mélange d'inhibiteurs } \\
\text { de protéases }\end{array}$ & TLCK $10 \mu \mathrm{M}$, PMSF $1 \mathrm{mM}$, leupeptine $1,8 \mu \mathrm{M}$, pepstatine $1,5 \mu \mathrm{M}$ \\
\hline $\begin{array}{l}\text { Sample Buffer" 10X } \\
\text { pour les protéines }\end{array}$ & $\begin{array}{l}2,1 \mathrm{ml} \text { de Tris-HCl } 3 \mathrm{M} \text { pH } 6,7,2 \mathrm{~g} \text { SDS, } 2 \mathrm{ml} \text { Bleu de bromophénol à } \\
0,2 \% \text {, sucrose } 50 \%, 0,5 \mathrm{ml} \text { EDTA } 200 \mathrm{mM} \mathrm{pH} 7 \text {, eau qsp } 10 \mathrm{ml}\end{array}$ \\
\hline Tampon de migration & Tris $25 \mathrm{mM}$, glycine $192 \mathrm{mM}$, SDS $0,1 \%(\mathrm{p} / \mathrm{v}), \mathrm{pH} 8,8$ \\
\hline $\begin{array}{l}\text { Colorant des gels SDS- } \\
\text { PAGE }\end{array}$ & $\begin{array}{l}\text { solution de bleu de Coomassie R250 0,25\% (p/v), méthanol 50\% (v/v), } \\
\text { acide acétique } 10 \%(\mathrm{v} / \mathrm{v}) \text {. }\end{array}$ \\
\hline Décolorant & acide acétique à $8 \%(\mathrm{v} / \mathrm{v})$, éthanol $27 \%(\mathrm{v} / \mathrm{v})$ \\
\hline $\begin{array}{l}\text { Tampon de transfert } \\
\text { semi-sec }\end{array}$ & $\begin{array}{l}\text { Tris } 25 \mathrm{mM} \text {, glycine } 129 \mathrm{mM} \text {, SDS } 0,01 \%(\mathrm{p} / \mathrm{v}) \text {, éthanol 10\% }(\mathrm{v} / \mathrm{v}), \mathrm{pH} \\
8,3) \text {. }\end{array}$ \\
\hline TBS & Tris-HCl 50 mM, NaCl 150 mM, pH 7,5 \\
\hline Assay Buffer & Tris- $\mathrm{HCl} 0,1 \mathrm{M}, \mathrm{NaCl} 0,1 \mathrm{M}, \mathrm{MgCl}_{2} 5 \mathrm{mM}$ \\
\hline \multicolumn{2}{|l|}{ Biologie Moléculaire } \\
\hline TAE 1X & 40 mM Tris-acétate, 1 mM EDTA, $\mathrm{pH} 8,0$ \\
\hline Sample Buffer $5 X$ & glycérol $30 \%$, bleu de bromophénol $0,25 \%$, xylène-cyanol FF $0,25 \%$ \\
\hline TBE $1 \mathrm{X}$ & $90 \mathrm{mM}$ Tris-Borate, 2 mM EDTA pH 8 \\
\hline TE & Tris $10 \mathrm{mM}$, EDTA $1 \mathrm{mM} \mathrm{pH} 8$ \\
\hline SSC X20 & $\mathrm{NaCl} 3 \mathrm{M}$, Citrate de sodium $0,3 \mathrm{M}$ pH 7 \\
\hline Tampon de lyse & Tris $50 \mathrm{mM}$ pH 7.5, $\mathrm{NaCl} 50 \mathrm{mM}, \mathrm{MgCl}_{2} 5 \mathrm{mM}$, DTT $1 \mathrm{mM}$ \\
\hline Tampon Urée $8 \mathrm{M}$ & Urée, 8 M, Tris-HCl, pH 7,5, 100 mM, DTT 5 mM, EDTA 2 mM \\
\hline Tampon glutathion & $\begin{array}{l}\text { Tris- } \mathrm{HCl} 50 \mathrm{mM} \mathrm{pH} 8, \mathrm{NaCl} 150 \mathrm{mM}, \mathrm{MgCl}_{2} 5 \mathrm{mM} \text {, DTT } 1 \mathrm{mM} \text {, le } \\
\text { pH est ajusté à } 7.5\end{array}$ \\
\hline Tampon facteur Xa & Tris $50 \mathrm{mM} \mathrm{pH} \mathrm{8,} \mathrm{NaCl} 150 \mathrm{mM}, \mathrm{CaCl}_{2} 2,5 \mathrm{mM}$ ajuster le $\mathrm{pH}$ à 8 \\
\hline Tampon thrombine & $\begin{array}{l}\text { Tris pH } 850 \mathrm{mM}, \mathrm{NaCl} 150 \mathrm{mM}, \mathrm{CaCl}_{2} 2,5 \mathrm{mM}, \mathrm{MgCl}_{2} 5 \mathrm{mM} \text {, DTT } 1 \\
\text { mM, ajuster le pH à 8) }\end{array}$ \\
\hline
\end{tabular}


Résultats

RESULTATS 
Résultats

\section{RESULTATS :}

Les résultats de ce travail s'articulent selon quatre grands chapitres :

- Analyse du phénotype en terme de Nox et de leurs partenaires au niveau transcriptionnel et protéique dans un modèle cellulaire de chondrocyte et phénotype en terme de métalloprotéase et TIMP.

- Mesure de l'activité NAD(P)H oxydase dans les trois lignées cellulaires sur cellules entières ou en systèmes acellulaires.

- Niveau d'expression de la pro-MMP-1 sous un stress cytokinique hIL-1 $\beta$ dans la lignée C-20/A4.

- Rôle de Nox 4 sur la régulation de cette expression.

\section{III-A Analyse phénotypique en terme de Nox et de leurs partenaires au niveau transcriptionnel et protéique dans un modèle cellulaire de trois lignées de chondrocytes (C-20/A4, T/C- 28a2 et C-28//2) :}

L'objectif de cette première partie est de faire une cartographie phénotypique exhaustive au niveau protéique et transcriptionnel des différentes Nox existantes (Nox1, Nox2 ou gp91 ${ }^{\text {-phox }}$, Nox 3, Nox4 et, Nox5), ainsi que leurs partenaires (p22 $2^{-p h o x}, \mathrm{p} 40^{\text {-phox }}, \mathrm{p} 47^{- \text {phox }}, \mathrm{p} 67^{- \text {phox }}$, Rac2) dans ces lignées de chondrocytes.

\section{III-A-1 Au niveau transcriptionnel :}

Les amorces utilisées sont détaillées dans le tableau 4 du paragraphe II-E-2 du chapitre « matériels et méthodes ». 


\section{III-A-1-a Analyse par RT-PCR :}

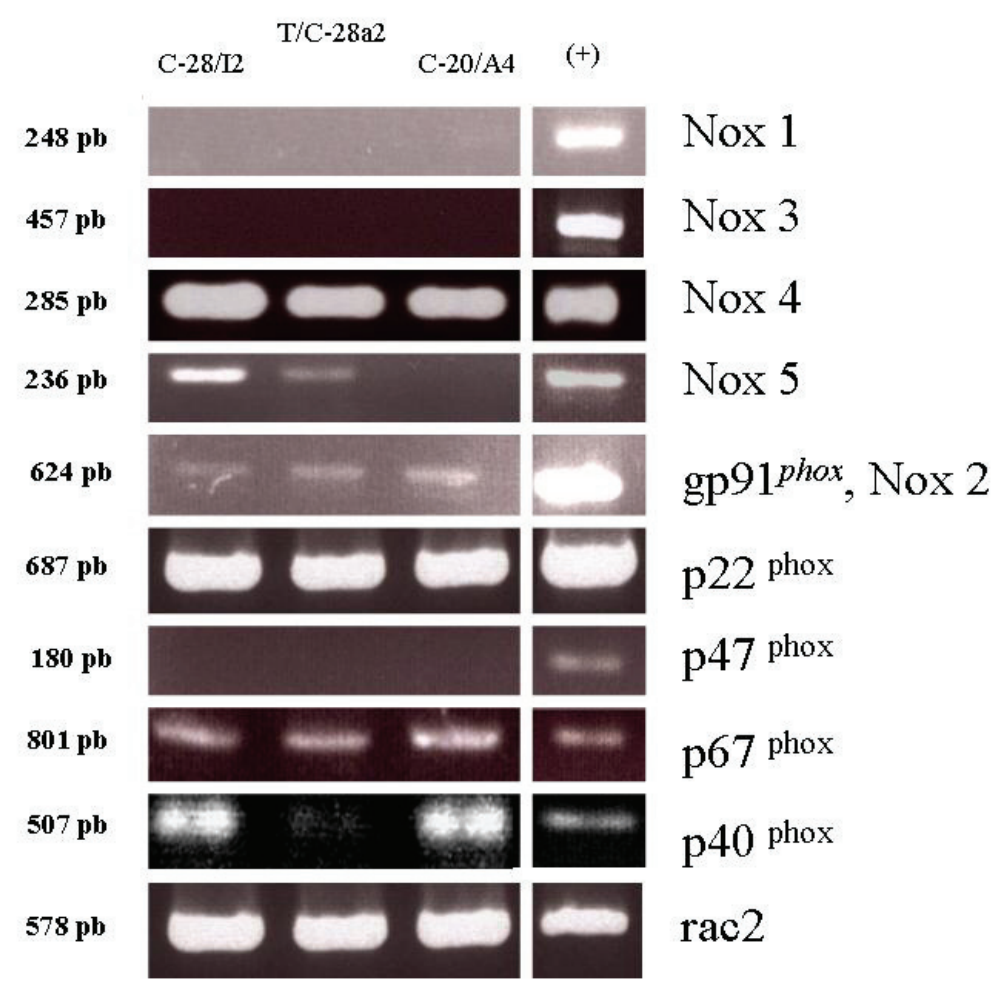

Figure 29 Analyse transcriptionelle par RT-PCR de l'expression des Nox et de leurs partenaires sur les lignées C-20/A4, T/C-28a2, C-28/I2.

L'ARN est extrait des lignées chondrocytaires C-20/A4, T/C-28a2, C-28/I2, pour réaliser une PCR comme décrit dans le chapitre matériel et méthodes. Des amorces spécifiques (cf. Tableau 4) sont utilisées pour étudier l'expression transcriptionelle de Nox2, p22 $2^{\text {-phox }}, \mathrm{p} 40^{\text {phox }}, \mathrm{p} 47^{\text {-phox }}, \mathrm{p} 67^{\text {-phox }}$, rac2 et enfin Nox1, Nox3, Nox4 et Nox5. $(+)=$ témions positifs.

L'ARN a été extrait des différentes lignées par la méthode utilisant le TRIzol ${ }^{\circledR}$ et transcrit en ADNc par RT (voir matériels et méthodes). Puis la mise en évidence de la présence de l'ARNm codant pour les différentes Nox (Nox1, Nox2, Nox3, Nox4, Nox5) et leurs partenaires (p22 $2^{\text {phox }}, \mathrm{p} 40^{\text {phox }}, \mathrm{p} 47^{\text {phox }}, \mathrm{p} 67^{\text {phox }}$ et la protéine G Rac2) a été effectuée par PCR sur l'ADNc grâce à des amorces correspondant à leurs séquences spécifiques (voir matériels et méthodes).

Nous avons utilisé comme témoins positifs une lignée de LB-EBV ou de PLB985 et aussi des plasmides exprimant Nox3 ou Nox5. Toutes les PCR ont été validées en vérifiant en parallèle la présence du gène de ménage G3PDH (résultat non montré). 
Résultats

Nous notons la présence de l'ARNm de Nox2 dans les trois lignées de chondrocytes et de ses partenaires $\mathrm{p} 22^{\text {phox }}, \mathrm{p} 40^{\text {phox }}, \mathrm{p} 67^{\text {phox }}$ et de la protéine $\mathrm{G}$ monomérique Rac2. Par contre la présence de l'ARNm de Nox1, Nox3 et de p4 $7^{\text {phox }}$ n'a pas été mise en évidence (Figure 29).

Seule la lignée C-20/A4 n'exprime pas au niveau transcriptionnel Nox5, par opposition aux deux autres lignées étudiées (C-28/I2 et T/C-28a2), qui elles, l'expriment bien. Ceci est probablement lié au fait qu'elles sont issues de la même lignée originelle ce qui n'est pas le cas de C-20/A4 (Goldring et coll. 2004).

Enfin nous démontrons pour la première fois la présence de 1'ARNm de Nox4 dans les trois lignées de chondrocytes.

\section{III-A-1-b Analyse par séquençage des gènes incriminés :}

Afin de vérifier la spécificité des amplifications obtenues par RT-PCR, nous avons séquencé les $\mathrm{ADNc}$ d'intérêt présents dans les trois lignées en utilisant le kit "sephaglass ${ }^{{ }^{\circledR}}$ (Pharmacia) :

Le Tableau 7 récapitule les résultats du séquençage et des RT-PCR pour les trois lignées en ce qui concerne les Nox et leurs partenaires; ainsi les colonnes « RNA » et «SEQ» représentent respectivement les résultats des RT- PCR et des séquençages.

Tableau 7 Synthèse des résultats de séquençage

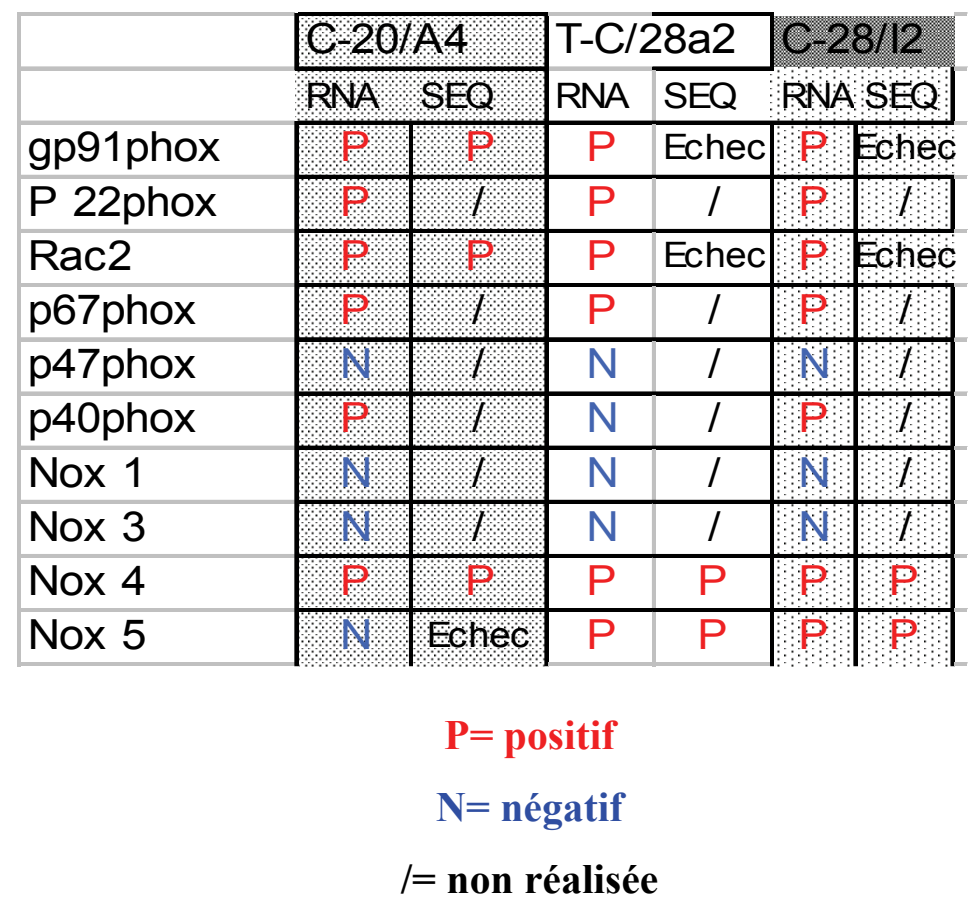


Résultats

Compte tenu du coût de ces techniques nous n'avons pas séquencé tous les gènes étudiés et nous avons sélectionné les plus pertinents pour notre travail.

Il faut signaler des échecs dans un certain nombre de cas notamment pour Nox5 dans C20/A4 et gp91 ${ }^{\text {phox }}$ et Rac2 dans C-28/I2 et T/C-28a2. Il est toutefois intéressant de signaler la présence évidente de Nox4 vérifiée par RT-PCR et par séquençage du gène, dans les trois lignées. Enfin si l'on s'intéresse à la lignée C-20/A4 nous notons la présence à la fois de l'ADNc codant pour gp91 ${ }^{\text {phox }}$ d'une part et pour Nox4 d'autre part.

\section{III-A-2 Au niveau protéique :}

Nous avons réalisé par la suite, une cartographie phénotypique des protéines d'une part des différentes Nox (Nox1, Nox2 ou gp91 ${ }^{\text {-phox }}$, Nox 3, Nox4 et, Nox5) présentes dans les lignées de chondrocytes, et d'autre part de leurs partenaires (p22-phox $, \mathrm{p} 40^{-\mathrm{phox}}, \mathrm{p} 47^{- \text {phox }}, \mathrm{p} 67^{- \text {phox }}$, Rac2).

\section{III-A-2-a Analyse par western blot:}

Après avoir préparé, selon le protocole détaillé dans le chapitre matériels et méthodes, le cytosol et les membranes des cellules d'intérêt (chondrocytes des différentes lignées étudiées et les cellules témoins comme les lymphocytes B immortalisés LB-EBV et les polynucléaires neutrophiles humains), nous avons réalisé une détection immunochimique (western blot) afin de mettre en évidence Nox 2 et ses partenaires. Pour ce faire nous avons déposé $100 \mu \mathrm{g}$ par puit de la fraction cytosolique ou membranaire, et nous avons utilisé des anticorps spécifiques détaillés dans le tableau 5 de la section II-G du chapitre «Matériels et Méthodes». 


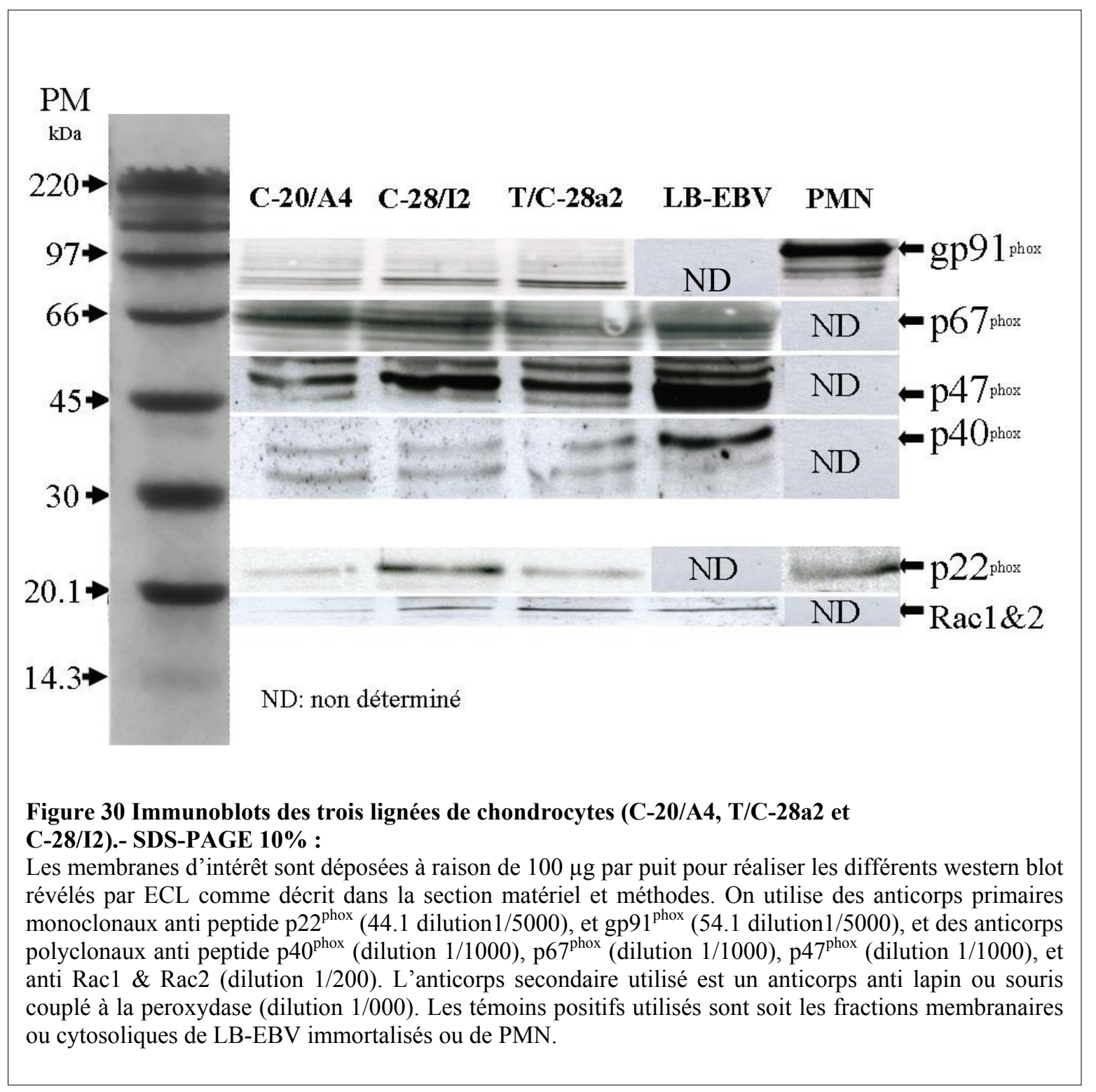

Nous démontrons au niveau protéique la présence de $\mathrm{p} 22^{\text {phox }}, \mathrm{p} 67^{\text {phox }}$, ainsi que Rac $1 / 2$ (Figure 30). Par contre les résultats concernant $\mathrm{p} 40^{\text {phox }}$ et $\mathrm{p} 47^{\text {phox }}$ sont plus difficiles à interpréter. Enfin, pour Nox2 nous n'avons pas pu mettre en évidence de manière certaine sa présence (nous avons mis en évidence au niveau des trois lignées de chondrocytes une bande dont le poids moléculaire est en dessous de celui attendu). Nous avons complété ces expériences avec des anticorps monoclonaux dirigés contre gp91 ${ }^{\text {-phox }}$ et ciblant un autre épitope (NL7) mais, sans succès (résultats non montrés).

Pour éliminer un état de glycosylation différent pouvant expliquer cette différence de poids moléculaire obtenue, nous avons déglycosylé (par traitement avec une N-Glucosidase F) des fractions membranaires de ces cellules (avant dépôt), mais les résultats obtenus ne sont pas meilleurs (résultats non montrés). 
Résultats

A partir de ces expériences préliminaires nous avons fait le choix de la lignée C-20/A4 (car à la différence des deux autres lignées, elle n'exprime que Nox4 et Nox2 à l'exclusion des autres Nox recherchées).

Pour poursuivre notre travail nous avons utilisé une approche de détection des protéines Nox plus sensible par cytométrie de flux.

\section{III-A-2-b Analyse par cytométrie en flux :}

Cette technique a permis de confirmer la présence de la protéine $\mathrm{p} 22^{\text {phox }}$ au niveau des chondrocytes. En effet après perméabilisation des cellules par de la saponine $0.01 \%(\mathrm{w} / \mathrm{v})$, nous assistons à une augmentation significative du marquage par 1'anticorps anti-p22 $2^{\text {phox }}$ (44.1) (Figure.31a) dirigé contre un épitope intra cellulaire de p22 ${ }^{\text {phox }}$ [démontré sur les polynucléaires neutrophiles humains (Roos et coll. 2004)]. Ce marquage ne se retrouve pas sur les chondrocytes entiers non perméabilisés confirmant la situation cytosolique de l'épitope reconnu par l'anticorps 44.1 anti p22 $2^{\text {phox }}$ dans le chondrocyte, comme dans les PMN humains (Ross et coll. 2004) (Figure. 31d).

Par cette même technique, nous démontrons et confirmons la présence de la protéine gp91 ${ }^{\text {phox }}$ (Nox2). En effet en utilisant 1'anticorps 7D5 anti-gp91 ${ }^{\text {phox }}$ nous voyons augmenter le signal du marquage de manière faible mais significative, uniquement sur les cellules perméabilisées par la saponine $0.01 \%$ (w/v) (Figure.31c, 31d), suggérant que cet épitope n'est pas accessible sur les cellules entières non perméabilisées. Comme l'anticorps 7D5 anti gp91 ${ }^{\text {phox }}$ (Nox2) reconnaît classiquement un épitope extracellulaire de cette protéine sur les PMNs (Burrit et col. 2001), ces résultats suggèrent que la protéine gp91 ${ }^{\text {phox }}$ du complexe NAD(P)H oxydase, aurait une localisation différente (intra cellulaire) dans les chondrocytes de la lignée C-20/A4 par rapport aux PMN humains. 


\section{p22phox $\mathrm{Ab}$}

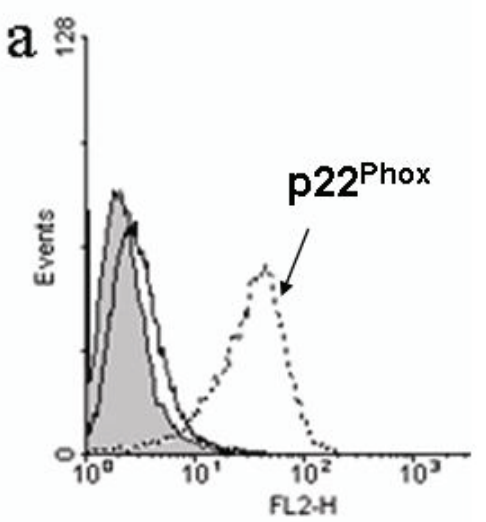

gp91 ${ }^{\text {phox }} \mathrm{Ab}(7 \mathrm{D} 5)$

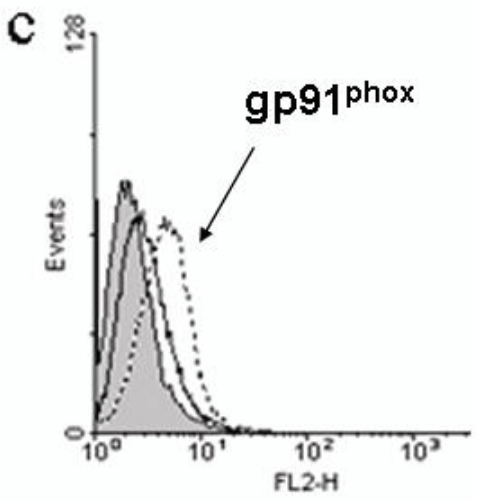

Nox4 504

b

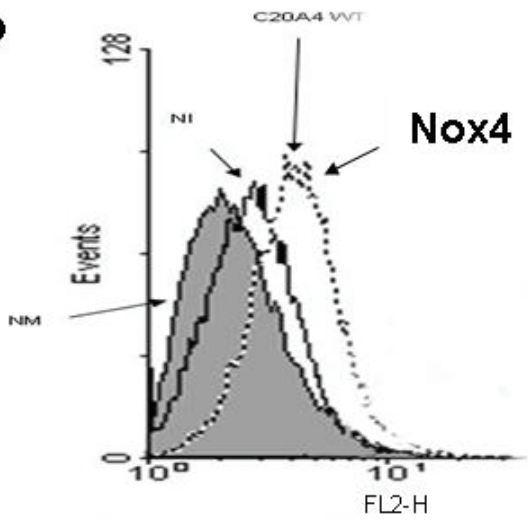

d

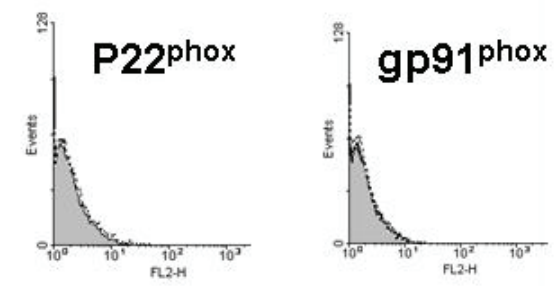

Nox4

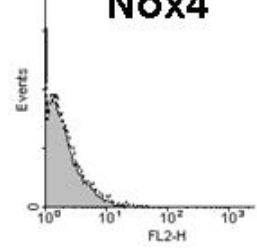

Figure 31 Analyse de l'expression protéique de Nox4, gp91 ${ }^{\text {phox }}$ et p22 $^{\text {phox }}$ par cytométrie en flux sur la lignée C-20/A4

$5 \times 10^{5}$ chondrocytes sont fixés avec $1 \%(\mathrm{w} / \mathrm{v})$ de paraformaldéhyde et marqués avec les anticorps monoclonaux anti-p22 $2^{\text {phox }}(44.1)$, anti-gp91 ${ }^{\text {phox }}(7 \mathrm{D} 5)$ et un anticorps polyclonal anti-Nox4 (504) sans perméabilisation (d) ou après perméabilisation par la saponine $(\mathrm{a}, \mathrm{b}, \mathrm{c})$ comme décrit dans le chapitre Matériels et Méthodes ; les anticorps sont tous utilisés à la concentration de $5 \mu \mathrm{g} / 5 \times 10^{5}$ cellules. Enfin l'anticorps secondaire est un anticorps conjugué à la phycoerythrine (dilution 1:200). La zone grise correspond aux cellules incubées sans anticorps primaires. Le trait noir plein correspond aux cellules incubées avec l'anticorps non immun SIGMA (5 $\left.\mathrm{gg} / 5 \times 10^{5} \mathrm{cellules}\right)$.

Enfin nous mettons en évidence pour la première fois la protéine Nox4 dans les chondrocytes perméabilisés de la lignée C-20/A4 (Figure. 31b, Figure.31d). Ceci confirme une localisation intracellulaire de l'épitope de Nox4 reconnu par l'anticorps « $504 »$. En effet, cet anticorps anti Nox4 fabriqué dans le laboratoire est un anticorps antipeptide polyclonal (résidus: KVPSRRTRRLLDKSR) issu de lapin qui reconnaît un épitope situé sur la deuxième boucle en position intracellulaire de la protéine Nox4 (cf. tableau 5 du chapitre matériels et méthodes). Il faut souligner les très faibles quantités de Nox2 et Nox 4 mises en évidence par cytométrie de flux, ce qui peut expliquer les résultats négatifs obtenus par western blot. Il est enfin intéressant de souligner que pour la première fois nous démontrons la présence de Nox4 dans les chondrocytes. 
Résultats

Pour confirmer l'existence d'un complexe NAD(P)H oxydase dans la lignée C-20/A4 nous allons essayer de démontrer par spectrophotométrie différentielle la présence du cytochrome $\mathrm{b}_{558}$.

\section{III-A-2-c Analyse par étude du spectre différentiel redox du cytochrome $b_{558}$ :}

Une fraction aliquotée $(0,5 \mathrm{mg} / \mathrm{ml})$ d'un extrait Triton X $1001 \%$ des membranes des cellules (C-20/A4, T/C-28a2 et C-28/I2 et des PMNs), est utilisée pour analyser le spectre différentiel redox du cytochrome $b_{558}$, selon le protocole décrit dans le chapitre matériels et méthodes.

Les résultats montrent sur la Figure 32 deux des trois bandes spécifiques à $426 \mathrm{~nm}$ et $558 \mathrm{~nm}$ correspondant à la signature caractéristique du cytochrome $b_{558}$ au niveau de chacun des spectres et confirment la présence d'un cytochrome de type b dans chacune des trois lignées C-20/A4, T/C-28a2 et C-28/I2 (Figure. 32), pouvant confirmer les observations illustrées par western blot et cytométrie en flux.

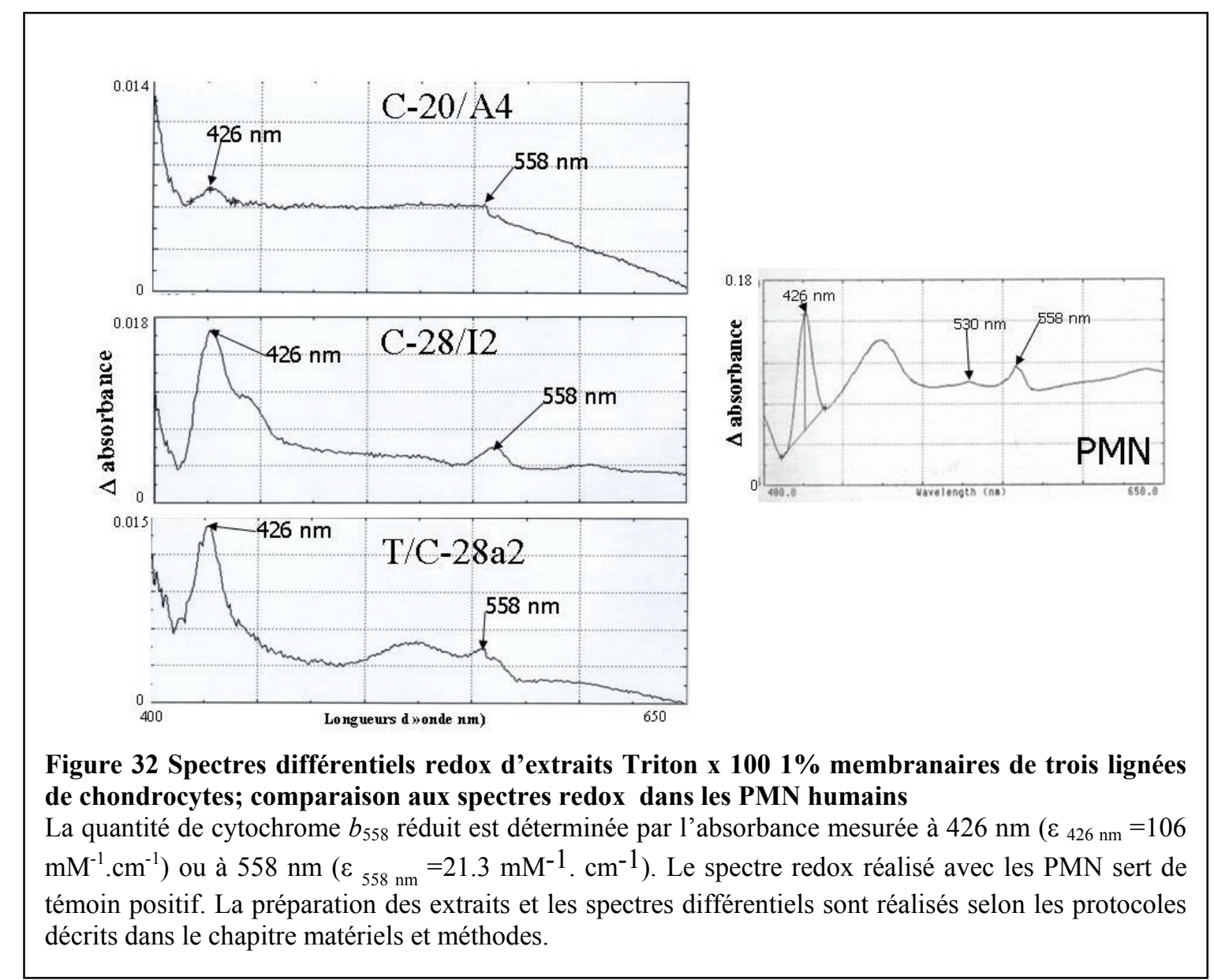


Résultats

Les résultats sont à interpréter avec précaution compte tenu de la présence éventuelle du cytochrome b mitochondrial.

On peut donc résumer les résultats observés dans le tableau ci-dessous :

Tableau 8 Synthèse du phénotype des cellules de la lignée C-20/A4

\begin{tabular}{|c|c|c|c|c|c|c|c|c|c|c|}
\hline $\mathrm{C}-20 / \mathrm{A} 4$ & Nox1 & Nox2 & Nox3 & Nox4 & Nox 5 & $\mathrm{p} 22^{\mathrm{phox}}$ & p 4070hox & p47phox & $\mathrm{p} 6 \mathrm{Tp}^{\mathrm{phox}} \mathrm{Y}$ & Rac2 \\
\hline Transcriptionnel & - & $\sqrt{ }$ & - & $\sqrt{ }$ & - & $\sqrt{ }$ & $\sqrt{ }$ & - & $\sqrt{ }$ & $\sqrt{ }$ \\
\hline Protéique & - & $\sqrt{ }$ & - & $\sqrt{ }$ & - & $\sqrt{ }$ & $\sqrt{ }$ & $\sqrt{ }$ & $\sqrt{ }$ & $\sqrt{ }$ \\
\hline
\end{tabular}

On note donc la présence de Nox2 et Nox4 ainsi que leurs partenaires notamment p22 $2^{\text {phox }}$ le partenaire privilégié des oxydases Nox1, 2, 3 et Nox4. Il faut signaler les difficultés rencontrées pour mettre en évidence l'ARNm et la protéine de $\mathrm{p} 47^{\text {phox }}$, contrairement aux résultats rapportés par Moulton et coll. (Moulton et coll. 1997). Nous pouvons donc penser que l'ARNm de $\mathrm{p} 47^{\text {phox }}$ à une demi-vie trop courte ou que les quantités extrêmement faibles de cet ARNm ne permettent pas de révéler la présence de l'ADNc après RT-PCR.

On peut aussi envisager que la protéine $\mathrm{P} 47^{\text {phox }}$ n'est pas présente dans notre lignée cellulaire. Si Nox 2 et Nox4 sont présents, qu'en est-il de la production des dérivés radicalaires de l'oxygène?

Pour la suite des expériences seule la lignée C-20/A4.sera utilisée

\section{III-B La mesure d'activité $N A D(P) H$ oxydase sur les chondrocytes :}

Existe-t-il une production d' $\mathrm{O}_{2}{ }^{-}$par les chondrocytes?

Pour répondre à cette question nous allons utiliser différentes techniques :

- Mesure de l'activité NAD(P)H oxydase par chimioluminescence sur cellules entières

- Mesure de l'activité NAD(P)H oxydase reconstituée en milieu acellulaire avec le système hétérologue «Membrane de chondrocyte / cytosol de neutrophiles humains » par réduction du cytochrome $c$. 
Résultats

\section{III-B-1 Dosage de l'activité NAD(P)H oxydase par la méthode de chimioluminescence sur cellules entières :}

Nous avons adopté la méthodologie utilisée avec les neutrophiles humains (Vergnaud et coll. 2000).

La stimulation des PMNs par un ligand soluble ou particulaire conduit à la production d'ions superoxyde $\mathrm{O}_{2}^{-}$. Les ions superoxyde sont ensuite dégradés dans une réaction de dismutation catalysée par la superoxyde dismutase (SOD), et aboutissant à la formation de peroxyde d'hydrogène :

$$
2 \mathrm{H}^{+}+2 \mathrm{O}_{2}^{-} \rightarrow \mathrm{H}_{2} \mathrm{O}_{2}+\mathrm{O}_{2}
$$

Le peroxyde d'hydrogène en présence de luminol et d'une peroxydase génère l'émission de photons qui seront quantifiés dans un luminomètre (Luminoscan ${ }^{\circledR}$ labsystem) avec une mesure toutes les 30 secondes; la somme des RLU est quantifiée après 1 heure 30 d'expérimentation.

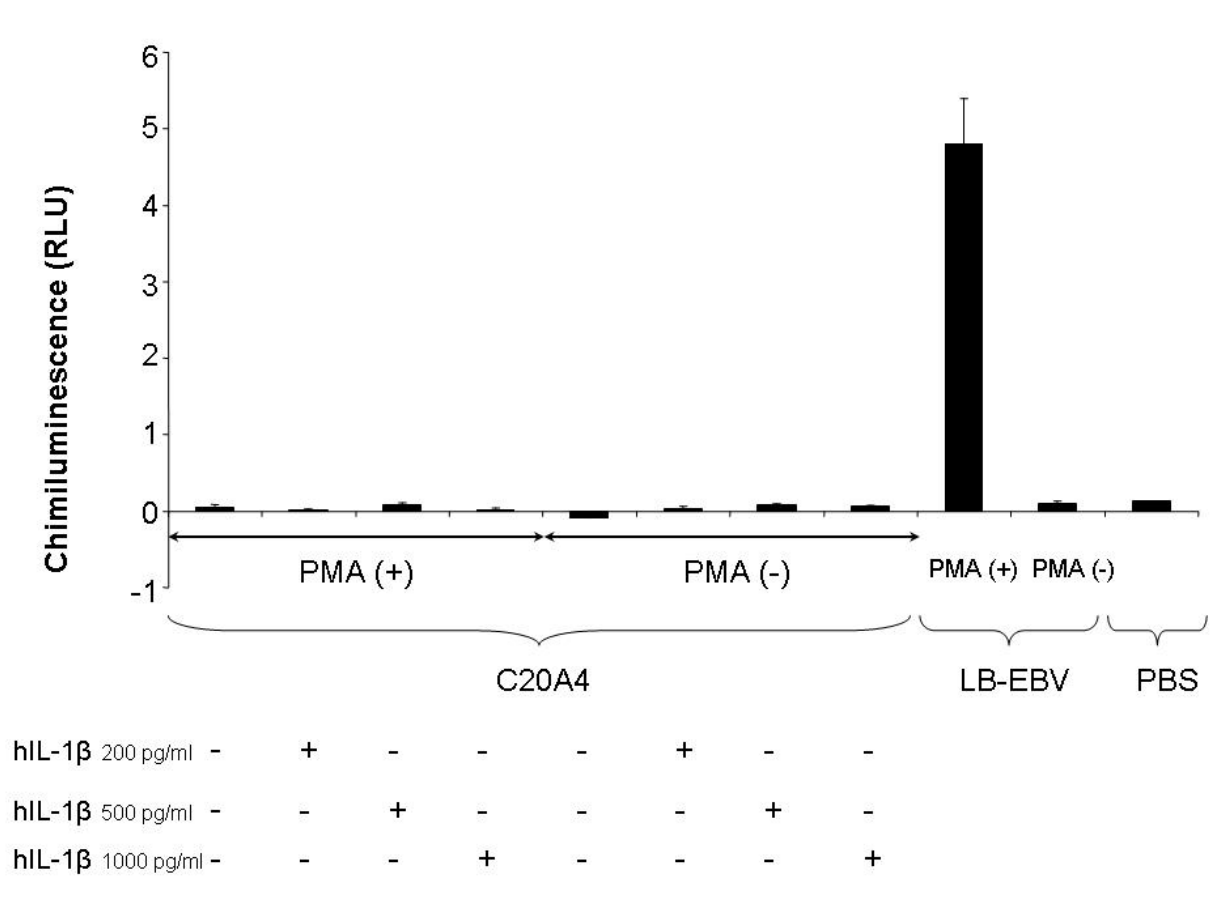

Figure 33 Dosage de l'activité oxydase par chimioluminescence sur cellules entières de la lignée C-20/A4

La production totale d $^{\prime} \mathrm{H}_{2} \mathrm{O}_{2}$ est mesurée à partir de $5 \times 10^{5}$ cellules entières après incubation par différentes concentrations hIL1- $\beta(200,500,1000 \mathrm{pg} / \mathrm{ml})$.

La somme des RLU est calculée après 1 heure 30 de lecture avec une mesure toutes les 30 secondes selon la technique et les conditions décrites dans le chapitre " matériels et méthodes »

Les chondrocytes et les LB-EBV ont été stimulés (ou non) par du PMA à $2 \mu \mathrm{g} / \mathrm{ml}$ en présence ou non de différentes concentrations d'hIL1-ß. Les LB-EBV utilisés dans les mêmes conditions ont servi de témoins (+). Les résultats sont exprimés par la moyenne de la somme des RLU (valeurs obtenues dans chaque condition). Les valeurs dans cette figure représentent la moyenne +/- SD de trois déterminations obtenues le même jour. 
Résultats

Compte tenu d'une production $\mathrm{d}^{\prime} \mathrm{O}_{2}{ }^{-}$extrêmement faible par les chondrocytes nous les avons stimulés par un stress cytokinique (IL1- $\beta$ humain) à différentes concentrations pour essayer de mettre en évidence une production d' $\mathrm{O}_{2}{ }^{-}$.

Ainsi $5 \times 10^{5}$ chondrocytes remis en suspension dans $50 \mu 1$ de PBS $^{-}$, sont plongés dans $200 \mu 1$ de milieu commun contenant $25 \mu 1$ de glucose $0.8 \mathrm{M}, 10 \mu 1$ de luminol 2mM (20\% DMSO), $20 \mu \mathrm{l}$ d'HRPO $500 \mathrm{U} / \mathrm{ml}$ et $945 \mu 1$ de PBS $^{(-)}$et incubés dans le luminomètre pendant 1 minute à $37^{\circ} \mathrm{C}$. La réaction est initiée par $10 \mu 1$ de PMA à $2 \mu \mathrm{g} / \mathrm{ml}(10 \% \mathrm{DMSO})$. L'émission de photons est suivie pendant 1 heure 30 avec une mesure toutes les trente secondes (500 itérations par secondes). La somme des RLU (Relative Luminescent Unit) est calculée dans les conditions déterminées dans le chapitre matériels et méthodes.

Nous ne représentons ici que les résultats obtenus avec les chondrocytes de la lignée C-20/A4 (Figure 33) Ils montrent que quel que soit le mode de stimulation, il n'y a pas de production significative d'O2' et de $\mathrm{H}_{2} \mathrm{O}_{2}$ dans les conditions utilisées. L'addition de PMA est sans effet, éliminant donc ici l'implication de Nox2.

\section{III-B-2 Mesure de l'activité NAD(P)H oxydase après reconstitution en milieu acellulaire :}

Depuis 1984, le complexe NAD(P)H oxydase des phagocytes peut être reconstitué et activé en milieu acellulaire (Heynemann et coll. 1984 ; Bromberg et coll. 1984) en incubant une fraction membranaire contenant le cytochrome $b_{558}$ des cellules non stimulées avec le cytosol contenant les facteurs cytosoliques de l'oxydase de ces mêmes cellules, et un agent amphiphile, l'acide arachidonique.

Cette technique a été validée avec les PMNs et les lymphocytes B. L'utilisation de cette approche expérimentale avec les chondrocytes aurait pour but de déverrouiller un système $\mathrm{NAD}(\mathrm{P}) \mathrm{H}$ oxydase qui fonctionne à très faible niveau dans les cellules intactes. Dans l'expérience, le système de reconstitution hétérologue est composé de la membrane plasmique des chondrocytes et du cytosol de PMN humains (cellules respectivement non stimulées). L'activité oxydase sera mesurée par réduction du cytochrome $c$ selon le protocole (décrit dans le chapitre matériels et méthodes). Une fraction aliquotée de la suspension membranaire des chondrocytes contenant le cytochrome $b_{558}$ est incubée avec le cytosol des PMNs contenant les facteurs d'activation, du GTP $\gamma \mathrm{S}$, du magnésium, et un agent amphiphile un acide gras à longue chaîne polyinsaturée (acide arachidonique) ou le dodécyl sulfate de sodium (SDS). 
Une fois le milieu commun préparé, l'optimum d'acide arachidonique est déterminé pour chaque système utilisé. Nous pouvons alors mesurer l'activité oxydase indirectement par la mesure de la réduction du cytochrome $c$ en présence ou non de superoxyde dismutase, et la cinétique d'activation de l'enzyme est suivie par spectrophotométrie. Seule la réduction du cytochrome $c$ sensible à la superoxyde dismutase (enzyme dismutant les ions superoxyde $\mathrm{O}_{2}{ }^{-}$ en $\mathrm{H}_{2} \mathrm{O}_{2}$ ), sera prise en compte, comme il est décrit dans le chapitre matériels et méthodes L'activité oxydase est alors exprimée en nmol $\mathrm{O}_{2}^{-}$produits / $\mathrm{min} / \mathrm{mg}$ de protéines membranaires.

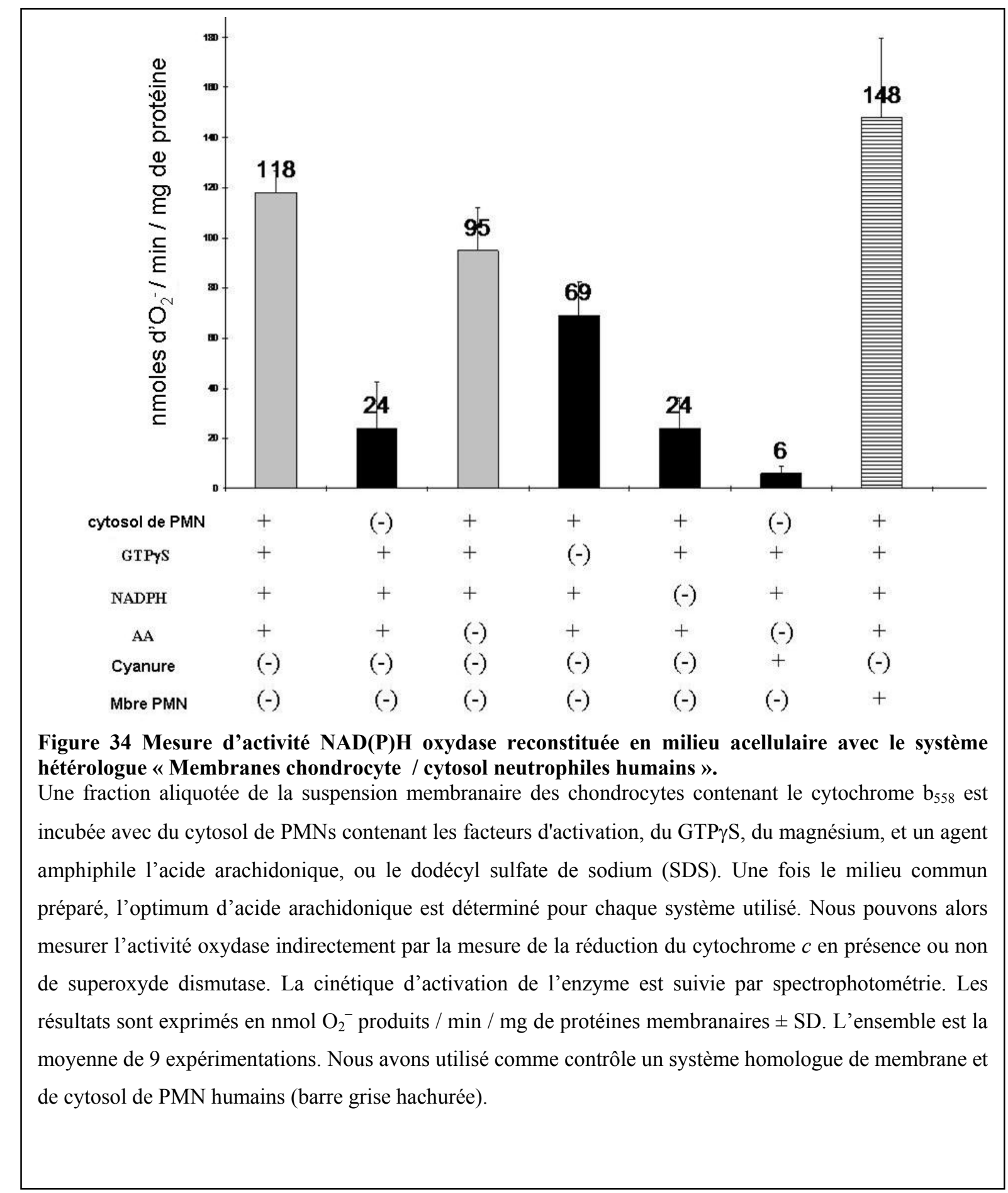


Résultats

Le système hétérologue (membrane de chondrocytes et cytosol de PMN), (Figure 34) permet d'obtenir une reconstitution de l'activité $\mathrm{NAD}(\mathrm{P}) \mathrm{H}$ oxydase intrinsèque des chondrocytes de cette lignée. L'activité NAD(P)H oxydase mesurée par la production de $\mathrm{O}_{2}{ }^{-}$est extrêmement faible, elle est déterminée par la différence d'activité en présence ou en absence d'acide arachidonique (Figure 34).

Nous avons utilisé comme contrôle un système homologue de membrane et de cytosol de PMN humains. Le niveau d'activité $\mathrm{NAD}(\mathrm{P}) \mathrm{H}$ oxydase des membranes de PMN est plus élevé que celui des membranes des chondrocytes ( colonne grise hachurée sur la Figure 34).

Il existe donc une activité $\mathrm{NAD}(\mathrm{P}) \mathrm{H}$ oxydase incontestable mais extrêmement faible dans les chondrocytes, toutes lignées confondues.

Cette activité $\mathrm{NAD}(\mathrm{P}) \mathrm{H}$ semble être dépendante de la présence du cytosol de PMN, de GTP $\gamma \mathrm{S}$ et du complexe $\mathrm{NAD}(\mathrm{P}) \mathrm{H}$ mais indépendante de la présence d'acide arachidonique.

\section{III-C Mesure de l'effet du stress cytokinique par interleukine $1 \beta$ humaine (hIL-1ß) sur l'expression métalloprotéasique :}

Le premier temps a consisté à valider le modèle cellulaire choisi à savoir la lignée C-20/4, en vérifiant sa sensibilité à l'hIL- $\beta$.

Nous nous proposons donc d'estimer la viabilité de ces cellules sous ce stress cytokinique, puis nous allons déterminer le temps d'incubation et la concentration optimale d'hIL- $\beta$ en se focalisant sur l'expression secondaire de la collagenase-1 (la métalloprotéase la plus impliquée dans la physiopathologie de l'arthrose). Le dosage de la MMP-1 après exposition à l'hIL- $\beta$ sera réalisé par méthode ELISA dans le surnageant de milieu de culture.

Enfin nous essayerons également d'estimer l'expression des deux gélatinases la MMP-2 et la MMP-9 après incubation avec l'hIL- $\beta$ par zymographie.

\section{III-C-1 Mise au point et validation de l'expérimentation \\ III-C-1-a Détermination du temps optimal d'incubation en présence hIL- $\beta$ :}

Après mise en suspension des cellules par trypsinisation d'une boîte de $175 \mathrm{~cm}^{2}$, les chondrocytes C-20/A4 sont mis en culture trois jours dans trois boîtes de $75 \mathrm{~cm}^{2}$ en conditions classiques (cf matériels et méthodes) afin d'obtenir une confluence à $90 \%$. Après 
Résultats

trois lavages en EBSS, les cellules sont incubées à $37^{\circ} \mathrm{C}$, et à $5 \%$ de $\mathrm{CO}_{2}$ avec le même milieu de culture mais sans sérum de veau en présence ou non de $500 \mathrm{pg} / \mathrm{ml}$ d'IL-1ß humaine (hIL-1ß). Afin de déterminer le temps optimal d'incubation en présence de hIL-1ß pour avoir la meilleure concentration de pro MMP-1 dans le surnageant de culture, à différents temps ( $\mathrm{T} 0, \mathrm{~T} 6 \mathrm{H}, \mathrm{T} 8 \mathrm{H}$ et $\mathrm{T} 23 \mathrm{H}$ ) le surnageant est récupéré puis, après centrifugation à $350 \mathrm{~g}$ durant 5 min et à température ambiante, il est aliquoté puis congelé pour réaliser par la suite, un dosage ELISA de pro MMP-1 et un dosage protéique selon la méthode de Bradford (cf.schéma simplifié de l'expérience Figure 35).

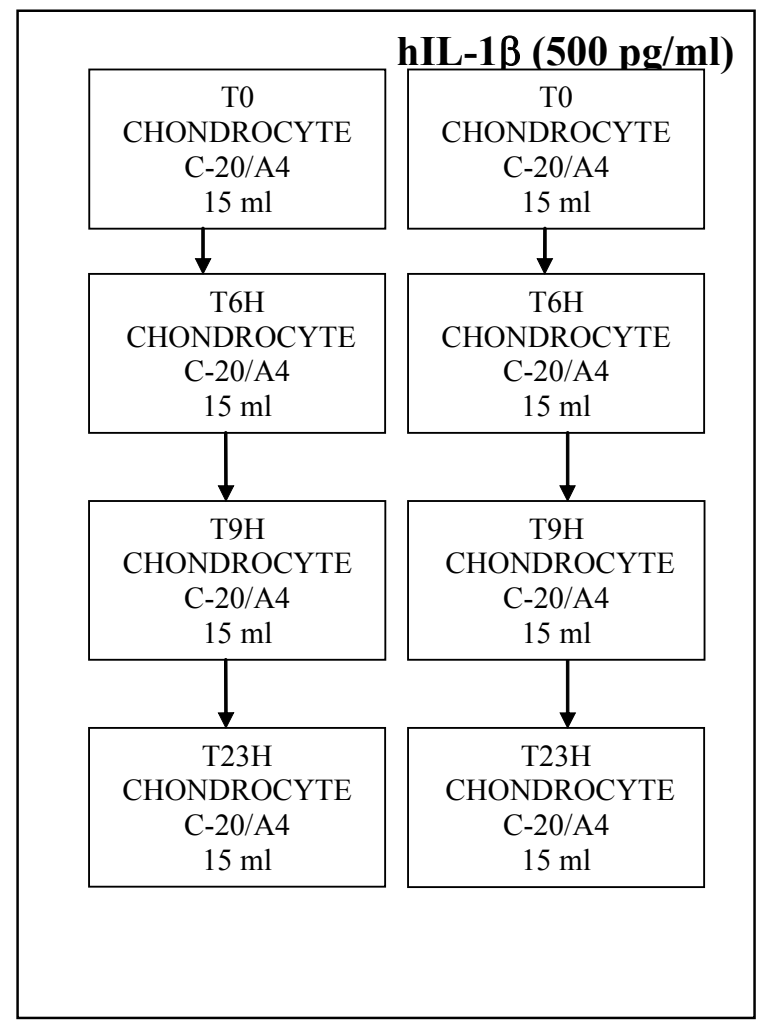

Figure 35 Schéma simplifié de l'expérimentation pour la détermination du temps optimal d'incubation en présence d' hIL1 13. 


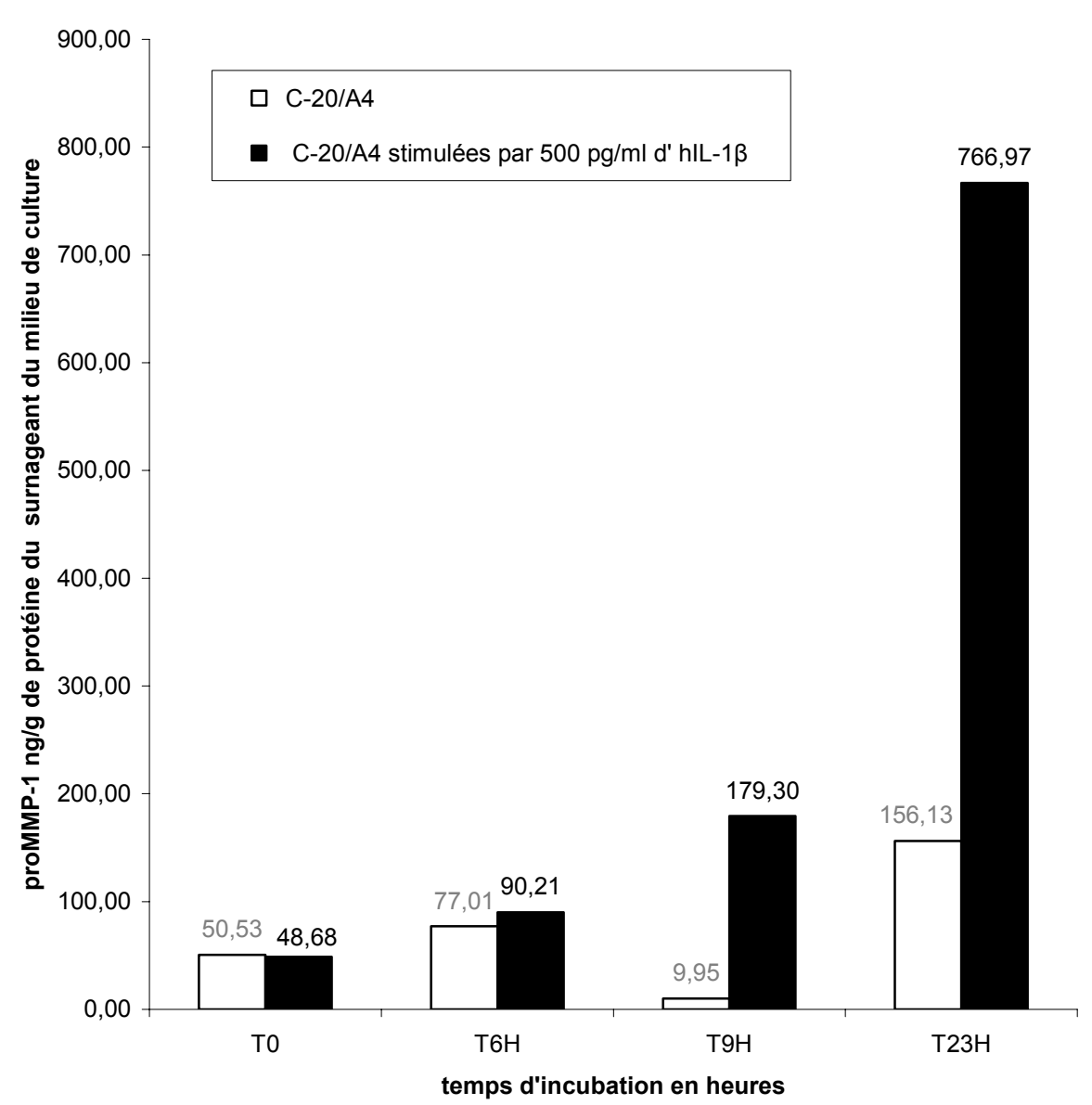

Figure 36 Effet de l'hIL-1ß sur l'expression de la pro MMP-1 dans le surnageant du milieu de culture au cours du temps : détermination du temps optimal d'incubation

Après trois lavages en EBSS les cellules sont incubées à $37^{\circ} \mathrm{C}, 5 \% \mathrm{CO}_{2}$ avec le milieu de culture mais sans sérum de veau en présence ou non de $500 \mathrm{pg} / \mathrm{ml}$ d'IL-1ß humaine (hIL-1ß). A différents temps $(\mathrm{T} 0, \mathrm{~T} 6 \mathrm{H}, \mathrm{T} 8 \mathrm{H}$ et $\mathrm{T} 23 \mathrm{H})$ le surnageant est récupéré puis, après centrifugation $350 \mathrm{~g}$ durant 5 min à température ambiante, on dose la concentration en proMMP-1 par méthode ELISA. Le résultat est exprimé en ng de proMMP-1/g de protéine du surnageant du milieu de culture-(n=1)

Les résultats de l'expérience illustrée sur la figure 36 confirment l'effet de l'hIL-1ß rapporté dans la littérature. On observe en effet dans les chondrocytes (la lignée C-20/A4) une surexpression de la collagenase-1 (pro MMP-1). Ce processus semble dépendre du temps d'incubation avec l'interleukine $1 \beta$. Les résultats montrent une différence dès la $9^{\text {éme }}$ heure en terme de concentration de proMMP-1 dans le surnageant du milieu de culture des cellules incubées avec l' hIL-1ß par rapport aux cellules témoins. L'augmentation de la sécrétion de proMMP-1 semble être maximale à $23 \mathrm{~h}$ d'incubation (Figure 36). Pour la suite de l'expérimentation nous incuberons donc, les cellules pendant $23 \mathrm{~h}$. 
Résultats

Nous avons pour la suite, estimé la viabilité des lignées en présence d'hIL-1ß et en absence de sérum de veau fœtal.

\section{III-C-1-b Etude de la viabilité cellulaire :}

La viabilité des chondrocytes C-20/A4 après $23 \mathrm{~h}$ d'exposition à l'hIL-1 $\beta$ en absence de sérum de veau fœtal est estimée par deux techniques :

- La méthode d'exclusion au bleu trypan (Tableau 9).

- Le dosage de la lactate deshydrogénase (LDH) (Figure 37).

Tableau 9 Viabilité cellulaire après stress cytokinique par hIL-ß après 23 h d'incubation sur la lignée de chondrocytes (C-20/A4) par la méthode d'exclusion au bleu trypan

\begin{tabular}{cccc}
\hline $\begin{array}{c}\text { Test de viabilité } \\
\text { Au bleu trypan à 23h } \\
\text { d'incubation }\end{array}$ & C-20/A4 témoin & $\begin{array}{c}\mathbf{C - 2 0 / A 4 ~ I L - 1 ~ B ~} \\
\mathbf{1 0 0 p g} / \mathbf{m l} \\
\mathbf{n}=\mathbf{5}\end{array}$ & $\begin{array}{c}\mathbf{C - 2 0 / A 4} \mathbf{~ I L - 1 ~ B ~} \\
\mathbf{5 0 0 p g} / \mathbf{m l} \\
\mathbf{n}=\mathbf{5}\end{array}$ \\
$\begin{array}{c}\text { viabilité } \\
\mathbf{a u} \\
\text { bleu trypan \% } \\
\text { écart type }\end{array}$ & 96,32 & 87,79 & 96,10 \\
& $+/-3,1$ & $+/-13,7$ & $+/-2,4$ \\
\hline
\end{tabular}

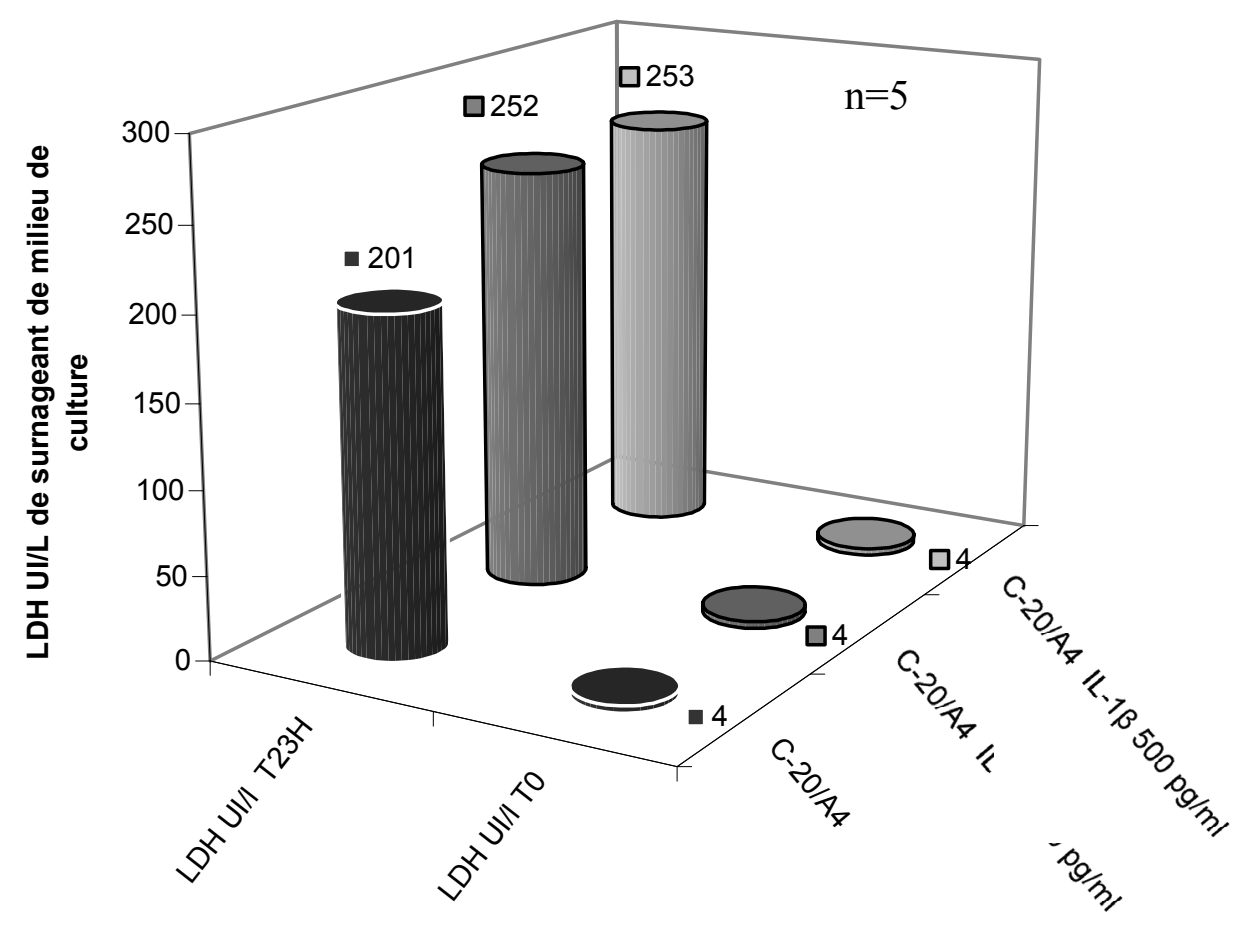

Figure 37 Viabilité cellulaire après stress cytokinique par hIL-ß après $23 \mathrm{~h}$ d'incubation sur la lignée de chondrocytes (C-20/A4) par dosage de la LDH dans le surnageant du milieu de culture à $\mathrm{T} 0$ et à $\mathrm{T} 23 \mathrm{~h}$ en présence de $100 \mathrm{ou} 500 \mathrm{pg} / \mathrm{ml}$ d'hIL-1 $\beta$. Les résultats sont exprimés en UI/l de surnageant de culture (boite de $15 \mathrm{ml})$. $(\mathrm{n}=5)$ 
Résultats

Nous constatons que quelle que soit la technique utilisée (bleu trypan ou dosage de la LDH) la viabilité des cellules C-20/A4 est bonne après $23 \mathrm{~h}$ sans sérum de veau. En effet plus de 96.3\% de cellules restent vivantes (Tableau 9 de viabilité au bleu trypan).

L'incubation avec de l'hIL-1ß pendant $23 \mathrm{~h}$ ne semble pas faire varier de manière significative cette viabilité quelle que soit la concentration d'hIL-1 ß utilisée (100 ou 500 pg/ml).

L'activité de la lactate déshydrogénase mesurée dans le surnageant du milieu de culture confirme ces résultats avec augmentation (de moins de 25\%) de l'activité de la LDH en co incubation avec hIL-1 ß sans différence significative entre les différentes conditions (100 ou $500 \mathrm{pg} / \mathrm{ml} \mathrm{d}$ 'hIL-1ß) $(\mathrm{p}<0,005)$.

Ces résultats sont à confronter à l'activité totale de la LDH retrouvée (13176 UI/L), après lyse par sonication de $2 \times 10^{6}$ cellules correspondant à la quantité moyenne de chondrocytes présents dans une boîte de $75 \mathrm{~cm}^{2}$ en condition de confluence à $100 \%$.

En conclusion, la viabilité après $23 \mathrm{~h}$ d'incubation sans SVF et en présence d'hIL-1 ß même à la dose de $500 \mathrm{ng} / \mathrm{ml}$ reste bonne, nous autorisant à poursuivre les expérimentations.

\section{III-C-1-c Effet de l'hIL-1ß, à 23h d'incubation sur l'expression de la pro-MMP-1 :}

Comme précédemment, après trypsinisation d'une boîte de $175 \mathrm{~cm}^{2}$, les cellules sont mises en culture trois jours dans trois boîtes de $75 \mathrm{~cm}^{2}$ en condition classique (cf. matériels et méthodes) afin d'obtenir une confluence à $90 \%$. Après trois lavages avec la solution d'EBSS, les cellules sont incubées à $37^{\circ} \mathrm{C}$, en présence de $5 \% \mathrm{CO}_{2}$ avec le milieu de culture mais sans sérum de veau en présence ou non de $500 \mathrm{pg} / \mathrm{ml} \mathrm{d}$ 'IL-1ß humaine (hIL-1ß) pendant $23 \mathrm{~h}$.

A T23h on prélève la totalité du milieu de culture, après centrifugation à $350 \mathrm{~g}$ et durant 5 min à température ambiante, le surnageant est aliquoté puis congelé en vue du dosage ELISA de la proMMP-1, et du dosage des protéines par la méthode de Bradford. 


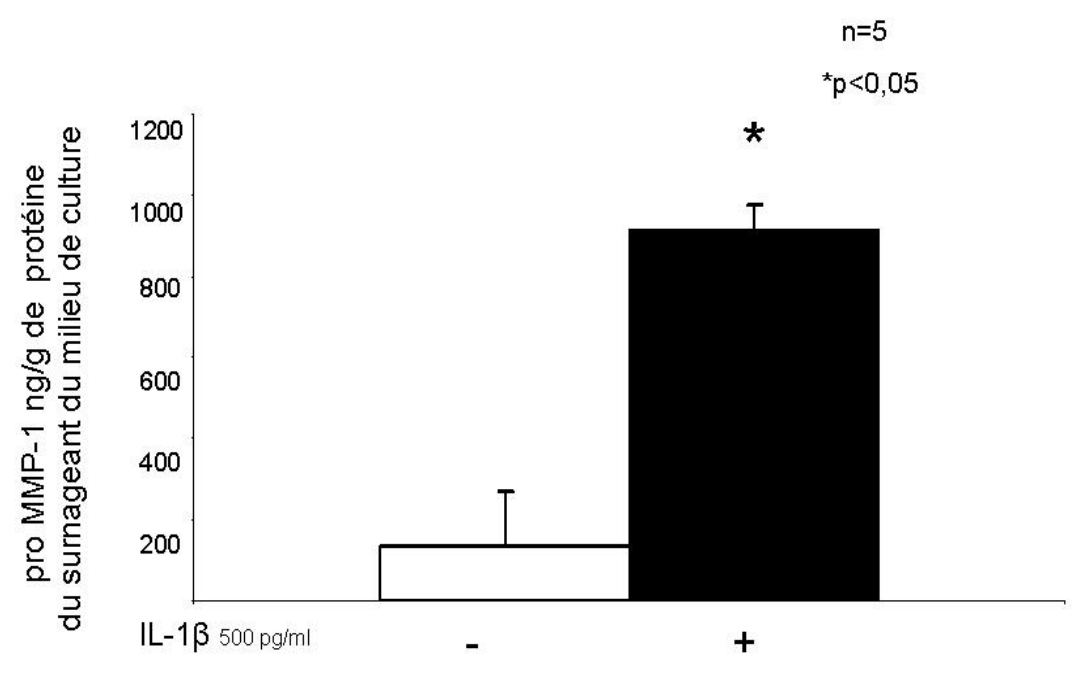

Figure 38 Expression de la proMMP-1 sous hIL-1ß après $23 \mathrm{~h}$ d'incubation par la lignée chondrocytaire C-20/A4.

En condition sans SVF, les chondrocytes C-20/A4 sont incubés en absence ou présence d'hIL-1 $ß$ pendant $23 \mathrm{~h}$. On prélève alors la totalité du milieu de culture; après centrifugation à $350 \mathrm{~g}$ et durant $5 \mathrm{mn}$ à température ambiante, le surnageant est aliquoté puis congelé pour dosage ELISA de la pro MMP-1, et dosage des protéines par la méthode de Bradford,. Les résultats sont exprimés en ng/g de protéine du surnageant du milieu de culture .et représentent la moyenne de 5 expérimentations identiques $+/$-déviation standard $\mathrm{P}<0.05$ versus les chondrocytes non stimulés par hIL-1ß.

Les résultats illustrés sur la Figure 38 démontrent donc qu'après $23 \mathrm{~h}$ d'incubation sans SFV les lignées C-20/A4 sécrètent environ 7 fois plus de proMMP-1 en présence d'hIL-1ß (913 versus $136 \mathrm{ng} / \mathrm{g}$ de protéine du surnageant de milieu de culture). Cette différence est statistiquement significative.

\section{III-C-1-d Effet de l'hIL-1ß, sur l'expression métalloprotéasique des gélatinases (MMP-2) \& (MMP-9) :}

Dans des conditions expérimentales strictement identiques, nous avons vérifié l'impact d'un stress cytokinique sur l'expression des gélatinases, MMP-2 et MMP-9. 
Après trois lavages en EBSS les cellules sont incubées à $37^{\circ} \mathrm{C}$, en présence de $5 \% \mathrm{CO}_{2}$ avec le milieu de culture classique mais sans sérum de veau en présence ou non de $500 \mathrm{pg} / \mathrm{ml}$ d'hIL-1ß humaine pendant $23 \mathrm{~h}$.

A T0 puis T23h on prélève quelques $\mathrm{ml}$ de milieu de culture que l'on centrifuge à $350 \mathrm{~g}$ durant 5 min à température ambiante pour éliminer les cellules en suspension; le surnageant de culture est alors aliquoté puis congelé pour une étude de l'activité de la MMP-2 et MMP-9 par zymographie. Après décongélation, et dosage protéique selon la technique de Bradford on dépose par puits l'équivalent de $50 \mu \mathrm{g}$ de protéines soit pures soit diluées au 1/2éme 1/5éme ou 1/10éme (cf. matériel et méthodes)

\begin{tabular}{|l|llllll}
\hline Dilution & $\mathrm{TM}$ \\
$94 \mathbf{~ k D a}$ \\
$\mathbf{6 7} \mathbf{~ k D a}$
\end{tabular}

Le produit d'exocytose d'une culture de lymphocyte B est utilisé comme témoin positif.

Nous démontrons la présence d'une activité gélatinolytique (Figure. 39) liée à la présence sur le zymogramme d'une protéine de $67 \mathrm{kDa}$ correspondant à la gélatinase A (MMP-2 dans sa forme active).

L'absence de plage de lyse à 92 kDa signe l'absence de MMP-9.

Par ailleurs il ne semble pas y avoir de différence en termes d'activité gélatinolytique avant et après $23 \mathrm{~h}$ d'incubation avec $500 \mathrm{pg} / \mathrm{ml}$ d'hIL-1ß 
Résultats

L'hIL-1 $\beta$ dans ce modèle, ne semble donc pas modifier la sécrétion de manière significative des gélatinases MMP-2 et MMP-9.

Mais l'expérience n'ayant été réalisée qu'une fois, il convient d'examiner les résultats avec prudence.

Pour la suite nous allons focaliser nos travaux sur 1'expression de la MMP-1 dans le contexte d'une stimulation par hIL-1 $\beta$, et examiner le rôle potentiel des dérivés radicalaires de l'oxygène sur cette surexpression.

\section{III-C-2 Impact de la modulation de la voie dépendante des ROS sur l'expression métalloprotéasique de la proMMP-1 en présence d'hIL-1 $\beta$ :}

En effet, nous avons démontré que sous hIL-1 B, la lignée C-20/A4 surexprime la proMMP-1 dans le milieu de culture. Cette surexpression est décrite comme étant régulée par la présence de radicaux oxydants qui joueraient un rôle de messager secondaire (Lo et coll. 1998, Mendes et coll. 2001).

Dans un premier temps, nous allons vérifier sur la lignée d'intérêt C-20/A4 l'impact des radicaux oxydants sur cette surexpression de collagénase en co-incubant les cellules avec soit une molécule le TIRON qui piége les radicaux oxydants, soit avec le "diphénylénechloride iodonium" « DPI » qui est un inhibiteur de la NAD(P)H oxydase des phagocytes.

Mais il faut tout d'abord, vérifier la viabilité des chondrocytes C-20/A4 après incubation avec ces différentes substances.

III-C-2-a Etude de la viabilité cellulaire des chondrocytes C-20/A4 en co-incubation avec du Tiron et du DPI

Après trois lavages en EBSS, les cellules C-20/A4 cultivées à 90\% de confluence en monocouche sont incubées à $37^{\circ} \mathrm{C}, 5 \% \mathrm{CO}_{2}$ avec le milieu de culture classique et $10 \%$ de SVF pendant $23 \mathrm{~h}$.

A T23h on prélève quelques $\mathrm{ml}$ de milieu de culture que l'on centrifuge à $350 \mathrm{~g}$ durant $5 \mathrm{~min}$ à température ambiante, pour éliminer les cellules en suspension, le dosage de la LDH est réalisée dans le surnageant du milieu de culture. Les résultats sont exprimés en UI/L de surnageant de milieu de culture. 
Les résultats sur la Figure 40 montrent que quelle que soit la concentration de TIRON ou de DPI, il n'existe pas d'augmentation significative de la concentration de la LDH dans le surnageant de milieu de culture démontrant l'absence de toxicité de ces produits dans les conditions utilisées.

A la lumière de ces résultats, et en accord avec les données de la littérature nous utiliserons la concentration finale de $5 \mathrm{mM}$ de TIRON et $10 \mu \mathrm{M}$ de DPI pour la suite des expériences.

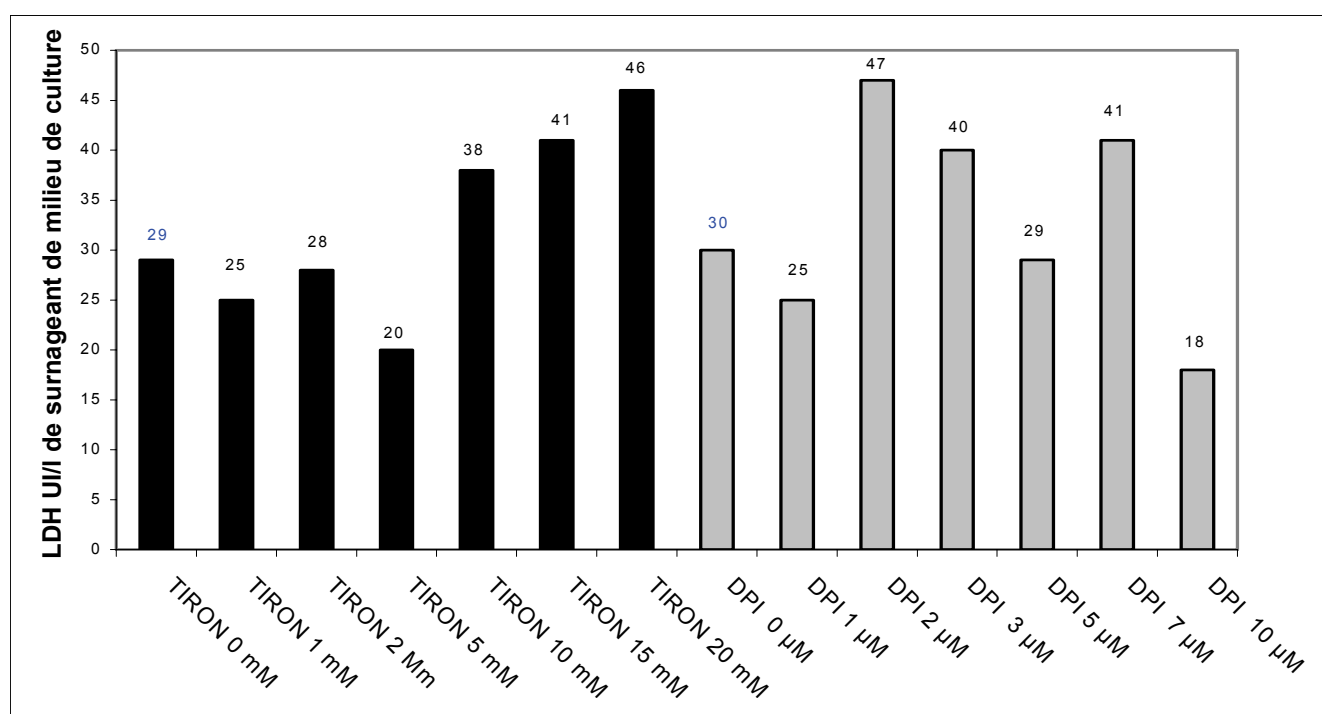

Figure 40 Mesure de la viabilité cellulaire des chondrocytes C-20/A4 après $23 \mathrm{~h}$ d'incubation en présence de TIRON et de DPI à différentes concentrations (respectivement de 0 à $20 \mathrm{mM}$ pour le TIRON et de 0 à $10 \mu M$ pour le DPI)

Après lavage trois fois en EBSS les cellules cultivées à $90 \%$ de confluence en monocouche sont incubées à $37^{\circ} \mathrm{C}, 5 \% \mathrm{CO}_{2}$ avec le milieu de culture classique et $10 \%$ de SVF pendant $23 \mathrm{~h}$. A T23h on prélève quelques $\mathrm{ml}$ de milieu de culture que l'on centrifuge à $350 \mathrm{~g}$ durant $5 \mathrm{~min}$ à température ambiante pour éliminer les cellules en suspension, le dosage des LDH est réalisé dans le surnageant de milieu de culture. Les résultats sont exprimés en $\mathrm{UI} / \mathrm{L}$ de surnageant de milieu de culture $(\mathrm{n}=1)$

\section{III-C-2-b Effet de l'hIL-1ß, à $23 \mathrm{~h}$ d'incubation en présence de TIRON ou de DPI sur l'expression de la collagénase}

Après trypsinisation d'une boîte de $175 \mathrm{~cm}^{2}$, les cellules sont mises en culture trois jours dans trois boîtes de $75 \mathrm{~cm}^{2}$ en condition classique décrite dans le chapitre matériels et méthodes afin d'obtenir une confluence à $90 \%$. Après trois lavages en EBSS, les cellules sont incubées à $37^{\circ} \mathrm{C}, 5 \% \mathrm{CO}_{2}$ avec le milieu de culture mais sans sérum de veau en présence ou non de $500 \mathrm{pg} / \mathrm{ml}$ d'IL-1ß humaine et en présence ou non de $10 \mu \mathrm{M}$ de DPI ou de $5 \mathrm{mM}$ de TIRON pendant $23 \mathrm{~h}$. On prélève alors la totalité du milieu de culture pour doser la LDH afin de valider la viabilité des cellules durant ces $23 \mathrm{~h}$ d'incubation. On dose aussi les protéines par la 
Résultats

méthode de Bradford, et enfin après centrifugation $350 \mathrm{~g}$ durant 5 min à température ambiante le surnageant est aliquoté puis congelé pour dosage ELISA de la pro MMP-1.

- Viabilité des cellules durant $23 \mathrm{~h}$ d'incubation en présence d'hIL-1 $\beta$, de DPI ou du TIRON

A T0 et T23h on prélève quelques $\mathrm{ml}$ de milieu de culture que l'on centrifuge à $350 \mathrm{~g}$ durant 5 min à température ambiante pour éliminer les cellules en suspension, le dosage de la LDH est réalisé. Les résultats sont exprimés en UI/L de surnageant de milieu de culture.

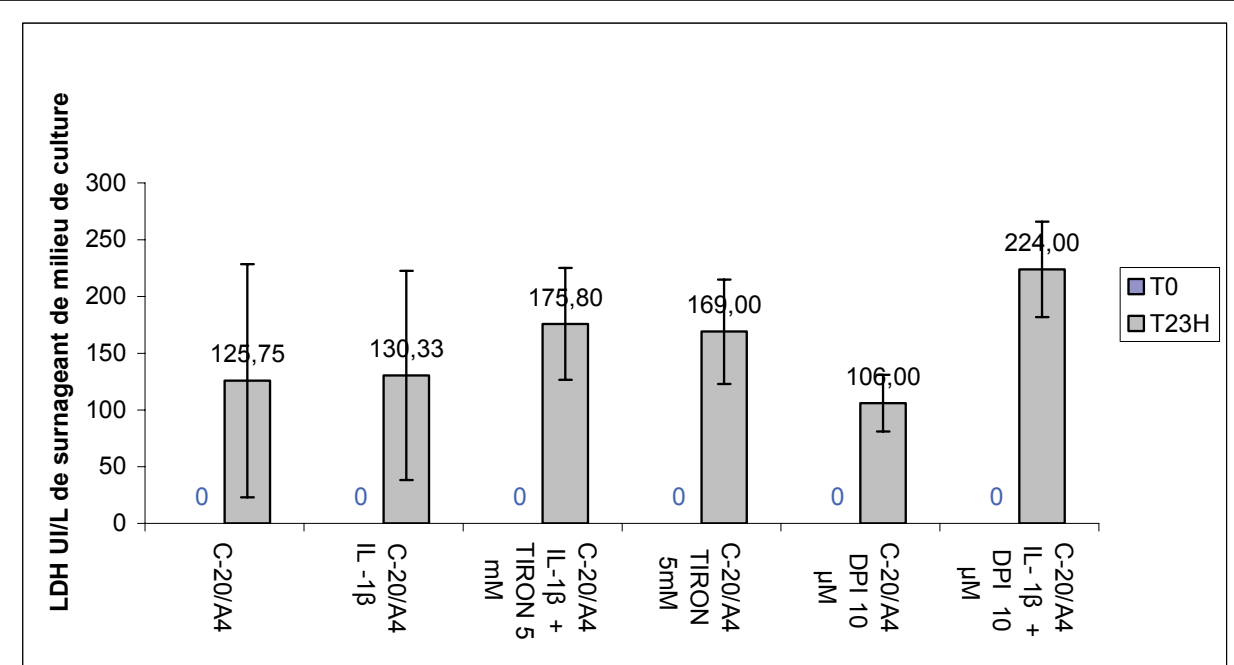

Figure 41 Mesure de la viabilité cellulaire des chondrocytes C-20/A4 après 23h d'incubation en présence ou non de TIRON, de DPI et d' hIL-1 B.

Après trois lavages en EBSS les cellules cultivées à 90\% de confluence en monocouche sont incubées à $37^{\circ} \mathrm{C}, 5 \% \mathrm{CO}_{2}$ avec le milieu de culture classique sans sérum de veau pendant $23 \mathrm{~h}$ dans les différentes conditions d'expérimentation à savoir en présence ou non de TIRON $(5 \mathrm{mM})$ ou de DPI $(10 \mu \mathrm{M})$ et $+/-$, d' hIL-1 $\beta(500 \mathrm{pg} / \mathrm{ml})$. A T0 et T23h on prélève quelques $\mathrm{ml}$ de milieu de culture que l'on centrifuge à $350 \mathrm{~g}$ durant 5 min à température ambiante pour éliminer les cellules en suspension, le dosage de la LDH est réalisé dans le surnageant du milieu de culture. Les résultats sont exprimés en UI/L de surnageant de milieu de culture. Chaque résultat réprésente la moyenne +-SD des résultats pour 5 expérimentations

Nous constatons dans les différentes conditions de culture (Figure 41), une augmentation non significative de l'activité de la LDH par rapport à son activité initiale (cellules avant incubation) et après $23 \mathrm{~h}$ d'incubation ; les activités mesurées sont à comparer à la valeur de 13176 UI/L de LDH retrouvée après lyse par sonication de $2 \times 10^{6}$ cellules correspondant à la quantité moyenne de chondrocytes présents dans une boîte de $75 \mathrm{~cm}^{2}$ en condition de confluence à $100 \%$. En prenant en compte ces résultats, la viabilité reste donc encore bonne pour ces différentes conditions d'expérimentation. 
Résultats

- Effet de l'hIL-1 $\beta$, en présence de TIRON ou de DPI sur l'expression de la collagénase :

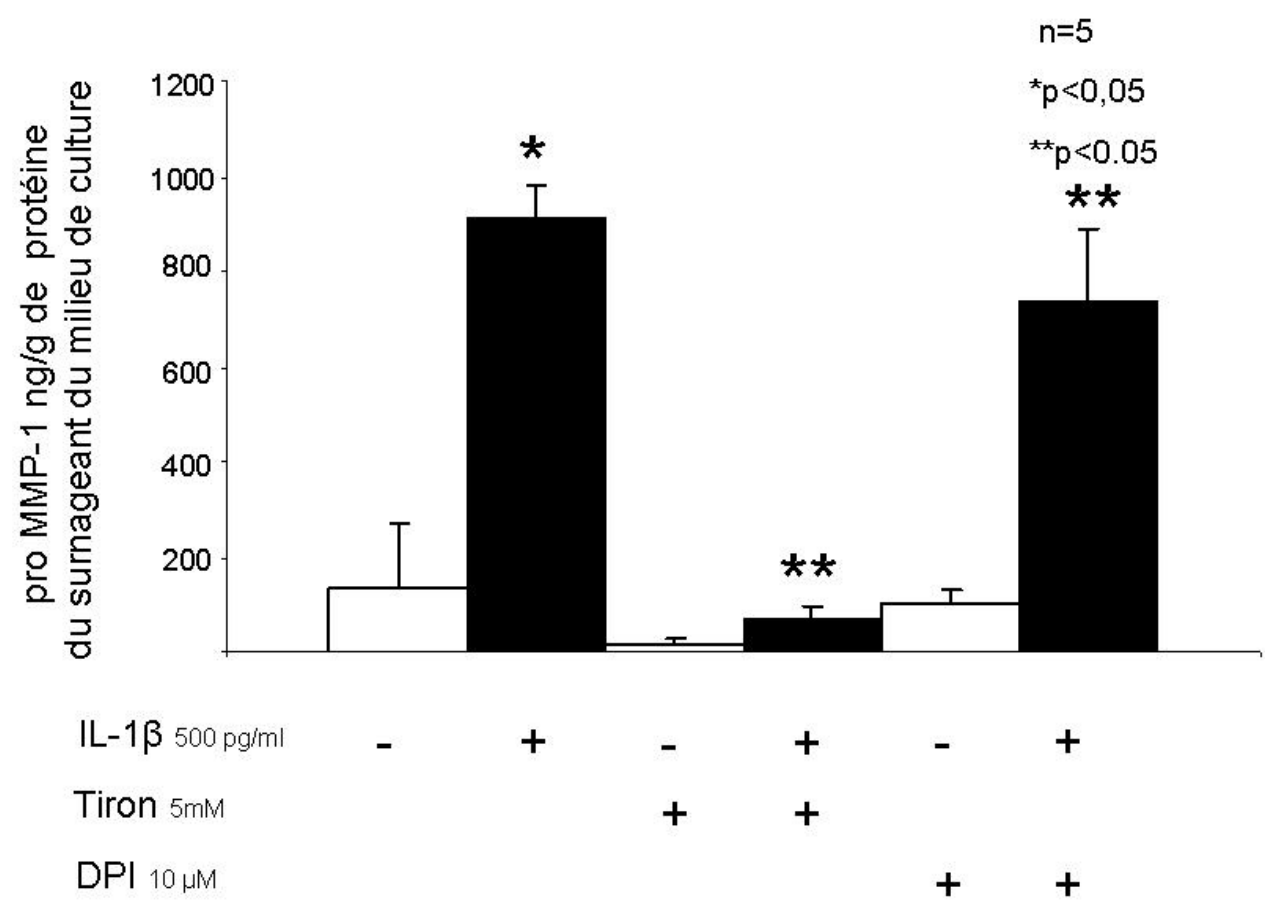

Figure 42 Effet sur les chondrocytes C-20/A4 de l'hIL-1 (500 ng/ml) modulé par la co-incubation avec du TIRON (5 mM) ou du DPI (10 $\mu \mathrm{M})$ sur l'expression de la pro MMP-1 après $23 \mathrm{~h}$ d'incubation Après trois lavages en EBSS les cellules cultivées à $90 \%$ de confluence en monocouche sont incubées à $37^{\circ} \mathrm{C}, 5 \% \mathrm{CO}_{2}$ avec le milieu de culture classique mais sans sérum de veau en présence ou non de 500 $\mathrm{pg} / \mathrm{ml}$ d'IL-1ß humaine et en présence ou non de $10 \mu \mathrm{M}$ de DPI ou de $5 \mathrm{mM}$ de TIRON pendant $23 \mathrm{~h}$. A T23h on prélève la totalité du milieu de culture pour doser les protéines par la méthode de Bradford, et enfin après centrifugation $350 \mathrm{~g}$ durant $5 \mathrm{~min}$ à température ambiante le surnageant est aliquoté puis congelé pour dosage ELISA de la pro MMP-1. Les résultats représentent la moyenne retrouvée pour cinq expérimentations exprimées en $\mathrm{ng} / \mathrm{g}$ de protéines de surnageant de milieu de culture $+/$ - une déviation standard.* $\mathrm{p}<0.05$ versus les cellules $\mathrm{C}-20 / \mathrm{A} 4$ non stimulées** $\mathrm{p}<0.05$ versus les cellules C-20/A4 stimulées par hIL-1ß

Les résultats confirment les observations précédentes à savoir l'augmentation de l'expression de la proMMP-1 dans le surnageant du milieu de culture après exposition à l'hIL-1ß (Figure 42).

Mais on observe aussi une diminution considérable et significative d'environ $92.7 \%$ de la concentration de la proMMP-1 dans le surnageant de milieu de culture pour les cellules activées par hIL-1ß, en présence de TIRON par rapport aux cellules activées mais n'ayant pas été incubées avec cette molécule. 
Résultats

Par contre pour le DPI la différence est faible, mais reste significative. En effet les résultats démontrent aussi une diminution de $19.3 \%$ de la concentration de la proMMP-1 dans le surnageant de milieu de culture pour les cellules activées par hIL-1ß, en présence ou non de DPI (avec un $\mathrm{p}=0,02)$

Les résultats suggèrent :

1. Une production de radicaux oxydants (piégés par le TIRON). Cette production peut avoir comme origine l'une des Nox présentes dans les chondrocytes.

2. Un lien étroit entre cette production et l'expression de la collagénase-1.

\section{III-D Impact de la surexpression de Nox4 sur l'expression métalloprotéasique de proMMP-1 dans la lignée C20/A4 :}

Nous avons montré qu'il existe deux isoformes des Nox (Nox2 et Nox4) avec leurs partenaires dans la lignée de chondrocytes C-20/A4.

Dans le but de discriminer quelle isoforme est potentiellement responsable du stress oxydant intervenant dans la régulation de l'expression de la collagénase-1, nous avons surexprimé dans cette lignée chondrocytaire d'une part Nox4 et d'autre part Nox2 afin d'observer son impact sur la production de ROS et sur la régulation de la MMP-1.

Ainsi la lignée chondrocytaire C-20A/4 a été transfectée de manière stable selon la technique par effectène de Qiagen (cf. matériel et méthodes) avec un vecteur contenant de l'ADNc codant pour Nox2 ou des vecteurs contenant de l'ADNc codant pour une des deux isoformes de Nox4 : Nox4A (Nox4A-V5/His)) ou Nox4B (Nox4B-V5/His). Les deux protéines Nox4A et NoxB ont une étiquette V5/histidine du coté $\mathrm{C}$ terminal. (cf. matériel et méthodes).

La protéine Nox4A-V5/His exprimée a la particularité de garder une activité NAD $(\mathrm{P}) \mathrm{H}$ malgré l'ajout de cette étiquette V5/his. La protéine Nox4B-V5/His a quant à elle la particularité d'avoir un site de fixation du NAD $(\mathrm{P}) \mathrm{H}$ manquant rendant la protéine incapable de produire des radicaux oxydants et lui conférant même un rôle de dominant négatif sur Nox4 selon des études récentes (Goyal et coll. 2005). Les transfections réalisées sont stables. Les cellules transfectées sont sélectionnées respectivement pour Nox4 A et Nox4B par de la blasticidine $(10 \mu \mathrm{g} / \mathrm{ml})$ et pour Nox2 par de la généticine $(1 \mu \mathrm{g} / \mathrm{ml}$ de généticine tamponnée par $20 \mu 1 / \mathrm{ml}$ de $\mathrm{NaOH} 5 \mathrm{~N})$.

Un témoin de transfection a été réalisé avec un vecteur exprimant la luciférase. 
Résultats

\section{III-D-1 Validation de la surexpression stable de Nox4A-V5/his, Nox4B-V5/his, et Nox2 :}

\section{III-D-1-a Au niveau transcriptionnel :}

La validité des diverses transfections a été étudiée au niveau transcriptionnel par RT-PCR en vérifiant l'expression des plasmides sur les cellules C-20/A4 transfectées (Figure 43a)

Les résultats montrent dans les cellules non transfectées, une expression faible de Nox2 et Nox4 comme nous l'avions déjà montré précédemment.

Par contre au niveau des cellules C-20/A4 transfectées respectivement par Nox2, Nox4A et Nox4B, nous démontrons une surexpression nette de l'ARNm au niveau de Nox2, ainsi que Nox4 (Figure 43a), appréciée par réalisation de RT-PCR.

Pour confirmer ces résultats, et en tenant compte du fait reconnu que la RT-PCR est une technique semi quantitative, nous avons utilisé une technique de PCR quantitative en respectant le protocole décrit dans le chapitre matériels et méthodes. Ainsi, pour valider l'expression de l'ARNm de Nox4 en PCR quantitative nous avons utilisé des amorces qui amplifient une région commune de l'ADNc à la fois de Nox4A et Nox4B.

Les résultats de cette expérience révèlent que le niveau d'expression de l'ARNm de Nox4 est augmenté de 22 fois dans la lignée transfectée par le gène codant pour Nox4A-V5/His et de 5 fois dans la lignée transfectée par le gène codant pour Nox4B-V5/His (Figure 43b). Nous confirmons aussi l'absence d'augmentation de cet ARNm dans les lignées transfectées par Nox2 ou par la luciférase notre témoin de transfection (Figure 43b).

Nous démontrons bien que les transfections sont effectives dans les chondrocytes. 
a
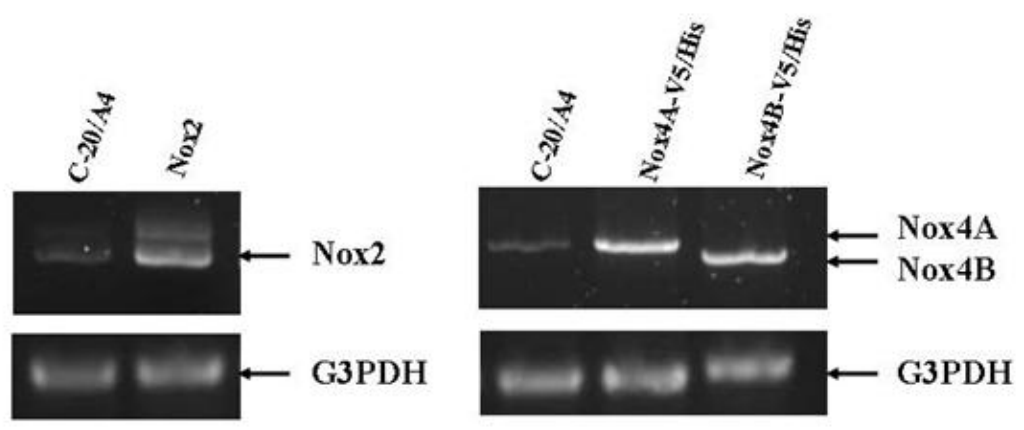

b

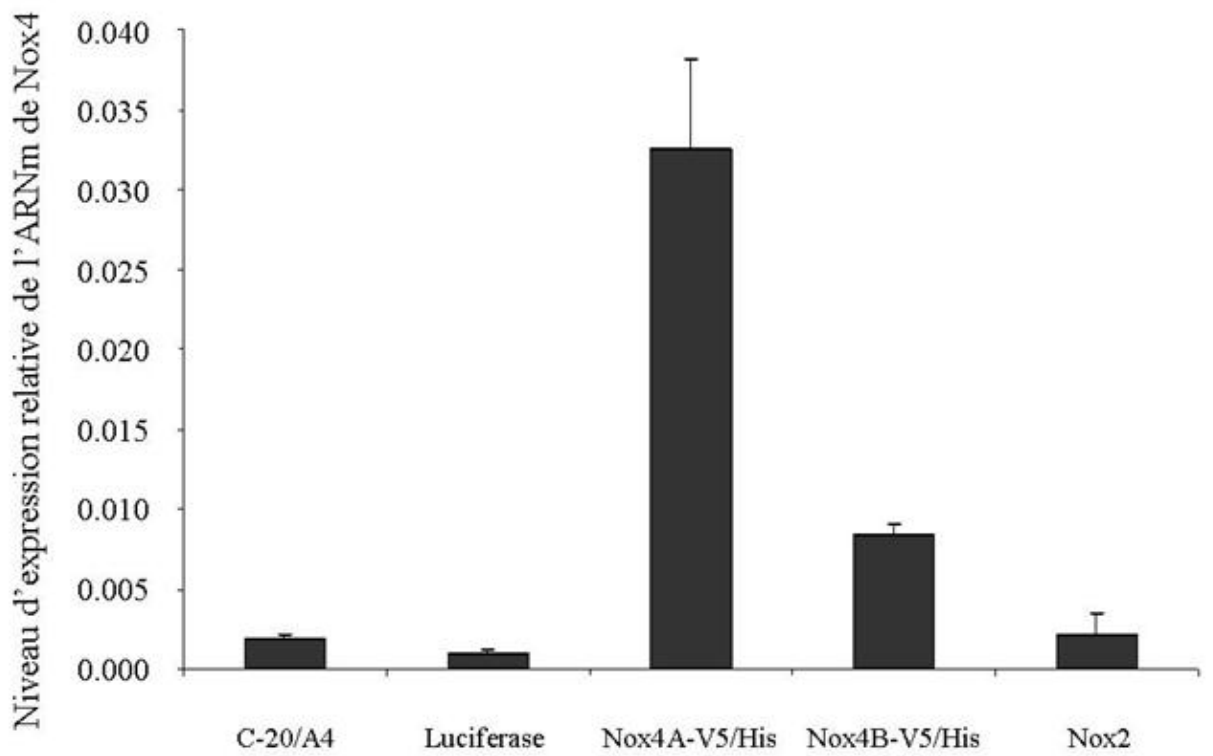

Figure 43 Efficacité d'expression des plasmides d'intérêts sur les cellules C-20/A4 transfectées

(a) Expression de ARNm de Nox4, Nox2 et G3PDH par RT-PCR

L'ARN total est extrait des cellules C-20/A4 non transfectées ou transfectées par Nox4A-V5/His, Nox4BV5/His ou Nox2. Une RT-PCR est réalisée pour chaque plasmide comme décrit dans le chapitre matériels et méthodes en utilisant les amorces F4/R4 pour Nox4 caractérisant ses deux isoformes, F2/R2 pour Nox2 et des amorces du commerce pour la G3PDH.

\section{(b) Expression relative de l'ARNm de Nox4 par RT-PCR quantitative}

L'ARN total est extrait à partir des cellules C-20/A4 non transfectées ou transfectées par Nox4A-V5/His, Nox4B-V5/His, luciférase ou Nox2. Une RT-PCR quantitative est réalisée en utilisant les amorces F4"'/R4" 'caractérisant les deux isoformes de Nox4. Les résultats sont exprimés en niveau d'expression relatif de l'ARNm de Nox4 par rapport au niveau d'expression de l'ARNm du gène de ménage G3PDH. Les PCRs pour chaque échantillon sont réalisées trois fois. 
Résultats

\section{III-D-1-b Au niveau protéique :}

Nous avons validé la qualité des transfections au niveau protéique en vérifiant la surexpression des protéines correspondantes dans les chondrocytes C-20/A4 transfectés par deux techniques :

- La cytométrie en flux.

- Le spectre différentiel redox du cytochrome $b_{558}$

\section{La cytométrie en flux}

L'expression protéique a été déterminée en réalisant une expérience de cytométrie en flux sur les cellules transfectées ou non par le plasmide codant Nox4A-V5His, par le plasmide codant Nox4B-V5/His ou Nox2. Ces cellules ont été fixées puis perméabilisées au préalable puis incubées avec les différents anticorps d'intérêt comme décrit dans le chapitre matériels et méthodes. Pour l'expression de la protéine Nox2, nous avons utilisé comme anticorps primaire deux anticorps monoclonaux NL7 et 54.1 qui ont pour cible un épitope intracellulaire (Figure 44a). Tout d'abord, nous confirmons les résultats précédemment décrits en démontrant encore une fois, la présence de Nox2 dans les cellules sauvages C-20/A4.

De plus, nous montrons une augmentation faible mais significative de l'expression de Nox2 dans les cellules transfectées par le plasmide codant pour Nox2, en comparaison à l'expression retrouvée dans les cellules sauvages C-20/A4. Puis, nous démontrons l'expression protéique de Nox4, toujours en cytométrie en flux, en utilisant deux anticorps primaires polyclonaux : 1'anticorps « 504 » dirigé contre la deuxième boucle intracellulaire de Nox4 (cf. chapitre matériels et méthodes.) et un anticorps anti-histidine du commerce marquant l'étiquette polyhistidine C-Terminale. Nous confirmons tout d'abord la présence de la protéine Nox4 dans les cellules natives C-20/A4 comme précédemment décrit. Les résultats montrent aussi une augmentation significative de l'expression de Nox4A et Nox4B dans les lignées transfectées par le plasmide codant respectivement pour la protéine Nox4A-V5/His et Nox4B-V5/His (Figure 44b). Il faut noter une expression protéique de Nox4B-V5/His supérieure à celle de Nox4A-V5/His alors qu'au niveau transcriptionnel les résultats montent une quantité d'ARNm de Nox4A-V5/His supérieure à celle de Nox4B-V5/His (Figure 43). Cette différence pouvant peut-être s'expliquer par une stabilité plus grande de la transfection pour Nox4B-V5/His ou un niveau de traduction différent de l'ARNm. 
a

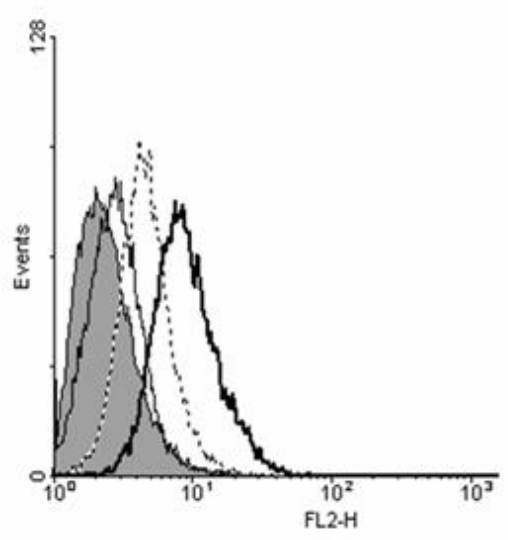

gp91 ${ }^{\text {phox }} \mathrm{Ab} \mathrm{NL7}$
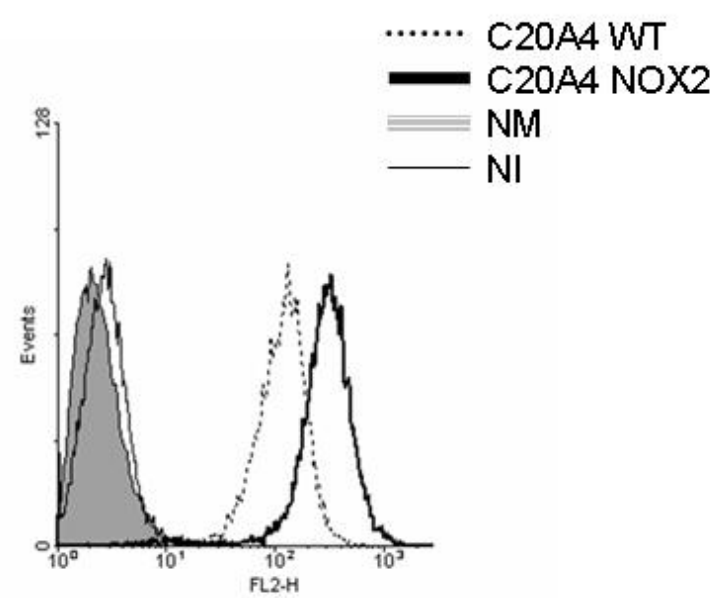

gp91 phox Ab 54.1

b

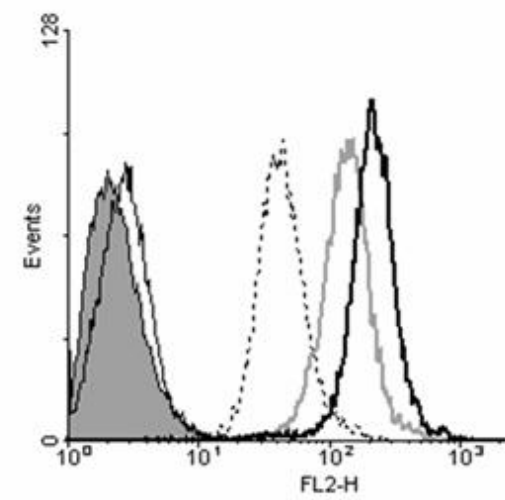

Histidine Ab
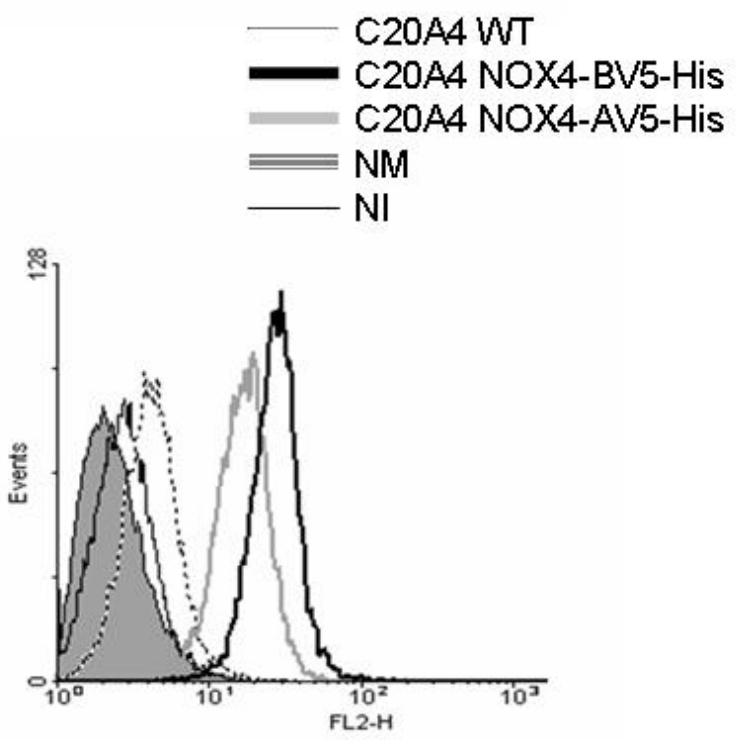

Nox4 Ab

Figure 44 Expression protéique de Nox2 et Nox4 par cytométrie de flux

(a) Analyse par FACS de l'expression de gp91 ${ }^{\text {phox }}$.

$5 \times 10^{5}$ cellules C-20/A4 sauvages ou transfectées par le gène codant Nox2 sont fixées par $1 \%$ (p/v) de paraformaldehyde et incubées avec un anticorps primaire monoclonal anti gp91 ${ }^{\text {phox }}$ ( NL7 ou 54.1), après avoir été perméabilisées par de la saponine comme décrit dans le chapitre matériels et méthode. Les anticorps secondaires sont conjugués avec de la phycoérythrine (dilution 1:200). Les cellules incubées avec les anticorps non immuns et les cellules non marquées sont représentées respectivement par une ligne noire pleine $\left(5 \mu \mathrm{g} / 5 \times 10^{5}\right.$ cellules $)$, et la zone grise pleine. Enfin les cellules C-20/A4 sauvages et les chondrocytes C-20/A4 Nox2 sont représentés respectivement par une ligne pointillée noire et une ligne noire pleine et grasse.

\section{(b) Analyse par FACS de l'expression de Nox4}

$5 \times 10^{5}$ C-20/A4 sauvages ou transfectées par les gènes codant Nox4A-V5/His ou Nox4B-V5/His sont fixées par $1 \%(\mathrm{p} / \mathrm{v})$ de paraformaldehyde et incubées avec un anticorps primaire monoclonal anti-Nox 4 ou antihistidine après avoir été perméabilisées par de la saponine comme décrit dans le chapitre matériels et méthodes Les anticorps secondaires sont conjugués avec de la phycoérythrine (dilution 1:200). Les cellules incubées avec les anticorps non immuns et les cellules non marquées sont représentées respectivement par une ligne noire pleine $\left(5 \mu \mathrm{g} / 5 \times 10^{5}\right.$ cellules $)$, et la zone grise pleine. Enfin les cellules C-20/A4 sauvages, les chondrocytes C-20/A4 Nox4A-V5/His et Nox4B-V5/His sont représentées respectivement par une ligne pointillée noire, une ligne grise pleine et une ligne noire pleine et grasse. 
Résultats

\section{Le spectre différentiel redox du cytochrome $b_{558}$}

Pour confirmer ces résultats et valider par une autre technique la transfection par le plasmide codant pour Nox4A dans la lignée C20/A4 Nox4A-V5/His, nous avons comparé les spectres différentiels redox d'extraits Triton $1 \%$ de membranes de chondrocytes sauvages avec le spectre différentiel redox d'extraits Triton 1\% de membranes de la lignée C20/A4 Nox4AV5His (transfectée par Nox4A). Nous avons utilisé comme témoin positif le spectre d'un extrait Triton $1 \%$ de cytochrome $\mathrm{b}_{558}$ issus de PMN humains.

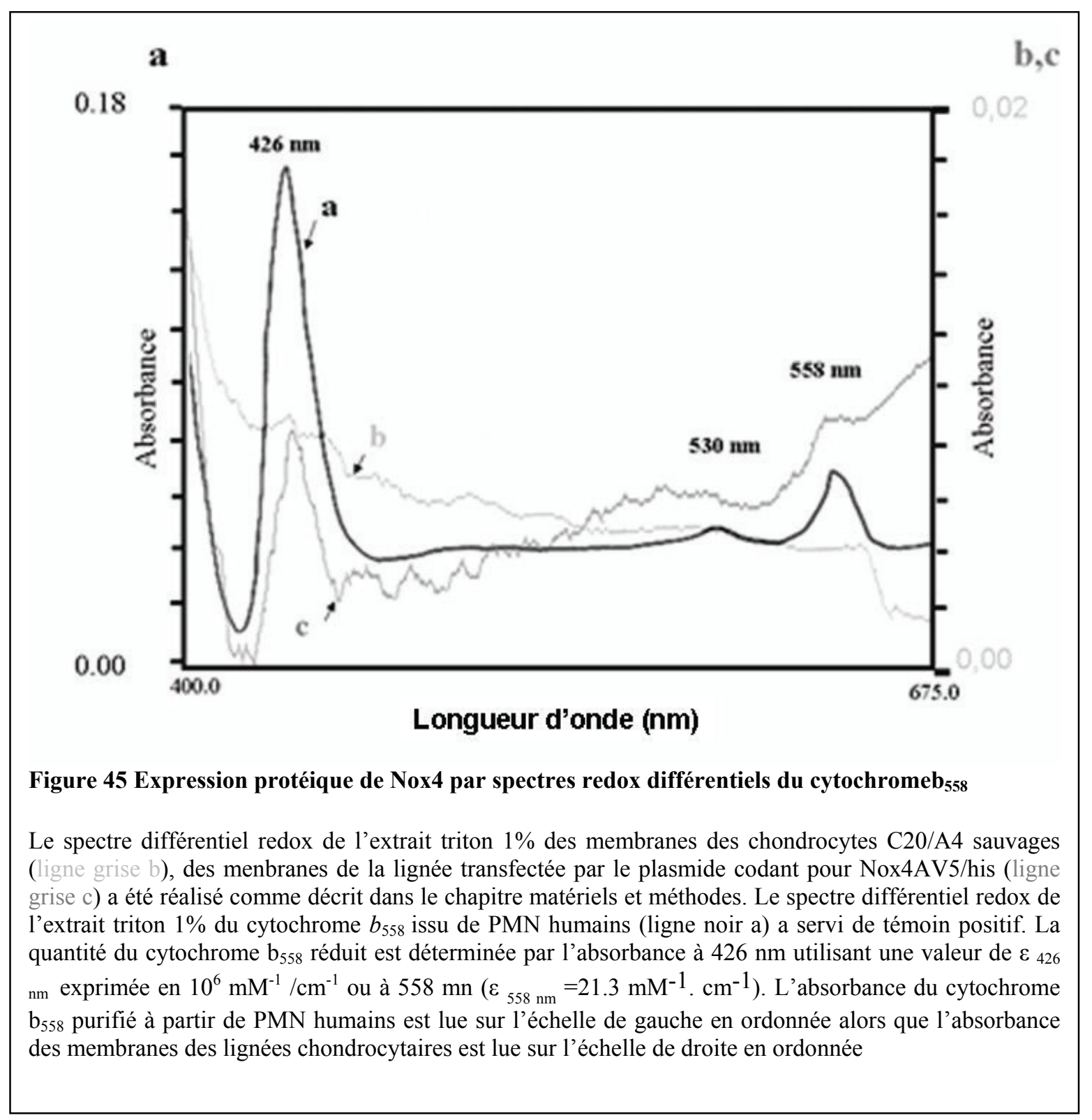


Ainsi les résultats montrent que le spectre différentiel redox du cytochrome $b_{558}$ de PMN présente trois pics d'absorption caractéristiques du cytochrome b $b_{558}$ à $426 \mathrm{~nm}$, 530 et $558 \mathrm{~nm}$. De plus, le spectre d'absorption démontre une expression de Nox4 dans les chondrocytes de la lignée sauvage en mettant en évidence un pic de faible amplitude caractéristique à $426 \mathrm{~nm}$, tout comme les PMN. Ce pic est aussi retrouvé dans les chondrocytes de la lignée transfectée par le plasmide codant pour Nox4A. Par ailleurs d'un point de vue quantitatif, si on compare le spectre des chondrocytes des lignées sauvages et transfectées nous observons une augmentation significative de l'expression de Nox4 dans la lignée transfectée (Figure 45).

Nous validons donc tant sur le plan transcriptionnel que protéique la qualité de la transfection des plasmides codant aussi bien pour Nox2, Nox4 A et B dans les chondrocyte C20/A4. Nous allons maintenant nous intéresser à l'impact sur un plan plus fonctionnel de ces transfections sur la capacité qu'ont ces cellules à engendrer un stress oxydatif.

\section{III-D-2 Impact sur l'activité NAD(P)H oxydase des lignées surexprimant Nox4A ou Nox4B et Nox2 :}

\section{III-D-2-a Détermination de la production de ROS par la méthode d'oxydation du DHE :}

Pour déterminer l'impact d'une surexpression des deux différentes isoformes de Nox4 et de Nox2 en terme de production de ROS, nous avons utilisé la technique d'oxydation du dihydroéthidium DHE qui donne un reflet du niveau de production d' $^{-}{ }_{2}^{-}$au niveau intra cellulaire (cf. matériels et méthodes). Les chondrocytes sauvages C-20/A4 ou transfectés C20/A4 Nox4A-V5His, C-20/A4 Nox4B-V5His et C-20/A4 Nox2 sont donc cultivés à 80\% de confluence sur des plaques de 6 puits en conditions classiques (DMEM-10\% de SVF) à $37^{\circ} \mathrm{C}$ et $5 \%$ de $\mathrm{CO}_{2}$.

Le jour de l'expérience les différents puits sont lavés 2 fois avec de l'EBSS et incubés avec 1 $\mathrm{ml}$ de milieu de culture (DMEM-10\% SVF) contenant $5 \mu \mathrm{M}$ final de DHE avec ou sans hIL$1 \beta(500 \mathrm{pg} / \mathrm{ml})$ pendant 20 minutes toujours à $37^{\circ} \mathrm{C}$ et $5 \%$ de $\mathrm{CO}_{2}$ et dans le noir strict durant toute la durée de l'expérimentation. Dans certains puits, nous avons incubé les cellules avec en plus de la $N$-acetyl cystéine à $30 \mathrm{nM}$ (NAC) qui est une molécule antioxydante ayant la propriété de piéger les dérivés radicalaires de l'oxygène. 
Après 20 minutes d'incubation, les plaques sont lues à l'abri de la lumière sur un microscope à fluorescence Nikon éclipse TE2000-E selon le protocole décrit dans le chapitre matériels et méthodes. Les images sont ensuite analysées par un logiciel Lucia software. Le niveau relatif de fluorescence entre les cellules est quantifié en déterminant l'intégrale des niveaux de gris en utilisant le logiciel Lucia de Imaging Systems. L'intégrale des gris est définie comme la zone de l'intensité de chaque pixel. Un minimum de 50 cellules est analysé par expérience. Les résultats sont exprimés en unité arbitraire de fluorescence.

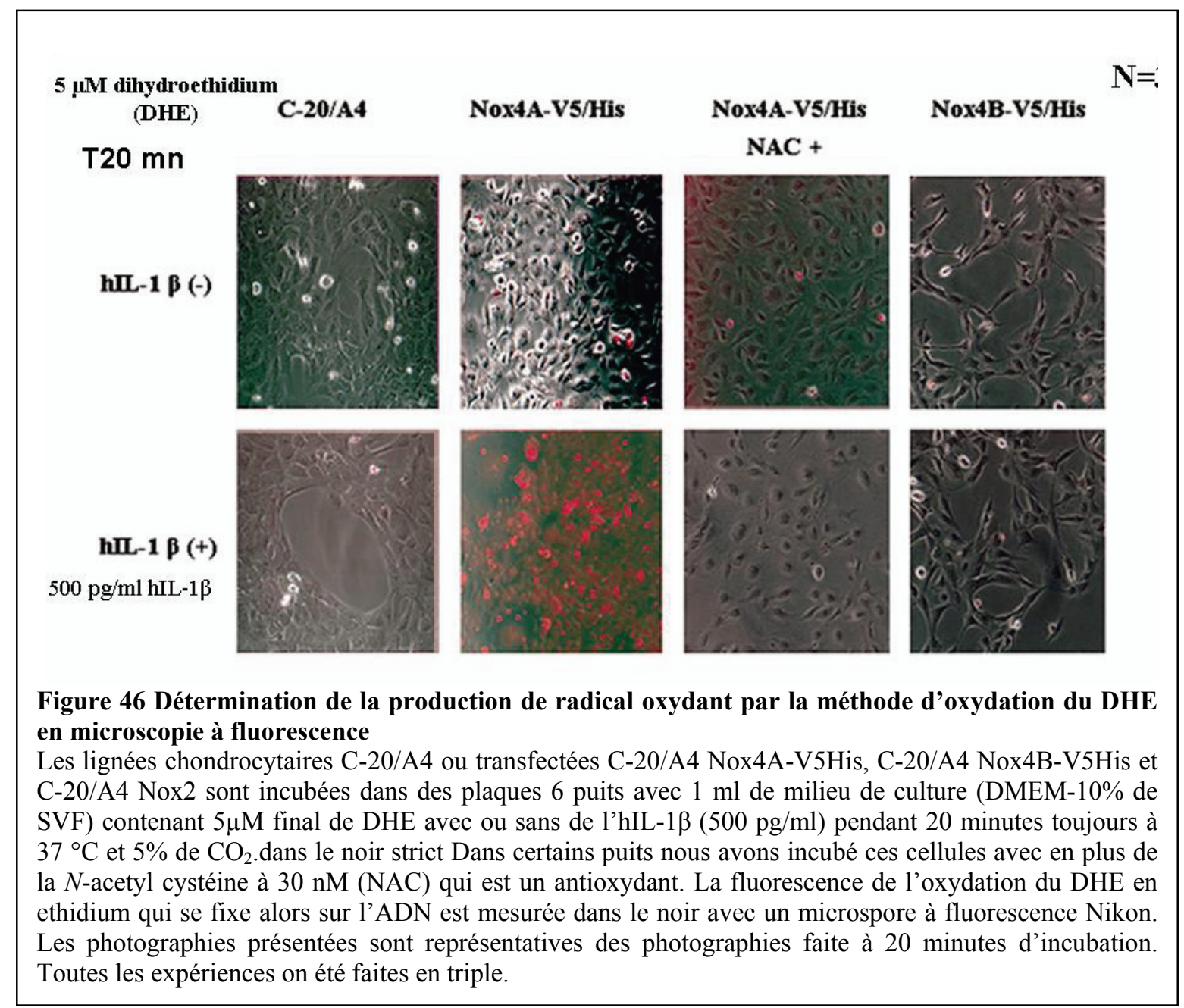

Les résultats nous permettent ainsi d'observer pour la première fois que les cellules sauvages C-20/A4, après stimulation avec $500 \mathrm{pg} / \mathrm{ml}$ d'hIL- $1 \beta$ produisent une quantité extrêmement faible d' $\mathrm{O}_{2}{ }^{-}$de l'ordre de 8 unités arbitraires (UA) (Figure 46).

Ceci explique que la mesure de l'activité $\mathrm{NAD}(\mathrm{P}) \mathrm{H}$ oxydase dans les chondrocytes par chimiluminescence ne puisse pas mettre en évidence cette production par manque simplement de sensibilité. 
Résultats

Par ailleurs, nous démontrons que sous hIL-1 $\beta$, la surexpression de Nox4A fonctionnelle dans cette lignée chondrocytaire C20/A4 entraîne une activation du stress oxydant en augmentant la production d'O2- intracellulaire d'un facteur 2 par rapport aux cellules C-20/A4 Nox4AV5His, non stimulées (35 UA versus 18 UA) (Figure 46).

Cette surproduction intracellulaire $\mathrm{d}^{\prime} \mathrm{O} 2^{-}$est encore plus spectaculaire si on compare le niveau de production des cellules C-20/A4 Nox4A-V5His par rapport à celui des chondrocytes sauvages (72 UA versus 8 UA) soit une différence d'un facteur 9 (Figure 46).

La spécificité des résultats est prouvée par la co-incubation avec un anti oxydant non spécifique qui piège $1^{\prime} \mathrm{O}_{2}{ }^{-}$, la $\mathrm{N}$-acetyl cystéine (NAC), et qui inhibe totalement l'apparition de la fluorescence (Figure 46).

En nous intéressant à la lignée C-20/A4 Nox4B-V5His, surexprimant une isoforme non fonctionnelle de Nox4, nous montrons une inhibition de la production $\mathrm{d}^{\prime} \mathrm{O}_{2}{ }^{-}$par rapport aux cellules sauvages après stimulation par l'hIL-1 $\beta$.

Ces résultats confortent le rôle de dominant négatif de cette isoforme de Nox4 précédemment décrit, (Goyal et coll. 2005).

$\mathrm{Au}$ total, nous démontrons que la surexpression de Nox4A dans une lignée de chondrocytes augmente leur capacité de production d' $\mathrm{O}_{2}{ }^{-}$d'un facteur 9 sous stress cytokinique (hIL-1 $\beta$ ).

Nous mettons ainsi en évidence pour la première fois d'une part, le rôle de Nox4 dans la production de radicaux oxydants dans le chondrocyte, et d'autre part le fait que Nox 4 puisse être activée et produire des radicaux oxydants suite à un stress cytokinique par hIL-1 $\beta$, démontrant donc, le caractère inductible de Nox4.

Pour confirmer ces résultats, nous allons essayer de mesurer cette augmentation d'activité oxydase par chimioluminescence.

\section{III-D-2-b Détermination de la production de ROS par chimioluminescence dans les chondrocytes surexpimant Nox4 :}

Nous avons utilisé exactement la même technique d'expérimentation que celle décrite dans le chapitre II-B-2 de la partie résultats. En effet, $5 \times 10^{5}$ chondrocytes sauvages C-20/A4 ou surexprimant Nox4A ou Nox4B (Nox4A-V5/His ou Nox4B-V5/His) sont remis en suspension dans $50 \mu \mathrm{lde} \operatorname{PBS}^{(-)}$et sont plongés dans $200 \mu 1$ de milieu commun contenant $25 \mu 1$ de glucose 0,8M, $10 \mu \mathrm{l}$ de luminol 2mM (20\% DMSO), 20 $\mu 1$ d'HRPO 500U/ml et $945 \mu 1$ de $\mathrm{PBS}^{(-)}$et incubés dans le luminomètre pendant 1 minute à $37^{\circ} \mathrm{C}$. La réaction est initiée par 10 
Résultats

$\mu 1$ de PMA $0,13 \mu \mathrm{M}$ ou de la ionomycine $(2,5 \mu \mathrm{M})$. Au préalable les différents chondrocytes ont été stimulés par une co-incubation avec $500 \mathrm{pg} / \mathrm{ml}$ d'hIL-1 $\beta$.

L'émission de photons est suivie pendant 1 heure 30 avec une mesure toutes les trente secondes (500 itérations par seconde). Pour la quantification, la somme des RLU (Relative Luminescent Unit) est calculée dans les conditions déterminées précédemment.

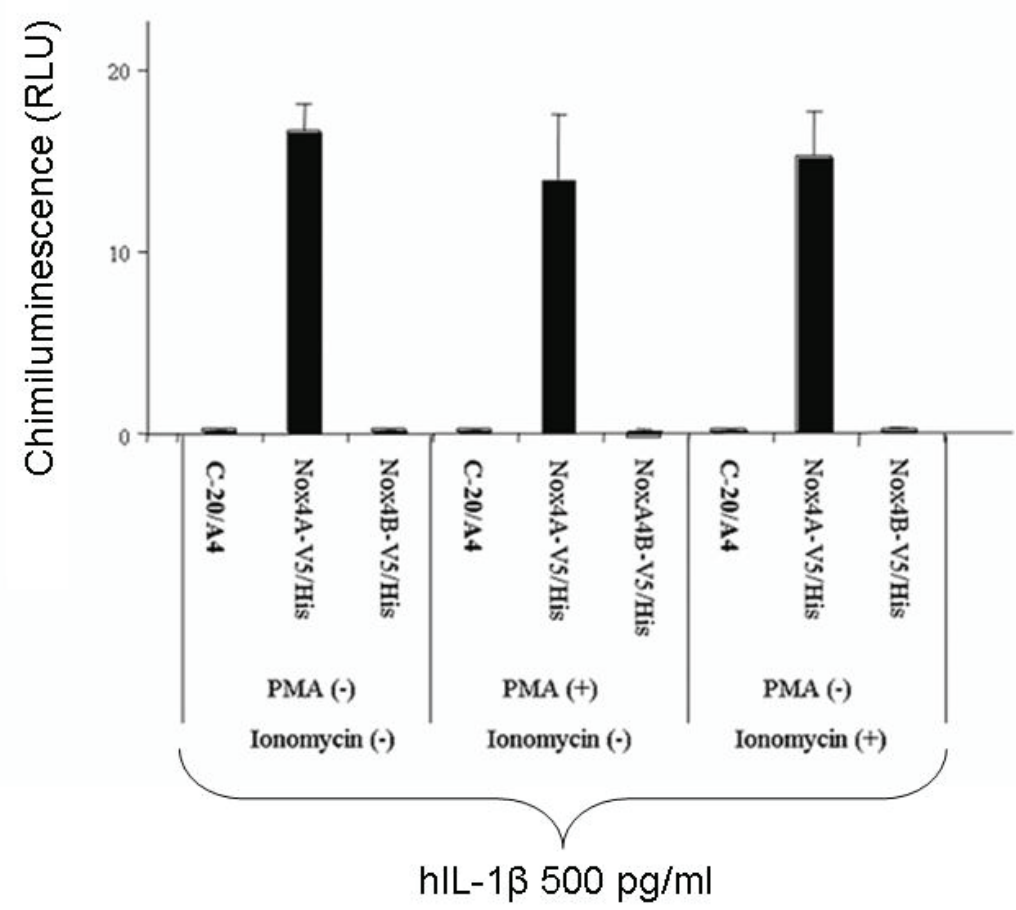

Figure 47 Dosage de l'activité oxydase par chimiluminescence sur cellule entière de la lignée C-20/A4

La production totale de ROS $\left(\mathrm{H}_{2} \mathrm{O}_{2}\right)$ est mesurée a partir de $5 \times 10^{5}$ cellules entières C-20/A4 sauvages, ou transfectées (Nox4A-V5/His ou Nox4B-V5/His) après incubation par de l' hIL1-ß (500 pg/ml). La somme des RLU est calculée après 1 heure 30 de lecture avec une mesure toutes les 30 secondes selon la technique et les conditions décrites dans le chapitre «matériels et méthodes » Les chondrocytes ont été stimulés ou non par du PMA $0,13 \mu \mathrm{M}$ ou de la ionomycine 2,5 $\mu \mathrm{M}$. Des LB-EBV utilisés dans les mêmes conditions et du PBS $^{(-)}$ont servi respectivement de témoins $(+)$et (-) (résultats non montrés). Les résultats sont exprimés par la moyenne de la somme des RLU; Valeurs obtenues pour chaque condition. Les valeurs dans cette figure représentent la moyenne $+/$ - SD de trois déterminations obtenues le même jour.

Les résultats montrent toujours l'impossibilité de mettre en évidence une production de radicaux oxydants significative avec les cellules sauvages même après stimulation avec hIL$1 \beta$ (Figure 47). Ceci est dû à un manque de sensibilité de cette technique au regard de la production extrêmement faible de ROS dans ces conditions (cf. résultats chapitre ci-dessus).

Par contre avec les cellules surexprimant Nox4A-V5/His on assiste à une augmentation significative de la production de dérivés radicalaires devenant mesurables par cette technique 
Résultats

$(14,87 \mathrm{RLU} \pm 0,44)$ comparée à la production de dérivés radicalaires avec les cellules contrôles $\mathrm{C}-20 / \mathrm{A} 4(0,17 \mathrm{RLU} \pm 0,011)$, et à la production de dérivés radicalaires avec les cellules surexprimant Nox4B-V5/His (0,17 RLU $\pm 0,024)$, (Figure 47).

Par ailleurs, nous constatons que la stimulation par le PMA ou par l'ionomycine, activateur spécifique de Nox2, ne modifie pas cette production, laissant penser que Nox 2 n'est pas la Nox impliquée dans ce processus au niveau des chondrocytes en présence d'hIL-1 $\beta$ (Figure 47).

Nous avons mis en évidence pour la première fois le rôle de Nox4 dans la génération constitutive de radical oxydant sous stress cytokinique dans les chondrocytes C-20/A4.

Pour finir, nous allons nous intéresser à l'impact de cette surexpression de Nox4A-V5/His ou Nox4B-V5/His ou de Nox2 sur la sécrétion de collagénase-1.

\section{III-D-3 Impact de la modulation de la production de ROS sur sur l'expression de la pro MMP-1 dans les lignées surexprimant Nox4A, Nox4B ou Nox2 en présence d'hlL-1 $\beta$ :}

Nous avons démontré que sous hIL-1 $\beta$ la sécrétion de MMP-1 dans le surnageant de milieu de culture est augmentée dans la lignée chondrocytaire immortalisée C-20/A4 (Figures 38 et 42) Cette augmentation de sécrétion est sous la dépendance de dérivés radicalaires de $1^{\prime} \mathrm{O}_{2}{ }^{-}$ puisqu'elle est inhibée par des molécules qui piègent les ROS comme le TIRON et le DPI (figure 42) ou la $\mathrm{N}$ acetyl cystéine (Figure 46)

Pour déterminer et confirmer le rôle de Nox4 dans ce mécanisme, nous avons réalisé exactement la même expérience que celle décrite précédemment, en incubant les différents chondrocytes des lignées sauvages ou transfectées surexprimant soit Nox4A-V5/His, soit Nox4B-V5/His ou Nox2 en présence ou non de l'hIL-1ß.

Après trypsinisation d'une boîte de $175 \mathrm{~cm}^{2}$, les cellules considérées sont mises en culture trois jours dans trois boîtes de $75 \mathrm{~cm}^{2}$ en conditions classiques afin d'obtenir une confluence à $90 \%$. Après trois lavages en EBSS, les cellules sont incubées à $37^{\circ} \mathrm{C}$, en présence de $5 \%$ $\mathrm{CO}_{2}$ avec le milieu de culture sans sérum de veau en présence ou non de $500 \mathrm{pg} / \mathrm{ml}$ d'hIL-1ß pendant $23 \mathrm{~h}$. A T23h, on prélève la totalité du milieu de culture, et, après centrifugation $350 \mathrm{~g}$ durant 5 min à température ambiante, le surnageant est aliquoté puis congelé pour le dosage ELISA de la pro MMP-1, et le dosage des protéines par la méthode de Bradford. La viabilité est vérifiée par dosage de la LDH dans le surnageant de culture. 
Résultats

Les résultats (Figure 48) confirment la surexpression de MMP-1 d'un facteur 6.7 sous stress cytokinique dans la lignée C-20/A4 native $(913 \mathrm{ng} / \mathrm{g}$ de protéine \pm 64 versus $136 \mathrm{ng} / \mathrm{g}$ de protéine \pm 63$)$.

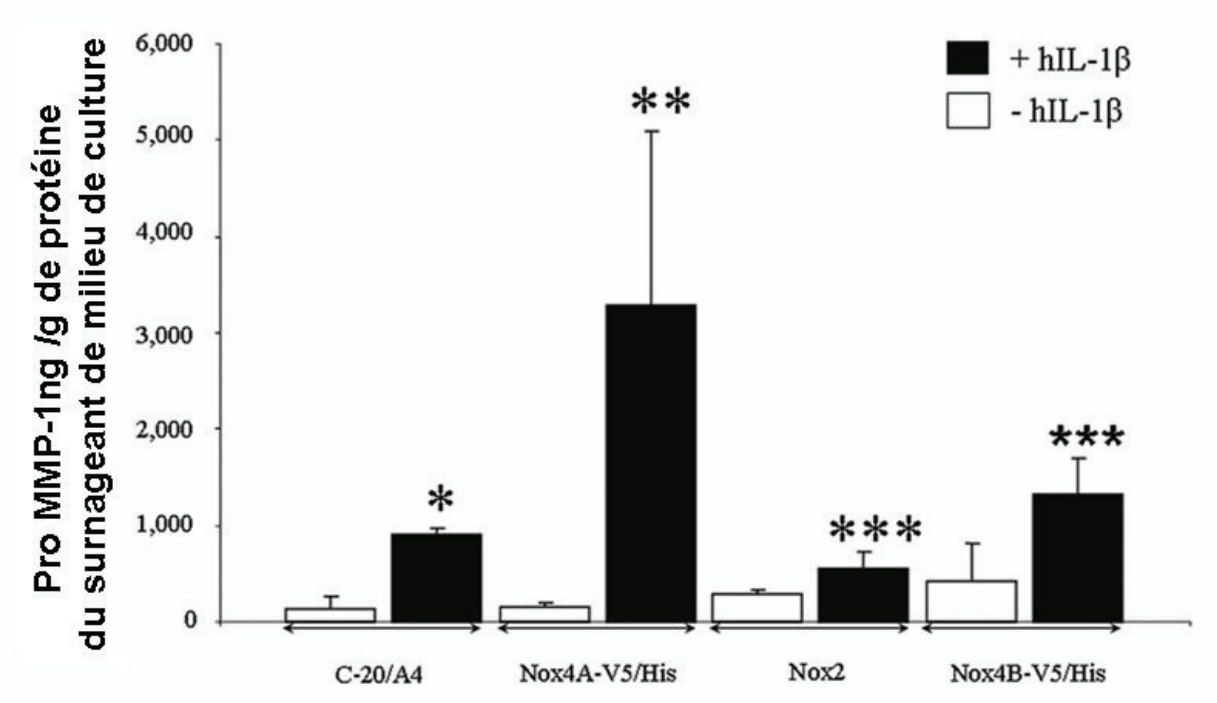

Figure 48 Modulation de l'expression de la pro-MMP-1 par Nox4 sur la lignée chondrocytaire C20/A4.

En condition sans SVF, les chondrocytes C-20/A4 sauvages, ou surexprimant Nox4A-V5/His, Nox4B$\mathrm{V} 5 / \mathrm{His}$ ou Nox2 sont incubés $23 \mathrm{~h}$ avec ou sans $500 \mathrm{pg} / \mathrm{ml}$ d'hIL-1 $\beta$. Après $23 \mathrm{~h}$ d'incubation à $37^{\circ} \mathrm{C}$ et $5 \% \mathrm{CO}_{2}$, on prélève alors la totalité du milieu de culture et après la centrifugation $350 \mathrm{~g}$ durant 5 min à température ambiante, le surnageant est aliquoté puis congelé pour dosage ELISA de la pro MMP-1, et le dosage des protéines par la méthode de Bradford. La viabilité cellulaire est estimée par dosage de la LDH dans le surnageant de milieu de culture. Les résultats sont exprimés en ng/g de protéine du surnageant du milieu de culture et représentent la moyenne de 4 expérimentations identiques $+/-$ DS.

$*: \mathrm{p}<0,05$ versus les chondrocytes sauvage non stimulés, $* * \mathrm{p}<0,05$ versus les chondrocytes sauvage stimulés par hIL- $1 \beta$, et $* * * \mathrm{p}<0,05$ versus les chondrocytes surexprimant Nox4A-V5/His stimulés par hIL- $1 \beta$.

Dans les cellules surexprimant Nox4A-V5/His, cette expression de MMP-1 sous hIL-1ß est augmentée par contre d'un facteur 20 par rapport à ces mêmes cellules non stimulées (3296 $\mathrm{ng} / \mathrm{g}$ protéine \pm 1789 versus $165 \mathrm{ng} / \mathrm{g}$ protéine \pm 26 ).

Le rapport d'expression de MMP-1 est donc augmenté d'un facteur 3,6 entre les cellules surexprimant Nox4 et les cellules sauvages dans les mêmes conditions de contrainte cytokinique (3296 ng g protéine \pm 1789 versus $913 \mathrm{ng} / \mathrm{g}$ de protéine \pm 64 ) (Figure 48).

En outre, nous observons aussi une augmentation de l'expression de la MMP-1 pour les chondrocytes surexprimant Nox2 avec une différence significative par rapport aux cellules sauvages sous le même stress cytokinique $(913 \mathrm{ng} / \mathrm{g}$ de protéine \pm 64 pour C-20/A4 native 
Résultats

versus $560 \mathrm{ng} / \mathrm{g}$ de protéine \pm 171 pour $\mathrm{C}-20 / \mathrm{A} 4$ Nox 2 ; avec un $\mathrm{p}=0,033$ selon le test de student)

Il existe enfin une différence significative ( $p=0,027$ selon le test de student) toujours sous hIL-1 $\beta$ entre les chondrocytes surexprimant Nox2 et ceux surexprimant Nox4A-V5/His (560 ng/g de protéine $\pm 171,12$ pour C-20/A4 Nox2 versus $3296 \mathrm{ng} / \mathrm{g}$ protéine \pm 1789 pour C20/A4 Nox4A-V5/His).

Sous hIL-1 $\beta$, nous assistons à une augmentation de 1'expression de MMP-1 beaucoup plus importante avec les cellules surexprimant Nox4A-V5/His qu'avec les cellules surexprimant Nox2.

Par ailleurs dans le but de démontrer la spécificité de l'augmentation de sécrétion de cette MMP-1 induite par Nox4 nous avons incubé dans les mêmes conditions la lignée surexprimant Nox4B-V5/His, qui est une protéine non fonctionnelle.

Les résultats montrent qu'il existe bien une augmentation faible de l'expression de MMP-1 sous stress cytokinique hIL-1ß sur cette lignée par rapport à la lignée sauvage avec une différence significative ( $\mathrm{p}=0,037$ selon le test de student) $(1313 \mathrm{ng} / \mathrm{g}$ de protéine \pm 383 pour C-20/A4 Nox4B-V5/His versus $136 \mathrm{ng} / \mathrm{g}$ de protéine \pm 63 pour les C-20/A4 natifs); (Figure 48).

Cette augmentation d'expression de MMP-1 est sans commune mesure avec celle retrouvée pour les cellules surexprimant Nox4A-V5/His. La différence est significative $(p=0,05) ;(1313$ $\mathrm{ng} / \mathrm{g}$ de protéine \pm 383 pour C-20/A4 Nox4B-V5/His versus $3296 \mathrm{ng} / \mathrm{g}$ protéine \pm 1789 pour C-20/A4 Nox4A-V5/His).

A noter un « $\mathrm{p} »$ à la limite de la significativité compte tenu d'une barre d'erreur importante pour la lignée C-20/A4 Nox4A-V5/His.

A noter enfin, que nous ne retrouvons pas d'effet dominant négatif de Nox4B sur l'expression de la proMMP-1 comme nous l'avions retrouvé sur la production $\mathrm{d}^{\prime} \mathrm{O}_{2}{ }^{-}$. 
Pour confirmer ces résultats et notamment la spécificité de la sécrétion de MMP-1 induite par Nox4, nous avons réalisé des transfections transitoires comme décrit dans le chapitre matériels et méthodes sur la lignée surexprimant déjà Nox4A-V5/His.

Nous avons transfecté dans ces cellules soit un vecteur vide le pCDNA 3.1, soit un vecteur pCDNA 3.1 Nox4 $\triangle \mathrm{FAD} / \mathrm{NADPH}$ contenant le gène codant pour une forme tronquée de Nox4, $\triangle F A D / N A D P H$. Cette protéine Nox4 $\triangle F A D / N A D P H$ (dont la partie C-terminale contenant les sites de fixation du FAD et du NAD(P)H ont été enlevés), a par ailleurs été décrite comme ayant un effet inhibiteur par compétition sur l'activité de Nox4 (Mahadev et coll. 2004, Hu et coll. 2005). Les cellules C-20/A4 surexprimant Nox4A-V5/His sont transfectées avec le plasmide pCDNA 3.1 V5/His ou le plasmide pCDNA 3.1 Nox4 $\triangle \mathrm{FAD} / \mathrm{NADPH}$ selon la méthode décrite dans le chapitre matériels et méthodes.

Les cellules ainsi transfectées sont alors cultivées dans des boîtes de $25 \mathrm{~cm}^{2}$ (Falcon) en conditions de culture classiques (DMEM/10\% de SVF). Quarante huit heures après la transfection, on analyse l'impact du stress cytokinique sur la quantité de proMMP-1 produite. Ainsi après trois lavages en EBSS, les cellules sont incubées sans SFV dans ces boîtes de 25 $\mathrm{cm}^{2}$ avec ou sans $500 \mathrm{pg} / \mathrm{ml}$ d'hIL- $1 \beta$. Après $23 \mathrm{~h}$ d'incubation à $37^{\circ} \mathrm{C}$ et $5 \% \mathrm{CO}_{2}$, on prélève alors la totalité du milieu de culture, après centrifugation $350 \mathrm{~g}$ durant 5 min à température ambiante. Le surnageant est aliquoté puis congelé pour le dosage de la pro MMP-1 par méthode ELISA, et le dosage des protéines par la méthode de Bradford. La viabilité cellulaire est estimée par dosage de la LDH dans le surnageant de milieu de culture. Les résultats sont exprimés en ng/g de protéine du surnageant du milieu de culture comme précédemment.

Ils montrent (Figure 49) que la production de MMP-1 par les cellules transfectées par le plasmide codant pour Nox $4 \mathrm{FAD} / \mathrm{NADPH}$ est réduite de $66 \%$ par rapport aux cellules transfectées par le vecteur vide ( $74 \mu \mathrm{g} / \mathrm{g}$ de protéine versus $215 \mu \mathrm{g} / \mathrm{g}$ de protéine) en absence d'hIL-1 $\beta$ (Figure 49).

Cette diminution se retrouve aussi dans les mêmes proportions en présence du stress cytokinique d'hIL-1 $\beta$ (les cellules transfectées avec le vecteurs Nox4 $\Delta$ FAD/NADPH (102 $\mu \mathrm{g} / \mathrm{g}$ de protéine) versus les cellules transfectées avec le vecteur vide (305 $\mu \mathrm{g} / \mathrm{g}$ de protéine) (Figure 49).

Cette expérimentation n'a été réalisée qu'une seule fois mais semble confirmer notre hypothèse.

Par ailleurs, il faut signaler une différence positive importante d'un facteur 10 en terme de niveau d'expression de la proMMP-1 dans cette expérience en comparaison aux autres 
expériences de stress cytokinique. Cette différence peut s'expliquer par les conditions différentes de réalisation de la dernière expérience (boite de $25 \mathrm{~cm}^{2}$ versus $75 \mathrm{~cm}^{2}$ ) qui peut suffire à modifier les conditions d'action de l'hIL-1 $\beta$ ou, peut être liée à la transfection ellemême.

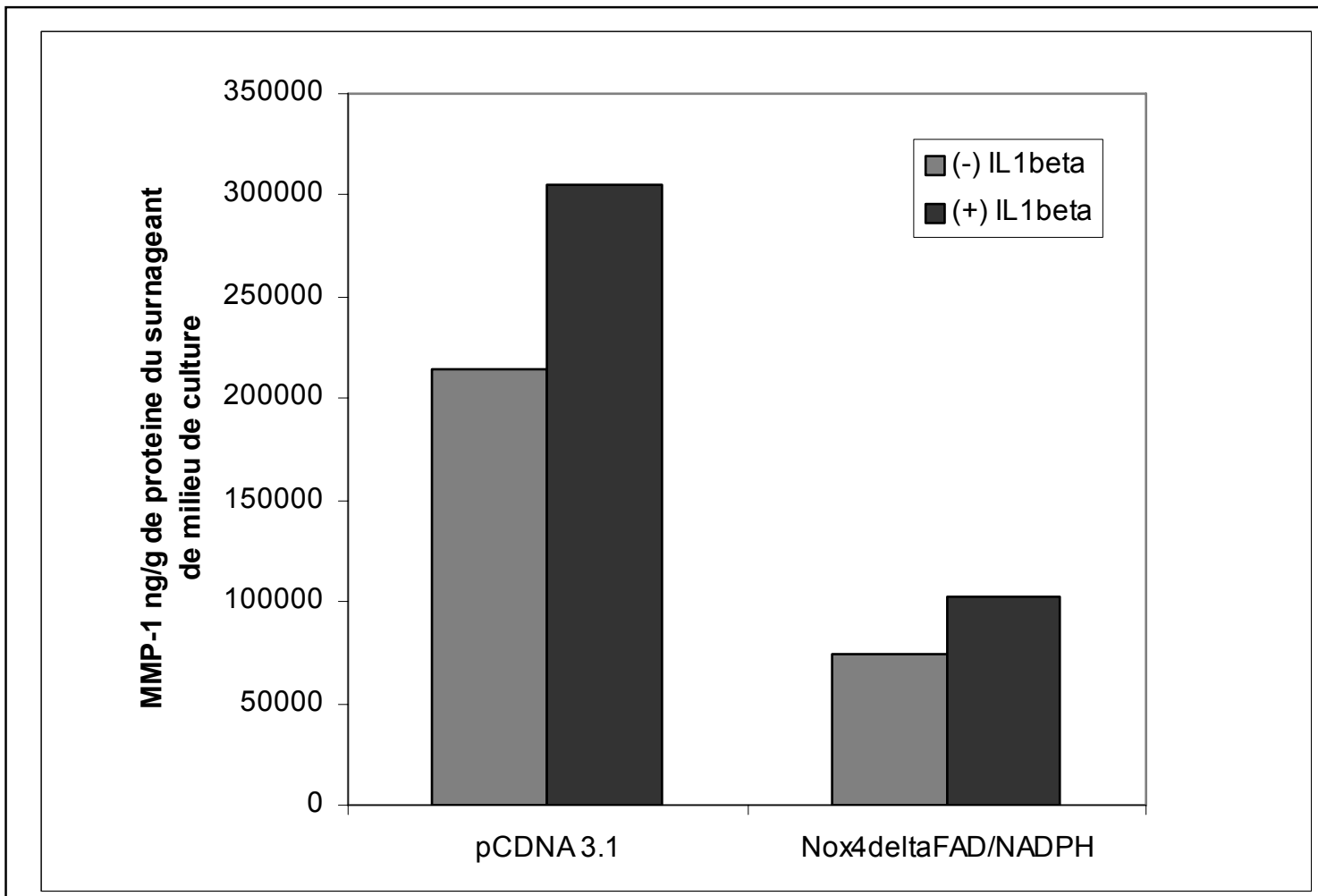

Figure 49 Modulation de l'expression de la pro-MMP-1 par Nox4 sur la lignée chondrocytaire C20/A4 Nox4A-V5/His après transfection avec un plasmide codant pour un dominant négatif de Nox4.

En condition sans SVF, les chondrocytes C-20/A4 surexprimant Nox4A-V5/His et après transfection avec le plasmide pCDNA 3.1 V5/His ou du plasmide pCDNA 3.1 Nox4 $\triangle$ FAD/NADPH sont incubées dans des boîtes de $25 \mathrm{~cm}^{2}$ pendant $23 \mathrm{~h}$ avec ou sans $500 \mathrm{pg} / \mathrm{ml} \mathrm{d'hIL-1 \beta}$. Après $23 \mathrm{~h}$ d'incubation à $37^{\circ} \mathrm{C}$ et $5 \% \mathrm{CO}_{2}$, on prélève alors la totalité du milieu de culture, et après centrifugation $350 \mathrm{~g}$ durant 5 min à température ambiante le surnageant est aliquoté puis congelé pour le dosage ELISA de la pro MMP-1, et le dosage des protéines par la méthode de Bradford,. La viabilité cellulaire est estimée par le dosage de la LDH dans le surnageant de milieu de culture. Les résultats sont exprimés en ng/g de protéine du surnageant du milieu de culture.

Nous pouvons conclure que Nox4 est bien responsable de la production des dérivés réactifs de l'oxygène après un stress cytokinique par l'hIL-1ß, et qu'elle intervient via la production d'ion superoxyde sur la régulation de la synthèse et de la sécrétion de MMP-1. 
Discussion

DISCUSSION 


\section{DISCUSSION}

L'arthrose est une pathologie extrêmement fréquente (Le Pen et coll. 2005). Au plan physiopathologique elle se traduit par une protéolyse matricielle médiée principalement par des métalloprotéases notamment la MMP-1 (Gowen et coll. 1984), mais aussi à un moindre degré la MMP-13 (Kubota et coll. 1997) et les gélatinases (les MMP-2 et MMP-9). Cette activité de protéolyse est sous la dépendance d'un stress cytokinique pro-inflammatoire induit par le TNF-alpha et surtout l'interleukine-1 beta humaine (hIL-1ß) illustré aussi bien dans 1'arthrose (Pelletier et coll. 1989, Gowen et coll. 1984, Kheradmand et coll. 1998) que dans la dégénérescence discale qui se rapproche très fortement de l'arthrose périphérique dans sa physiopathologie (Le Maitre et coll. 2005). Cette contrainte cytokinique induite par l'hIL-1ß conduit à un stress oxydatif avec la production de dérivés radicalaires de l'oxygène (ROS) (Tiku et coll. 1998, Loeser et coll. 2002). Les NAD(P)H oxydases, Nox, sont les principaux médiateurs de la production de ces espèces réactives de l'oxygène; Ces dérivés, outils bactéricides dans la phagocytose, jouent un rôle essentiel dans les cellules et les tissus en tant que messager de signalisation ainsi que dans l'équilibre redox. Les ROS sont impliqués dans les pathologies inflammatoires, et les maladies du vieillissement. Le complexe de la $\mathrm{NAD}(\mathrm{P}) \mathrm{H}$ oxydase des phagocytes est le prototype le mieux caractérisé. La sous-unité $\beta$, gp9 $1^{\text {phox }} \mathrm{du}$ cytochrome $\mathrm{b}_{558}$ est la flavodéshydrogénase en charge du transfert d'électrons depuis le $\mathrm{NAD}(\mathrm{P}) \mathrm{H}$ jusqu'à l'oxygène qui est réduit en anion $\mathrm{O}_{2}{ }^{--}$. Les gènes codant des isoformes de gp91-phox (Nox 1-5) ont été identifiés récemment dans les cellules non phagocytaires suggérant l'existence d'une famille de NADPH oxydases (NOX) au caractère ubiquitaire (Krause et coll. 2004).

Depuis 1997, nous savons que les chondrocytes ont la potentialité de produire des ions $\mathrm{O}_{2}{ }^{--}$ sous contrainte d' hIL-1ß (Hiran et coll. 1997, Moulton et coll. 1997, 1998, Lo et coll. 1998, Van Lent et coll. 2005). Il avait été aussi démontré la présence de gp $91^{\text {phox }}$ et ses partenaires cytosoliques dans une lignée de chondrocytes immortalisés C-20/A4 (Moulton et coll. 1997).

Dans notre étude, nous avons confirmé la présence de Nox2 (gp91 $\left.{ }^{\text {phox }}\right)$ et de ses partenaires principalement $\mathrm{p} 22^{\text {phox }}$ et $\mathrm{p} 67^{\text {phox }}$, et pour la première fois dans la littérature, nous avons mis en évidence la présence d'une isoforme de gp91 ${ }^{\text {phox }}$, l'oxydase Nox4, dans des lignées chondrocytaires.

Le développement de lignées chondrocytaires immortalisées C-20/A4, T/C-28a2, et C-28/I2 a permis d'obtenir des modèles cellulaires validés pour étudier les différentes fonctions des 


\section{Discussion}

chondrocytes et leur rôle dans la physiopathologie de l'arthrose au sein même du cartilage articulaire (Finger et coll. 2004, Goldring et coll. 1994, 2004), en particulier au cours de contraintes cytokiniques induites par l'hIL-1ß (Robbins et coll. 2000).

Nous nous sommes focalisés sur la lignée C-20/A4 qui a la particularité d'exprimer à la fois 1'isoforme Nox2 et Nox4 tant sur le plan transcriptionnel que protéique.

Le complexe oxydase activée est un complexe multi protéique au sein duquel la protéine membranaire gp91 ${ }^{\text {phox }}$ (Nox2) est intimement associée à $\mathrm{p} 22^{\text {phox }}$. Son activation requiert un assemblage avec p4 $47^{\text {phox }}$, p6 $7^{\text {phox }}$ et Rac. Dans le chondrocyte (la lignée C-20/A4), Nox2 est très faiblement exprimée. Par ailleurs $\mathrm{p} 47^{\text {phox }}$, essentielle in vivo pour l'activation de Nox 2 est peu ou pas présente; enfin la production de $\mathrm{O}_{2}{ }^{--}$dans les chondrocytes porcins n'est pas stimulable par l'addition de PMA comme l'a bien démontré Hiran et coll. en 1997. Ces différentes observations sont des arguments en faveur de la non implication de Nox 2 dans le processus oxydatif des chondrocytes.

Nous avons démontré qu'il existe de manière inconstestable une coexpression de Nox4 (isoforme de gp91 ${ }^{\text {phox }}$ ) et $\mathrm{p} 22^{\text {phox }}$, son partenaire, sans lequel il n'y a pas d'activité oxydase catalysée (Ambasta et coll. 2004, Sumimoto et coll. 2005). Nox2 n'est pas en cause dans la synthèse de $\mathrm{O}_{2}{ }^{--}$et donc des ROS.

La surexpression du gène qui code Nox4 contrairement à ce que l'on observe avec Nox2, conduit dans les chondrocytes stimulés par l'interleukine $1 \beta$, à une augmentation significative de la production des espèces réactives de l'oxygène toxiques.

Dans les chondrocytes humains de la lignée C-20/A4, l'activité NAD(P)H oxydase est inductible par l'hIL-1ß. L'isoforme tronquée de Nox4, Nox4B-V5/His (Goyal et coll. 2005) est inactif. Nous avons par la suite révélé un lien étroit entre l'activité $\mathrm{NAD}(\mathrm{P}) \mathrm{H}$ oxydase (Nox4/p22 $\left.2^{\text {phox }}\right)$ qui conduit à une production de radicaux oxydants dans les chondrocytes et l'expression de la collagénase MMP-1 mise en évidence dans le surnageant du milieu de culture des cellules de la lignée C-20/A4 après 23 h de stimulation par l'hIL-1ß. Le rôle des ROS dans la transcription des métalloprotéases a déjà été rapporté (Lo et coll. 1998, Mendes et coll. 2003).

Mais c'est la premiére fois qu'une isoforme de gp9 $1^{\text {phox }}$, Nox4, est mise en cause. 


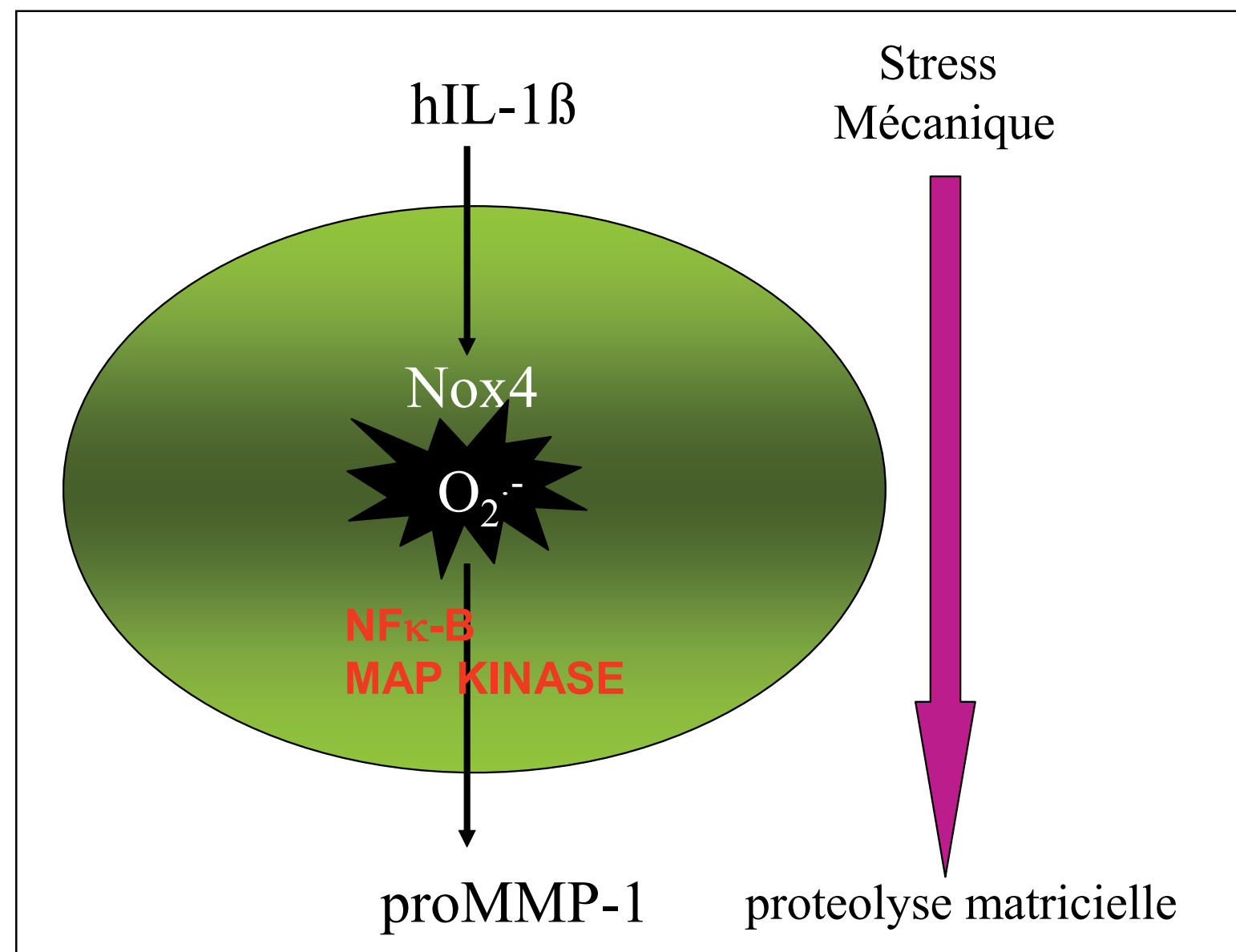

Figure 50 Proposition de la schématisation du rôle de Nox4 dans la physiopathologie de l'arthrose 


\section{Discussion}

Ces résultats montrent le rôle pivot que joue Nox4 dans le stress oxydatif et l'activité transcriptionnelle de la MMP-1 en réponse à une stimulation par hIL-1 $\beta$.

Ces nouvelles données ouvrent la voie à de nouveaux axes de recherche : ils concernent

1. les voies de signalisation qui conduisent à une activation de Nox4 mais aussi de la MMP-1, et des autres métalloprotéases intervenant dans la physiopathologie de l'arthrose sont également à considérer (Lo et coll. 1996, Barchowsky et coll. 2000, Mengshol et coll. 2000, Vincenti et coll. 2001, Liacini et coll. 2002, Martin et coll. 2003)

2. Le stress mécanique dans l'arthrose. Nous savons en effet que le surmenage articulaire et les contraintes surpa physiologiques sont connus depuis longtemps pour être des facteurs de risque de l'arthrose. Le stress mécanique représenté par des cycles de contraintes, en tension, en compression et en étirement, occupe donc une position centrale très en amont dans la physiopathologie de la dégénérescence cartilagineuse. Des études ont démontré que dans le chondrocyte in vitro de telles contraintes mécaniques conduisent à un stress cytokinique (hIL-1 $\beta$ ) et à une augmentation significative de la production de MMP-1 et de la dégradation du cartilage (Fujisawa et coll. 1999, Honda et coll. 2000). Quel est dans ces conditions le rôle de Nox4 ?

3. Une éventuelle approche de thérapeutique Nox4 est en effet une cible potentielle. Des modulateurs préférentiels de Nox4 ont été rapportés dans la littérature. Le cannabidiol (Mc Kallip et coll. 2006) augmente l'expression de l'ARNm de Nox4. Nous sommes à la recherche d'inhibiteurs spécifiques, l'un d'entre eux la Plumbagine (Ding et coll. 2005) est à l'étude. 
Bibliographie

BIBLIOGRAPHIE 


\section{BIBLIOGRAPHIE :}

A

ABO A., PICK E., HALL A., TOTTY N., TEAHAN C.G., SEGAL A.W. Activation of the NADPH oxidase involves the small GTP-binding protein p21rac1. Nature, 353: 668-670, 1991.

ADAMS R. A treatise on rheumatic gout or chronic rheumatic arthritis of all the joints. London : J Churchill, 1857.

THENET S, BENYA PD, DEMIGNOT S, FEUNTEUN J, ADOLPHE M. SV40-immortalization of rabbit articular chondrocytes: alteration of differentiated functions. J Cell Physiol. 150:158-67, 1992.

AGARWAL S, DESCHNER J, LONG P, VERMA A, HOFMAN C, EVANS CH, PIESCO N. Role of NFkappaB transcription factors in anti inflammatory and pro inflammatory actions of mechanical signals. Arthritis Rheum. 50: 3541-8, 2004.

AGO T., KURIBAYASHI F., HIROAKI H., TAKEYA R., ITO T., KOHDA D., SUMIMOTO H. Phosphorylation of p47phox directs phox homology domain from SH3 domain toward phosphoinositides, leading to phagocyte NADPH oxydase activation. Proc. Natl. Acad. Sci., 100: 4474-4479, 2003.

AGO T, KITAZONO T, OOBOSHI H, IYAMA T, HAN Y.H., TAKADA J, WAKISAKA M, IBAYASHI S, UTSUMI H, IIDA M.Nox4 as the major catalytic component of an endothelial NAD(P)H oxidase. Circulation. 109: 227-33, 2004.

AMBASTA RK, KUMAR P, GRIENDLING KK, SCHMIDT HH, BUSSE R, AND BRANDES RP. Direct interaction of the novel Nox proteins with p22phox is required for the formation of a functionally active NADPH oxidase. J Biol Chem 279: 45935-45941, 2004.

ATTUR MG, DAVE M, AKAMATSU M, KATOH M, AMIN AR. Osteoarthritis or osteoarthrosis: the definition of inflammation becomes a semantic issue in the genomic era of molecular medicine. Osteoarthritis Cartilage. 10: 1-4, 2002.

AUSUBEL F., BRENT R., KINGSTON R.E., MOORE D.D., DEIDMAN J.G., SMITH J.A., STRUHL K .Current protocols in molecular biology (John Wiley \& Sons, Inc), 1992.

AYACHE N., BOUMEDIENE K., MATHY-HARTERT M., REGINSTER J.Y., HENROTIN Y., PUJOL J.P. Expression of TGF-betas and their receptors is differentially modulated by reactive oxygen species and nitric oxide in human articular chondrocytes. Osteoarthritis Cartilage. 10: 344-52, 2002.

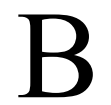

BANFI B, MATURANA A, JACONI S, ARNAUDEAU S, LAFORGE T, SINHA B, LIGETI E, DEMAUREX $\mathrm{N}$, KRAUSE KH. A mammalian $\mathrm{H}+$ channel generated through alternative splicing of the $\mathrm{NAD}(\mathrm{P}) \mathrm{H}$ oxidase homolog NOH-1. Science. 287: 138-42, 2000.

BANFI B., MOLNAR G., MATURANA A., STEGER K., HEGEDUS B., DEMAUREX N., KRAUSE K.H. A $\mathrm{Ca}(2+)$-activated NADPH oxidase in testis, spleen and lymph nodes. J. Biol. Chem., 276: 37594-37601, 2001.

BANFI, B., CLARK, R.A., STEGER, K., KRAUSE, K.H. Two novel proteins activate superoxide generation by the NADPH oxidase NOX1. J. Biol. Chem. 278: 3510-3513, 2003.

BANFI B., MALGRANGE B., KNISZ J., STEGER K., DUBOIS-DAUPHIN M., KRAUSE K.H. NOX3, a superoxide-generating NADPH oxidase of the inner ear. J. Biol. Chem., 279: 46065-46072, 2004.

BARCHOWSKY A, FRLETA D, VINCENTI MP: Integration of the NF-kappaB and mitogen-activated protein kinase/AP-1 pathways at the collagenase-1 promoter: divergence of IL-1 and TNF-dependent signal transduction in rabbit primary synovial fibroblasts. Cytokine 12:1469-1479, 2000. 
BASBAUM C.B., WERB Z. Focalized proteolysis: spatial and temporal regulation of extracellular matrix degradation at the cell surface. Curr. Op. Cell Biol. 8:731-738, 1996.

BAYNES J.W. Role of oxidative stress in development of complications in diabetes. Diabetes. 40: 405-12, 1991.

BENOV L, SZTEJNBERG L, FRIDOVICH I. Critical evaluation of the use of hydroethidine as a measure of superoxide anion radical.: Free Radic Biol Med. 25: 826-31, 1998.

BENTON HP, TYLER JA: Inhibition of cartilage proteoglycan synthesis by interleukin I. Biochem Biophys Res Commum. 154: 421-428, 1988.

BIBERSTINE-KINKADE K.J., DE LEO F.R., EPSTEIN R.I., LE ROY B.A., NAUSEEF W.M., DINAUER M.C. Heme-ligating histidines in flavocytochrome $b_{558}$ : identification of specific histidines in gp91phox. J. Biol. Chem., 276: 31105-31112, 2001.

BOKOCH G.M., QUILLIAM L.A., BOHL B.P., JESAÏTIS A.J., QUINN M.T. Inhibition of Rap1A binding to cytochrome $b_{558}$ of NADPH oxidase by phosphorylation of Rap1A. Science, 254: 1794-1796, 1991.

BORREGAARD, N., HEIPLE, J.M., SIMONS, E.R., CLARK, R.A. Subcellular localization of the bcytochrome component of the human neutrophil microbicidal oxidase: translocation during activation. J. Cell. Biol., 97: 52-61, 1983.

BOUIN A.P., GRANDVAUX N., VIGNAIS P.V., FUCHS A. p40 (phox) is phosphorylated on threonine 154 and serine 315 during activation of the phagocyte NADPH oxidase. Implication of a protein kinase c-type kinase in the phosphorylation process. J. Biol. Chem., 273: 30097-30103, 1998.

BRAR S.S., KENNEDY T.P., STURROCK A.B., HUECKSTEADT T.P., QUINN M.T., WHORTON A.R., HOIDAL J.R. An NAD(P)H oxidase regulates growth and transcription in melanoma cells. Am J Physiol Cell Physiol. 282: C1212-24, 2002.

BRADFORD, MM. A rapid and sensitive method for the quantification of microgram quantities of protein utilizing the principle of protein-dye binding. Anal. Biochem. 72: 248-254, 1976.

BROMBERG, H., PICK, E. Unsaturated fatty acid stimulate NADPH-oxidase superoxide production by cell free system derived from macrophages. Cell. Immunol. 88: 213-221, 1984

BUCKWALTER JA, MANKIN HJ. Articular cartilage: degeneration and osteoarthritis, repair, regeneration, and transplantation. Instr Course Lect. 47: 487-504, 1998.

BURCH W, WEIR S, AND WYK JV: Embryonic chick cartilage produces its own somatomedin-like peptide to stimulate cartilage growth in vitro. Endocrinology (Baltimore). 119:1370-1376, 1986.

BURKHARDT H, SCHWINGEL M, MENNINGER H, MACARTNEY HW, TSCHESCHE H. Oxygen radicals as effectors of cartilage destruction. Direct degradative effect on matrix components and indirect action via activation of latent collagenase from polymorphonuclear leukocytes. Arthritis Rheum. 29: 379-87, 1986.

BURRAGE PS, MIX KS, BRINCKERHOFF CE.Matrix metalloproteinases: role in arthritis. Front Biosci. 11:529-43, 2006.

BURRITT JB, DELEO FR, MCDONALD CL, PRIGGE JR, DINAUER MC, NAKAMURA M, NAUSEEF WM, AND JESAITIS AJ. Phage display epitope mapping of human neutrophil flavocytochrome b558. Identification of two juxtaposed extracellular domains. J Biol Chem 276: 2053-2061, 2001. 


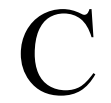

CHARCOT JM. Leçons cliniques sur les maladies des vieillards et les maladies chroniques. Paris : Lecrosnier et Babé, 1890.

CHEVALIER X. Physiopathology of arthrosis. The normal cartilage Presse Med. 27: 75-80, 1998.

CHEVALIER X., RICHETTE P. Cartilage articulaire normal : anatomie, physiologie, métabolisme, vieillissement. Encycl. Méd. Chir. (Elsevier, Paris) Appareil locomoteur. 14-003-A-10, 2005.

CHOMCZYNSKI P., SACCHI N. Single-step method of RNA isolation by acid guanidium thiocyanate-phenolchloroform extraction. Anal. Biochem. 162 : 156-159, 1987.

CHOWDHURY TT, SALTER DM, BADER DL, LEE DA. Integrin-mediated mechanotransduction processes in TGF beta-stimulated monolayer-expanded chondrocytes. Biochem Biophys Res Commun. 318: 873-81, 2004.

CLANCY R, REDISKE J, KOEHNE C, STOYANOVSKY D, AMIN A, ATTUR M, IYAMA K, ABRAMSON SB.Activation of stress-activated protein kinase in osteoarthritic cartilage:evidence for nitric oxide dependence. Osteoarthritis Cartilage. 9: 294-9, 2001.

COLE AA., MARGULIS A., KUETTNER KE. Distinguishing ankle and knee articular cartilage Foot Ankle Clin. 8: 305-316, 2003.

CROSS A.R., RAE J., CURNUTTE J.T. Cytochrome $b-245$ of the neutrophil superoxide-generating system contains two non identical hemes. Potentiometric studies of a mutant form of gp91phox. J. Biol. Chem., 270: 17075-17077, 1995.

CROSS A.R., NOACK D., RAE J., CURNUTTE J.T., HEYWORTH P.G. Hematologically important mutations: the autosomal recessive forms of chronic granulomatous disease (first update). Blood Cells Mol. Dis., 26: 561565,2000 .

COHEN-TANUGI, L., MOREL, F., PILLOUD-DAGHER, M.C., SEIGNEURIN, J.M., FRANCOIS, P., BOST, M., VIGNAIS, P.V. Activation of the $\mathrm{O}_{2}{ }^{-}$generating oxidase in an heterologous cell-free system derived from EBV-transformed human B lymphocytes and bovine neutrophils. Eur. J. Biochem. 202: 649-655, 1991.

CRUVEIHIER J. Observations sur les cartilages diarthrodiaux et les maladies des articulations. Arch Gen M. 4 : 161-198, 1824.

CUCORANU I, CLEMPUS R, DIKALOVA A, PHELAN PJ, ARIYAN S, DIKALOV S, SORESCU D. NAD(P)H Oxidase 4 Mediates Transforming Growth Factor-\{beta $\}$ 1-Induced Differentiation of Cardiac Fibroblasts Into Myofibroblasts Circ Res. 97: 900-7, 2005

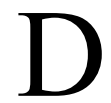

DAHAN I., ISSAEVA I., GORZALCZANY Y., SIGAL N., HIRSHBERG M., PICK E. Mapping of functional domains in the p22phox subunit of flavocytochrome $b_{559}$ participating in the assembly of the NADPH oxidase complex by "peptide walking". J. Biol. Chem., 227: 8421-8432, 2002.

DAVIDSON RK, WATERS JG, KEVORKIAN L, DARRAH C, COOPER A, DONELL ST, CLARK IM. Expression profiling of metalloproteinases and their inhibitors in synovium and cartilage. Arthritis Res Ther. Jul. 8:R124, 2006.

DEL CARLO M JR, LOESER RF: Nitric oxide-mediated chondrocyte cell death requires the generation of additional reactive oxygen species.Arthritis Rheum. 46: 394-403, 2002.

DELCARLO M., LOESER R.F. Chondrocyte cell death mediated by reactive oxygen species-dependent activation of PKC-betaI. Am J Physiol Cell Physiol. 290: C802-11, 2006. 
DE LEO F.R., YU L., BURRITT J.B., LOETTERLE L.R., BOND C.W., JESAÏTIS A.J., QUINN M.T. Mapping sites of interaction of $\mathrm{p} 47$-phox and flavocytochrome $b$ with random-sequence peptide phage display libraries. Proc. Natl. Acad. Sci., 92: 7110-7114, 1995.

DE MENDEZ I., ADAMS A.G., SOKOLIC R.A., MALECH H.L., LETO T.L. Multiple SH3 domain interactions regulate NADPH oxidase assembly in whole cells. EMBO J., 15: 1211-1220, 1996.

DENKO CW, BOJA B, MOSKOWITZ RW. Growth promoting peptides in osteoarthritis: insulin, IGF-1, growth hormone. J Rheumatol. 17: 1217-1221, 1990.

DIJKGRAAF AL., DIJKGRAAF LC, DE BONT LG, BOERING G, LIEM RS.Normal cartilage structure, biochemistry, and metabolism: a review of the literature. J Oral Maxillofac Surg. 53: 924-9, 1995.

DINAUER M.C., ORKIN S.H., BROWN R., JESAÏTIS A.J., PARKOS C.A. the glycoprotein encoded by the Xlinked chronic granulomatous disease locus is a component of the neutrophil cytochrome $b$ complex. Nature, 327: 717-720, 1987.

DINAUER M.C., PIERCE E.A., BRUNS G.A., CURNUTTE J.T., ORKIN S.H.. Human neutrophil cytochrome $b$ light chain (p22phox). Gene structure, chromosomal location, and mutations in cytochrome-negative autosomal recessive chronic granulomatous disease. J. Clin. Invest., 86: 1729-1737, 1990.

DING Y, CHEN ZJ, LIU S, CHE D, VETTER M, CHANG CH. Inhibition of Nox-4 activity by plumbagin, a plant-derived bioactive naphthoquinone. J Pharm Pharmacol. 57: 111-6, 2005.

DISTLER JHW, WENGER RH, GASSMANN M, KUROWSKA M, HIRTH A, GAY S, DISTLER O: Physiologic responses to hypoxia and implications for hypoxia-inducible factors in the pathogenesis of rheumatoid arthritis. Arthritis Rheum. 50: 10-23, 2004.

DOUSSIERE J., LAPORTE F., VIGNAIS P.V. Photolabeling of a $\mathrm{O}_{2}^{-}$generating protein in bovine polymorphonuclear neutrophils cytochrome $b_{558}$ by photoaffinity and immunochemical labelling. Biochem. Biophys. Res. Commun., 139: 85-93, 1986.

DOUSSIERE J., BUZENET G., VIGNAIS P.V Photoaffinity labeling and photoinactivation of the $\mathrm{O}_{2}^{-}-$ generating oxidase of neutrophils by an azido derivative of FAD. Biochemistry, 34: 1760-1770, 1995.

DOZIN B, MALPELI M, CAMARDELLA L, CANCEDDA R AND PIETRANGELO A. Response of young, aged and osteoarthritic human articular chondrocytes to inflammatory cytokines: molecular and cellular aspects, Matrix Biology. 21: 449-459, 2002.

DUMONT P, BURTON M, CHEN QM, FRIPPIAT C, PASCAL T, DIERICK JF, ELIAERS F, CHAINIAUX F, REMACLE J, TOUSSAINT O: Human diploid fibroblasts display a decreased level of c-fos mRNA at 72 hours after exposure to sublethal $\mathrm{H}_{2} \mathrm{O}_{2}$ stress. Ann NY Acad Sci. 908: 306-309, 2000.

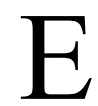

EL BENNA, J. FAUST L.P., BABIOR B.M. The phosphorylation of the respiratory burst oxidase component p47phox during neutrophil activation. Phosphorylation of sites recognized by protein kinase $\mathrm{C}$ and by prolinedirected kinases. J. Biol. Chem., 269: 23431-23436, 1994

EL BENNA J., DANG P.M.C. GAUDRY M., FAY M., MOREL F., HAKIM J., GOUGEROT-POCIDALO M.A. Phosphorylation of the respiratory burst oxidase subunit p67-phox during human neutrophil activation. Regulation by protein kinase C-dependent and independent pathways. J. Biol. Chem., 272: 17204-17208, 1997.

ENDO K, TAKINO T, MIYAMORI H, KINSEN H, YOSHIZAKI T, FURUKAWA M, SATO H. Cleavage of syndecan-1 by membrane type matrix metalloproteinase-1 stimulates cell migration. J Biol Chem. 278: 4076470, 2003. 
ETOH T, INOGUCHI T, KAKIMOTO M, SONODA N, KOBAYASHI K, KURODA J, SUMIMOTO H, NAWATA $H$. Increased expression of NAD $(\mathrm{P}) \mathrm{H}$ oxidase subunits, NOX4 and p22phox, in the kidney of streptozotocin-induced diabetic rats and its reversibity by interventive insulin treatment. Diabetologia. 46: 1428$37,2003$.

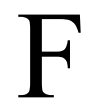

FAUTREL B, HILLIQUIN P, ROZENBERG S, ALLAERT FA, COSTE P, LECLERC A, ROSSIGNOL M. Impact of osteoarthritis: results of a nationwide survey of 10,000 patients consulting for OA. Joint Bone Spine. 72(3): 235-40, 2005.

FELSON DT. Epidemiology of hip and knee. Osteoarthritis Epidemiol Rev. 10: 1-28, 1988.

FELSON DT, ANDERSON JJ, NAIMARK AA. Does smoking protect against osteoarthritis. Arthritis Rheum. 32: $166-172,1989$.

FINGER F, SCHÖRLE C, SODER S, ZIEN A, GOLDRING MB, AND AIGNER T. Phenotypic characterization of human chondrocyte cell line C-20/A4: a comparison between monolayer and alginate suspension culture. Cells Tissues Organs. 178: 65-77, 2004.

FONTAYNE A., DANG P.M., GOUGEROT-POUCIDALO M.A., EL BENNA J. Phosphorylation of p47phox sites by PKC alpha, beta II, delta and zeta: effect on binding to p22phox and on NADPH oxidase activation. Biochemistry., 41: 7743-7750, 2002.

FOREMAN J, DEMIDCHIK V, BOTHWELL JH, MYLONA P, MIEDEMA H, TORRES MA, LINSTEAD P, COSTA S, BROWNLEE C, JONES JD, DAVIES JM, DOLAN L. Reactive oxygen species produced by NADPH oxidase regulate plant cell growth. Nature. 422: 442-6, 2003.

FORMAN H.J., TORRES M. Reactive oxygen species and cell signaling: respiratory burst in macrophage signaling. Am J Respir Crit Care Med. 2002 166: S4-8, 2002.

FREEMAN J.L., LAMBETH J.D. NADPH oxidase activity is independent of p47 $7^{\text {-phox }}$ in vitro. J. Biol. Chem., 271: 22578-22582, 1996.

FREEMONT AJ. The pathophysiology of cartilage and synovium. Br J Rheumatol. 35:10-3, 1996.

FRENKEL SR, CLANCY RM, RICCI JL, DI CESARE PE, REDISKE JJ, ABRAMSON SB. Effects of nitric oxide on chondrocyte migration, adhesion, and cytoskeletal assembly. Arthritis Rheum. 39: 1905-12, 1996.

FUCHS A., BOUIN A.P., RABILLOUD T., VIGNAIS P.V. The 40-kDa component of the phagocyte NADPH oxidase (p40phox) is phosphorylated during activation in differentiated HL60 cells. Eur. J. Biochem., 249: 531539, 1997.

FUJISAWA T, HATTORI T, TAKAHASHI K, KUBOKI T, YAMASHITA A, AND TAKIGAWA M. Cyclic mechanical stress induces extracellular matrix degradation in cultured chondrocytes via gene expression of matrix metalloproteinases and interleukin-1. J Biochem (Tokyo). 125: 966-975, 1999.

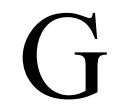

GABIG T.G., CREAN C.D., MANTEL P.L., ROSLI R. Function of wilt-type or mutant Rac2 and Rap1A GTPases in differentiated HL60 cell NADPH oxidase activation. Blood, 85: 804-811, 1995.

GAUDIN P., BERTHIER S., BARRO C., ZAOUI P., MOREL F. Proteolytic potential of human neutrophil membranes. Eur. J. Cell Biol. 72: 345-351, 1997.

GAUDIN P., TROCMÉ C., MONIER F., ZAOUI P., BARROC. , POLACK B., HADJIANA. , BERTHIER S., MOREL F. Protéolyse matricielle, protéolyse focalisée et inflammation Ann. Biol. Clin. 56: 661-9, 1998. 
GAVAZZI G, BANFI B, DEFFERT C, FIETTE L, SCHAPPI M, HERRMANN F, KRAUSE KH. Decreased blood pressure in NOX1-deficient mice. FEBS Lett. 580: 497-504, 2006.

GEISZT M, KOPP JB, VARNAI P, LETO TL. Identification of renox, an NAD(P)H oxidase in kidney. Proc Natl Acad Sci U S A. 97: 8010, 2000.

GEISZT M, LEKSTROM K, WITTA J, LETO T.L. Proteins homologous to p47phox and p67phox support superoxide production by NAD(P)H oxidase 1 in colon epithelial cells. J Biol Chem. 278: 20006-12, 2003 a.

GEIZST M., WITTA J., BAFFI J., LEKSTROM K., LETO T.L. Dual oxidases represent novel hydrogen peroxide sources supporting mucosal surface host defense. FASEB J., 17: 1502-1504, 2003 b.

GEISZT M., LETO T.L. The Nox family of NAD(P)H oxidases: host defense and beyond. J. Biol. Chem. 279 : 51715-18, 2004.

GOLDRING MB. Immortalization of human articular chondrocytes for generation of stable, differentiated cell lines. Methods Mol Med. 100:23-36, 2004

GOLDRING, MB., BIRKHEAD, J. R., SUEN, L. F., YAMIN, R. AND MIZUNO, S. Interleukin-1 betamodulated gene expression in immortalized human chondrocytes. J Clin Invest. 94 (6):2307-16, 1994

GOMEZ D.E, ALONSO D.F., YOSHIJI H., THORGEIRSSON U.P. Tissue inhibitors of métalloprotéinases : structure, regulation and biological function. Eur. J. Cell. Biol. 74: 11-22, 1997.

GORIN Y., RICONO J.M., KIM N.H., BHANDARI B., CHOUDHURY G.G., ABBOUD, H.E. Nox 4 mediates angiotensin II-induced activation of Akt / protein kinase B in mesangial cells. Am. J. Physiol. Renal. Physiol., 285: 219-229, 2004.

GORIN Y, BLOCK K, HERNANDEZ J, BHANDARI B, WAGNER B, BARNES JL, ABBOUD HE. Nox4 $\mathrm{NAD}(\mathrm{P}) \mathrm{H}$ oxidase mediates hypertrophy and fibronectin expression in the diabetic kidney. J Biol Chem. 280: 39616-26, 2005.

GORLACH A, DIEBOLD I, SCHINI-KERTH V.B, BERCHNER-PFANNSCHMIDT U, ROTH U, BRANDES RP, KIETZMANN T, BUSSE R. Thrombin activates the hypoxia-inducible factor-1 signaling pathway in vascular smooth muscle cells: Role of the p22(phox)-containing NADPH oxidase. Circ Res. 89: 47-54, 2001.

GOWEN M, WOOD DD, IHRIE EJ, MEATS JE, AND RUSSELL RG. Stimulation by human interleukin 1 of cartilage breakdown and production of collagenase and proteoglycanase by human chondrocytes but not by human osteoblasts in vitro. Biochim Biophys Acta 797: 186-193, 1984.

GOYAL P, WEISSMANN N, ROSE F, GRIMMINGER F, SCHAFERS HJ, SEEGER W, AND HANZE J. Identification of novel Nox4 splice variants with impact on ROS levels in A549 cells. Biochem Biophys Res Commun 329: 32-39, 2005.

GRIZOT S., GRANDVAUX N., FIESCHI F., FAURE J., MASSENET C., ANDRIEU J.P., FUCHS A., VIGNAIS P.V., TIMMINS P.A., DAGHER M .C., PEBAY-PEYROULA E. Small angle neutron scattering and gel filtration analyses of neutrophil NADPH oxidase cytosolic factors highlight the role of the C-terminal end of p47phox in the association with p40phox. Biochemistry., 40: 3127-3133, 2001.

GROEMPING Y., RITTINGER K. Activation and assembly of the NADPH oxidase: a structural perspective. Biochem. J. 386: 401-416, 2005.

GROSS J., LAPIERE C.M. Collagenolytic activity in amphibian tissues: a tissue culture assay. Proc Natl Acad Sci U S A. 48 :1014-22, 1962.

$\mathrm{H}$

HAATAJA L., GROFFEN J., HEISTERKAMP N. Characterization of RAC3, a novel member of the Rho family. J. Biol. Chem., 272: 20384-20388, 1997. 
HADDAD J.J, LAND S.C. A non-hypoxic, ROS-sensitive pathway mediates TNF-alpha-dependent regulation of HIF-1alpha. FEBS Lett. 505: 269-74, 2001.

HAN C.H., FREEMAN J.L., LEE T., MOTALEBI S.A., LAMBETH J.D. Regulation of the neutrophil respiratory burst oxidase. Identification of an activation domain in p67phox. J. Biol. Chem., 273: 16663-16668, 1998.

HARPER A.M., CHAPLIN M.F., SEGAL A.W. Cytochrome $b_{-245}$ from human neutrophils is a glycoprotein. Biochem. J., 227: 783-788, 1985.

HEBERDEN W. Commentaries on the history and cure of disease. London : T Payne, 1802.

HENROTIN Y, DEBY-DUPONT G, DEBY C, DE BRUYN M, LAMY M, FRANCHIMONT P. Production of active oxygen species by isolated human chondrocytes. Br J Rheumatol. 32: 562-7, 1993.

HENROTIN YE, ZHENG SX, DEBY GP, LABASSE AH, CRIELAARD JM, REGINSTER JY. Nitric oxide downregulates interleukin 1beta (IL-1beta) stimulated IL-6, IL-8, and prostaglandin E2 production by human chondrocytes. J Rheumatol. 25: 1595-601, 1998.

HENROTIN Y, KURZ B, AIGNER T. Oxygen and reactive oxygen species in cartilage degradation: friends or foes? Osteoarthritis Cartilage. 13: 643-54, 2005.

HEYNEMANN, R.A., VERCAUTEREN, R.E. Activation of the NADPH oxidase from horse polymorphonuclear leukocytes in a cell-free system. J. Leukoc. Biol. 36: 751-759, 1984

HEYWORTH P.G., BOHL B.P., BOKOCH G.M., CURNUTTE J.T. Rac translocates independently of the neutrophil NADPH oxidase component p47phox and p67phox. Evidence for its interaction with flavocytochrome $b_{558 .}$ J. Biol. Chem., 269: 30749-30752, 1994.

HILENSKI L.L., CLEMPUS R.E., QUINN M.T, LAMBETH J.D., GRIENDLING K.K. Distinct Subcellular Localizations of Nox1 and Nox4 in Vascular Smooth Muscle Cells.Arterioscler Thromb Vasc Biol. 24: 677-83, 2004

HIRAN TS, MOULTON PJ, AND HANCOCK JT. Detection of superoxide and NADPH oxidase in porcine articular chondrocytes. Free Radic Biol Med 23: 736-743, 1997.

HONDA K, OHNO S, TANIMOTO K, IJUIN C, TANAKA N, DOI T, KATO Y, AND TANNE K. The effects of high magnitude cyclic tensile load on cartilage matrix metabolism in cultured chondrocytes. Eur J Cell Biol 79: 601-609, 2000.

HU T, RAMACHANDRARAO SP, SIVA S, VALANCIUS C, ZHU Y, MAHADEV K, TOH I, GOLDSTEIN BJ, WOOLKALIS M, AND SHARMA K. Reactive oxygen species production via NADPH oxidase mediates TGF-beta-induced cytoskeletal alterations in endothelial cells. Am J Physiol Renal Physiol 289: F816-F825, 2005 .

HUANG, J., HITT, N.D., KLEINBERG, M.E. Stoichiometry of p22phox and gp91phox in phagocyte cytochrome $b_{558}$. Biochemistry, 34: 16753-16757, 1995.

HUNTER W. Of The structure and diseases of articulating cartilages. Phil. Trans. 42: 514-521, 1743

I

IBI M, KATSUYAMA M, FAN C, IWATA K, NISHINAKA T, YOKOYAMA T, YABE-NISHIMURA C. NOX1/NADPH oxidase negatively regulates nerve growth factor-induced neurite outgrowth. Free Radic Biol Med. 40: 1785-95, 2001.

ITO T., MATSUI Y., AGO T., OTA K., SUMIMOTO H. Novel modular domain PB1 recognizes PC motif to mediate functional protein-protein interactions. EMBO J., 20: 3938-3946, 2001. 


\section{J}

JOHNSON K, JUNG A, MURPHY A, ANDREYEV A, DYKENS J, TERKELTAUB R.

Mitochondrial oxidative phosphorylation is a downstream regulator of nitric oxide effects on chondrocyte matrix synthesis and mineralization. Arthritis Rheum. 43: 1560-70, 2000.

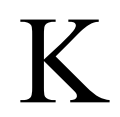

KAMATA H, HIRATA H.Redox regulation of cellular signalling. Cell Signal. 11: 1-14, 1999.

KANG T, NAGASE H, PEI D.Activation of membrane-type matrix metalloproteinase 3 zymogen by the proprotein convertase furin in the trans-Golgi network. ancer Res. 62: 675-81, 2002.

KHERADMAND F, WERNER E, TREMBLE P, SYMONS M, AND WERB Z. Role of Rac1 and oxygen radicals in collagenase-1 expression induced by cell shape change. Science. 280: 898-902, 1998.

KIKUCHI H., HIKAGE M., MIYASHITA H., FUKUMOTO M. NADPH oxidase subunit, gp91phox homologue, preferentially expressed in human colon epithelial cells. Gene, 254: 237-243, 2000.

KLEINBERG M.E., MITAL D., ROTROSEN D., MALECH H.L. Characterization of a phagocyte cytochrome $b_{558}$ 91-kilodalton subunit functional domain : identification of a peptide sequence and amino acids essential for activity. Biochemistry, 31: 2686-2690, 1992.

KNAUS U.G., HEYWORTH P.G., EVANS T., CURNUTTE J.T., BOKOCH G.M. Regulation of phagocyte oxygen radical production by the GTP-binding protein Rac2. Science, 254: 1512-1515, 1991.

KOGA H., TERASAWA H., NUNOI H., TAKESHIGE K., INAGAKI F., SUMIMOTO H. Tetratricopeptide repeat (TPR) motifs of p67phox participate in interaction with the small GTPase Rac and activation of the phagocyte NADPH oxidase. J. Biol. Chem., 274: 25051-25060, 1999.

KOLEV K., LERANT I., TENEKEJIEV K., MACHOVICH R. Regulation of fibrinolytic activity of neutrophil leukocyte elastase, plasmin, and minoplasmin by plasma protease inhibitors. J. Biol. Chem. 269: 17030-17034, 1994.

KONO T, NISHIKORI T, KATAOKA H, UCHIO Y, OCHI M, ENOMOTO K. Spontaneous oscillation and mechanically induced calcium waves in chondrocytes. Cell Biochem Funct. 2006 24: 103-11, 2006.

KOSHKIN V., LOTAN O., PICK E. The cytosolic component p47phox is not a sine qua non participant in the activation of NADPH oxidase but is required for optimal superoxide production. J. Biol. Chem., 271: 3032630329, 1996.

KOSHY P.J., LUNDY C.J., ROWAN A.D., PORTER S., WARDS D.R., HOGAN A., CLARK I.M., CAWSTON T.E. The modulation of matrix metalloproteinase and ADAM gene expression in human chondrocytes by interleukin-1 and oncostatin $\mathrm{M}$ : a time-course study using real-time quantitative reverse transcription-polymerase chain reaction. Arthritis Rheum. 46:961-7, 2002.

KRAUSE KH. Tissue distribution and putative physiological function of NOX family NADPH oxidases. J Infect Dis. 57: S28-9, 2004.

KUBOTA E, IMAMURA H, KUBOTA T, SHIBATA T, Interleukin 1 beta and stromelysin (MMP3) activity of synovial fluid as possible markers of osteoarthritis in the temporomandibular joint. J Oral Maxillofac Surg. 1:20$7 ; 27-8,1997$

KUBOTA E, KUBOTA T, MATSUMOTO J, SHIBATA T, MURAKAMI KI. Synovial fluid cytokines and proteinases as markers of temporomandibular joint disease. J Oral Maxillofac Surg. 156: 192-8, 1998. 
KURIBAYASHI F., NUNOI H., WAKAMATSU K., TSUNAWAKI S., SATO K., ITO T., SUMIMOTO H. The adaptor protein $\mathrm{p} 40$ phox as a positive regulator of the superoxide-producing phagocyte oxidase. EMBO J., 21: 6312-6320, 2002.

KURODA J., NAKAGAWA K., YAMASAKI T., NAKAMURA K., TAKEYA R., KURIBAYASHI F., IMAJOH-OHMI S., IGARASHI K., SHIBATA Y., SUEISHI K., SUMIMOTO H. The superoxide-producing NAD(P)H oxidase Nox4 in the nucleus of human vascular endothelial cells. Genes Cells. 10: 1139-51, 2005.

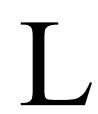

LAEMMLI, U.K., FAVRE, M. Maturation of the head of bacteriophage T4. J. Mol. Biol. 80: 575-599, 1973.

LAMBETH JD, CHENG G, ARNOLD RS, EDENS WA. Novel homologs of gp91phox. Trends Biochem Sci. 25: 459-61, 2000.

LAMBETH, J.D. Nox/Duox family of nicotinamide adenine dinucleotide (phosphate) oxidases. Curr. Opin. Hematol., 9: 11-17, 2002.

LANDER HM, OGISTE JS, TENG KK, NOVOGRODSKY A. p21 ras as a common signaling target of reactive free radicals and cellular redox stress. J Biol Chem. 270: 21195-8, 1995.

LANE NE Exercice : a cause of osteoarthritis. J Rheumatol. 22 (suppl 43) : 3-6, 1995.

LAPOUGE K., SMITH S.J., GROEMPING Y., RITTINGER K. Architecture of the p40-p47-p67phox complex in the resting state of the NADPH oxidase. A central role for p67phox. J. Biol. Chem. 277: 10121-10128, 2002.

LARDY B, BOF M, AUBRY L, PACLET MH, MOREL F, SATRE M, KLEIN G. NADPH oxidase homologs are required for normal cell differentiation and morphogenesis in Dictyostelium discoideum. Biochim Biophys Acta. 1744:199-212, 2005.

LEQUESNE M. MENKES C.J. Atlas de l'arthrose. Laboratoire NEGMA juillet 1995.

LASSEGUE B, SORESCU D, SZOCS K, YIN Q, AKERS M, ZHANG Y, GRANT SL, LAMBETH JD, GRIENDLING KK. Novel gp91 (phox) homologues in vascular smooth muscle cells: nox1 mediates angiotensin II-induced superoxide formation and redox-sensitive signaling pathways. Circ Res. 88: 888-94, 2001.

LASSEGUE B., CLEMPUS R.E. Vascular NAD(P)H oxidases: specific features, expression, and regulation. Am. J. Physiol. Regul. Integr. Comp. Physiol. 285: R277-97, 2003.

LE MAITRE CL, FREEMONT AJ, AND HOYLAND JA. The role of interleukin-1 in the pathogenesis of human intervertebral disc degeneration. Arthritis Res Ther 7: R732-R745, 2005.

LE PEN C. REYGROBELLET C. GERENTES I. Financial cost of osteoarthritis in France the "COART" France study. Joint Bone Spine. 72 : 567-70, 2005.

LEROY V, MONIER F, BOTTARI S, TROCME C, STURM N, HILLERET MIN, MOREL F, ZARSKI JP. Circulating matrix metalloproteinases 1, 2, 9 and their inhibitors TIMP-1 and TIMP-2 as serum markers of liver fibrosis in patients with chronic hepatitis C: comparison with PIIINP and hyaluronic acid. Am J Gastroenterol. 99 : 271-9, 2004.

LETO T.L. ADAMS A.G. DE MENDEZ I. Assembly of the phagocyte NADPH oxidase: Binding of Src homology 3 domains to proline-rich targets. Proc. Natl. Acad. Sci., 91: 10650-10654, 1994.

LEUSEN J.H., DE BOER M., BOLSCHER B.G., HILARIUS P.M., WEENING R.S., OCHS H.D., ROOS D., VERHOEVEN A.J. A point mutation in gp91phox of cytochrome $b_{558}$ of the human NADPH oxidase leading to defective translocation of the cytosolic proteins p47phox and p67phox. J. Clin. Invest., 93: 2120-2126, 1994.

LEVY E, FERME A, PEROCHEAU D, BONO I. Les coûts socioéconomiques de l'arthrose en France. Rev Rhum Mal Osteoartic. 60 : 63S-67S, 1993. 
LI WQ, QURESHI HY, LIACINI A, DEHNADE F, ZAFARULLAH M Transforming growth factor Beta1 induction of tissue inhibitor of metalloproteinases 3 in articular chondrocytes is mediated by reactive oxygen species. Free Radic Biol Med. 7: 196-207, 2004.

LI J, STOUFFS M, SERRANDER L, BANFI B, BETTIOL E, CHARNAY Y, STEGER K, KRAUSE KH, JACONI ME. The NADPH Oxidase NOX4 Drives Cardiac Differentiation: Role in Regulating Cardiac Transcription Factors and MAP Kinase Activation. Mol Biol Cell. [ahead of print], 2006.

LI N., YI F.X., SUPRRIER J.L. Production of superoxide through NADH oxidase in thick ascending limb of Henle's loop in rat kidney. Am J Physiol-Renal Physiol. 282: F1111-F1119, 2002.

LO YY, CRUZ TF. Involvement of reactive oxygen species in cytokine and growth factor induction of c-fos expression in chondrocytes. J Biol Chem. 270: 11727-30, 1995.

LO YY, CONQUER JA, GRINSTEIN S, AND CRUZ TF. Interleukin-1 beta induction of c-fos and collagenase expression in articular chondrocytes: involvement of reactive oxygen species. Cell Biochem 69: 19-29, 1998.

LO YY, WONG JM, CRUZ TF. Reactive oxygen species mediate cytokine activation of c-Jun NH2-terminal kinases. Biol Chem. 271:15703-7, 1996.

LOESER RF, CARLSON CS, DEL CARLO M, COLE A: Detection of nitrotyrosine in aging and osteoarthritic cartilage: Correlation of oxidative damage with the presence of interleukin-1beta and with chondrocyte resistance to insulin-like growth factor 1.Arthritis Rheum. 46: 2349-2357, 2002.

LOMAX K.J., LETO T.L., NUNOI H., GALLIN J.I., MALECH H.L. Recombinant 47-kilodalton cytosol factor restores NADPH oxidase in chronic granulomatous disease. Science, 245: 409-412, 1989.

LOPES L.R., DAGHER M.C., GUTIERREZ A., YOUNG B., BOUIN A.P., FUCHS A., BABIOR, B.M. Phosphorylated p40phox as a negative regulator of NADPH oxidase. Biochemistry, 43: 3723-3730, 2004.

LIACINI A, SYLVESTER J, LI WQ, AND ZAFARULLAH M. Inhibition of interleukin-1-stimulated MAP kinases, activating protein-1 (AP-1) and nuclear factor kappa B (NF-kappa B) transcription factors downregulates matrix metalloproteinase gene expression in articular chondrocytes. Matrix Biol 21: 251-262, 2002.

LU Y, WAHL LM.Oxidative stress augments the production of matrix metalloproteinase-1, cyclooxygenase-2, and prostaglandin E2 through enhancement of NF-kappa B activity in lipopolysaccharideactivated human primary monocytes. J Immunol. 175: 5423-9, 2005.

$\mathrm{M}$

MCKALLIP RJ, JIA W, SCHLOMER J, WARREN JW, NAGARKATTI PS, NAGARKATTI M. Cannabidiolinduced apoptosis in human leukemia cells: A novel role of cannabidiol in the regulation of p22phox and Nox4 expression. Mol Pharmacol. 70:897-908, 2006

MAHADEV K, MOTOSHIMA H, WU X, RUDDY JM, ARNOLD RS, CHENG G, LAMBETH JD, AND GOLDSTEIN BJ. The NAD(P)H oxidase homolog Nox4 modulates insulin-stimulated generation of $\mathrm{H}_{2} \mathrm{O}_{2}$ and plays an integral role in insulin signal transduction. Mol Cell Biol 24: 1844-1854, 2004.

MALY F.E., QUILLIAM L.A., DORSEUIL O., DER C.J., BOKOCH G.M. Activated or dominant inhibitory mutants of Rap1A decrease the oxidative burst of Epstein-Barr virus transformed human B lymphocytes. J. Biol. Chem., 269: 18743-18746, 1994.

MARTEL-PELLETIER J, ALAAEDDINE N, PELLETIER JP. Cytokines and their role in the pathophysiology of osteoarthritis Front Biosci. 15: D694-703, 1999.

MARTEL-PELLETIER J, MCCOLLUM R, DIBATTISTA J, FAURE MP, CHIN JA, FOURNIER S , ET AL. The interleukin-1 receptor in normal and osteoarthritic human articular cartilage. Arthritis Rheum. 35: 530-540, 1992. 
MARTIN G, BOGDANOWICZ P, DOMAGALA F, FICHEUX H, PUJOL JP. Rhein inhibits interleukin-1 betainduced activation of MEK/ERK pathway and DNA binding of NF-kappa B and AP-1 in chondrocytes cultured in hypoxia: a potential mechanism for its disease-modifying effect in osteoarthritis. Inflammation. 27: 233-46, 2003.

MARTIN G, ANDRIAMANALIJAONA R, GRASSEL S, DREIER R, MATHY-HARTERT M, BOGDANOWICZ P, BOUMEDIENE K, HENROTIN Y, BRUCKNER P, PUJOL JP. Effect of hypoxia and reoxygenation on gene expression and response to interleukin-1 in cultured articular chondrocytes. Arthritis Rheum. 50:3549-60, 2004.

MARTIN JA, BROWN TD, HEINER AD, BUCKWALTER JA. Chondrocyte senescence, joint loading and osteoarthritis. Clin Orthop Relat Res. 427: S96-103, 2004.

MATHY-HARTERT M, DEBY-DUPONT GP, REGINSTER JY, AYACHE N, PUJOL JP, HENROTIN YE. Regulation by reactive oxygen species of interleukin-1beta, nitric oxide and prostaglandine(E2) production by human chondrocytes. Osteoarthritis Cartilage. 10: 547-55, 2002.

MATHY-HARTERT M., MARTIN G., DEVEL P., DEBY-DUPONT G., PUJOL J.P., REGINSTER J.Y, HENROTIN Y. Reactive oxygen species downregulate the expression of pro-inflammatory genes by human chondrocytes. Inflamm Res. 52:111-8, 2003.

MATHY-HARTERT M, BURTON S, DEBY-DUPONT G, DEVEL P, REGINSTER JY, HENROTIN Y.Influence of oxygen tension on nitric oxide and prostaglandin E2 synthesis by bovine chondrocytes. Osteoarthritis Cartilage. 13:74-9, 2005.

MATTHEWS JR, WAKASUGI N, VIRELIZIER JL, YODOI J, HAY RT. (1992) - Thioredoxin regulates the DNA binding activity of NF-kappa B by reduction of a disulphide bond involving cysteine 62. Nucleic Acids Res. 20: 3821-30, 1992.

MAQUART FX, BELLON G, PASCO S, MONBOISSE JC. Matrikines in the regulation of extracellular matrix degradation. Biochimie. 87: 353-60, 2005.

MAZIERES B., BLANCKAERT A., ARLET J. La problématique pratique de l'arthrose en 1988. Rev Rhum Mal Osteoartic. 56 : 173-179, 1989.

MAZIERES B., TRESSOL-VERROUIL E. Généralités sur l'arthrose. Encycl. Méd. Chir. (Elsevier, Paris) Appareil locomoteur. 14-003-C-10, 1997.

MAZZETTI I., GRIGOLO B., PULSATELli L., DOLZANI P., SILVESTRI T., ROSETI L., MELICONI R., FACCHINI A. Differential roles of nitric oxide and oxygen radicals in chondrocytes affected by osteoarthritis and rheumatoid arthritis. Clin Sci (Lond). 101: 593-9, 2001.

MENDES AF, CARVALHO AP, CARAMONA MM, LOPES MC. Diphenyleneiodonium inhibits NF-kappaB activation and iNOS expression induced by IL-1beta: involvement of reactive oxygen species. Mediators Inflamm. 10:209-15, 2001.

MENDES AF, CARVALHO AP, CARAMONA MM, AND LOPES MC. Differential roles of hydrogen peroxide and superoxide in mediating IL-1-induced NF-kappa B activation and iNOS expression in bovine articular chondrocytes. J Cell Biochem 88: 783-793, 2003.

MENGSHOL JA, VINCENTI MP, COON CI, BARCHOWSKY A, BRINCKERHOFF CE: Interleukin-1 induction of collagenase 3 (matrix metalloproteinase 13) gene expression in chondrocytes requires p38, c-Jun Nterminal kinase, and nuclear factor kappaB: differential regulation of collagenase 1 and collagenase 3. Arthritis Rheum. 43: 801-811, 2000.

MEYER J.W., SCHMITT M.E. A central role for the endothelial NADPH oxidase in atherosclerosis. FEBS Lett. 472: 1-4, 2000. 
MICHAELIS J, VISSERS MC, WINTERBOURN CC. Different effects of hypochlorous acid on human neutrophil metalloproteinases: activation of collagenase and inactivation of collagenase and gelatinase. Arch Biochem Biophys. 292: 555-62, 1992.

MILLWARD-SADLER SJ, WRIGHT MO, DAVIES LW, NUKI G, SALTER DM. Mechanotransduction via integrins and interleukin-4 results in altered aggrecan and matrix metalloproteinase 3 gene expression in normal, but not osteoarthritic, human articular chondrocytes. Arthritis Rheum. 43:2091-9, 2000.

MONTERO I, ORBE J, VARO N, BELOQUI O, MONREAL JI, RODRIGUEZ JA, DIEZ J, LIBBY P, PARAMO JA. C-reactive protein induces matrix metalloproteinase-1 and -10 in human endothelial cells: implications for clinical and subclinical atherosclerosis. J Am Coll Cardiol. 47: 1369-78, 2006.

MOREL F., DOUSSIERE J., STASIA M.J., VIGNAIS P.V. The respiratory burst of bovine neutrophils. Role of a $b$ type cytochrome and coenzyme specificity. Eur. J. Biochem., 152: 669-679, 1985.

MOREL F., DIDIER F., BERTHIER S., DEWALD B. Purification of gelatinase secreted by human polynuclear neutrophils. Ann Biol Clin.49:468-76, 1991.

MOREL F., DOUSSIERE J., VIGNAIS, P.V. The superoxide-generating oxidase of phagocytic cells. Physiological, molecular and pathology aspects. Eur. J. Biochem., 201: 523-546, 1991.

MOREL F., BOULAY F., DOUSSIERE J., VIGNAIS P.V. Bases moléculaires de la granulomatose septique chronique. Med. Sci. 8: 912-920, 1992.

MORT JS, BILLINGTON CJ.Articular cartilage and changes in arthritis: matrix degradation. Arthritis Res. 3:337-41, 2001.

MOULTON, P. J., HIRAN, T. S., GOLDRING, M. B. ET HANCOK, J. T.. Detection of protein and mRNA of various components of the NADPH oxidase complex in an immortalized human chondrocyte line. Br. J. Rheumatol. 36: 522-529, 1997.

MOULTON PJ, GOLDRING MB, AND HANCOCK JT. NADPH oxidase of chondrocytes contains an isoform of the gp91phox subunit. Biochem J 329: 449-451, 1998.

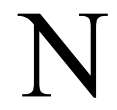

NAGASE H. Activation mechanisms of matrix metalloproteinases. Biol. Chem. 378: 151-160, 1997.

NAGASE H. WOESSNER J.F. Matrix Metalloproteinases . J.B.C. 274: 21491-94, 1999.

NAUSEEF, W.M., VOLPP, B.D., CLARK, R.A. Immunochemical and electrophoretic analyses of phosphorylated native and recombinant neutrophil oxidase component p47-phox. Blood. 76: 2622-2629, 1990.

NICOLS EH. RICHARDSON FL. Arthritis deformans. J Med Res 21 : 149-222, 1909.

NISHIMURA S, AKAGI M, YOSHIDA K, HAYAKAWA S, SAWAMURA T, MUNAKATA H, HAMANISHI C. Oxidized low-density lipoprotein (ox-LDL) binding to lectin-like ox-LDL receptor-1 (LOX-1) in cultured bovine articular chondrocytes increases production of intracellular reactive oxygen species (ROS) resulting in the activation of NF-kappaB. Osteoarthritis Cartilage. 12: 568-76, 2004.

NISIMOTO Y., OGAWA H., MIYANO K., TAMURA M. Activation of the flavoprotein domain of gp91phox upon interaction with N-terminal p67phox (1-210) and the Rac complex. Biochemistry, 43: 9567-9575, 2004.

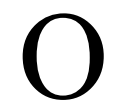

OSBORNE KD, TRIPPEL SB, MANKIN HJ. Growth factor stimulation of adult cartilage. J Orthop Res. 7: 35 42, 1989. 
$\mathrm{P}$

PACLET, M.H., COLEMAN, A.W., VERGNAUD, S., MOREL, F.- P67phox mediated NADPH oxidase assembly : imaging of cytochrome $b_{558}$ liposomes by atomic force microscopy. Biochemistry 39: 9302-9310, 2000.

PAFFENHOLZ R., BERGSTROM R.A, PASUTTO F., WABNITZ P., MUNROE R.J., JAGLA W., HEINZMANN U., MARQUARDT A., BAREISS A., LAUFS J., RUSS A., STUMM G., SCHIMENTI J.C., BERGSTROM D.E. Vestibular defects in head-tilt mice result from mutations in Nox3, encoding an NADPH oxidase. Genes Dev, 18: 486-491, 2004.

PALOTIE A, VÄISÄNEN P, OTT J.Predisposition to familial osteoarthritis linked to type II collagen gene. Lancet. 1: 924-927, 1989.

PARDO A, SELMAN. MMP-1: the elder of the family. M.Int J Biochem Cell Biol.37:283-8, 2005

PARK M.Y., IMAJOH-OHMI S., NUNOI H., KANEGASAKI S. Synthetic peptides corresponding to various hydrophilic regions of the large subunit of cytochrome $b_{558}$ inhibit superoxide generation in a cell-free system from neutrophils. Biochem. Biophys. Res. Commun., 234: 531-536, 1997.

PELLETIER JP, MARTEL-PELLETIER J. Evidence for the involvement of interleukin 1 in human osteoarthritic cartilage degradation: protective effect of NSAID. J Rheumatol. 16:19-27, 1989.

PICK E., GORZALCZANY Y., ENGEL S. Role of the rac1 p21-GDP-dissociation inhibitor for rho heterodimer in the activation of the superoxide-forming NADPH oxidase of macrophages. Eur. J. Biochem., 217: 441-455, 1993.

PILLOUD-DAGHER, M.C., VIGNAIS, P.V. Purification and characterization of an oxidase activating factor of 63 kilodaltons from bovine neutrophils. Biochemistry. 30: 2753-2760, 1991.

PORTER C.D., KURIBAYASHI F., PARKAR M.H., ROOS D., KINNON C. Detection of gp91phox precursor protein in B-cell lines from patients with X-linked chronic granulomatous disease as an indicator for mutations impairing cytochrome $b_{558}$ biosynthesis. Biochem. J., 315: 571-575, 1996.

PRIAULT M., BESSOULE JC., GRELAUD-COQ A., CAMOUGRAND N. ET MANON S. Bax-induced cell death in yeast depends on mitochondrial lipid oxidation Eur. J. Biochem. 269: 5440-5450, 2002.

PUJOL JP. L"'aggrécanase, enzyme-clé de la dégradation du cartilage dans l'arthrose. Médecine / Sciences. 16:276-8, 1998.

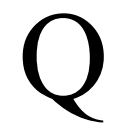

QUILLIAM L.A., MUELLER H., BOHL B.P., PROSSNITZ V., SKLAR L.A., DER, C.J., BOKOCH, G.M. Rap1A is a substrate for cyclic AMP-dependent protein kinase in human neutrophils. J. Immunol., 147: 1628$1635,1991$.

QUINN M.T., PARKOS C.A., WALKER L., ORKIN S.H., DINAUER M.C. JESAÏTIS A.J. Association of a Ras-related protein with cytochrome $b$ of human neutrophils. Nature, 342: 198-200, 1989.

QUINN M.T., MULLEN M.L., JESAÏTIS A.J., LINNER J.G. Subcellular distribution of the Rap1A protein in human neutrophils: colocalization and cotranslocation with cytochrome $b_{559}$. Blood, 79: 1563-1573, 1992.

QUINN M.T., GAUSS K.A. Structure and regulation of the neutrophil respiratory burst oxidase: comparison with non phagocyte oxidases. J. Leukoc. Biol., 76: 760-781, 2004. 


\section{$\mathrm{R}$}

RAVEL P., LEDERER F. Inactivation of NADPH oxidase from human neutrophils by affinity labeling with pyridoxal 5'-diphospho-5'-adenosine. Biochem. Biophys. Res. Commun., 181: 1259-1265n, 1991.

RAVANTI L, KAHARI VM. Matrix metalloproteinases in wound repair (review). Int J Mol Med. 6: 391-407, 2000 .

REUNANEN N, WESTERMARCK J, HAKKINEN L, HOLMSTROM TH, ELO I, ERIKSSON JE, KAHARI VM: Enhancement of fibroblast collagenase (matrix metalloproteinase-1) gene expression by ceramide is mediated by extracellular signal-regulated and stress-activated protein kinase pathways. J Biol Chem. 273: 5137$5145,1998$.

ROBBINS JR, THOMAS B, TAN L, CHOY B, ARBISER JL, BERENBAUM F, AND GOLDRING MB. Immortalized human adult articular chondrocytes maintain cartilage-specific phenotype and responses to interleukin-1 $\beta$. Arthritis Rheum 43: 2189-2201, 2000.

ROOS D., VAN BRUGGEN R., MEISCHL C. Oxidative killing of microbes by neutrophils. Microbes Infect., 5: 1307-1315, 2003.

ROSS M. TAYLOR, JAMES B. BURRITT, DANAS BANIULIS, THOMAS R. FOUBERT, CONNIE I. LORD, MARY C. DINAUER, CHARLES A. PARKOS, AND ALGIRDAS J. JESAITIS. Site-Specific Inhibitors of NADPH Oxidase Activity and Structural Probes of Flavocytochrome b: Characterization of Six Monoclonal Antibodies to the p22 ${ }^{\text {phox }}$ Subunit. J. Immunol.173: 7349-7357, 2004.

ROTROSEN D., KLEINBERG M.E., NUNOI H., LETO T., GALLIN J.I., MALECH H.L. vidence for a functional cytoplasmic domain of phagocyte oxidase cytochrome $b_{558}$. J. Biol. Chem., 265: 8745-8750, 1990.

ROTROSEN D., YEUNG C.L., LETO T.L., MALECH H.L., KWONG C.H. Cytochrome $b_{558}$ : the flavinbinding component of the phagocyte NADPH oxidase. Science, 256: 1459-1462, 1992.

ROVETTA G, BUFFRINI L, MONTEFORTE P, GRIGNOLO MC, MOLFETTA L. HLA-DRB1alleles and osteoarthritis in a group of patients living in Liguria-Italy. Minerva Med. 97 (3):271-5, 2006.

ROYER-POKORA, B., KUNKEL, L.M., MONACO, A.P., GOFF, S.C, NEWBURGER, P.E., BAEHNER, R.L., COLE, F.S., CURNUTTE, J.T., ORKIN, S.H. cloning the gene for an inherited human disorder-chronic granulomatous disease- on the basis of its chromosomal location. Nature, 322: 32-38, 1986.

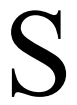

SALCEDA S, CARO J. Hypoxia-inducible factor 1alpha (HIF-1alpha) protein is rapidly degraded by the ubiquitin-proteasome system under normoxic conditions. Its stabilization by hypoxia depends on redox-induced changes. J Biol Chem. 272: 22642-7, 1997.

SALTER DM, WRIGHT MO, MILLWARD-SADLER SJ.NMDA receptor expression and roles in human articular chondrocyte mechanotransduction. Biorheology. 41:273-81, 2004.

SAMBROOK J., FRITSCH E.F., MANIATIS T. Molecular cloning: a laboratory manual. (2nd Ed.). Cold Spring Harbor, NY: Cold Spring Harbor Laboratory Press, 1989.

SATHYAMOORTHY M., DE MENDEZ I., ADAMS A.G., LETO T.L. p40 (phox) down-regulates NADPH oxidase activity through interactions with its SH3 domain. J. Biol. Chem., 272: 9141-9146, 1997.

SATO H, KINOSHITA T, TAKINO T, NAKAYAMA K, SEIKI M. Activation of a recombinant membrane type 1-matrix metalloproteinase (MT1-MMP) by furin and its interaction with tissue inhibitor of metalloproteinases(TIMP)-2. FEBS Lett. 393: 101-4, 1996. 
SEGAL A.W., JONES O.T. Novel cytochrome $b$ system in phagocytic vacuoles of human granulocytes. Nature, 276: 515-517, 1978

SEGAL A.W., HEYWORTH P.G., COCKCROFT S., BARROWMAN M.M. Stimulated neutrophils from patients with autosomal recessive chronic granulomatous disease fail to phosphorylate a Mr-44,000 protein. Nature, 316: 547-549, 1985.

SEGAL A.W., WEST I., WIENTJES F., NUGENT J.H., CHAVAN A.J., HALEY B., GARCIA R.C., ROSEN H., SCRACE G. Cytochrome b-245 is a flavocytochrome containing FAD and the NADPH-binding site of the microbicidal oxidase of phagocytes. Biochem. J., 284: 781-788, 1992.

SEIGNEURIN J.M., GUILBERT B., BOURGEAT M.J., AVRAMEAS S. () - Polyspecific natural antibodies and autoantibodies secreted by human lymphocytes immortalized with Epstein-Barr virus. Blood 71: 581-585, 1988.

SHABANI F, MCNEIL J, TIPPETT L. The oxidative inactivation of tissue inhibitor of metalloproteinase-1 (TIMP-1) by hypochlorous acid (HOCI) is suppressed by anti rheumatic drugs. Free Radic Res. 28: 115-23, 1998.

SHAO D., SEGAL A.W., DEKKER L.V. Lipid rafts determine efficiency of NADPH oxidase activation in neutrophils. FEBS Lett., 550: 101-106, 2003.

SHIOSE A., KURODA J., TSUNUYA K., HIRAI M., HIRAKATA H., NAITO S., HATTORI M., SAKAKI Y., SUMIMOTO H. A novel superoxide-producing NADPH oxidase in kidney. J. Biol. Chem., 276: 1417-1423, 2001 .

SLACK J, MCMAHAN C.J., WAUGH S., SCHOOLEY K., SPRIGGS M.K., SIMS J.E., DOWER S.K: Independent binding of interleukin-1 alpha and interleukin-1 beta to type I and type II interleukin-1 receptors. $J$ Biol Chem. 268: 2513-24, 1993.

SOMERVILLE R.P. OBLANDER S.A. APTE S.S. Matrix metalloproteinases: old dogs with new tricks. Genome Biol. 4: 216, 2003.

SOMEYA A., NUNOI H., HASEBE T., NAGAOKA I. Phosphorylation of p40phox during activation of neutrophil NADPH oxidase. J. Leukoc. Biol. 66: 851-857, 1999.

SOMMARIN Y, LARSSON T, AND HEINEGARD D : Chondrocyte-matrix interactions. Exp. Cell. Res. 184: 181-192, 1989.

STADLER J, STEFANOVIC-RACIC M, BILLIAR TR, CURRAN RD, MCINTYRE LA, GEORGESCU HI, SIMMONS RL, EVANS CH. Articular chondrocytes synthesize nitric oxide in response to cytokines and lipopolysaccharide. J Immunol. 147: 3915-3920, 1991.

STASIA MJ, LARDY B, MATURANA A, ROUSSEAU P, MARTEL C, BORDIGONI P, DEMAUREX N, MOREL F. Molecular and functional characterization of a new X-linked chronic granulomatous disease variant (X91+) case with a double missense mutation in the cytosolic gp91phox C-terminal tail. Biochim Biophys Acta 1586: 316-30, 2002.

STEFANOVIC-RACIC M, MORALES TI, TASKIRAN D, MCINTYRE LA, EVANS CH. The role of nitric oxide in proteoglycan turnover by bovine articular cartilage organ cultures. J Immunol. 156: 1213-1220, 1996.

STUDER RK, LEVICOFF E, GEORGESCU H, MILLER L, JAFFURS D, EVANS CH. Nitric oxide inhibits chondrocyte response to IGF-I: inhibition of IGF-IR beta tyrosine phosphorylation. Am J Physiol Cell Physiol. 279: C961-9, 2000.

STUDER RK. Nitric oxide decreases IGF-1 receptor function in vitro; glutathione depletion enhances this effect in vivo. Osteoarthritis Cartilage. 12: 863-9, 2004.

SUH YA, ARNOLD RS, LASSEGUE B, SHI J, XU X, SORESCU D, CHUNG AB, GRIENDLING KK,LAMBETH JD. Cell transformation by the superoxide-generating oxidase Mox1. Nature. 401:79-82, 1999. 
SUMIMOTO H., SAKAMOTO N., NOZAKI M., SAKAKI Y., TAKESHIGE K., MINAKAMI S. Cytochrome $b_{558}$, a component of the phagocyte NADPH oxidase, is a flavoprotein. Biochem. Biophys. Res. Commun., 186: 1368-1375, 1992.

SUMIMOTO H., KAGE Y., NUNOI H., SASAKI H., NOSE T., FUKUMAKI Y., OHNO M., MINAKAMI S., TAKESHIGE K. Role of Src homology 3 domains in assembly and activation of the phagocyte NADPH oxidase. Proc. Natl. Acad. Sci., 91: 5345-5349, 1994.

SUMIMOTO H., HATA K., MIZUKI K., ITO T., KAGE Y., SAKAKI Y., FUKUMAKI Y., NAKAMURA M., TAKESHIGE K. Assembly and activation of the phagocyte NADPH oxidase. Specific interaction of the Nterminal Src homology 3 domain of p47phox with p22phox is required for activation of the NADPH oxidase. $J$. Biol. Chem., 271: 22152-22158, 1996.

SUMIMOTO H, MIYANO K, AND TAKEYA R. Molecular composition and regulation of the Nox family NAD(P)H oxidases. Biochem Biophys Res Commun. 338: 677-86, 2005.

SZOEKE CE, CICUTTINI FM, GUTHRIE JR, CLARK MS, DENNERSTEIN L. Factors affecting the prevalence of osteoarthritis in healthy middle-aged women: Data from the longitudinal Melbourne Women's Midlife Health Project. Bone. 2006 [ahead of print].

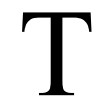

TAKAHASHI T, KONDOH T, FUKUDA M, YAMAZAKI Y, TOYOSAKI T, SUZUKI R. Proinflammatory cytokines detectable in synovial fluids from patients with temporomandibular disorders. Oral Surg Oral Med Oral Pathol Oral Radiol Endod. 85:135, 1998.

TAKAÏ Y., SASAKI T., MATOZAKI T. Small GTP-Binding Proteins. Phys. Rev., 81: 153-208, 2001.

TIKU ML, LIESCH JB, ROBERTSON FM. Production of hydrogen peroxide by rabbit articular chondrocytes: enhancement by cytokines. J Immunol. 145: 690-696, 1990.

TIKU ML, YAN YP, CHEN KY: Hydroxyl radical formation in chondrocytes and cartilage as detected by electron paramagnetic resonance spectroscopy using spin trapping reagents. Free Radic Res. 29: 177-187, 1998.

TIKU ML, GUPTA S, DESHMUKH DR. Aggrecan degradation in chondrocytes is mediated by reactive oxygen species and protected by antioxidants. Free Radic Res. 30: 395-405, 1999.

TIKU ML, SHAH R, ALLISON GT. Evidence linking chondrocyte lipid peroxidation to cartilage matrix protein degradation. Possible role in cartilage aging and the pathogenesis of osteoarthritis. J Biol Chem. 275: 20069-76, 2000 .

TOUSSAINT O, MEDRANO EE, VON ZGLINICKI T: Cellular and molecular mechanisms of stress-induced premature senescence (SIPS) of human diploid fibroblasts and melanocytes. Exp Gerontol. 35: 927-945, 2000.

TSUNAWAKI S., KAGARA S., YOSHIKAWA K., YOSHIDA L.S., KURATSUJI T., NAMIKI H. Involvement of p40phox in activation of phagocyte NADPH oxidase through association of its carboxylterminal, but not its amino-terminal, with p67phox. J. Exp. Med., 184: 893-902, 1996.

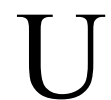

UENO N., TAKEYA R., MIYANO K., KIKUCHI H., SUMIMOTO H. The NADPH oxidase Nox3 constitutively produces superoxide in a p22phox-dependent manner: its regulation by oxidase organizers and activators. J. Biol. Chem. 280: 23328-23339, 2005.

URBANO FL. Heberden's nodes. Hospital physicians 38 : 29-31, 2001. 
$\mathrm{V}$

VANDEN HOEK, TL, LI C, SHAO Z, SCHUMACKER PT, AND BECKER LB. Significant levels of oxidants are generated by isolated cardiomyocytes during ischemia prior to reperfusion. J Mol Cell Cardiol 29: 25712583, 1997

VAN LENT PL, NABBE KC, BLOM AB, SLOETJES A, HOLTHUYSEN AE, KOLLS J, VAN DE LOO FA, HOLLAND SM, AND VAN DEN BERG WB. NADPH-oxidase-driven oxygen radical production determines chondrocyte death and partly regulates metalloproteinase-mediated cartilage matrix degradation during interferon-gamma-stimulated immune complex arthritis. Arthritis Res Ther 7: R885-895, 2005.

VERGNAUD S., PACLET M.H., EL BENNA J., POCIDALO M.A. MOREL F. Complementation of NADPH oxidase in p67phox-deficient CGD patients p67phox / p40phox interaction. Eur. J. Biochem., 267: 1059-1067, 2000.

VIEDT C., SOTO U., KRIEGER-BRAUER H.I., FEI J, ELSING C., KUBLER W., KREUZER J. Differential activation of mitogen-activated protein kinases in smooth muscle cells by angiotensin II: involvement of p22phox and reactive oxygen species. Arterioscler Thromb Vasc Biol. 20: 940-8, 2000.

VIGNAIS PV. The superoxide-generating NADPH oxidase: structural aspects and activation mechanism. Cell Mol Life Sci 59: 1428-1459, 2002.

VIGNON E., ARLOT M., HARTMAN D., NOYER D. Étude microdilumétrique et biochimique du cartilage articulaire humain. Comparaison de diverses jointures Rev. Rhum. Mal. Osteoartic. 47 :715-718, 1980.

VILHARDT F., VAN DEURS B. The phagocyte NADPH oxidase depends on cholesterol-enriched membrane microdomains for assembly. EMBO J., 23: 739-748, 2004.

VINCENTI MP, BRINCKERHOFF CE. Early response genes induced in chondrocytes stimulated with the inflammatory cytokine interleukin-1beta. Arthritis Res. 3: 381-8, 2001.

VISSERS M.C.M., GEORGE P.M., BATHURST I.C., BRENNAN S.O., WINTERBOURN C.C. Cleavage and inactivation of alpha-1-antitrypsin by metalloproteinases released from neutrophils. J. Clin. Invest. 82:706-711, 1988

\section{$\mathrm{W}$}

WALLACH T.M., SEGAL A.W. Stoichiometry of the subunits of flavocytochrome $b_{558}$ of the NADPH oxidase of phagocytes. Biochem. J., 320: 33-38, 1996.

WALLACH T.M., SEGAL A.W. Analysis of glycosylation sites on gp91phox, the flavocytochrome of the NADPH oxidase, by site-directed mutagenesis and translation in vitro. Biochem. J., 320: 33-38, 1997.

WANG EA, ROSEN V, CORDES P, HEWICK RM, KRIZ MJ, LUXENBERG DP, SIBLEY BS, WOZNEY JM Purification and characterisation of other distinct bone-inducing factors. Proc. Natl Acad. Sci. USA. 85: 94848,1988

WANG EA, ROSEN V, D'ALESSANDRO JS, BAUDUY M, CORDES P, HARADA T, ISRAEL DI, HEWICK RM, KERNS KM, LAPAN P, et al., Recombinant human bone morphogenetic protein induces bone formation. Proc. Natl Acad. Sci. USA. 87: 2220-4, 1990.

WANG GL, SEMENZA GL. Characterization of hypoxia-inducible factor 1 and regulation of DNA binding activity by hypoxia. $J$ Biol Chem. 268: 21513-8, 1993.

WANG MX, WEI A, YUAN J, TRICKETT A, KNOOPS B, MURRELL GA. Expression and regulation of peroxiredoxin 5 in human osteoarthritis. FEBS Lett. 531: 359-62, 2002. 
WANG YD, YAN PY. Expression of matrix metalloproteinase-1 and tissue inhibitor of metalloproteinase-1 in ulcerative colitis. World J Gastroenterol. 12: 6050-3, 2006.

WARNAAR N, HOFKER HS, MAATHUIS MH, NIESING J, BRUGGINK AH, DIJKSTRA G, PLOEG RJ, SCHUURS TA. Matrix metalloproteinases as profibrotic factors in terminal ileum in Crohn's disease. Inflamm Bowel Dis. 12:863-9, 2006.

WERB Z., ALEXANDER C.M. Proteinases and matrix degradation. In Kelley W., Harris E.D.Jr, Ruddy S., Sledge C.B. Textbook of Rheumatology, 5th ed., Philadelphia, WB Saunders. 248-267, 1993.

WERB Z. ECM and cell surface proteolysis: regulating cellular ecology. Cell. 91: 439-442, 1997.

WESTACOTT CI, SHARIF M. Cytokines in osteoarthritis: mediators or markers of joint destruction? Semin Arthritis Rheum.25: 254-272, 1996.

WESTERMARCK J, KAHARI VM. Regulation of matrix metalloproteinase expression in tumor invasion. FASEB J. 13: 781-92, 1999.

WILKINS RJ, HALL AC. Control of matrix synthesis in isolated bovine chondrocytes by extracellular and intracellular pH. J Cell Physiol. 164: 474-81,1995.

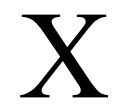

XIE J, HAN ZY, MATSUDA T. Mechanical compressive loading stimulates the activity of proximal region of human COL2A1 gene promoter in transfected chondrocytes. Biochem Biophys Res Commun. 344: 1192-9, 2006.

Y

YAMADA H, SAITO F, FUKUTA-OHI H, ZHONG D, HASE A, ARAI K, OKUYAMA A, MAEKAWA R, SHIMIZU T, MATSUMURA. K. Processing of beta-dystroglycan by matrix metalloproteinase disrupts the link between the extracellular matrix and cell membrane via the dystroglycan complex. Hum Mol Genet. 10: 1563-9, 2001.

YAMAZAKI K, FUKUDA K, MATSUKAWA M, HARA F, MATSUSHITA T, YAMAMOTO N, YOSHIDA K. MUNAKATA H, HAMANISHI C. Cyclic tensile stretch loaded on bovine chondrocytes causes depolymerization of hyaluronan: involvement of reactive oxygen species. Arthritis Rheum. 48: 3151-8, 2003.

YASUHARA R, MIYAMOTO Y, AKAIKE T, AKUTA T, NAKAMURA M, TAKAMI M, MORIMURA N, YASU K, KAMIJO R. Interleukin-1beta induces death in chondrocyte-like ATDC5 cells through mitochondrial dysfunction and energy depletion in a reactive nitrogen and oxygen species-dependent manner. Biochem J. 389 : $315-23,2005$.

YANG S., MADYASTHA P., BINGEL S., RIES W., KEY L. A new superoxide-generating oxidase in murine osteoclasts. J. Biol. Chem., 276: 5452-5458, 2001.

YU L., ZHEN L., DINAUER M.C. Biosynthesis of the phagocyte NADPH oxidase cytochrome $b_{558}$. Role of heme incorporation and heterodimer formation in maturation and stability of gp91phox and p22phox subunits. $J$. Biol. Chem., 272: 27288-27293, 1997.

YU L., DE LEO F.R., BIBERSTINE-KINKADE K.J, RENEE J., NAUSEEF W.M., DINAUER M.C. Biosynthesis of flavocytochrome $b_{558}$. gp $19^{\text {phox }}$ is synthesized as a $65-\mathrm{kda}$ precursor (p65) in the endoplasmic reticulum. J. Biol. Chem., 274: 4364-4369, 1999.

YUDOH K, NGUYEN T, NAKAMURA H, HONGO-MASUKO K, KATO T, AND NISHIOKA K. Potential involvement of oxidative stress in cartilage senescence and development of osteoarthritis: oxidative stress induces chondrocyte telomere instability and downregulation of chondrocyte function. Arthritis Res Ther 7: R380-391, 2005. 


\section{Bibliographie}

\section{Z}

ZHAO H, KALIVENDI S, ZHANG H, JOSEPH J, NITHIPATIKOM K, VASQUEZ-VIVAR J, AND KALYANARAMAN B. Superoxide reacts with hydroethidine but forms a fluorescent product that is distinctly different from ethidium: potential implications in intracellular fluorescence detection of superoxide. Free Radic BiolMed 34: 1359-1368, 2003 
Annexe

ANNEXES 


\section{ANNEXE}

\section{TRAVAUX SCIENTIFIQUES EN RAPPORT AVEC LE SUJET}

\section{ABSTRACTS / AFFICHES SCIENTIFIQUES}

1. Grange L., Gaudin Ph., Favre JJ., Peoc'h M., Juvin R., Phelip X., Chirossel JP., Morel F. Intervertebral disc herniation: Involvment of metalloproteines. Paul Basset Memorial Meeting, Strasbourg, 24 et 25 Novembre 2000.

2. Grange L., Gaudin Ph., Trocmé C., Phelip X., Morel F., Juvin R Intervertebral disc herniation: involvment of metalloproteinases. Annales of the rheumatic diseases; vol 60 number 6 jun 2001. Congrès Européen de Rhumatologie EULAR 2001, Prague 13 -16 juin 2001.

3. Grange L., Stasia MJ. Vergnaud S., Lu J.S., Trocmé C., Gaudin P., Morel F. Human chondrocytes, reactive oxygen species production and Nox. Osteoarthritis and Cartilage vol 10, Supl. A. PS 57. $7^{\text {th }}$ world congress of OARSI Sydney, 25-26 sept 2002.

4. Grange L.,_Stasia MJ. Vergnaud S., Lu J.S., Trocmé C., Gaudin P., Morel F. Human chondrocytes and reactives oxygen species production :NOX in the spotlight. Arthritis, vol 46, number 9, PS121 septembre 2002. American College of Rheumatology. New orleans, 24- 29 octobre 2002.

5. Grange L., Stasia MJ., Vergnaud S., Lu J.S., Trocmé C., Gaudin P., Morel F. Chondrocyte humain et production de radicaux libres oxygénés: NOX dans le collimateur. Rev. Rhum (Ed. Française) 2002, N $10-11$ - p1120. $15^{\text {ème }}$ Congrès Français de Rhumatologie, Paris 18-19 novembre 2002.

6. Trocmé C., Grange L., Stasia MJ., Gaudin P., Morel F. Different expression pattern of matrilysin by epstein-barr virus immortalized B lymphocytes from healthy donors and chronic granulomatous disease patients Biochemical society chritmas meeting 16-18 décembre 2002

7. Grange L., Stasia MJ., Vergnaud S., Lu J.S., Trocmé C., Gaudin P., Morel F. Human chondrocytes and reactives oxygen species production :NOX in the spotlight. Arthritis. Res. Ther 2003, 5 (suppl. 1), 100. $23^{\text {rd }}$ European Workshop for Rheumatology Research, Marseille, 27 Février-2 mars 2003.

8. Duc C., Grange L., Gaudin Ph., Juvin R. Les métalloprotéases sériques ont elles un intérêt pronostique dans la polyarthrite rhumatoide Rev. Rhum (Ed. Française) 2003, 70; 458-9. Journées nationales de la Société Français de Rhumatologie, Montpellier 1617 mai 2003.

9. Grange L, Nguyen MV, Lardy B, Derouazi M, Campion Y, Trocme C, Paclet MH, Gaudin P, Morel F Nox4 the essential link between IL-1 $\beta$, reactive oxygen species and matrix proteolysis in osteoarthritis. Osteoarthritis and Cartilage.World congress of OARSI, 8-10 décember .abstract session poster number 184. 


\section{COMMUNICATIONS ORALES}

1. Grange L., Gaudin Ph., Trocmé C., Phelip X., Morel F., Juvin R Disque intervertébral et hernie discale: rôle des métalloprotéases. Congrès de la Société Française de Rhumatologie, Paris, 21 Novembre 2000.

2. Grange L., Gaudin Ph., Favre JJ., Peoc'h M., Juvin R., Phelip X., Chirossel JP., Morel F. De la dégénérescence discale à la hernie discale : rôle des métalloprotéases Journée EURALP de Rhumatologie, Turin, 5 Mai 2001

3. Grange L., Gaudin Ph., Trocmé C., Morel F., Juvin R Métalloprotéases et cytokines, de la dégénérescence discale à la hernie discale : états des lieux. EURALP 2002 Saint Etienne, 24 mai 2002.

4. Grange L., Gaudin Ph., Juvin R. Les limites des greffes de chondrocytes . Journée Grenobloise de Rhumatologie, Grenoble 18 Octobre 2002.

5. Grange L., Trocmé C.Gaudin Ph., Morel F., Juvin R Qu'est-ce qu'une discopathie inflammatoire? Aspects biochimiques et perspectives thérapeutiques (Dr GRANGE, CHU Grenoble). Communication orale aux 16èmes Actualités Médicales du Rachis, Paris, 14 Juin 2003.

6. Grange L., Trocmé C., Gaudin Ph., Morel F., Juvin R Sciatique discale, TNF alpha et anti TNF alpha (Dr GRANGE, CHU Grenoble). Communication orale aux 16èmes Actualités Médicales du Rachis, Paris, 14 Juin 2003.

7. Grange L Histoire naturelle de la hernie discale lombaire. . Communication orale aux 2éme journée de pathologie de l'appareil locomoteur de l'hôpital sud Grenoble le 7 octobre 2006.

8. Lardy B., Grange L., Chuong MV., Gaudin P., Morel F. Physiopathologie de l'arthrose / conséquence du stress oxydant médie par la NAD(P)H oxydase Nox 4 sur 1 expression de la collagénase MMP-1. Réunion annuelle ANPMCB Nancy 7-9 septembre 2006.

9. Grange L, Nguyen MV, Lardy B, Derouazi M, Campion Y, Trocme C, Paclet MH, Gaudin P, Morel F. Influence des dérivés réactifs de l'oxygène sur l'expression de métalloprotéases dans une lignée de chondrocytes : rôle de la NAD(P)H OXYDASE Nox 4. absctract Rev. Rhum (Ed. Française) 2006, Congrès Français de Rhumatologie, Paris 36 décembre 2006. 


\section{ARTICLES SCIENTIFIQUES (avec comite de lecture)}

1. Grange L., Gaudin Ph., Trocmé C., Phelip X., Morel F., Juvin R. Intervertebral disk degeneration and herniation: the role of metalloproteinases and cytokines. Joint Bone Spine 2001, $68: 1-7$.

2. Grange L., Gaudin Ph., Trocmé C., Phelip X., Morel F., Juvin R. Dégénérescence discale et hernie discale : rôle des métalloprotéases et des cytokines. Rev. Rhum (Ed. Française) 2001, 68 : 913-919.

3. Grange L., Gaudin Ph., Trocmé C., Morel F., Juvin R. Qu'est-ce qu'une discopathie inflammatoire? Aspects biochimiques et perspectives thérapeutiques revue médecine vertebrale (juin 2003).

4. Grange L., Gaudin Ph., Trocmé C., Morel F., Juvin R. Sciatique discale, TNF- $\alpha$ et anti TNF- $\alpha$ revue médecine vertebrale (juin 2003).

5. Grange L, Nguyen MV, Lardy B, Derouazi M, Campion $\mathrm{Y}$, Trocme C, Paclet MH, Gaudin P, Morel F. NAD(P)H oxidase activity of Nox4 in chondrocytes is both inducible and involved in collagenase expression. Antioxid Redox Signal. 2006 Sep-Oct;8 (910):1485-96. 


\title{
Forum Original Research Communication
}

\section{NAD(P)H Oxidase Activity of Nox4 in Chondrocytes Is Both Inducible and Involved in Collagenase Expression}

\author{
LAURENT GRANGE, ${ }^{1,2 *}$ MINH VU CHUONG NGUYEN, ${ }^{*}$ BERNARD LARDY, ${ }^{1}$ \\ MADIHA DEROUAZI, ${ }^{1}$ YANNICK CAMPION,${ }^{1}$ CANDICE TROCME, ${ }^{1}$ \\ MARIE-HELENE PACLET, ${ }^{1}$ PHILIPPE GAUDIN,${ }^{1,2}$ and FRANCOISE MOREL ${ }^{1}$
}

\begin{abstract}
Reactive oxygen species (ROS) are regulators of redox-sensitive cell signaling pathways. In osteoarthritis, human interleukin-1 $\beta$ is implicated in cartilage destruction through an ROS-dependent matrix metallopro-

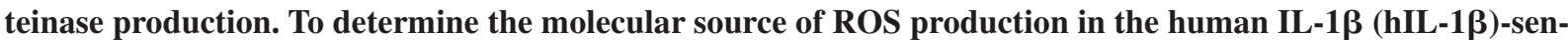
sitive chondrocyte immortalized cell line $\mathrm{C}-20 / \mathrm{A4}$, transfected cells were constructed that overexpress NAD(P)H oxidases. First, RT-PCR analysis showed that the C-20/A4 cell line expressed Nox2, Nox4, p22phox, and p67phox, but not p47phox. It was found that ROS production by C-20/A4 chondrocytes does not depend on PMA and ionomycin activation. This indicates that Nox2 was not involved in the production of ROS. In C20/A4 cells that overexpress Nox4, hIL-1 $\beta$ stimulated ROS production three times more than the normal production of C-20/A4 cells. Moreover, there was a fourfold increase in the production of collagenase (MMP-1) by chondrocytes that overexpress Nox4. Interestingly, MMP-1 production in cells that overexpress Nox 2 was

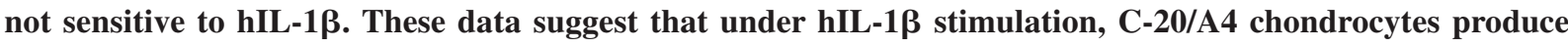
MMP-1 through a Nox4-mediated, ROS-dependent pathway. Antioxid. Redox Signal. 8, 1485-1496.
\end{abstract}

\section{INTRODUCTION}

I N RECENT YEARS it has become evident that reactive oxygen species (ROS), such as superoxide and hydrogen peroxide, act as important regulators of redox-sensitive cell signaling pathways. ROS are involved in diverse cellular processes, such as host defense, oxygen sensing, proliferation, apoptosis, and response to mechanical strain. However, in a pathological sense, overproduction of ROS has been associated with inflammation, vascular atherosclerosis, diabetes, hypertension, tumorigenesis, and osteoarthritis (OA) (26). Osteoarthritis represents one of the most frequent musculoskeletal diseases, affecting over $60 \%$ of the elderly population. The pathogenesis of primary osteoarthritis involves an intrinsic and progressive erosion of articular cartilage, leading to incapacity of movement and chronic pain. An imbalance between anabolic and catabolic pathways by chondrocytes occurs in OA (2). These catabolic pathways are characterized by an excessive production of proteolytic enzymes, the matrix metalloproteinases (MMPs), which are directly involved in cartilage resorption.
Articular chondrocytes actively produce ROS, released in response to interleukin-1 $\beta(26-42)$. It has been suggested that ROS act as secondary messengers in bovine chondrocytes and are involved in mitogen-activated protein kinase (MAPK) stimulation, and c-jun and NF-kappaB activation required for transcription of cytokine-induced MMP-1 (collagenase-1) and MMP-13 (collagenase-3) metalloproteinases (22, 25, 28, 48).

Recent studies indicate that $\mathrm{NAD}(\mathrm{P}) \mathrm{H}$ oxidases play a major role in ROS production in many nonphagocytic cells $(14,15)$. It has been proposed that $\mathrm{NAD}(\mathrm{P}) \mathrm{H}$ oxidase Nox2 (gp91phox) could produce superoxide anions in the immortalized chondrocyte cell line C-20/A4, similar to those found in phagocyte cells $(15,30,31)$. However, the involvement of Nox2 in superoxide production in osteoarthritis has not been proven. In porcine chondrocytes, no production of ROS was seen after addition of phorbol ester (PMA), a Nox2 activator (15). Indeed, p47phox and gp91 ${ }^{\text {phox }}$-deficient mice have the same tissue damage as wild type mice in experimental arthritis models (another joint disease) (45). Recent efforts to identify oxidases responsible for ROS generation in nonphagocytic cells led to the discovery of

Center for Biomedical EPR Spectroscopy and Imaging, and Comprehensive Wound Care Center, Davis Heart and Lung Research Institute, The Ohio State University, Columbus, Ohio. 
gp91phox isoforms. To date, the Nox family consists of five members, all of which are structurally similar to the Nox 2 protein (20). One member of this family, Nox4, is the major source of ROS in kidneys $(9,11)$ and is also abundant in the vascular system and in many others tissues (19). In osteoclast cells, Nox 4 has been identified and shown to produce superoxide that directly contributes to bone resorption (49). Strong evidence indicates that superoxide production in chondrocytes could be responsible for the overexpression of metalloproteinases.

To address these questions, we studied the effect of the expression of the Nox family and its partners in chondrocyte immortalized cell lines. We focused our study on Nox4 and Nox2, and used the C-20/A4 chondrocyte cell line, which provides a stable expression of both protein types to compare their roles under cytokinic stress and their impact on MMP-1 expression. In this study, we report that Nox4 is the main $\mathrm{NAD}(\mathrm{P}) \mathrm{H}$ oxidase involved in ROS production under human interleukin1 beta (hIL-1ß) stimulation in the C-20/A4 chondrocyte cell line, and that ROS are directly related to MMP-1 production.

\section{MATERIALS AND METHODS}

\section{Materials and cells}

Human chondrocyte cell lines immortalized by SV40, C-20/A4, T/C-28a2, or C-28/I2, are a gift from M.B. Goldring (Harvard Institutes of Medicine, Boston, MA). Monoclonal antibodies anti-p22phox 44.1 and monoclonal antibodies antiNox2 (54.1 \& NL7) were from A.J. Jesaïtis (Montana State University, Bozeman, MT) monoclonal antibodies anti-Nox2 7D5 were purchased at MBL Medical \& Biological Laboratories Co., Ltd (NaKa-ku Nagoya, Japan) and monoclonal antibodies antihistidine from Qiagen (Courtaboeuf, France). Irrelevant monoclonal IgG1 was obtained from Immunotech (Marseille, France) and phycoerythrine-conjugated secondary antibodies from Dianova (Hamburg, Germany). Penicillin, streptomycin, L-glutamine, Dulbecco's modified Eagle's medium (DMEM), fetal bovine serum (FBS), trypsin, EBSS, geneticin, and TRIzol ${ }^{\circledR}$ were obtained from Invitrogen (Cergy Pontoise, France). Human IL-1beta (hIL-1 $\beta$ ) and LightCycler FastStart DNA Master plus SYBR Green I kit were purchased from Roche Applied Science (Meylan, France), blasticidin from Funakoshi Co (Japan), and AMV reverse transcriptase from QBiogene (Illkirch, France). ProMMP-1 ELISA kits were obtained from R\&D Systems (Lille, France) and Effectene Transfection reagent from Qiagen. Luminol, ionomycin, phorbol 12-myristate 13-acetate (PMA), horseradish peroxidase, and dihydroethidium were from Sigma (Saint Quentin Fallavier, France).

\section{Chondrocyte cell line culture}

C-20/A4, T/C-28a2, and C-28/I2 chondrocyte cell lines were maintained in DMEM supplemented with $10 \%(\mathrm{v} / \mathrm{v})$ FBS, 100 units $/ \mathrm{ml}$ penicillin, $100 \mu \mathrm{g} / \mathrm{ml}$ streptomycin, $2 \mathrm{~m} M$ L-glutamine at $37^{\circ} \mathrm{C}$ in a humidified $5 \% \mathrm{CO}_{2}$ atmosphere. Blasticidin, 10 $\mu \mathrm{g} / \mathrm{ml}$, was added to the culture medium of cells transfected with the mammalian expression plasmid $\mathrm{pEF}_{\mathrm{b}}$ (Invitrogen, Cergy Pontoise, France) and $1 \mu \mathrm{g} / \mathrm{ml}$ geneticin was added to the culture medium of Nox 2 transfected cells. All experiments were performed within cell passages 3 to 10 at $60-90 \%$ confluency.

\section{Generation of plasmid constructs for the expression of Nox4 isoforms and Nox2}

Human Nox4 and Nox 2 were cloned: two Nox4 cDNA ESTs were characterized by PCR using UNI-ZAP human kidney lambda cDNA library (Stratagene, La Jolla, CA) as a template. Nox4A corresponds to the full-length Nox4 usually described in Genbank No.AF254621, and Nox4B is an exon 14 spliced isoform (Genbank No.AJ704726). N-terminal V5-Histagged Nox4A and Nox4B were produced with the forward primer Nox4 F4" $4^{\prime \prime}$ (5'-GTTTGGTACCATGGCTGTGTCCTGGAGG-3') including a Kpn I site (shown in bold type) and the reverse primer Nox4 R4' (5'-GTTTACTAGTGCTGAAAGACTCTTTATTGTATTC- $3^{\prime}$ ) comprising a Spe I restriction site (shown in bold type) instead of the stop codon. Both purified PCR products were subcloned into the pCR Blunt II-TOPO vector according to the manufacturing protocol (Zero Blunt TOPO PCR cloning kit, Invitrogen). pCRBluntII-TOPO plasmid containing Nox4A or Nox4B was digested by Kpn I and Spe I, and the insert was ligated into a linearized pEF6V5/HisB vector (Invitrogen). Dominantnegative pCDNA 3.1 Nox4 $\triangle$ FAD/NADPH plasmid was constructed using the forward primer Nox4 F4 and the reverse primer Nox4 R4" (5'-GTTTGCGGCCGCTCAAATGATGGTGACTGGCTTATTGC- $3^{\prime}$ ) containing a Not I restriction site (shown in bold type). This purified PCR product was digested by Kpn I and Not I and ligated into linearizd pCDNA $3.1 \mathrm{~V} 5 / \mathrm{HisB}$ vector (Invitrogen). The construction that expressed Nox2 in pEF-PGK neo plasmid was obtained from Stasia et al. (39). All inserts were verified by sequencing (Genome Express, Grenoble, France) on an Abi Prism automatic sequencer (Perkin Elmer, France Office).

\section{Transfection of mammalian expression plasmids}

Stable transfection. C-20/A4 chondrocyte cells were trypsinized and counted. $4 \times 10^{5} \mathrm{C}-20 \mathrm{~A} / 4$ cells were seeded in 6-well plates and allowed to grow for $24 \mathrm{~h}$ to reach a $60 \%$ confluency in a $2 \mathrm{ml}$ DMEM culture medium. Cells were transfected with $0.4 \mu \mathrm{g}$ of pEF6V5HisB vectors, which encoded the Nox4A-V5/His, or the Nox4B-V5/His, or with pEF-PGK neo, which encoded Nox2 according to the manufacturing protocol (Effectene Transfection reagent, Quiagen, Courtaboeuf, France). After $24 \mathrm{~h}$, stable transfected cells were selected with either $10 \mu \mathrm{g} / \mathrm{ml}$ blasticidin for Nox4A-V5/His, Nox4B-V5/His, and luciferase, or $1 \mathrm{mg} / \mathrm{ml}$ geneticin for Nox 2 for 3 weeks (37).

Transient transfection. C-20/A4 chondrocyte cells were seeded in a $25 \mathrm{~cm}^{2}$ flask to obtain $50 \%$ confluency on the day of transfection. Five $\mu \mathrm{g}$ of plasmid of pCDNA 3.1 V5/His empty vector (Invitrogen) or pCDNA 3.1 Nox4 $\triangle F A D / N A D P H$ were diluted in $200 \mu \mathrm{l}$ of $\mathrm{CaCl} 2(250 \mathrm{mM})$ buffer and $200 \mu \mathrm{l}$ of HEPES-phosphate buffer (140 m $M \mathrm{NaCl}, 50 \mathrm{~m} M$ HEPES, 1.4 $\mathrm{m} M \mathrm{NaH} 2 \mathrm{PO} 4, \mathrm{pH} 7.05$ ) was added. After $60 \mathrm{sec}$ of incubation at room temperature, the transfection solution was added to cells immersed in $1.8 \mathrm{ml}$ of complete DMEM culture medium. Four hours after transfection, the medium was replaced. Fortyeight hours after transfection, the quantity of MMP-1 was measured as described below. 


\section{$R N A$ and $R T-P C R$}

Chondrocytes were harvested and resuspended in TRIzol ${ }^{\circledR}$ at approximately $10^{8}$ cells $/ \mathrm{ml}$, as described in the manufacturer's instructions. RNA concentrations were determined spectroscopically at $260 \mathrm{~nm}$. Reverse transcription reactions were performed from $5 \mu \mathrm{g}$ of RNA with $20 \mathrm{U}$ of AMV reverse transcriptase, as described in Trocme et al. (44). All PCRs were processed during 35 cycles from $2.5 \mu \mathrm{l}$ cDNA with $2.5 \mathrm{U}$ of Taq polymerase and primer sets spanning intron/exon boundaries to avoid genomic DNA amplification (Table 1). Two primer sets were used to characterize Nox4, the first-F4/R4 - amplifying a 500 bp sequence in the 5' part of the transcript (40) and the second-F4'/R4' differentiating the two Nox 4 isoforms at 1317 bp for Nox4A and $1197 \mathrm{bp}$ for Nox4B. cDNA integrity and quantity were checked by amplification of a housekeeping gene G3PDH using commercial primers (BD Bioscience, Le Pont de Claix, France).

\section{Quantitative real-time $R T-P C R$ analysis}

Total RNA was extracted from C-20/A4 cells using Trizol reagent (Invitrogen), according to the manufacturer's instructions. Two $\mu \mathrm{g}$ of RNA were converted to cDNA by reverse transcription with $40 \mathrm{U}$ of AMV reverse transcriptase (Roche). Expression levels of human Nox-4 and housekeeping G3PDH mRNAs were determined using the specific primers as follows: forward Nox-4 F4" " (5'-CTGAATGCAGCAAGATACCGAGAT-3') and reverse Nox-4 R4" "' (5'-CTGGCTTATTGCTCCGGA-3'), and forward G3PDH F9 (5'-GTGGTGGACCTGACCTGC-3') and reverse G3PDH R9 (5'-CCCTGTTGCTGTAGCCAAATTCG-3'). Realtime quantitative Nox4 and G3PDH PCRs of each reversetranscribed cDNA sample were made on the Light Cycler 1.5 apparatus using the LightCycler FastStart DNA Master plus SYBR Green I kit (Roche). The incubation conditions were as follows: $95^{\circ} \mathrm{C}$ for $10 \mathrm{~min}$, followed by 45 cycles of denaturation at $95^{\circ} \mathrm{C}$ for $15 \mathrm{sec}$, annealing at $66^{\circ} \mathrm{C}$ for $10 \mathrm{sec}$ for Nox 4 or G3PDH, and extension at $72^{\circ} \mathrm{C}$ for $21 \mathrm{sec}$ for Nox4, or $10 \mathrm{sec}$ for G3PDH. PCRs of each sample were done in duplicate. Nox4 mRNA expression was quantified by relating the PCR cycle obtained from samples to a standard curve and was then normalized to the G3PDH mRNA expression level. Product specificity was confirmed for each fragment by a melting curve analysis and gel electrophoresis.

\section{FACS analysis}

Protein expression of p22phox, Nox2 (gp91 phox), Nox4AV5/His, and Nox4B-V5/His in the human C-20/A4 chondrocyte cell line was assessed by flow cytometry analysis, according to Stasia et al. (38) and Paclet et al. (34), and was modified as follows: $5 \times 10^{5}$ cells were fixed with $1 \%(\mathrm{w} / \mathrm{v})$ paraformaldehyde for $15 \mathrm{~min}$ at $0^{\circ} \mathrm{C}$ and labeled with antibodies immediately or after membrane permeabilization by saponin $0.01 \%(\mathrm{w} / \mathrm{v})$ for 10 $\min$ at $0^{\circ} \mathrm{C}$. Nox 2 expression was evaluated with monoclonal antibodies 7D5 $\left(5 \mu \mathrm{g} / 5 \times 10^{5}\right.$ cells $)$, NL7 $\left(5 \mu \mathrm{g} / 5 \times 10^{5}\right.$ cells $), 54.1$ $\left(5 \mu \mathrm{g} / 5 \times 10^{5}\right.$ cells) (32), and p22phox expression was characterized with monoclonal antibodies $44.1\left(5 \mu \mathrm{g} / 5 \times 10^{5} \mathrm{cells}\right)(6)$.

Nox4A-V5/His and Nox4B-V5/His expression were assessed by two polyclonal antibodies, the former raised against the polyhistidine tail $\left(5 \mu \mathrm{g} / 5 \times 10^{5}\right.$ cells $)$, and the latter against the Nox4 peptide ${ }^{88}$ KVPSRRTRRLLDKSR ${ }^{102}$, synthesized by Neosystem (Strasbourg, France) $\left(5 \mu \mathrm{g} / 5 \times 10^{5} \mathrm{cells}\right)(35)$.
Table 1. Primer Sequences Used in This Study

\begin{tabular}{|c|c|}
\hline Name & $\left(5^{\prime} \ldots 3^{\prime}\right)$ \\
\hline F1 & $\begin{array}{l}\text { Noxl } \\
\text { GTACAAATTCCAGTGTGCAGACCAC }\end{array}$ \\
\hline $\mathrm{R} 1$ & AGACTGGAATATCGGTGACAGCA \\
\hline $\mathbf{F} 2$ & ATAAGCAGGAGTTTCAAGAT Nox2 \\
\hline $\mathrm{R} 2$ & GTTTTCTAGACTGAAGTTTTCCTTGTTGAAAATGAAATG \\
\hline F 3 & ATGAACACCTCTGGGGTCAGCTGA \\
\hline R3 & GGATCGGAGTCACTCCCTTCGCTG \\
\hline F4 & CAGCAAGATACCGAGATG Nox4 \\
\hline $\mathrm{R} 4$ & CTGGCTTATTGCTCCGGA \\
\hline F4' & CTGAATGCAGCAAGATACCGAGATG \\
\hline R4' & GTTTACTAGTGCTGAAAGACTCTTTATTGTATTC \\
\hline R4" & GTTTGCGGCCGCTCAAATGATGGTGACTGGCTTATTGC \\
\hline F4"' & CTGAATGCAGCAAGATACCGAGAT \\
\hline R4"' & CTGGCTTATTGCTCCGGA \\
\hline FS & ATCAAGCGGCCCCCCTTTTTTTCAC ${ }^{\text {Nox5 }}$ \\
\hline RS & CTCATTGTCACACTCCTCGAC \\
\hline F6 & CAGTGTCCCAGCCGGGTTCGTGTC p22 $^{\text {patox }}$ \\
\hline R6 & ATTGCAGGTGGGTGCACCTGGTGGGAG \\
\hline $\mathrm{m}$ & TGTCTTTGTCTTGAAGAAGGGC p67phox \\
\hline $\mathrm{R} 7$ & GACTTCTCTCCGAGTGCTTTC \\
\hline P8 & GAGCACTGGGGGCCACCCAGTC ${ }^{\text {p47phox }}$ \\
\hline $\mathrm{R} 8$ & GTTTTATGGAACTCGTAGATCTCCG \\
\hline F & TGGCAGCTCCGAGAGCAGAG \\
\hline $\mathrm{Re}$ & GGCATCGTGTTGTAGACCCTG \\
\hline F10 & GTGGTGGACCTGACCTGC \\
\hline R10 & CСCTGTTGCTGTAGCCAAATTCG \\
\hline
\end{tabular}

Monoclonal IgG1 $\left(5 \mu \mathrm{g} / 5 \times 10^{5}\right.$ cells $)$ was used as a control. The antibody-labeled cells were stained with phycoerythrine-conjugated secondary antibodies (dilution 1:200), and the fluorescence emission was measured at $578 \mathrm{~nm}$ after excitation at $488 \mathrm{~nm}$ on a FACS Calibur apparatus (BD Bioscience). All experiments were performed in triplicate.

\section{Cytochrome b spectroscopy}

The cytochrome $b$ absorption spectra were performed with the C-20/A4 chondrocyte cell line WT, or transfected with the Nox 4 gene resuspended in a PBS buffer containing $1 \%$ of triton $\times 100$. They were recorded at room temperature with a DU 640 spectrophotometer (Beckman Coulter, Roissy, France). Reduction was achieved in the cuvette by addition of 
a few grains of sodium dithionite, and reduced minus oxidized difference spectra were recorded. The amount of reduced cytochrome $b_{558}$ was determined by absorbancy at 426 $\mathrm{nm}$ using an $\epsilon_{426 \mathrm{~nm}}$ value of $106 \mathrm{mM}^{-1} \mathrm{~cm}^{-1}$, or at $558 \mathrm{~nm}$ $\left(\epsilon_{558 \mathrm{~nm}}=21.3 \mathrm{mM} M^{-1} \mathrm{~cm}^{-1}\right)$. A positive control was performed on cytochrome $b_{558}$ purified from human neutrophils (33).

\section{Measurement of NADPH oxidase activity in intact cells by luminescence assay}

Hydrogen peroxide production was measured as described in Bionda et al. (3). Briefly, cells were washed twice with PBS, detached with trypsin and collected by centrifuge. The viability of the suspended cells was over $90 \%$, as determined by the trypan blue exclusion method. In a 96-well plate, $5 \times 10^{5}$ live chondrocytes per well were resuspended in $250 \mu 1$ of PBS containing $0.9 \mathrm{~m} M \mathrm{CaCl}_{2}, 0.5 \mathrm{~m} M \mathrm{MgCl}_{2}, 16 \mathrm{~m} M$ glucose, $16 \mu M$ luminol, and 8 units $/ \mathrm{ml}$ horseradish peroxidase. In some experiments, a final concentration of $80 \mathrm{ng} / \mathrm{ml}$ phorbol myristate acetate (PMA) or $2.5 \mu M$ ionomycin was added to initiate the reaction. Relative luminescence unit (RLU) counts were recorded every $30 \mathrm{sec}$ for a total of $90 \mathrm{~min}$ at $37^{\circ} \mathrm{C}$, using a Luminoscan ${ }^{\circledR}$ luminometer (Labsystems, Helsinki, Finland).

\section{Measurement of superoxide production in intact cells by fluorescence microscopy}

Cell cultures were made in a 6 -well plate until $80 \%$ confluency. Cells were rinsed twice with EBSS and incubated in $1 \mathrm{ml}$ of the complete culture medium (DMEM-10\% FBS) containing $5 \mu M$ final dihydroethidium (DHE) with or without hIL-1 $\beta$ $(500 \mathrm{pg} / \mathrm{ml})$ for $20 \mathrm{~min}$ at $37^{\circ} \mathrm{C}$ in a $5 \% \mathrm{CO}_{2}$ atmosphere protected from light. In some experiments, $N$-acetylcysteine 30 $\mathrm{n} M$ (NAC) final was added. Fluorescence was recorded with a Nikon digital sight DS-1QM (Nikon, Rollay, France), mounted on a Nikon eclipse TE2000-E fluorescence microscope (Nikon). Dihydroethidium fluorescence was analyzed using a filter with an excitation wavelength of $488 \mathrm{~nm}$ and an emission wavelength of $580 \mathrm{~nm}$. Images were acquired $20 \mathrm{~min}$ after DHE addition using identical exposure times, and analyzed with the Lucia software (Lucia Imaging systems, Laboratory Imaging Ltd, Prague, Czech Republic). Relative superoxide levels between cells were quantified by determining the integral gray values using Lucia Imaging systems. The integral gray value is defined as the sum of intensity in every pixel of the object. A minimum of 50 cells were analyzed per experiment. Results were expressed in arbitrary units.

\section{MMP-1 assays}

Cells cultured at $90 \%$ confluency in a $75 \mathrm{~cm}^{2}$ flask were washed three times in EBSS and incubated for $23 \mathrm{~h}$ in $15 \mathrm{ml}$ of

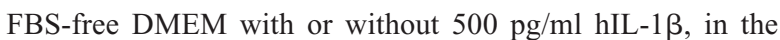
presence or not of $5 \mathrm{~m} M$ Tiron. For inhibition experiments using the dominant-negative construct pCDNA Nox4 deltaFAD/ $\mathrm{NADPH}$, cells cultured at $50 \%$ confluency in a $25 \mathrm{~cm}^{2}$ flask for $48 \mathrm{~h}$ after transient transfection were washed three times in EBSS and incubated for $23 \mathrm{~h}$ in $2 \mathrm{ml}$ of FBS-free DMEM, with or without $500 \mathrm{pg} / \mathrm{ml} \mathrm{hIL-1 \beta}$. At the end of the incubation, proMMP-1 (the precursory form of MMP-1) concentration was measured in the supernatant culture by a commercial ELISA assay. The detection limit was $0.021 \mathrm{ng} / \mathrm{ml}$. Results are expressed as ng proMMP-1/g of supernatant protein, measured by the Bradford technique (4).

\section{Statistical methods}

The variations are expressed as mean \pm S.E.; $p$ values were calculated by Student's paired $t$ test.

\section{RESULTS}

\section{Superoxide production is involved in hIL-1 $\beta$ stimulation of MMP-1 expression}

Treatment of the C-20/A4 chondrocyte cell line with hIL-1 $\beta$ for $23 \mathrm{~h}$ significantly increased the secretion of collagenase MMP-1 in the culture medium from $136.28 \mathrm{ng} / \mathrm{g}$ of supernatant protein \pm 63.54 to $913.36 \mathrm{ng} / \mathrm{g}$ of supernatant protein \pm 64.54 , suggesting an effect of hIL-1 $\beta$ on metalloproteinase expression (Fig. 1). Since it has been proposed that ROS may act as secondary messengers in cytokine signaling $(23,27)$, antioxidants that can inactivate ROS would be expected to prevent MMP-1 induction by hIL-1 $1 \beta$. We therefore examined whether Tiron, a superoxide scavenger, can inhibit hIL-1 $\beta$-induced MMP-1 expression. Indeed, the release of MMP-1 was considerably decreased by Tiron to 13.75 times in cells activated by hIL-1 $\beta$ and even by 6.97 times in control cells. We verified that neither Tiron nor hIL-1 $\beta$ affected cell integrity through the LDH measurement in the cell culture medium at the end of each experiment (data not shown).

\section{Expression of Nox and partners in chondrocyte cell lines}

In most cell types, the Nox family is the main system involved in superoxide production. There are five human NADPH oxidases, namely Nox1 to Nox5. To determine if C20/A4, C-28/I2, and T/C-28a2 chondrocyte cell lines express genes encoding components of NADPH oxidases, the presence of the relevant mRNA was estimated by RT-PCR. cDNA integrity was checked simultaneously by amplification of the housekeeping gene G3PDH (results not shown). The cDNAs corresponding to Nox4, Nox2, p22-phox, and p67-phox were highlighted in the three chondrocyte cell lines (Fig. 2A). Data showed that Nox 5 mRNA was also present in C-28/I2 and T/C28a2, but not in the C-20/A4 cell line. None of the chondrocyte types expressed Nox1, Nox3, or p47phox mRNA (Fig. 2A).

For the remaining experiments, the C-20/A4 cell line, which expresses only two Nox isoforms, was used. To assess the presence of Nox 2 and p22phox proteins, FACS experiments were carried out in both intact and permeabilized C-20A/4 chondrocytes with monoclonal antibodies directed against Nox2 (7D5) or p22phox (44.1) (Fig. 2B) (5). There was no binding of either antibody 7D5 (Nox2) or 44.1 (p22 ${ }^{\text {phox }}$ ) on intact C-20/A4 cells, suggesting that the epitopes are not accessible. On the contrary, following permeabilization of chondrocytes with $0.01 \%(\mathrm{w} / \mathrm{v})$ saponin, the mAb44.1 binding was significantly increased in comparison with results obtained with mAb7D5. The labeling on permeabilized but not on intact chondrocytes by mAb44.1 suggested a cytosolic accessible epitope for 44.1(p22phox) in chondrocytes, as is reported in neutrophils (43). Finally, as shown with mAb7D5, there was a slight expression of gp91phox (Nox2) in chondrocytes (Fig. 2B). 


\begin{abstract}
FIG. 1. Effect of cytokinic stress on MMP-1 expression in the $\mathrm{C}-20 / \mathrm{A} 4$ chondrocyte cell line. Monolayer-cultivated cells at $90 \%$ confluency were incubated with $500 \mathrm{pg} / \mathrm{ml} \mathrm{hIL}-1 \beta$ in the presence (or not) of $5 \mathrm{mM}$ Tiron. After $23 \mathrm{~h}$ incubation, the supernatant was recovered for MMP-1 quantification by ELISA. Results are expressed as ng MMP$1 / \mathrm{g}$ of supernatant protein (measured by the Bradford technique). In addition, cell viability was verified by measurement of the LDH in the supernatant culture by an automated method (Hitachi automat). Values represent the mean \pm S.E. of four experiments. ${ }^{*} p<0.05$ versus nonstimulated cells; $* * p<0.05$ versus Tiron-free hIL-1 $\beta$ stimulated cells.
\end{abstract}

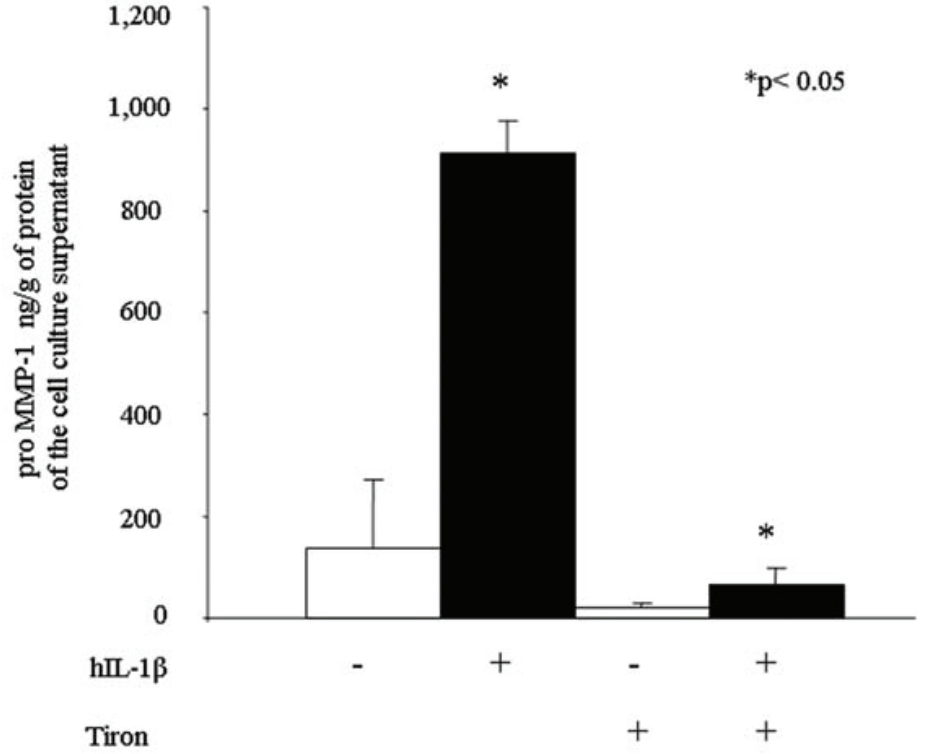

Superoxide production

Since NAD(P)H oxidases are ROS-generating enzymes, it was of interest to investigate the effects of Nox 2 and Nox4 variants on ROS generation. Because of its sensitivity, the chemiluminescence agent, luminol, was used to quantify hydrogen peroxide production in cells (for review, cf. Miller and Griendling, Ref. 29). Oxygen derivatives were quantified in experiments in which PMA and ionomycin stimulated C-20/A4 chondrocytes. Results illustrated in Fig. 5 showed a significant hydrogen peroxide synthesis in Nox4A-V5His transfected cells $(14.87 \mathrm{RLU} \pm 0.44)$ compared with the control C-20/A4 (0.17 RLU \pm 0.011$)$ and with cells that express Nox4B $(0.17$ RLU \pm 0.024$)$. Moreover, no significant difference was observed after PMA and/or ionomycin stimulation, suggesting that neither Nox 2 nor calcium is implicated in this $\mathrm{H}_{2} \mathrm{O}_{2}$ production. This reflects a constitutive generation of ROS mediated by Nox4 in C-20/A4 chondrocytes.

Intracellular levels of superoxide production were investigated in C-20/A4 cells with the DHE dye by fluorescence microscopy (Fig. 6). Nox4A overexpressing cells stimulated by $500 \mathrm{pg} / \mathrm{ml}$ hIL-1 $\beta$ produced significantly more superoxide (71,824 arbitrary units) than stimulated control C-20/A4 cells $(7,993)$. Nox4A overexpressing cells that were not stimulated showed approximately a twofold reduction in fluorescence (35, 54). Moreover, the Nox4-mediated superoxide production was significantly reduced by the ROS scavenger $N$-acetylcysteine (NAC) (Fig. 6). Interestingly, Nox4B overexpressing cells produced less superoxide than control C-20/A4 cells after stimulation with hIL-1 $\beta$. Indeed, in this case, the integral gray quantification was not possible as it appeared below the detection threshold of the software. These results confirm the dominant negative effect of Nox4B, as previously described $(12,17,24)$.

\section{MMP-1 production by hIL-1 $\beta$ stimulated C-20/A4 through Nox4}

We and others have shown that hIL-1 $\beta$ increases MMP-1 production and excretion in C-20/A4 cell line (Fig. 1). To determine whether Nox 4 or Nox 2 have a role in this pathway, we 
A

A

248 pb

$457 \mathrm{pb}$

$285 \mathrm{pb}$

$236 \mathrm{ph}$

$624 \mathrm{pb}$

$687 \mathrm{pb}$

$180 \mathrm{pb}$

801 pb

507 pb

B

p22 phox $\mathrm{Ab}$

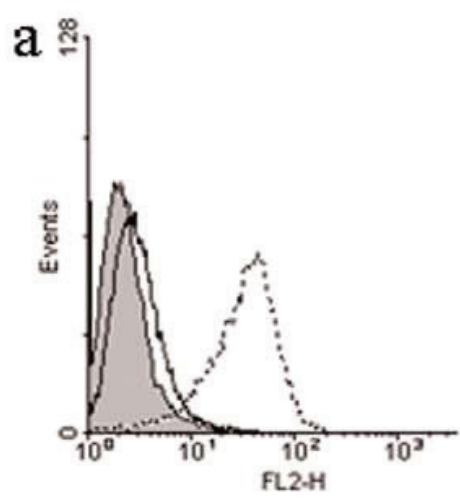

gp91 ${ }^{\text {phox }} \mathrm{Ab}$ (7D5)

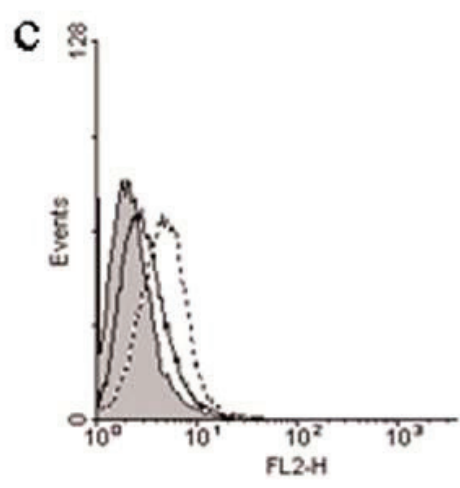

GRANGE ET AL.

(+)

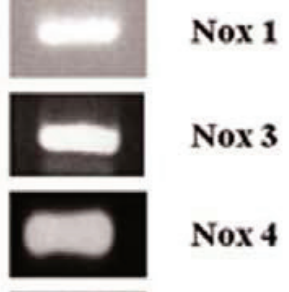

Nox 5

$\operatorname{gp91}^{\text {hox }}$, Nox 2

p22 phox

p47 phox

p67 phox

p40 phox

onswate

1 
A

FIG. 3. Efficiency of plasmidic expression in transfected cells. (A) Total RNA was extracted from nontransfected $\mathrm{C}-20 / \mathrm{A} 4$ chondrocytes or Nox4A-V5/His, Nox4BV5/His, or Nox 2 transfected cells. PCRs for each plasmid were performed as previously described, using the primer sets F4'/R4' for Nox4 (characterizing both Nox4 isoforms), F2/R2 for Nox2, and commercial primers for G3PDH. (B) Nox4 mRNA expression by real-time RT-PCR. Total RNA was extracted from nontransfected C-20/A4 chondrocytes, Nox4AV5/His, Nox4B-V5/His, luciferase, or Nox2 transfected cells. qRT-PCRs for each sample were performed as previously described, using the primer sets F4"'/R4" (characterizing both Nox4 isoforms). Bars indicate the relative expression of Nox 4 versus G3PDH mRNA levels.

B
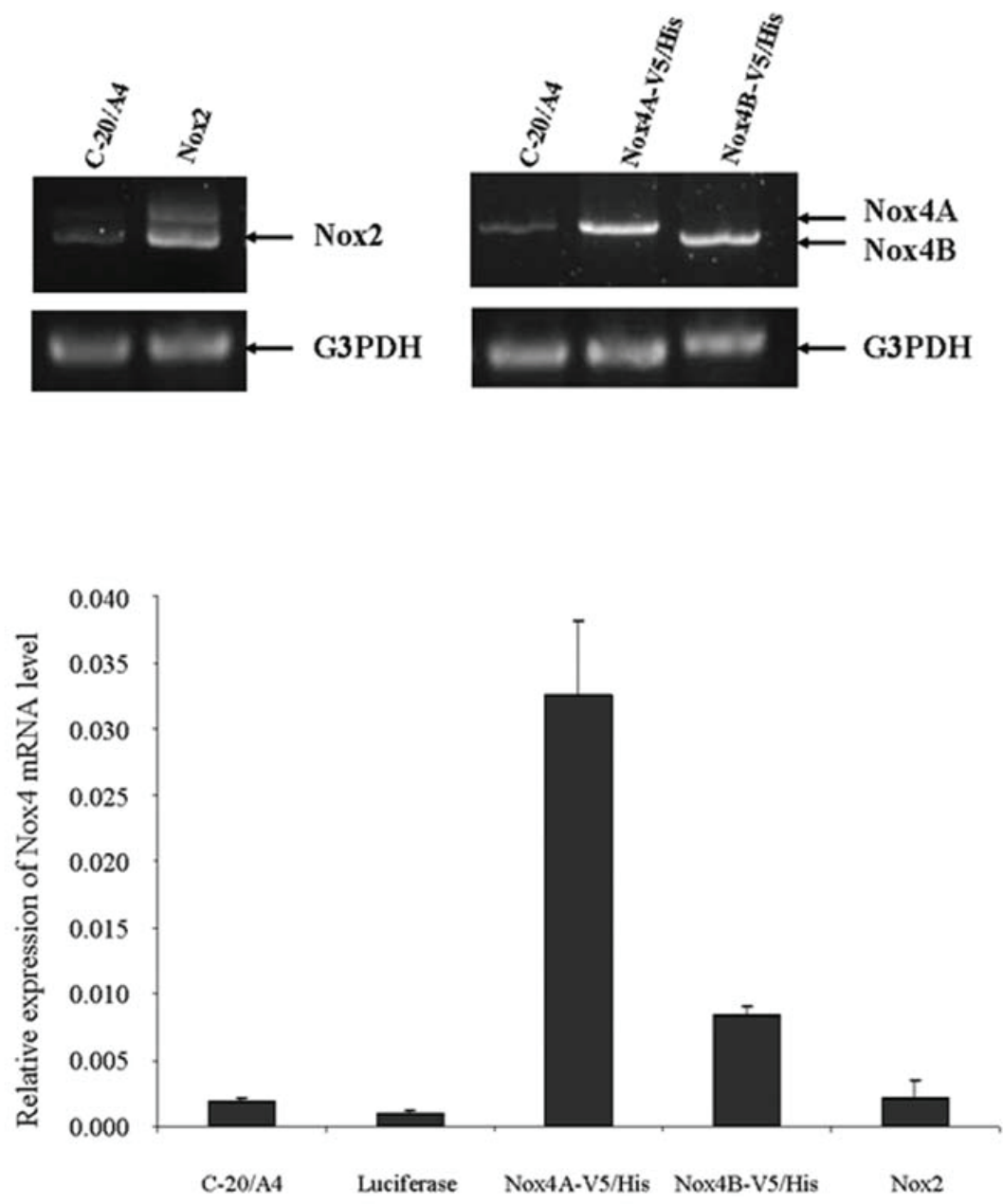

measured MMP-1 secretion under cytokinic stress in C-20/A4 cells that express both $\mathrm{NAD}(\mathrm{P}) \mathrm{H}$ oxidases. MMP-1 production by chondrocytes expressing Nox4A-V5His was increased by $3.6(3,296.55 \mathrm{ng} / \mathrm{g}$ protein $\pm 1,789.11)$ compared with MMP-1 synthesis by control C-20/A4 cells $(913.36 \mathrm{ng} / \mathrm{g}$ protein \pm 64.54) (Fig. 7). However, there was no significant rise in MMP1 secretion by cells expressing Nox 2 or the Nox4B-V5His isoform. To demonstrate the specificity of MMP-1 production induced by Nox4, we used a truncated Nox $4 \triangle$ FAD/NADPH protein described as a dominant-negative by Mahadev $(17,24)$. C-20/A4 cells expressing Nox4A-V5/His were transfected by an empty vector pCDNA 3.1 or by a pCDNA 3.1 Nox $4 \triangle$ FAD/NADPH and exposed (or not) with hIL-1 $\beta$ (500 $\mathrm{ng} / \mathrm{ml}) 48 \mathrm{~h}$ after transfection. The amount of MMP-1 was assessed in the cultured medium $23 \mathrm{~h}$ later. MMP-1 production by cells transfected by Nox 4 dominant-negative $(74 \mu \mathrm{g} / \mathrm{g}$ protein) was reduced by $66 \%$ compared to cells that had been transfected by the empty vector $(215 \mu \mathrm{g} / \mathrm{g}$ protein $)$ but not exposed to hIL-1 $\beta$. The range of MMP-1 inhibition was the same between cells expressing Nox4A $\triangle$ FAD/ NADPH (102 $\mu \mathrm{g} / \mathrm{g}$ protein $)$ and cells containing the empty vector $(305 \mu \mathrm{g} / \mathrm{g}$ protein) incubated with $\mathrm{hIL}-1 \beta$. We verified that the construct gave raise to the functional protein Nox2 in PLB cells (data not shown).

\section{DISCUSSION}

In this study, we have described the presence of Nox4, one of the members of the NAD(P) H oxidase family, in chondrocytes. Moreover, we have demonstrated that Nox4 is directly

FIG. 2. mRNA and protein expression analysis of Nox and partners. (A) mRNA transcription analysis by RT-PCR. RNA was extracted from C-20/A4, T/C-28a2, and C-28/12 chondrocyte cell lines, and reverse transcripted to cDNA as described in the Materials and Methods section. Specific primer sets (in parentheses) were used to study the expression of Nox2 (F2/R2) p22phox (F6/R6), p40phox (F9/R9), p47phox (F8/R8), p67phox (F7/R7), Nox1 (F1/R1), Nox3 (F3/R3), Nox4 (F4/R4), and Nox5 (F5/R5). Positive controls $(+)$ assess the efficiency of PCR experiments. They were performed on PLB8985, EBV-8 lymphocytes, or on plasmids that were encoded with Nox 3 or Nox5. (B) Protein expression analysis by FACS, $5 \times 10^{5} \mathrm{C}$-20/A4 chondrocytes were fixed with $1 \%(\mathrm{w} / \mathrm{v})$ paraformaldehyde and labeled with $\mathrm{p} 22^{\text {phox }}$ and gp91 phox antibodies either immediately $(b, d)$ or after saponin permeabilization $(a, c)$, as described in the text. The antibodies used were: nonimmune immunoglobulin (black solid line; $5 \mu \mathrm{g} / 5 \times$ $10^{5}$ cells), anti-gp91 phox7D5, or anti-p22phox 44.1 (black dotted line, $5 \times 10^{5}$ cells), and phycoerythrine-conjugated secondary antibodies (dilution 1:200), no AB (gray area). 


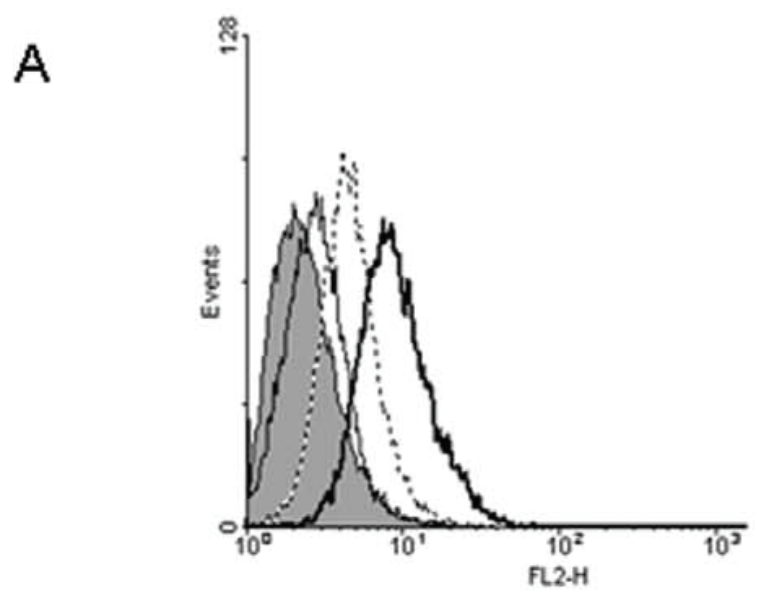

gp91 $1^{\text {phox }} \mathrm{Ab}$ NL 7

B

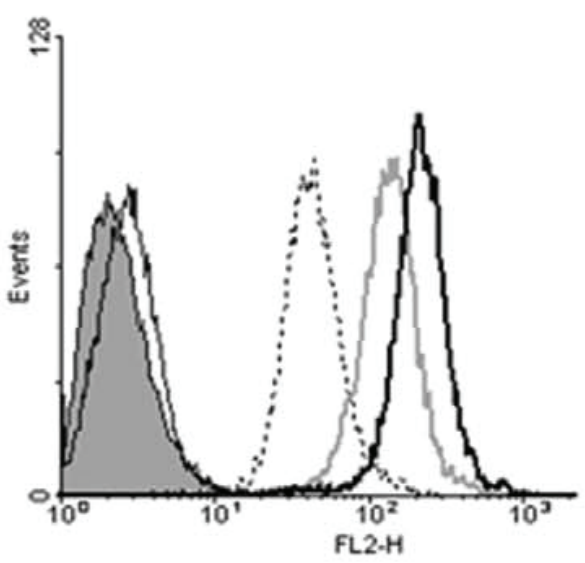

Histidine $\mathrm{Ab}$

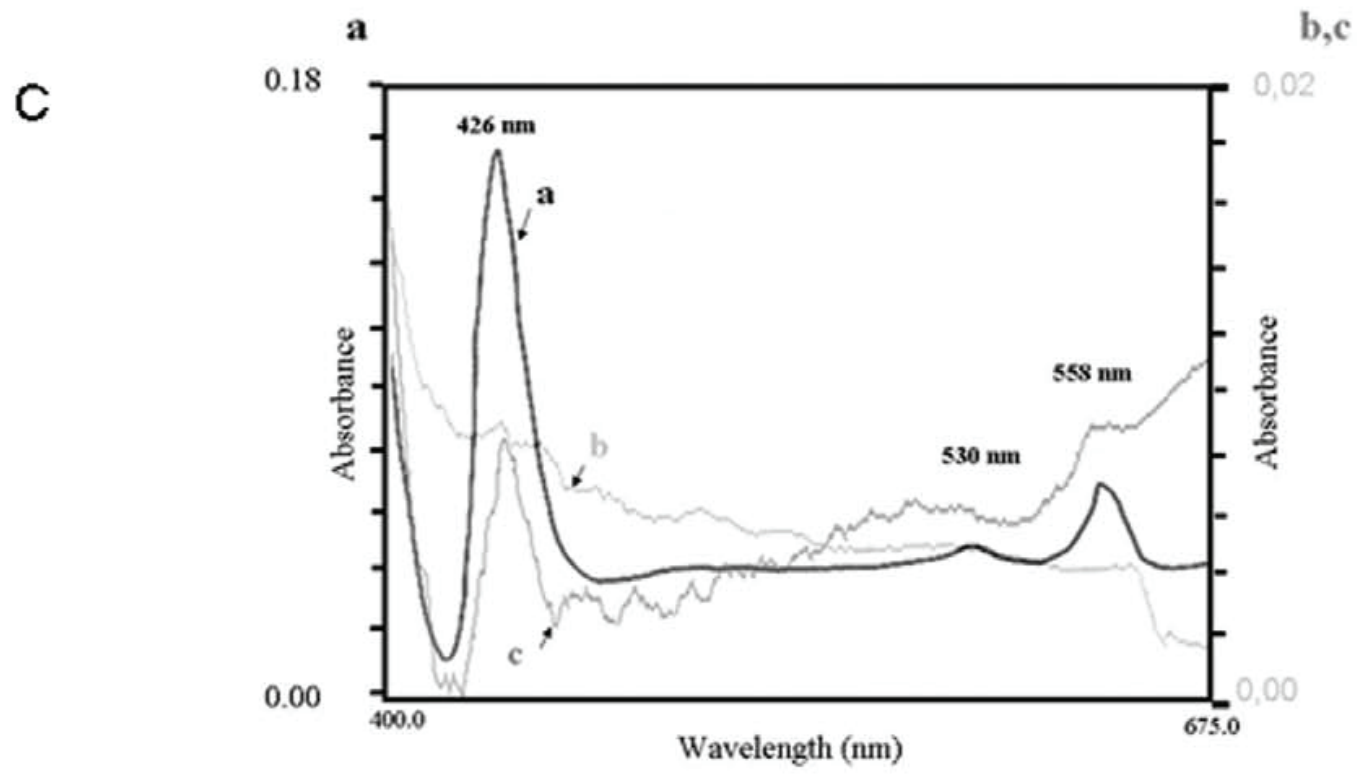

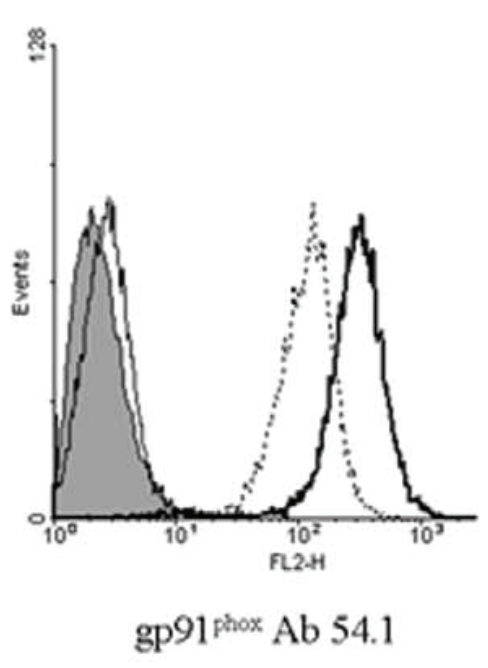

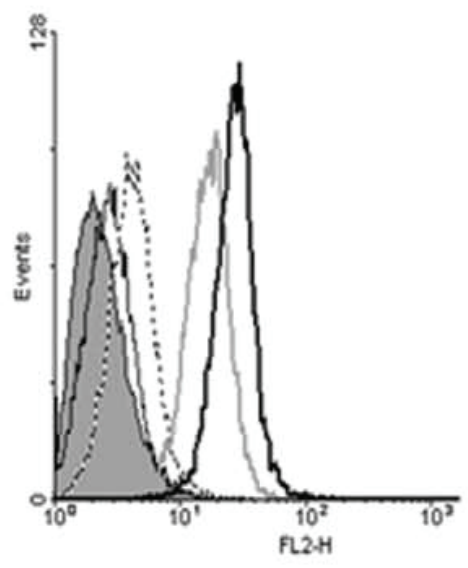

Nox $4 \mathrm{Ab}$ 
FIG. 5. Measurement of reactive oxygen species generation. ROS production was measured by chemiluminescence method from $5 \times 10^{5}$ intact C-20/A4 cells, Nox4A$\mathrm{V} 5 / \mathrm{His}$, or Nox4B-V5/His transfected chondrocytes. Cells were stimulated or not with $80 \mathrm{ng} / \mathrm{ml}$ PMA and/or $2.5 \mu M$ ionomycin. Results expressed the sum of all RLU measurements for $90 \mathrm{~min}$ for each condition. Values represent the mean \pm S.E. of triplicate determinations obtained the same day.

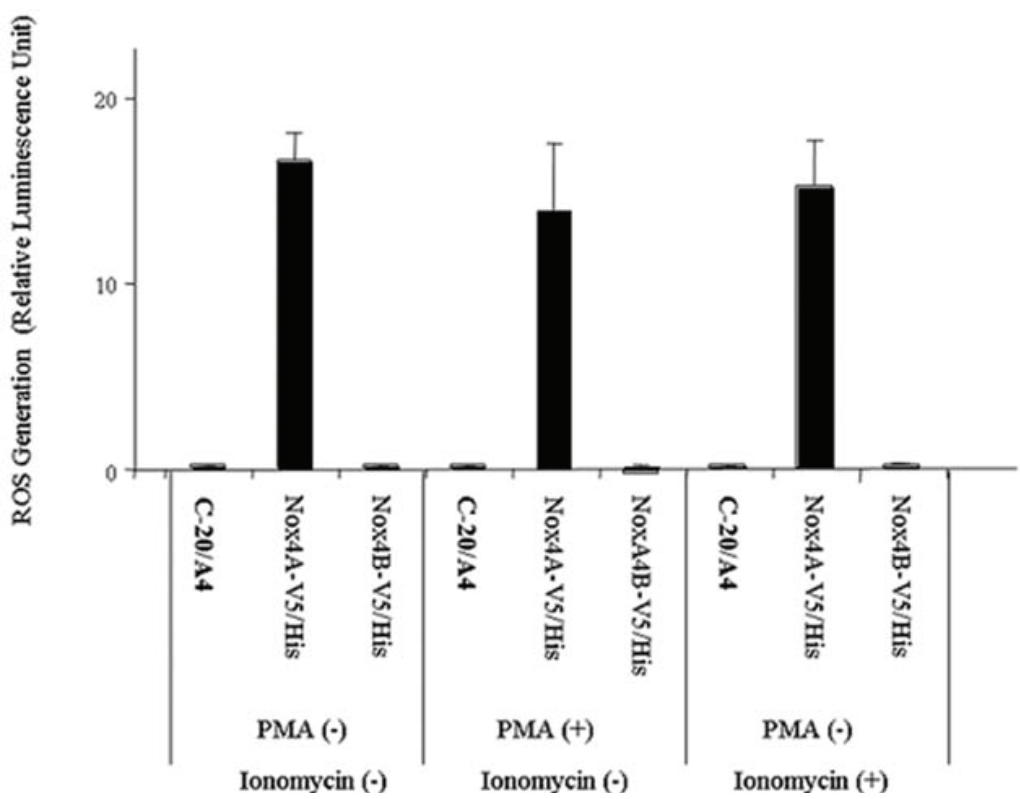

involved in the expression of collagenase MMP-1, through the generation of ROS in response to the cytokinic stress, hIL-1 $\beta$.

Human articular chondrocyte cell lines (C-20/A4, T/C-28a2, or C-28/I2) were developed to obtain reproducible cellular models, and used to study differentiated chondrocyte functions, and in particular, the cartilage-specific modulation induced by hIL-1 $\beta(7,10,36)$. All our experiments were carried out in the C-20/A4 cell line that expresses only Nox 2 and Nox 4 isoforms.

Oxidative stress was reported to increase the risk of osteoarthritis, but the precise mechanism remains unclear. It has been shown that it may lead to chondrocyte and cartilage senescence $(50)$, and that cartilage degeneration can be mediated by locally produced matrix metalloproteinases (13). Finally, it was found that $\mathrm{NAD}(\mathrm{P}) \mathrm{H}$ oxidase-driven ROS production determines chondrocyte death and aggravates MMP-mediated cartilage destruction during osteoarthritis (46). There is now clear evidence that hIL-1 $\beta$ initiates inflammation $(13,18,21)$, but it is necessary to investigate the specific pathway between the stimulus (hIL-1 $\beta$ ) and the downstream inflammatory gene induction. The active phagocyte NADPH oxidase is a multiprotein complex in which the membrane-integrated protein

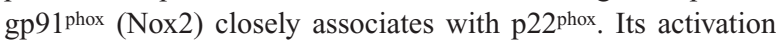
requires assembly with p47phox, p67phox, and Rac. p47phox, which is a regulatory adaptor protein, is not present in the chondrocyte cell line C-20/A4: there is no possibility of oxidase activation, even if Nox 2 is slightly expressed, as the complex does not assemble in the absence of p47phox (not shown) (47).

The close association of the Nox 2 isoform with $\mathrm{p} 22^{\text {phox }}$ has recently been reported to be necessary for their enzymatic activity $(1,41)$. Our results demonstrate a significant coexpression of Nox 4 and p22phox , suggesting the presence of a functional Nox 4 in chondrocytes. In all cell types where Nox4 has been identified, oxidase activity was shown to be constitutive. In this study, we have demonstrated that C-20/A4 chondrocyte oxidase activity of Nox4 was inducible. As expected, there was no significant increase in ROS production in Nox4B-V5/His overexpressing C20/A4 cells. In fact, the truncated isoform Nox4 B has been reported to act as a dominant negative for Nox4 activity (12).

We have found that hIL-1 $\beta$ increases ROS production within 20 min after stimulation, which does not support a Nox neosynthesis. This suggests that Nox4 not only functions in a constitutive manner, but can also be activated by hIL-1 $\beta$. The fact that the culture medium of hIL- $1 \beta$ stimulated C-20/A4 chondrocytes and the increase in MMP-1 argues in favor of a direct involvement of ROS as a secondary messenger leading to gene transcription of metalloproteinases. Further investigation into

FIG. 4. Nox 2 and Nox4 expression analysis by FACS and cytochrome b spectroscopy. (A) gp91phox FACS analysis. $5 \times 10^{5} \mathrm{C}-$ 20/A4 WT or C-20/A4 Nox2 chondrocytes were fixed with 1\% (w/v) paraformaldehyde and labeled with gp91 phox (NL7 or 54.1) antibodies after saponin permeabilization, as described in the text. The following antibodies were used: nonimmune immunoglobulin (black solid line; $5 \mu \mathrm{g} / 5 \times 10^{5}$ cells), no $\mathrm{Ab}$ (gray area), and phycoerythrine-conjugated secondary antibodies (dilution 1:200). The C-20/A4 WT and C-20/A4 Nox 2 were represented, respectively, by black dotted line and black bold solid line. (B) Nox4 FACS analysis. $5 \times 10^{5}$ C-20/A4WT, C-20/A4 Nox4A-V5/His, or C-20/A4 Nox 4B-V5/His chondrocytes were fixed with $1 \%$ (w/v) paraformaldehyde and labeled with antihistidine or anti-Nox4 antibodies after saponin permeabilization, as described in the text. The antibodies used were as in (A). The C-20/A4 WT were represented by a black dotted line; C-20/A4 Nox4A-V5/His and C-20/A4 Nox4B-V5/His, respectively, by gray solid line and black bold solid line. (C) The reduced minus oxidized difference spectra of C-20/A4 chrondrocyte cell line WT (line $b$ in gray), transfected with Nox4 gene (line $c$ in gray) were performed as described in the text, (positive conrol: cytochrome b558 purified from human neutrophils, absorbance at $426 \mathrm{~nm}$ using an $\epsilon 426 \mathrm{~nm}$ value of $106 \mathrm{mM}^{-1} . \mathrm{cm}^{-1}$ or at $558 \mathrm{~nm}(\epsilon 558 \mathrm{~nm}=21.3$ $\mathrm{m} M^{-1} \mathrm{~cm}^{-1}$ ). The absorbance of the cytochrome b558 purified from human neutrophils (line A) was read at the left side of the figure, and the absorbance of the C-20/A4 chrondocyte cell line WT or transfected with Nox4 gene were read at the right side of the figure. 


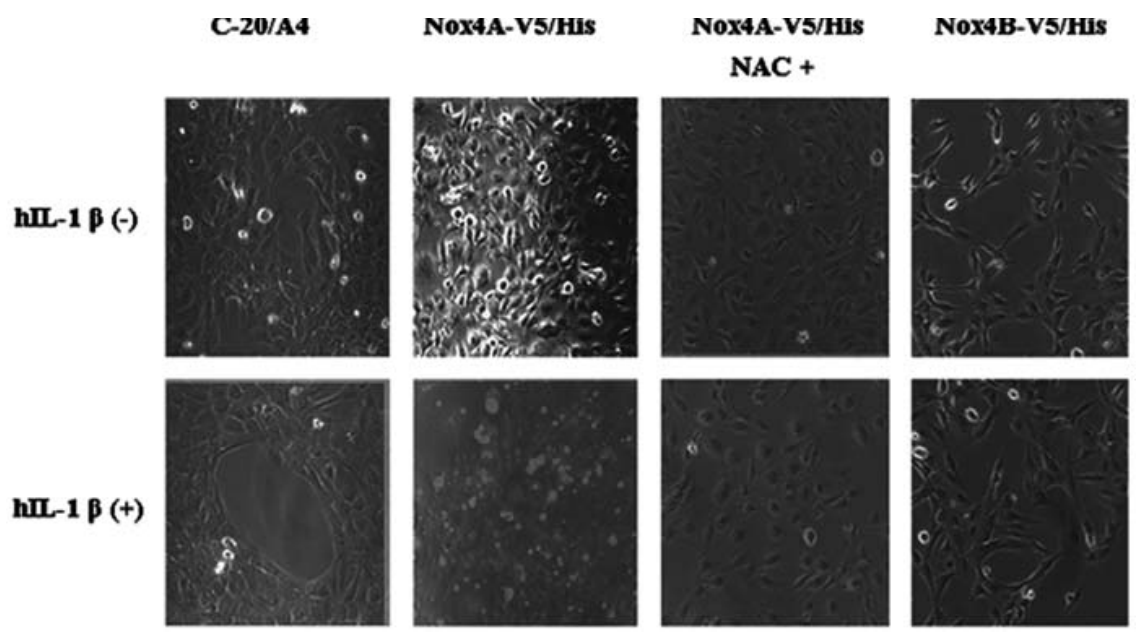

FIG. 6. Measurement of superoxide generation. Nontransfected chondrocytes C-20/A4, Nox4A-V5/His, or Nox4B-V5/His, or Nox 2 transfected C-20/A4 were incubated with or without $500 \mathrm{pg} / \mathrm{ml} \mathrm{hIL-1 \beta}$ in the complete DMEM medium containing $5 \mu M$ dihydroethidium (DHE) for $20 \mathrm{~min}$ in 6-well plates with or without $30 \mathrm{n} M$ final NAC. Fluorometric measurements of the DHE oxidation in cell layers were carried out using a fluorescence microscope. Three replicates per treatment group were run for each experiment.

the specificity and modality of the signal transduction pathway is needed and this research opens a new area for therapeutic exploration.

Furthermore, we know that excessive and continuous cyclic mechanical stress and high magnitude cyclic tensile induce a production of IL-1 $\beta$, MMP-1, and other MMPs, causing a quantitative imbalance between catabolic and anabolic pathways, ultimately resulting in cartilage degradation $(8,16)$.

What, then, is the role of ROS? Mechanical stress may increase a Nox4-mediated ROS production and activate matrix metalloproteinase expression: this question is currently being investigated.

\section{ACKNOWLEDGMENTS}

The authors acknowledge M. B. Goldring, A.L. Jesaitis, and M. J. Stasia for their generous gift of immortalized chondrocyte cell lines and monoclonal antibodies, and the Nox2 pEF-PGK neoplasmid, respectively. We thank S. Vergnaud, M. Guillot, and S. Papacatzis, for their helpful discussions, and G. Butt for his English revision. This work was supported by grants from the Ministère de l'enseignement supérieur de la recherche et technologie, MENRT, Paris; the Région Rhône-Alpes, programme Emergence; the Délégation Régionale à la Recherche Clinique CHU Grenoble DRRC-CHU, Grenoble.

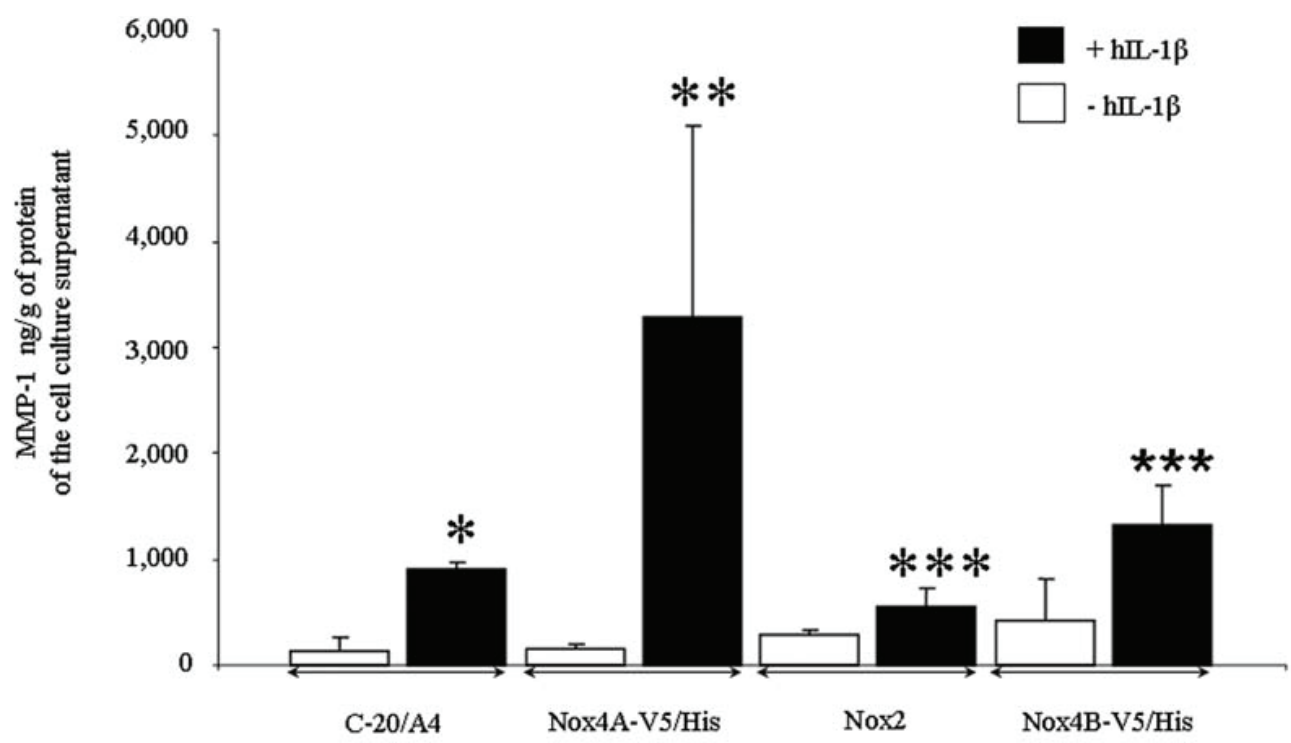

FIG. 7. Modulation of MMP-1 expression by Nox4 in C-20/A4 chrondrocytes, Nox4A-V5/His, Nox4B-V5/His, and Nox2 transfected cells. C-20/A4 cells were incubated for $23 \mathrm{~h}$ with or without $500 \mathrm{pg} / \mathrm{ml} \mathrm{hIL}-1 \beta$. The culture medium was then recovered for MMP-1 quantification by ELISA. Results are expressed as ng MMP-1/g of supernatant protein (determined by the Bradford technique). In addition, cell viability was checked by measurement of the LDH in the supernatant culture. Values represent the mean \pm S.E. of four determinations. ${ }^{*} p<0.05$ versus nonstimulated cells; ${ }^{*} p<0.05$ versus nontransfected hIL- $1 \beta$ stimulated cells; and $* * * p<0.05$ versus Nox4A-V5/His transfected hIL-1 $\beta$ stimulated cells. 


\section{ABBREVIATIONS}

DHE, dihydroethidium; DMEM, Dulbecco's modified Eagle's medium; EBSS, Earle's balanced salts; FBS, fetal bovine serum; hIL-1 $\beta$, human interleukin-1 beta; IgG1, immunoglobulin $\mathrm{G} 1$; LDH, lactate dehydrogenase; $\mathrm{mAb}$, monoclonal antibody; MAPK, mitogen-activated protein kinase; NAC, $N$-acetylcysteine; OA, osteoarthitis; PBS, phosphate buffer saline; PMA, phorbol 12-myristate 13-acetate; MMP-1, metalloproteinase 1; ROS, reactive oxygen species; RT-PCR, reverse transcription- polymerase chain reaction.

\section{REFERENCES}

1. Ambasta RK, Kumar P, Griendling KK, Schmidt HH, Busse R, and Brandes RP. Direct interaction of the novel Nox proteins with $\mathrm{p} 22^{\text {phox }}$ is required for the formation of a functionally active NADPH oxidase. $J$ Biol Chem 279: 45935-45941, 2004.

2. Benton HP and Tyler JA. Inhibition of cartilage proteoglycan synthesis by interleukin-I. Biochem Biophys Res Commun 154: 421-428, 1988.

3. Bionda C, Li XJ, Bruggen RV, Eppink M, Roos D, Morel F, and Stasia MJ. Functional analysis of two-amino acid substitutions in gp91 ${ }^{\text {phox }}$ in a patient with X-linked flavocytochrome b558-positive chronic granulomatous disease by means of transgenic PLB-985 cells. Hum Genet 115: 418427, 2004

4. Bradford MM. A rapid and sensitive method for the quantitation of microgram quantities of protein utilizing the principle of protein-dye binding. Anal Biochem 72: 248254, 1976.

5. Burritt JB, DeLeo FR, McDonald CL, Prigge JR, Dinauer MC, Nakamura M, Nauseef WM, and Jesaitis AJ. Phage display epitope mapping of human neutrophil flavocytochrome b558. Identification of two juxtaposed extracellular domains. J Biol Chem 276: 2053-2061, 2001.

6. Burritt JB, Quinn MT, Jutila MA, Bond CW, and Jesaitis AJ. Topical mapping of neutrophil cytochrome $b$ epitopes with phage-display libraries J Biol Chem 270: 16974-16980, 1995.

7. Finger F, Schörle C, Soder S, Zien A, Goldring MB, and Aigner T. Phenotypic characterization of human chondrocyte cell line C-20/A4: a comparison between monolayer and alginate suspension culture. Cells Tissues Organs 178: 65-77, 2004

8. Fujisawa T, Hattori T, Takahashi K, Kuboki T, Yamashita A, and Takigawa M. Cyclic mechanical stress induces extracellular matrix degradation in cultured chondrocytes via gene expression of matrix metalloproteinases and interleukin-1. J Biochem (Tokyo) 125: 966-975, 1999.

9. Geiszt M, Kopp JB, Varnai P, and Leto TL. Identification of renox, an NAD(P)H oxidase in kidney. Proc Natl Acad Sci USA 97: 8010-8014, 2000.

10. Goldring MB, Birkhead JR, Suen LF, Yamin R, Mizuno S, Glowacki J, Arbiser JL, and Apperley JF. Interleukin-1 beta-modulated gene expression in immortalized human chondrocytes. J Clin Invest 94: 2307-2316, 1994.

11. Gorin Y, Block K, Hernandez J, Bhandari B, Wagner B, Barnes JL, and Abboud HE. Nox4 NAD(P)H oxidase me- diates hypertrophy and fibronectin expression in the diabetic kidney. J Biol Chem 280:39616-39626, 2005.

12. Goyal P, Weissmann N, Rose F, Grimminger F, Schafers HJ, Seeger W, and Hanze J. Identification of novel Nox4 splice variants with impact on ROS levels in A549 cells. Biochem Biophys Res Commun 329: 32-39, 2005.

13. Gowen M, Wood DD, Ihrie EJ, Meats JE, and Russell RG. Stimulation by human interleukin-1 of cartilage breakdown and production of collagenase and proteoglycanase by human chondrocytes but not by human osteoblasts in vitro. Biochim Biophys Acta 797: 186-193, 1984.

14. Griendling KK. Novel NAD(P)H oxidases in the cardiovascular system. Heart 90: 491-493, 2004.

15. Hiran TS, Moulton PJ, and Hancock JT. Detection of superoxide and NAD $(\mathrm{P}) \mathrm{H}$ oxidase in porcine articular chondrocytes. Free Radic Biol Med 23: 736-743, 1997.

16. Honda K, Ohno S, Tanimoto K, Ijuin C, Tanaka N, Doi T, Kato Y, and Tanne K. The effects of high magnitude cyclic tensile load on cartilage matrix metabolism in cultured chondrocytes. Eur J Cell Biol 79: 601-609, 2000.

17. Hu T, Ramachandrarao SP, Siva S, Valancius C, Zhu Y, Mahadev K, Toh I, Goldstein BJ, Woolkalis M, and Sharma K. Reactive oxygen species production via $\mathrm{NAD}(\mathrm{P}) \mathrm{H}$ oxidase mediates TGF-beta-induced cytoskeletal alterations in endothelial cells. Am J Physiol Renal Physiol 289: F816-F825, 2005.

18. Kheradmand F, Werner E, Tremble P, Symons M, and Werb Z. Role of Rac1 and oxygen radicals in collagenase-1 expression induced by cell shape change. Science 280: 898-902, 1998.

19. Krause KH. Tissue distribution and putative physiological function of NOX family NAD(P)H oxidases. Jpn J Infect Dis 57: S28-S29, 2004

20. Lambeth JD. NOX enzymes and the biology of reactive oxygen. Nat Rev Immunol 4: 181-189, 2004.

21. Le Maitre CL, Freemont AJ, and Hoyland JA. The role of interleukin-1 in the pathogenesis of human intervertebral disc degeneration. Arthritis Res Ther 7: R732-R745, 2005.

22. Liacini A, Sylvester J, Li WQ, and Zafarullah M. Inhibition of interleukin-1-stimulated MAP kinases, activating protein-1 (AP-1) and nuclear factor kappa B (NF-kappa B) transcription factors down-regulates matrix metalloproteinase gene expression in articular chondrocytes. Matrix Biol 21: 251-262, 2002.

23. Lo YY, Conquer JA, Grinstein S, and Cruz TF. Interleukin1 beta induction of $\mathrm{c}$-fos and collagenase expression in articular chondrocytes: involvement of reactive oxygen species. Cell Biochem 69: 19-29, 1998.

24. Mahadev K, Motoshima H, Wu X, Ruddy JM, Arnold RS, Cheng G, Lambeth JD, and Goldstein BJ. The NAD(P)H oxidase homolog Nox4 modulates insulin-stimulated generation of $\mathrm{H} 2 \mathrm{O} 2$ and plays an integral role in insulin signal transduction. Mol Cell Biol 24: 1844-1854, 2004.

25. Martin G, Bogdanowicz P, Domagala F, Ficheux H, and Pujol JP. Rhein inhibits interleukin-1 beta-induced activation of MEK/ERK pathway and DNA binding of NF-kappa $\mathrm{B}$ and AP-1 in chondrocytes cultured in hypoxia: a potential mechanism for its disease-modifying effect in osteoarthritis. Inflammation 27: 233-246, 2003.

26. Mendes AF, Carvalho AP, Caramona MM, and Lopes MC. Diphenyleneiodonium inhibits NF-kappaB activation and iNOS expression induced by IL-1beta: involvement of reactive oxygen species. Mediators Inflamm 10: 209-215, 2001. 
27. Mendes AF, Carvalho AP, Caramona MM, and Lopes MC. Differential roles of hydrogen peroxide and superoxide in mediating IL-1-induced NF-kappa B activation and iNOS expression in bovine articular chondrocytes. J Cell Biochem 88: 783-793, 2003.

28. Mengshol JA, Vincenti MP, Coon CI, Barchowsky A, and Brinckerhoff CE: Interleukin-1 induction of collagenase 3 (matrix metalloproteinase 13) gene expression in chondrocytes requires p38, c-Jun N-terminal kinase, and nuclear factor kappaB: differential regulation of collagenase 1 and collagenase 3. Arthritis Rheum 43: 801-811, 2000.

29. Miller FJ and Griendling KK. Functional evaluation of non phagocytic NAD(P)H oxidases. Methods Enzymol 74: 220-233, 2002.

30. Moulton PJ, Hiran TS, Goldring MB, and Hancock JT. Detection of protein and mRNA of various components of the NADPH oxidase complex in an immortalized human chondrocyte line. Br J Rheumatol 36: 522-529, 1997.

31. Moulton PJ, Goldring MB, and Hancock JT. NADPH oxidase of chondrocytes contains an isoform of the gp91phox subunit. Biochem J 329: 449-451, 1998.

32. Nakamura M, Murakami M, Koga T, Tanaka Y, and Minakami S. Monoclonal antibody 7D5 raised to cytochrome $b_{558}$ of human neutrophils: immunocytochemical detection of the antigen in peripheral phagocytes of normal subjects, patients with chronic granulomatous disease, and their carrier mothers. Blood 69: 1404-1408, 1987.

33. Paclet MH, Coleman AW, Vergnaud S, and Morel F. P67phox-mediated NADPH oxidase assembly: imaging of cytochrome $b_{558}$ liposomes by atomic force microscopy. Biochemistry 39: 9302-9310, 2000.

34. Paclet MH, Henderson LM, Campion Y, Morel F, and Dagher MC. Localization of Nox $2 \mathrm{~N}$ - terminus using polyclonal antipeptide antibodies. Biochem $J$ 382: 981-986, 2004

35. Pedruzzi E, Guichard C, Ollivier V, Driss F, Fay M, Prunet C, Marie JC, Pouzet C, Samadi M, Eblin C, O’Dowd Y, Bens M, Vandewalle A, Gougerot-Pocidalo MA, Lizard G and Ogier-Denis E. NAD(P)H Oxidase Nox-4 mediates 7ketocholesterol induced endoplasmic reticulum stress and apoptosis in human aortic smooth muscle cells. Mol Cell Biol 24:10703-10717, 2004.

36. Robbins JR, Thomas B, Tan L, Choy B, Arbiser JL, Berenbaum F, and Goldring MB. Immortalized human adult articular chondrocytes maintain cartilage-specific phenotype and responses to interleukin-1 $\beta$. Arthritis Rheum 43: 2189-2201, 2000.

37. Sambrook J., Fritsch EF, and Maniatis T (Eds). Molecular Cloning-A Laboratory Manual (2nd Ed.) Cold Spring Harbor, NY: Cold Spring Harbor Laboratory Press, 1989.

38. Stasia MJ, Brion JP, Boutonnat J, and Morel F. Severe clinical forms of cytochrome b-negative chronic granulomatous disease (X91-) in 3 brothers with a point mutation in the promoter region of CYBB. J Infect Dis 188: 1593-1604, 2003.

39. Stasia MJ, Lardy B, Maturana A, Rousseau P, Martel C, Bordigoni P, Demaurex N, Morel F. Molecular and functional characterization of a new X-linked chronic granulomatous disease variant $(\mathrm{X} 91+)$ case with a double missense mutation in the cytosolic gp91phox C-terminal tail. Biochim Biophys Acta 1586: 316-330, 2002.
40. Suliman HB, Ali M, and Piantadosi CA. Superoxide dismutase-3 promotes full expression of the EPO response to hypoxia. Blood 104: 43-50, 2004.

41. Sumimoto H, Miyano K, and Takeya R. Molecular composition and regulation of the Nox family NAD(P)H oxidases. Biochem Biophys Res Commun. 338: 677-686, 2005.

42. Tawara T, Shingu M, Nobunaga M, and Naono T. Effects of recombinant human IL-1 beta on production of prostaglandin E2, leukotriene B4, NAG, and superoxide by human synovial cells and chondrocytes. Inflammation 15: 145 157, 1991.

43. Taylor RM, Burritt JB, Baniulis D, Foubert TR, Lord CI, Dinauer MC, Parkos CA, and Jesaitis AJ. Site-specific inhibitors of NADPH oxidase activity and structural probes of flavocytochrome b: characterization of six monoclonal antibodies to the p22phox subunit. J Immunol 173: 7349-7357, 2004.

44. Trocme C, Gaudin P, Berthier S, Barro C, Zaoui P, and Morel F. Human B lymphocytes synthesize the $92-\mathrm{kDa}$ gelatinase, matrix metalloproteinase-9. J Biol Chem 273: 20677-20684, 1998.

45. Van de Loo FA, Bennink MB, Arntz OJ, Smeets RL, Lubberts E, Joosten LA, van Lent PL, Coenen-de Roo CJ, Cuzzocrea S, Segal BH, Holland SM, and van den Berg WB. Deficiency of NADPH oxidase components p47phox and gp91phox caused granulomatous synovitis and increased connective tissue destruction in experimental arthritis models. Am J Pathol 163: 1525-1537, 2003.

46. Van Lent PL, Nabbe KC, Blom AB, Sloetjes A, Holthuysen AE, Kolls J, Van De Loo FA, Holland SM, and Van Den Berg WB. NADPH-oxidase-driven oxygen radical production determines chondrocyte death and partly regulates metalloproteinase-mediated cartilage matrix degradation during interferon-gamma-stimulated immune complex arthritis. Arthritis Res Ther 7: R885-895, 2005.

47. Vignais PV. The superoxide-generating NADPH oxidase: structural aspects and activation mechanism. Cell Mol Life Sci 59: 1428-1459, 2002.

48. Vincenti MP and Brinckerhoff CE. Early response genes induced in chondrocytes stimulated with the inflammatory cytokine interleukin-1beta. Arthritis Res 3: 381-388, 2001.

49. Yang S, Zhang Y, Ries W, and Key L. Expression of Nox4 in osteoclasts. J Cell Biochem 92: 238-248, 2004.

50. Yudoh K, Nguyen T, Nakamura H, Hongo-Masuko K, Kato T, and Nishioka K. Potential involvement of oxidative stress in cartilage senescence and development of osteoarthritis: oxidative stress induces chondrocyte telomere instability and downregulation of chondrocyte function. Arthritis Res Ther 7: R380-391, 2005.

Address reprint requests to: Laurent Grange, M.D., Ph.D. student GREPI EA 2938 UJF

Lab Enzymology/DBPC

Hospital A. Michallon Grenoble 38043 Cedex 09, France

E-mail: LGrange@chu-grenoble.fr

Date of first submission to ARS Central, April 24, 2006; date of acceptance, April 26, 2006. 